\begin{abstract}
UNIVERSIDADE DE SÃO PAULO
ESCOLA DE ENGENHARIA DE SÃO CARLOS

PROGRAMA DE PÓS-GRADUAÇÃO EM CIÊNCIAS DA ENGENHARIA AMBIENTAL
\end{abstract}

Ghislain Mwamba Tshibangu

CARACTERIZAÇÃO DO USO DA AVALIAÇÃO AMBIENTAL ESTRATÉGICA POR AGÊNCIAS MULTILATERAIS DE DESENVOLVIMENTO

São Carlos

2015 
Ghislain Mwamba Tshibangu

\title{
CARACTERIZAÇÃO DO USO DA AVALIAÇÃO AMBIENTAL ESTRATÉGICA POR AGÊNCIAS MULTILATERAIS DE DESENVOLVIMENTO
}

\begin{abstract}
Dissertação apresentada à Escola de Engenharia de São Carlos, da Universidade de São Paulo, como requisito para obtenção do Título de Mestre em Ciências da Engenharia Ambiental.
\end{abstract}

Orientador: Prof. Dr. Marcelo Montaño

São Carlos

2015 
AUTORIZO A REPRODUÇÃO TOTAL OU PARCIAL DESTE TRABALHO, POR QUALQUER MEIO CONVENCIONAL OU ELETRÔNICO, PARA FINS DE ESTUDO E PESQUISA, DESDE QUE CITADA A FONTE.

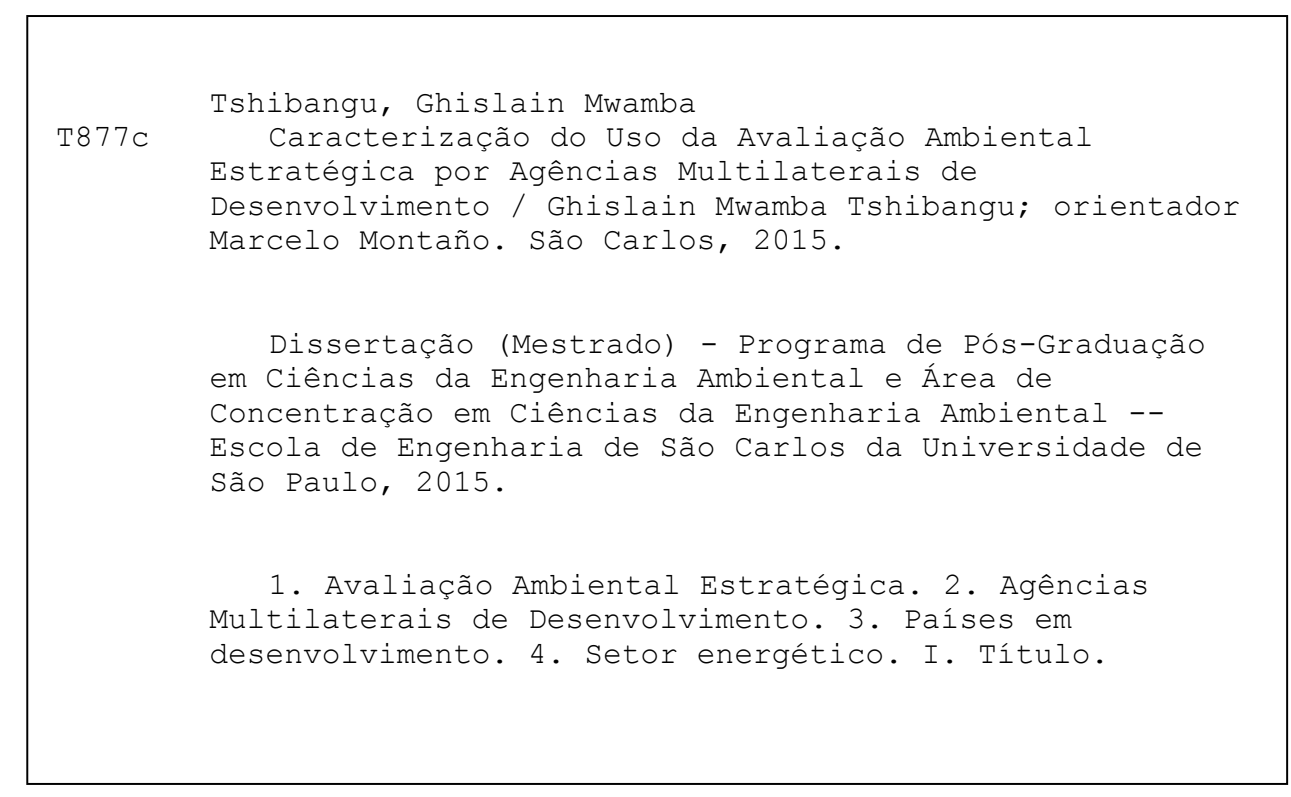




\section{FOLHA DE JULGAMENTO}

Candidato: Bacharel e Licenciado GHISLAIN MWAMBA TSHIBANGU.

Título da dissertação: "Caracterização do uso da avaliação ambiental estratégica por agências multilaterais de desenvolvimento".

Data da defesa: 23/02/2015

Comissão Julgadora:

Resultado:

Prof. Dr. Victor Eduardo Lima Ranieri

APROVADO (Orientador designado)

(Escola de Engenharia de São Carlos/EESC)

Prof. Dr. Tomás Augusto Barros Ramos

(Universidade Nova de Lisboa)

Profa. Dra. Maria Rita Raimundo e Almeida

(Universidade Federal de Uberlândia/UFU)

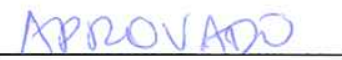

Coordenador do Programa de Pós-Graduação em Ciências da Engenharia Ambiental:

Prof. Associado Frederico Fabio Mauad

Presidente da Comissão de Pós-Graduação:

Prof. Associado Paulo César Lima Segantine 
Aos meus pais Etienne e Thérèse, com amor, gratidão e admiração por sua presença e incansável apoio ao longo do período de elaboração deste trabalho. 


\section{AGRADECIMENTO}

“Gratidão é a memória do coração" (Antistenes)

A Deus que nos momentos de desespero e desânimo carregou-me no colo, não permitindo que eu me afastasse de meu propósito.

"Se você quer um arco-íris, tem que aguentar a chuva"

(Dolly Parton)

À Nossa Senhora por me amparar nos momentos de dor e estar ao meu lado na minha alegria.

“O mundo não está interessado nas tempestades que você encontrou. Querem saber se trouxe o navio" (William McFee)

Ao Mindu, meu orientador, meus maiores e mais sinceros agradecimentos. Sua confiança e orientação foram capazes de me fazer trilhar por um crescimento profissional que julgava impossível em tão pouco tempo. Muito obrigado pelo incentivo e seus conhecimentos repassados durante todo o desenvolvimento do meu trabalho.

"Você não escolhe sua família. Eles são um presente de Deus para você, assim como você é para eles" (Desmond Tutu)

Meu agradecimentos à minha família. Em especial aos meus pais, Etienne e Thérèse, heróis que me deram apoio, incentivo nas horas difíceis, de desânimo e cansaço. Obrigado aos meus irmãos (Grace, Fanny, Flavy e Mike) e sobrinhos (Jelani, Imani, Shiloh, Eleora e Johana) que nos momentos de minha ausência dedicados ao estudo, sempre me fizeram entender que o futuro é feito a partir da constante dedicação no presente!

"O ideal deve, como a árvore, ter suas raízes na terra" (August Graf Von Platen)

À banca examinadora do exame de qualificação, Professor Marcelo Pereira de Souza e Professor Tomás Ramos, pelas valiosas contribuições. O mesmo vale para o apoio incondicional recebido dos professores (em especial o Professor Vitor Ranieri) e funcionários (Zé, Sônia, Nelson, Caio, Paulo) do Crhea. Um forte abraço ao Cidão e a Regina pela deliciosa comida do bandejão. 
"A capacidade de se iludir pode ser uma importante ferramenta de sobrevivência" (Jane Wagner)

Meus agradecimentos aos amigos da pós-graduação Duda, Anne (presidenta), Priscila, Tiago (monsieur), Joyce (pelo cuscuz), Vitor (mio amico), Fernanda (mãe da Jú), Fábia, Alejandra (mãe da Lu) e André. Companheiros de trabalhos e irmãos na amizade fizeram parte da minha formação e vão continuar presentes em minha vida com certeza. Em especial, agradecimentos a Duda pela revisão das figuras da dissertação.

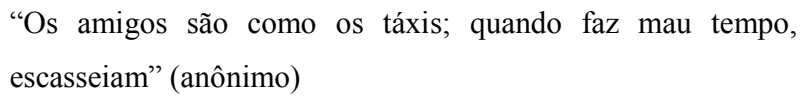

A Vanessa Ntika (Ntikinha), Rebecca Kapia (la fille du Boss!), Thiago Hoshino (filho de Orixás), Rita e Idelma pelo consolo e segurança que me oferecem nos momentos diffíceis.

"Não há prazer em possuir algo e não o partilhar" (Erasmo de Rotterdam)

A Richard Kapia pela disponibilização de documentos sobre o Projeto Inga.

“A única certeza do planejamento é que as coisas nunca ocorrem como foram planejadas" (Lucio Costa)

A CAPES pelo apoio financeiro.

“A gratidão é apenas uma esperança secreta de novos favores" (La Rochefoucauld)

A todos que direta ou indiretamente fizeram parte da minha formação, o meu muito obrigado. 


\section{RESUMO}

\section{TShIBANGU, G. M. Caracterização do Uso da Avaliação Ambiental Estratégica por}

Agências Multilaterais de Desenvolvimento. 217p. Dissertação (Mestrado) - Universidade de São Paulo, São Carlos, 2015.

A Avaliação Ambiental Estratégica (AAE) tem se destacado como um instrumento que auxilia no processo de tomada de decisões de Política, Planos e Programas, com aplicações que se distribuem por vários setores. Nos países desenvolvidos, os sistemas de Avaliação Ambiental Estratégica dispõem dos elementos essenciais para a integração do instrumento aos processos de tomada de decisões estratégicas, ao contrário dos países em desenvolvimento. Nesses países, as Agências Multilaterais de Desenvolvimento (AMD) despontam como grandes responsáveis pela disseminação da aplicação da $\mathrm{AAE}$, o que remete à necessidade de sua adaptação aos diferentes contextos verificados. Neste sentido, a presente dissertação de Mestrado é voltada para a caracterização e análise da utilização da AAE pelas AMDs no contexto dos acordos multilaterais de financiamento estabelecidos com países em desenvolvimento. Para tanto, foram identificados o perfil geral de aplicação das AAES pelas AMDs selecionadas (Banco Mundial, Banco Africano de Desenvolvimento, Banco Interamericano de Desenvolvimento, Banco Asiático de Desenvolvimento), bem como as diretrizes operacionais estabelecidas pelas agências para o uso do instrumento, tendo sido cotejadas diante de princípios de boas práticas para a aplicação da AAE. De modo complementar, para seis casos selecionados, foram aplicados procedimentos voltados à identificação dos aspectos estratégicos relacionados aos objetos submetidos à avaliação, bem como o alinhamento entre os Termos de Referência e as Avaliações Ambientais. Finalmente, foram aplicados critérios para revisão da qualidade dos relatórios das AAEs selecionadas. Os resultados obtidos indicam que as AMDs analisadas têm contribuído para a disseminação da AAE nos países em desenvolvimento, tendo solicitado 214 estudos em 59 países até o ano de 2014. Contudo, a abordagem empregada pelas AMDs - derivadas basicamente a partir das diretrizes operacionais estabelecidas em 1999 pelo Banco Mundial - apresenta diferenças importantes com as boas práticas internacionais no que diz respeito à avaliação de alternativas estratégicas e participação pública, além de serem aplicadas a objetos com baixo enfoque estratégico. Os resultados obtidos a partir da revisão de qualidade dos relatórios analisados mostram-se coerentes e alinhados com o contexto de aplicação das AAEs, apresentando baixa qualidade em termos da descrição da baseline, estabelecimento de alternativas e participação pública.

Palavras-chave: Avaliação Ambiental Estratégica, Agências Multilaterais de Desenvolvimento, países em desenvolvimento, setor energético. 


\begin{abstract}
TSHIBANGU, G. M. Characterization of the use of Strategic Environmental Assessment by Multilateral Development Agencies. 217p. Dissertation (Master) - Universidade de São Paulo, São Carlos, 2015.

Strategic Environmental Assessment (SEA) has been highilighted as an instrument that assist the process of Policy, Plan and Program decision making, with applications distributed in various sectors. In developed countries, the SEA systems have the essential elements which promote the integration of this instrument to strategic decision making processes, as opposed to developing countries. In these countries, the Multilateral Development Agencies (MDA) emerge as responsible for the widespread of SEA application, which lead to the need to adapt this tool to different contexts. In this sense, this Master's thesis is focused on the characterization and analysis of the use of SEA by MDAs in the context of multilateral financing agreements established with developing countries. Thus, the general profile of SEA applications required by MDAs (World Bank, African Development Bank, Inter-American Development Bank and Asian Development Bank) and the SEA operating guidelines established by these agencies have been identified, and faced to principles of SEA good practice. Moreover, to six selected cases, procedures were applied aimed at identifying the strategic aspects related to the objects undergoing assessment as well as the alignment between the Terms of Reference and Environmental Assessments. Finally, criteria to review the quality of reports were applied to the selected SEAs. The results indicate that MDAs analyzed have contributed to the spread of the SEA in developing countries, requiring 214 studies in 59 countries by 2014. However, the approach used by MDAs - basically derived from the operational guidelines established by the World Bank in 1999 - has important differences compared to international best practice with regard to the evaluation of strategic alternatives and public participation, beside being applied to objects with low strategic focus. The results from the reports quality review are conherent and aligned to the SEAs context application, showing low quality in the baseline description, alternatives establishment and public participation.
\end{abstract}

Keywords: Strategic Environmental Assessment, Multilateral Agencies Development, developing countries, energy sector. 


\section{Lista de Figuras}

Figura 1 - Processamento Ambiental das Agências Multilaterais de Desenvolvimento .......... 48

Figura 2 - Número de aplicações de Avaliações Ambientais Estratégicas por Setor ................60

Figura 3 - Evolução do número de aplicações ao longo do tempo ........................................... 61

Figura 4 - Número de aplicações de AAEs por país asiático ..................................................62

Figura 5 - Número de aplicações de AAEs por país africano .................................................62

Figura 6 - Número de aplicações de AAEs por país da América Latina e Caribe ....................63

Figura 7 - Componentes do Projeto Energia Manantali ........................................................... 67

Figura 8 - Dimensões Estratégicas do Projeto Energia Manantali ......................................... 68

Figura 9 - Alinhamento do TR e AA do Projeto Energia Manantali em relação a aspectos-

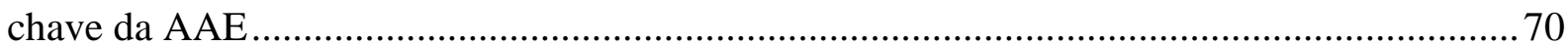

Figura 10 - Localização da República dos Camarões........................................................... 73

Figura 11 - Componentes do Projeto Energia Gasosa Kribi ................................................ 75

Figura 12 - Dimensões Estratégicas do Projeto Energia Gasosa Kribi ................................... 77

Figura 13 - Alinhamento do TR e AAR do Projeto Energia Gasosa Kribi em relação a

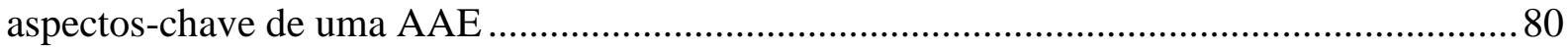

Figura 14 - Dimensões Estratégicas do Projeto de Desenvolvimento de Energia Nepal .........87

Figura 15 - Alinhamento do TR e AAR do Projeto de Desenvolvimento de Energia Nepal... 89

Figura 16 - Dimensões Estratégicas do Projeto hidrelétrico Kabeli « A » ..............................93

Figura 17- Alinhamento do TR e AIC do Projeto hidrelétrico Kabeli «A » ...........................95

Figura 18 - Dimensões Estratégicas do Projeto Nam Theun 2 ............................................ 102

Figura 19 - Alinhamento do TR e AIC do Projeto Nam Theun 2 ......................................... 108

Figura 20 - Dimensões Estratégicas do Projeto Hidrelétrico Rampur................................... 114

Figura 21 - Alinhamento do TR e AICI do Projeto Hidréletrico Rampur...............................116

Figura 22 - Dimensões estratégicas apresentadas pelos projetos analisados.......................... 120

Figura 24 - Alinhamento dos TRs em relação a aspectos-chave da AAE ............................. 121

Figura 23 - Alinhamento das Avaliações Ambientais em relação a aspectos-chave da AAE 122

Figura 25 - Revisão de qualidade dos relatórios................................................................ 182

Figura 26 - Seções das revisões de qualidade dos relatórios .............................................. 182 


\section{Lista de Quadros}

Quadro 1 - Distribuição por setor dos três maiores empréstimos das Agências Multilaterais de

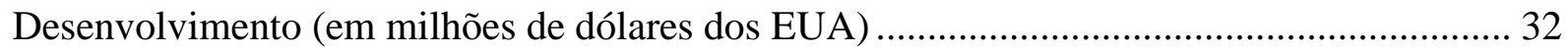

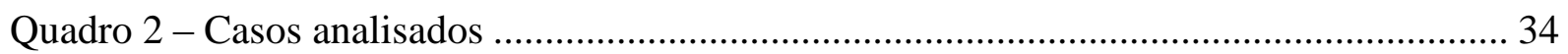

Quadro 3 - Dimensões características de Instrumentos de Planejamento ............................... 36

Quadro 4 - Critérios de avaliação para revisão de qualidade de relatório ............................... 40

Quadro 5 - Categorização Ambiental das Agências Multilaterais de Desenvolvimento ......... 47

Quadro 6 - Categorias e Níveis de aplicação da Avaliação Ambiental Estratégica no Banco

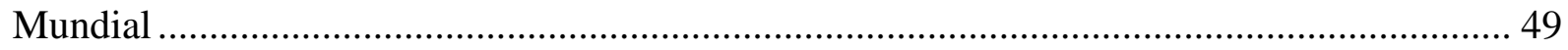

Quadro 7 - Alinhamento da política ambiental de AAE do BM com boas práticas ............... 50

Quadro 8 - Categorias e Níveis de aplicação da Avaliação Ambiental e Social Estratégica no

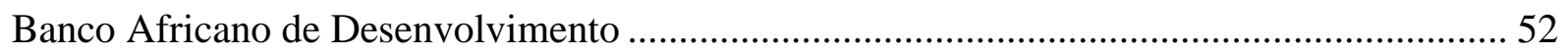

Quadro 9 - Alinhamento da política ambiental de AAE do BAD com boas práticas .............. 52

Quadro 10 - Categorias e Níveis de aplicação da Avaliação Ambiental Estratégica no Banco

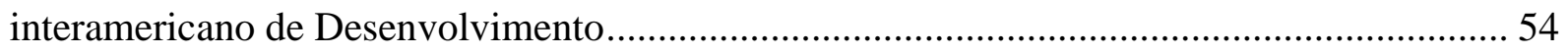

Quadro 11 - Alinhamento da política ambiental de AAE do BID com boas práticas ............. 55

Quadro 12 - Categorias e Níveis de aplicação da Avaliação Ambiental Estratégica no Banco

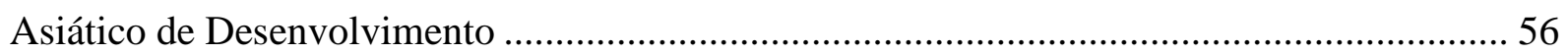

Quadro 13 - Alinhamento da política ambiental de AAE do ADB com boas práticas ............ 57

Quadro 14 - Relação TR padrão e TR específico do Projeto Energia Manantali .................... 71

Quadro 15 - Relação TR padrão e TR específico do Projeto Energia Gasosa Kribi ............... 80

Quadro 16 - Relação TR padrão e TR específico do Projeto hidrelétrico Kabeli «A »......... 96

Quadro 17 - Relação TR padrão e TR específico do Projeto hidrelétrico Nam Theun 2 ...... 108

Quadro 18 - Relação TR padrão e TR específico do Projeto hidrelétrico Rampur ................ 117

Quadro 19 - Informações sobre Avaliações Ambientais analisadas .................................... 118

Quadro 20 - Termo de Referência padrão e Termos de Referência específicos .................... 123

Quadro 21- Elementos solicitados nos Termos de Referência e atendidos pelas Avaliações

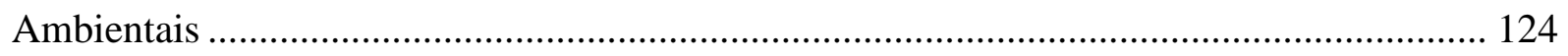

Quadro 22 - Revisão de qualidade do relatório da Avaliação Ambiental do Projeto Energia Manantali

Quadro 23 - Revisão de qualidade do relatório da Avaliação Ambiental Regional do Projeto Energia Gasosa Kribi .... 
Quadro 24 - Revisão de qualidade do relatório da Avaliação Ambiental Setorial do Projeto de Desenvolvimento de Energia Nepal

Quadro 25 - Revisão de qualidade do relatório da Avaliação de Impacto Cumulativo do Projeto hidrelétrico Kabeli «A » 154

Quadro 26 - Revisão de qualidade do relatório da Avaliação de Impacto Cumulativo do Projeto Nam Theun 2 162

Quadro 27 - Revisão de qualidade do relatório da Avaliação de Impacto Cumulativo e Induzido do Projeto Hidrelétrico Rampur 169

Quadro 28 - Revisão de qualidade dos relatórios 176 


\section{Lista de Siglas}

AA - Avaliação Ambiental

AAE - Avaliação Ambiental Estratégica

AAP - Avaliação Ambiental de Política

AAR - Avaliação Ambiental Regional

AAS - Avaliação Ambiental Setorial

ADB - Banco Asiático de Desenvolvimento

AIA - Avaliação de Impactos Ambientais

AIC - Avaliação de Impacto Cumulativo

AID - Associação Internacional de Desenvolvimento

AMD - Agência Multilateral de Desenvolvimento

BAD - Banco Africano de Desenvolvimento

BID - Banco Interamericano de Desenvolvimento

BIRD - Banco Internacional de Reconstrução e Desenvolvimento

BM - Banco Mundial

EIA - Estudo de Impacto Ambiental

EIAP - Estudo de Impactos Ambientais de Programa

FDE - Fundo de Desenvolvimento Energético

FUMIN - Fundo Multilateral de Investimentos

GBM - Grupo do Banco Mundial

$\mathrm{kV}$ - Quilovolt

$\mathrm{kW}$ - Quilowatt

LT - Linha de Transmissão

MW - Megawatt

NT2 - Projeto Nam Theun 2

ONG - Organizações Não Governamentais

PIB - Produto Interno Bruto

PPP - Políticas, Planos e Programas

TR - Termo de Referência 


\section{SUMÁRIO}

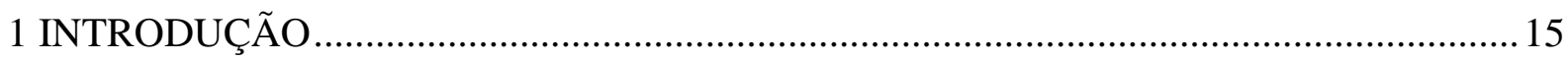

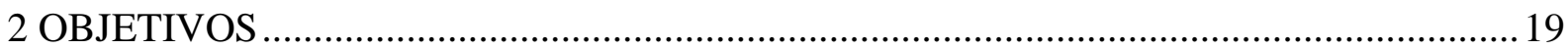

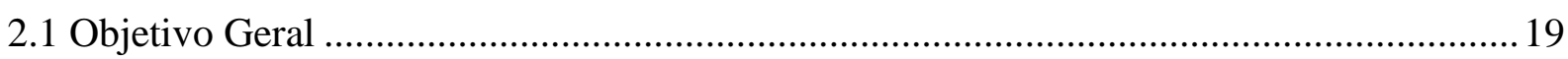

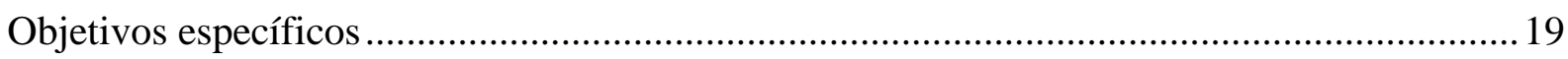

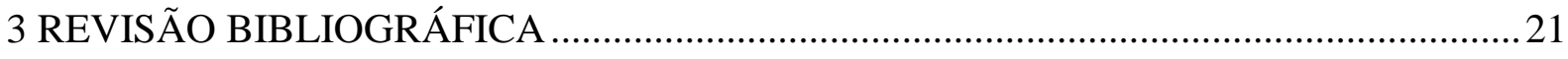

3.1 Origem e disseminação da Avaliação Ambiental Estratégica ..............................................21

3.2 Definição, Benefícios e Lacunas da Avaliação Ambiental Estratégica................................23

3.3 Nível de aplicação da Avaliação Ambiental Estratégica.....................................................25

3.4 A Avaliação Ambiental Estratégica no âmbito das AMDs ..................................................22

3.5 A influência do contexto na aplicação da Avaliação Ambiental Estratégica .......................29

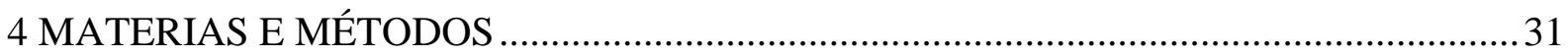

4.1 Contexto de Aplicação da AAE pelas AMDs .......................................................................33

4.1.1 Caracterização das diretrizes operacionais estabelecidas para a AAE ..............................33

4.1.2 Levantamento do perfil de aplicação das AAEs nos países em desenvolvimento ...........33

4.2 Verificação de Aspectos Estratégicos Associados às AAEs - Estudo de Casos

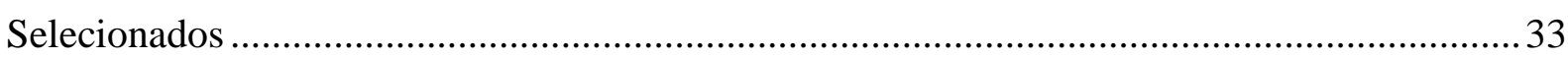

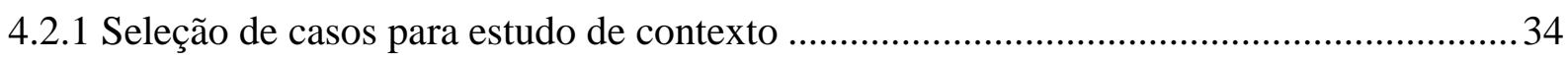

4.2.2 Levantamento de dimensões características de PPPs ......................................................35

4.2.3 Alinhamento de Termos de Referência e Avaliações Ambientais em relação a aspectos-

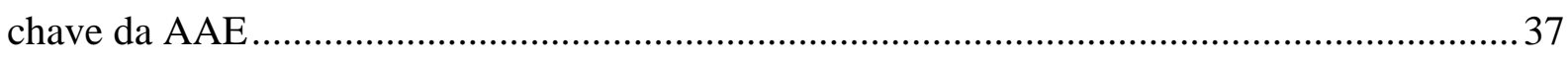

4.3 Revisão de qualidade de relatórios de Avaliações Ambientais .............................................38

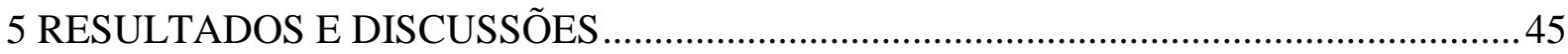

5.1 Contexto de Aplicação da AAE pelas AMDs .......................................................................4

5.1.1 Caracterização das políticas ambientais voltadas para AAE ..............................................45

5.1.2 Levantamento das AAEs solicitadas pelas AMDs ……………………………….........59 
5.2 Verificação de Aspectos Estratégicos associados às AAEs - Estudo de Casos Selecionados

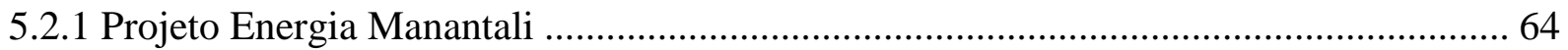

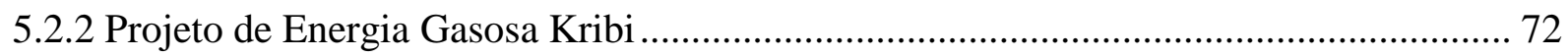

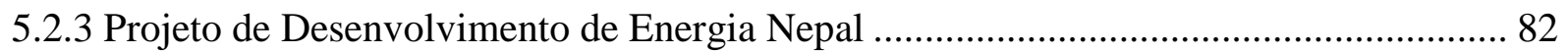

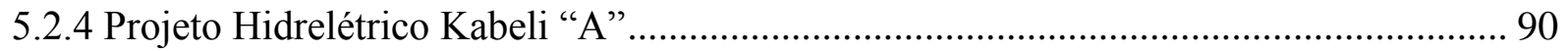

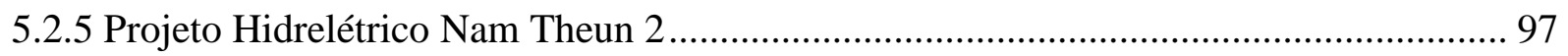

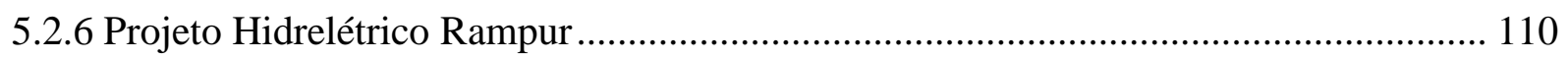

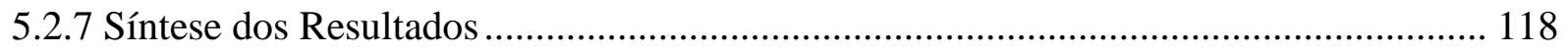

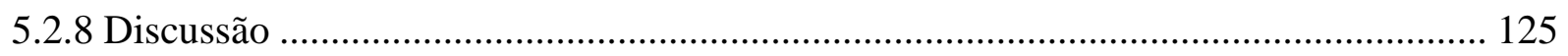

5.3 Revisão de qualidade de relatórios de Avaliações Ambientais....................................... 129

5.3.1 Revisão de qualidade do relatório da Avaliação Ambiental do Projeto Energia Manantali 129

5.3.2 Revisão de Qualidade do Relatório da Avaliação Ambiental Regional do Projeto de Energia Gasosa Kribi 137

5.3.3 Revisão de Qualidade do Relatório da Avaliação Ambiental Setorial do Projeto de Desenvolvimento de Energia Nepal. 146

5.3.4 Revisão de Qualidade do Relatório da Avaliação de Impacto Cumulativo do Projeto Hidrelétrico Kabeli "A" 152

5.3.5 Revisão de Qualidade do Relatório da Análise de Impacto Cumulativo do Projeto Hidrelétrico Nam Theun 2 160

5.3.6 Revisão de qualidade do relatório da Análise de Impacto Cumulativo e Induzido do

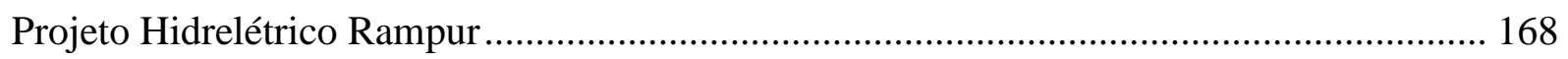

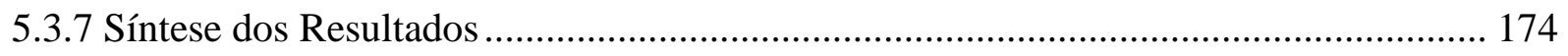

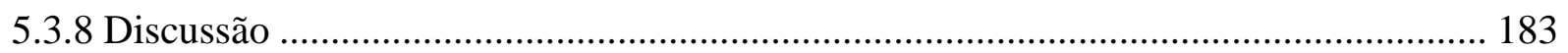

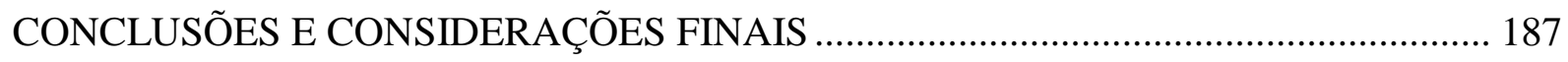

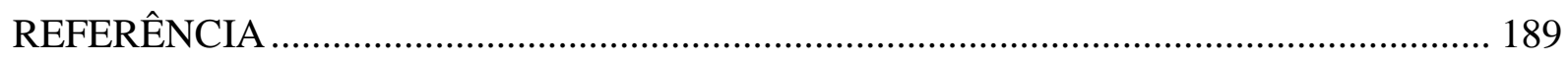

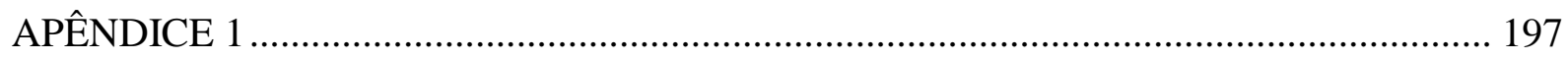




\section{INTRODUÇÃO}

A variável ambiental é um dos três pilares a serem considerados na busca pelo desenvolvimento sustentável. Uma das maneiras de se inserir esta dimensão no processo de tomada de decisão é por meio da Avaliação de Impactos Ambientais (AIA) aplicada tradicionalmente em nível de projetos. Embora amplamente difundida e formalizada mundialmente, a AIA de projetos apresenta limitações reconhecidamente importantes, tais como dificuldades de integração de efeitos cumulativos; visão reativa aos impactos de projetos em vez de preventiva; e limitações quanto à consideração de alternativas locacionais e tecnológicas que poderiam contribuir para evitar determinados impactos conforme evidencia a literatura (ALSHUWAIKHAT, 2005; BINA, 2007; DALAL-CLAYTON; SADLER, 2005; LEE; WALSH, 1992; LOBOS; PARTIDÁRIO, 2007, 2014; TETLOW; HANUSCH, 2012). O reconhecimento das limitações desse instrumento avaliativo - que, no cenário mundial, estabelece-se hegemonicamente como um dos requisitos legais para empreendimentos e projetos $^{1}$ - tem estimulado a adoção de procedimentos de avaliação ambiental (AA) voltados para os níveis anteriores (na cadeia decisória) ao nível de projeto, ou seja, para os níveis estratégicos da tomada de decisão.

Sendo assim, a Avaliação Ambiental Estratégica (AAE) surge como um instrumento que auxilia o processo de tomada de decisões de Políticas, Planos e Programas (PPP) podendo, posteriormente, facilitar a aplicação da AIA de projetos conforme sugerem Alshuwaikhat (2005), Burian (2006), Noble (2009) e Partidário (2007). Para Fischer (2007), a AAE é um processo sistemático de apoio à decisão que visa garantir que aspectos ambientais e, possivelmente, outros aspectos de sustentabilidade sejam considerados na elaboração de PPP. Partidário (2000) define a Avaliação Ambiental Estratégica como: "um método, um procedimento administrativo formal, uma série de tarefas bem definidas em um processo racionalizado ou um quadro para uma melhor tomada de decisão ...”. Esse instrumento deve procurar promover certo rigor científico às alternativas que irão definir as ações estratégicas ${ }^{2}$ e prover um quadro estruturado de informações para a tomada de decisão (FISCHER, 2007).

Dentre os benefícios dessa ferramenta, Partidário (2007) destaca a possibilidade em auxiliar o processo de planejamento na decisão de rumos estratégicos a se seguir, refletindo sobre as oportunidades e os riscos ou potenciais consequências - positivas e negativas - das

\footnotetext{
${ }^{1}$ De acordo com Morgan (2012), 191 dos 193 membros das Nações Unidas apresentam legislação específica para que se faça referência ao uso da AIA.

${ }^{2} \mathrm{O}$ termo Ações Estratégicas, bastante utilizado na literatura, refere-se a Políticas, Planos e Programas.
} 
possíveis direções; ou estratégias que podem levar ao futuro desejado. Outro aspecto positivo já apontado por Lee e Walsh (1992), reforçado por Dalal-Clayton e Sadler (2005) e salientado por Lobos e Partidário (2014) é o fato de ela propiciar a consideração de opiniões dos principais interessados pelos tomadores de decisão. Ainda é capaz de possibilitar a consideração de alternativas, muitas vezes ignoradas ou inviáveis em nível de projeto, conforme apontaram Alshuwaikhat, (2005), Fischer (2003), Noble (2009), Partidário (1996, 2000, 2007) e Wood e Dejeddour, (1992); de proporcionar a consideração de efeitos cumulativos, sinergéticos e secundários na tomada de decisão (LEE; WALSH, 1992; WOOD; DEJEDDOUR, 1992); e de se adaptar ao contexto de aplicação como demonstram as publicações de Verheem e Tonk (2000), Dalal-Clayton e Sadler (2005), João e Mclauchlan (2014) e Lobos e Partidário (2014).

No entanto, devido aos diversos contextos em que é aplicada, a literatura alerta para a existência de uma extensa variedade de modelos e abordagens de Avaliação Ambiental Estratégica (DALAL-CLAYTON; SADLER，2005; FISCHER; GAZZOLA， 2006; PARTIDÁRIO, 2000; VERHEEM; TONK, 2000). A AAE opera de diversas formas, sob múltiplos quadros institucionais e metodológicos, e expectativas (NOBLE, 2009). Dada essa diversidade, todas as tentativas em racionalizar a AAE para que esse instrumento sirva para todos os quadros de tomada de decisão não são úteis. Desta forma, não existe uma abordagem universal para essa ferramenta. Assim, de acordo com González, Torre e Milán (2014); Runhaar e Driessen (2007) e Polido, João e Ramos (2004), deve-se salientar que a AAE exige grande capacidade de adaptação e flexibilidade ao contexto em que é aplicada, uma vez que lida com uma série de forças mistas atuando em várias frentes, diferentes valores sociais, e altos níveis de incerteza em termos de resultados esperados (PARTIDÁRIO, 2000).

A finalidade e o papel da AAE devem ser específicos ao contexto, isto é, enquadrados aos aspectos institucional, administrativo, político e cultural em que está sendo aplicado (DALAL-CLAYTON; SADLER, 2005; FISCHER; GAZZOLA, 2006).

Desta forma, entende-se que a compreensão dos elementos contextuais que influenciam na aplicação da AAE é essencial para o estabelecimento de seu valor junto ao processo decisório (HILDING-RYDEVIK; BJARNADÓTTIR, 2007; NOBLE, 2009).

No caso dos países em desenvolvimento, que via de regra não dispõem de um arcabouço institucional específico para a aplicação e integração da AAE ao processo de formulação de ações estratégicas, as Agências Multilaterais de Desenvolvimento (AMDs) surgem como os elementos principais de estímulo à utilização deste instrumento, vinculado às 
políticas de salvaguarda das instituições financeiras e acionado - como destacam Tetlow e Hanusch (2012) - no âmbito de ações de cooperação para o desenvolvimento.

Ainda que a literatura seja contundente quanto à necessidade de flexibilidade e adaptação ao contexto de aplicação, as pesquisas em AAE não têm considerado o percurso verificado nos países em desenvolvimento (FISCHER; ONYANGO, 2012) ${ }^{3}$. Nesse sentido, a presente pesquisa de Mestrado é voltada para a análise da aplicação da AAE em países em desenvolvimento, buscando-se caracterizar um conjunto de elementos contextuais associados à sua utilização pelas AMDs no âmbito do estabelecimento de acordos de cooperação para o desenvolvimento.

\footnotetext{
${ }^{3}$ Os resultados obtidos por Fischer e Onyango (2012), ao analisar as publicações das duas últimas décadas, revelam que mais da metade de projetos de pesquisa se reporta a países da América do Norte e Europa.
} 


\section{OBJETIVOS}

\subsection{Objetivo Geral}

Caracterização e análise da utilização da Avaliação Ambiental Estratégica pelas Agências Multilaterais Desenvolvimento, no contexto dos acordos multilaterais de financiamento estabelecidos com países em desenvolvimento.

\section{Objetivos específicos}

i. Identificação da abordagem preconizada para a aplicação da Avaliação Ambiental Estratégica pelas Agências Multilaterais de Desenvolvimento, a partir da caracterização de suas políticas de salvaguarda.

ii. Estabelecer o perfil de aplicação da Avaliação Ambiental Estratégica pelas Agências Multilaterais de Desenvolvimento selecionadas.

iii. Caracterização dos aspectos estratégicos dos objetos submetidos às avaliações.

iv. Verificação do alinhamento dos Termos de Referência e avaliações ambientais com aspectos-chave que orientam uma Avaliação Ambiental Estratégica.

v. Revisão da qualidade dos relatórios de Avaliação Ambiental Estratégica elaborados. 


\section{REVISÃO BIBLIOGRÁFICA}

A presente pesquisa foi amparada por revisão bibliográfica sistemática, observando-se os procedimentos descritos por Conforto, Amaral e Silva (2011). Sendo assim, as etapas de busca, análise dos resultados e documentação seguiram um processo iterativo aplicado sobre as principais bases de artigos científicos (Scopus, ScienceDirect e Web of Science.), empregando-se strings de busca que auxiliassem na identificação do estado-da-arte da AAE no contexto de sua aplicação pelas Agências Multilaterais de Desenvolvimento.

\subsection{Origem e disseminação da Avaliação Ambiental Estratégica}

A Política Nacional do Meio Ambiente dos Estados Unidos (NEPA) de 1969 foi o primeiro instrumento jurídico de Avaliação Ambiental no mundo (FISCHER, 2007), contendo as bases para tanto a AIA e AAE conforme relacionam González, Torre e Milán (2014) e Morgan (2012). Antes desta política, a consideração dos aspectos ambientais na tomada de decisão para projetos e ações estratégicas ocorreu de forma incremental, ou seja, a prática se afastava dos problemas, em vez de buscar alcançar os objetivos. A fim de remediar esta situação insatisfatória, Fischer (2003) aponta que a avaliação ambiental formal foi introduzida como um instrumento proativo para enfrentar consequências ambientais antes da ação prática.

Segundo Dalal-Clayton e Sandler (2005), desde a regulamentação do conceito de AAE nos Estados Unidos da América, a avaliação ambiental de PPPs foi introduzida nas estruturas legais dos governos nacionais, organizações internacionais e bancos de desenvolvimento em todo o mundo. A ampla adoção de procedimentos de Avaliação Ambiental Estratégica está indissoluvelmente ligada a uma maior compreensão da relação entre desenvolvimento e meio ambiente, que passou por profundas mudanças desde o início do movimento ambientalista moderno nos anos 1960 e 1970. No entanto, para Tetlow e Hanusch (2012), a disseminação da Avaliação Ambiental Estratégica acelerou-se rapidamente a partir desse ponto no tempo, em parte devido a três gatilhos importantes: (i) o Banco Mundial e outras agências doadoras estimulando a prática de AAE no contexto de cooperação para o desenvolvimento, (ii) a adoção e transposição da Diretiva Europeia 2001/42/EC e (iii) a aprovação e negociação do Protocolo AAE da Convenção de Espoo.

Em particular, a Diretiva Europeia (2001/42/CE) de AAE e o Protocolo de AAE da Comissão Econômica das Nações Unidas para a Europa, num Contexto Transfronteiriço, são 
dois dos mais significativos quadros jurídicos internacionais para AAE. Ambos os instrumentos prescrevem, para a Avaliação Ambiental Estratégica, um procedimento baseado na Avaliação de Impacto Ambienal de projetos e se norteiam muito na Diretiva Europeia (1997/00/CE) sobre AIA (DALAL-CLAYTON; SADLER, 2005). Desde 21 de Julho de 2004, a Avaliação Ambiental Estratégica é exigida, em atendimento à Diretiva 2001/42/CE, para a avaliação de efeitos de determinados planos e programas no meio ambiente em todos os Estados membros da União Europeia como mencionam João e Mclauchlan (2014). Esta diretiva destina-se a ajudar a proteger o meio ambiente e promover o desenvolvimento sustentável por meio da integração da dimensão ambiental na tomada de decisões (FISCHER, 2003).

O Protocolo AAE da Convenção de Espoo foi adotado em 21 de Maio de 2003, durante a Conferência Ministerial "Meio Ambiente para a Europa" em Kiev. Ele entrou em vigor em julho de 2010, sendo ratificado por 16 estados. O Protocolo estabelece um quadro não obrigatório de aplicação de Avaliação Ambiental Estratégica para as políticas e legislação, além de planos e programas, que é o âmbito da diretiva europeia. Ele também coloca uma forte ênfase na consideração da saúde dentro de avaliações ambientais. Estando aberto a todos os Estados-Membros das Nações Unidas, o Protocolo de AAE tem uma aplicação potencialmente global (TETLOW; HANUSCH, 2012).

Dalal-Clayton e Sadler (2005) salientam que muitos observadores acreditam que a Diretiva Europeia e o Protocolo de Avaliação Ambiental Estratégica se tornarão padrões internacionais de referência, particularmente no âmbito da esfera de influência da União Europeia, e as suas atividades de ajuda e assistência.

Atualmente, além de países europeus, poucos países têm requisitos legais ou formalizados para AAE como China (incluindo Hong Kong), Indonésia, Taiwan, Coreia do Sul, Japão e Vietnã onde a Avaliação Ambiental Estratégica é regulamentada por lei (VICTOR; AGAMUTHU, 2014). A África do Sul, segundo Dalal-Clayton e Sadler (2005), estabeleceu diretrizes para guiar a aplicação desta ferramenta e consequentemente promover um desenvolvimento sustentável.

Em um número crescente de países e organizações internacionais, a AAE é realizada tanto formal como informalmente. No Brasil, Pellin et al. (2011) discorrem que as práticas voluntárias acompanham a tendência mundial de considerações da variável ambiental nos PPPs. A Comissão do Rio Mekong, agência intergovernamental, tem aplicado essa ferramenta para avaliar impactos regionais. Em muitos países asiáticos, o requerimento da aplicação de instrumentos de Avaliação Ambiental pelas Agências Multilaterais de Desenvolvimento para 
conceder financiamentos resultou em uma consideração da dimensão ambiental na tomada de decisão apenas como uma medida política sem uma verdadeira conscientização da sua importância conforme relatou Alshwaikhat (2005).

\subsection{Definição, Benefícios e Lacunas da Avaliação Ambiental Estratégica}

A literatura existente sobre Avaliação Ambiental Estratégica oferece um número considerável de definições que de alguma forma refletem os mais diversos tipos de abordagens. Algumas definições foram selecionadas para ilustrar o conceito de AAE:

- Para Lee e Walsh (1992), Avaliação Ambiental Estratégica é o termo usado para descrever o processo de avaliação ambiental das políticas, planos e programas que são aprovados antes da autorização dos projetos individuais;

- Partidário (2000) define a Avaliação Ambiental Estratégica como sendo um método, um procedimento administrativo formal, uma série de tarefas bem definidas em um processo simplificado. Segunda a autora este instrumento pode ser visto como um quadro para uma melhor tomada de decisão, com elementos centrais estrategicamente colocados no processo de tomada de decisão de PPPs para assegurar que os princípios de sustentabilidade e avaliação de impacto sejam totalmente integrados à tomada de decisão;

- Para Herrera (2007), a avaliação ambiental estratégica é um processo destinado a melhorar a consistência do processo de tomada de decisões a partir de uma perspectiva ambiental, promovendo a aplicação dos requisitos de consistência de decisões específicas para o contexto de decisão avaliada. Os requisitos de consistência das decisões são específicos para cada sociedade e mudam ao longo do tempo;

- Para Fischer (2007) a Avaliação Ambiental Estratégica é um processo sistemático de apoio à decisão que visa garantir que aspectos ambientais e, possivelmente, outros aspectos de sustentabilidade sejam considerados na elaboração de PPPs.

A terminologia encontrada na literatura, quando se refere à Avaliação Ambiental (AA) em nível estratégico, é bastante diversificada: AA de política; Avaliação do Impacto de Políticas; Avaliação Ambiental Estratégica; AA setoriais; Estudos de Impacto Ambiental de programas; AA de política, plano e programa; integração de AA à formulação de políticas, planos e desenvolvimento de programas; integração das questões ambientais ao processo de 
tomada de decisão; AA de propostas governamentais. Estes são talvez os termos mais usados para se referir às formas de AAE conforme Partidário (1996) menciona.

No entanto, ainda que algumas vezes as definições diferissem, a maioria - como apontam Verheem e Tonk (2000); Herrera (2007) - concorda em considerar o conceito geral de Avaliação Ambiental Estratégica como um processo estruturado, proativo, usado para reforçar o papel das questões ambientais na tomada de decisões estratégicas.

Segundo Tetlow e Hanusch (2012), a AAE é aplicada em níveis diferentes de atividade estratégica (por exemplo, legislação, empréstimos, políticas, planos e programas) em todo o mundo. Esta ferramenta pode ser aplicada a uma área geográfica específica (por exemplo, regional, local ou nacional), um setor em particular (por exemplo, transportes, agricultura, silvicultura, energia, gestão de resíduos, turismo) ou a uma questão específica (por exemplo, alterações climáticas, biodiversidade). Geralmente, os setores de aplicação deste instrumento vão depender dos tipos de PPPs e disposições de Avaliação Ambiental Estratégica específicas do país.

A aplicação da AAE aos diversos níveis de decisão estratégica está associada a potenciais benefícios, como reportado na literatura. Com efeito, a AAE estimula a abordagem proativa e a consideração de uma ampla variedade de alternativas (ALSHUWAIKHAT, 2005; LEE; WALSH, 1992; PARTIDÁRIO, 1996); melhor e ampla consideração de efeitos cumulativos e indiretos (LEE; WALSH, 1992); redução da carga de trabalho da AIA de projeto (ALSHUWAIKHAT, 2005; FISCHER, 2003; LEE; WALSH, 1992; PARTIDÁRIO, 1996); subsídio do reforço das capacidades das instituições (LOBOS; PARTIDÁRIO, 2014); consideração de fatores ambientais na concepção de planejamento e desenvolvimento de propostas (ALSHUWAIKHAT, 2005; BINA, 2007; DALAL-CLAYTON; SADLER 2005; FISCHER, 2003; HERRERA, 2007; JOÃO; MCLAUCHLAN, 2014; LEE; WALSH, 1992; PARTIDÁRIO, 1996, 2000); auxílio no processo de planejamento na decisão de rumos estratégicos a seguir, refletindo sobre as oportunidades e os riscos ou potenciais consequências positivas e negativas, das possíveis direções, ou estratégias, que podem levar ao futuro desejado (PARTIDÁRIO, 2007); consideração de opiniões dos principais interessados pelos tomadores de decisão (DALAL-CLAYTON; SADLER 2005; LEE; WALSH, 1992; LOBOS; PARTIDÁRIO, 2014); consideração de alternativas, muitas vezes ignoradas ou inviáveis em nível de projeto (ALSHUWAIKHAT, 2005; LEE; WALSH, 1992; PARTIDÁRIO, 1996); subsídio do processo de desenvolvimento de políticas, planos e programas, que é contínuo por natureza, e não apenas com o instrumento política, plano ou programa por si só (PARTIDÁRIO, 1996); adaptação ao contexto de aplicação (DALAL- 
CLAYTON; SADLER 2005; JOÃO; MCLAUCHLAN, 2014; LOBOS; PARTIDÁRIO, 2014; VERHEEM; TONK, 2000).

Todavia, a prática da Avaliação Ambiental Estratégica apresenta algumas lacunas, dificultando o proveito dos benefícios que esta ferramenta proporciona. Para Bina (2007), apesar de ter sido concebido como uma resposta à crise verificada na prática da AIA de projetos, durante o seu período inicial de conceptualização e implementação a AAE não se distanciou fundamentalmente da Avaliação de Impacto Ambiental. Para a autora, o papel da AAE, na contribuição para um desenvolvimento sustentável, ainda não é bem compreendido e discutido. Para González, Torre e Milán (2014) várias questões importantes, tais como a busca por uma participação pública mais ampla e a incorporação de considerações ambientais nos planos de desenvolvimento do México e China têm sido esquecidas. Ademais, os autores discutem o fato de que a implementação de leis e regulamentos baseados em princípios sociais, ecológicos, económicos e científicos permanece um desafio. Noble (2009), analisando a AAE no Canadá, aponta a falta de conexão e a transmissão limitada entre os resultados de avaliações de níveis estratégicos superiores e resultados de avaliações de níveis estratégicos subsequentes. Para Lobos e Partidário (2014) há uma subestimação do papel da Avaliação Ambiental Estratégica em moldar o design de PPPs e a proposta final durante todo o processo de concepção da ação estratégica.

Percebe-se que embora a Avaliação Ambiental Estratégica proporcione muitos benefícios, a sua aplicação apresenta lacunas. Contudo, vale lembrar que esta ferramenta atua em diferentes contextos devendo ser adaptando aos vários objetos de estudo. Sendo assim, as lacunas também são contextuais e não são vivenciadas em todos os contextos de aplicação de AAE.

\subsection{Nível de aplicação da Avaliação Ambiental Estratégica}

A AAE tem evoluído de um mecanismo reativo baseado, em grande parte, na AIA de projetos, para um processo muito mais proativo de desenvolvimento de soluções sustentáveis, como parte integrante de atividades de planejamento estratégico (TETLOW; HANUSCH, 2012).

A Avaliação de Impacto Ambiental é uma ferramenta que se aplica em projeto para avaliar os impactos ambientais causados por ele. O fato de que a AIA de projetos não se aplica a Políticas, Planos e Programas continua a ser a razão mais citada como justificativa da necessidade da Avaliação Ambiental Estratégica. O principal argumento tem sido que 
importantes decisões são tomadas antes da aprovação de projetos, durante a formulação de PPPs, e estas decisões devem ser objeto de avaliação ambiental (LOBOS; PARTIDÁRIO, 2014). A tarefa de avaliar uma série de iniciativas estratégicas, amplamente referidas como PPPs, tornou-se a chave empregada para distinguir AAE de AIA de projetos (BINA, 2007).

Um aspecto importante remete às diferenças entre os objetos avaliados na esfera de projetos e na esfera estratégica, destacando-se: (i) a diferença na precisão de definição de implicações espaciais: enquanto os projetos são normalmente localizados com precisão, os impactos geográficos de políticas, planos e programas, com exceção de planos de uso da terra, muitas vezes são menos definidos; (ii) a diferença no que diz respeito a detalhes de desenvolvimento físico: muitas vezes, não há detalhes sobre desenvolvimentos físicos específicos propostos nas políticas, planos e, em menor grau, nos programas (PARTIDÁRIO, 1996); (iii) a diferença no prazo de entrega: um projeto é geralmente executado em um espaço de tempo mais curto sendo que o prazo de execução de uma política ou um plano pode abranger vários anos ou mesmo décadas; (iv) a diferença nos procedimentos e entidades envolvidas: o projeto geralmente tem um proponente e uma entidade competente responsável pelo licenciamento, em muitos casos estes são corpos distintos. Além disso, os projetos geralmente são restritos a apenas um setor. Por outro lado, as ações estratégicas são, muitas vezes, concebidas e sancionadas pela mesma entidade; além de envolver vários setores (LEE; WALSH, 1992).

Estas diferenças evidenciam a necessidade de uma ferramenta que lide com aspectos estratégicos. No entanto, a AAE segue padrão de práticas, atividades e processos da AIA, tais como a triagem, a escopo, a avaliação, a mitigação, a elaboração de relatórios e o monitoramento. A Avaliação Ambiental Estratégica herdou os elementos básicos e a metodologia de Avaliação de Impacto Ambiental, embora olhando para diferentes níveis de decisão - Política, Plano e Programa - como Lee e Walsh (1992), Lobos e Partidário (2014) e Partidário (2007) revelam.

Para Lee e Walsh (1992), Noble (2009) e Partidário (2007), idealmente, a AAE e a AIA de projeto devem ser aplicadas em sequência, sendo que a AAE examina proativamente uma gama de alternativas e escolhe o melhor curso de ação. A avaliação de projeto é, então, iniciada para determinar com mais detalhes os potenciais impactos e opções de implementação da "melhor" alternativa.

Devem-se esclarecer as sobreposições entre AAE e AIA, e assumir a AAE como uma excelente ferramenta, diferente em suas características da AIA, em relação ao âmbito de 
aplicação; mas, acima de tudo, em relação ao contexto de aplicação, objetivo, foco e condução da AA (PARTDÁRIO, 2007).

\subsection{A Avaliação Ambiental Estratégica no âmbito das AMDs}

As Agências Multilaterais de Desenvolvimento têm sido apontadas como estimuladoras e incentivadoras da aplicação de Avaliações Ambientais como elementos de salvaguarda aos empréstimos realizados. Uma das avaliações aplicadas é a Avaliação de Impactos Ambientais que já se firmou no âmbito das Instituições Internacionais de Financiamento. Esta ferramenta se aplica em nível de projeto objetivando inserir a dimensão ambiental na tomada de decisão. No entanto, embora este instrumento seja amplamente aplicado há mais de quatro décadas e valioso para tratar aspectos ambientais de projetos, ele tem mostrado limitações (já na década de 1990) ao lidar com aspectos estratégicos que envolvem, dentre outros, efeitos cumulativos e indiretos. O reconhecimento dos limites desta ferramenta tem estimulado a adoção de procedimentos de Avaliação Ambiental Estratégica voltados para os níveis anteriores (na cadeia decisória) ao nível de projeto, ou seja, para os níveis estratégicos da tomada de decisão (ALSHUWAIKHAT, 2005; REES, 1999).

Foi neste cenário que a Avaliação Ambiental Estratégica foi adotada e o seu uso enfatizado pelas AMDs com o propósito de promover um desenvolvimento sustentável (DALAL-CLAYTON; SADLER, 2005; GOODLAND, 2005). A adoção desta ferramenta no âmbito das AMDs decorreu não somente das limitações da AIA como também da mudança (na década de 1990) da política de financiamento dessas instituições. Estas passaram a financiar além de projetos (como antes), Políticas, Planos e Programas no intuito de se tornar mais influentes sobre o país mutuário, uma vez que uma ação estratégica envolve muitos projetos (ANNANDALE et al., 2001), portanto, o seu alcance é maior.

O Banco Mundial foi a primeira AMD a adotar a Avaliação Ambiental Estratégia em 1999 (WORLD BANK, 2013a); em seguida foram o Banco Africano de Desenvolvimento e o Banco Asiático de Desenvolvimento respectivamente em 2001 (BANQUE AFRICAINE DE DÉVELOPPEMENT, 2001) e 2003 (ASIAN DEVELOPMENT BANK, 2003b); e por fim o Banco Interamericano de Desenvolvimento em 2007 (INTER-AMERICAN DEVELOPMENT BANK, 2007).

A Avaliação Ambiental exige a introdução de um quadro regulamentar forte, juntamente com instituições, práticas, tecnologias e profissionais de campos que podem tornar possível o tratamento rigoroso dos aspectos ambientais e sociais do desenvolvimento, dentro 
do que é considerado como um processo legítimo. No entanto, isso inevitavelmente levanta questões sobre a capacidade dos mecanismos de governança existentes de lidar com esses desafios, fato que por sua vez leva os seus defensores a argumentar que a Avaliação Ambiental, em si, pode revelar fraquezas mais profundas da governança em relação ao meio ambiente. Isto vai exigir a fixação destas imperfeições para obter os financiamentos almejados. Essa imposição é decorrente da falta de vontade em questionar os princípios que fundamentam as cooperações de desenvolvimento contemporâneas: quando uma assistência ao desenvolvimento falha é porque a implementação foi problemática, não porque os princípios subjacentes foram equivocados. Assim, há um interesse emergente em uma forma de AA que tem um foco institucional, transformando-o em um instrumento que lida precisamente com a má governança ambiental (RICHARDSON; CASHMORE, 2011).

A AAE aplicada pelo Banco Mundial parece fornecer uma ferramenta orientada para a remodelação da cultura política e regulação de condutas por meio de uma racionalidade de empoderamento e boa governança (CASHMORE; RICHARDSON; AXELSSON, 2014). A tentativa do BM de usar a AAE para para mudar as normas de governança, regras e práticas em países-alvo pode ser interpretada como uma ação para desestruturar a má-governança existente, promover novas normas estruturais e estimular a aceitação de novas tendências (RICHARDSON; CASHMORE, 2011).

Uma AAE centrada na instituição evidencia elementos de má governança e uma série de propostas para a criação de "boa governança" através de uma reforma institucional, mas não tem por si só, a autoridade ou influência de trazer as mudanças prescritas. Há uma lacuna potencial entre as intenções normativas do BM e as formas pelas quais os Estados e os atores governamentais, em diferentes níveis, levam, ativamente, em conta as análises e recomendações da avaliação. Claramente, as implicações de uma AAE, centrada na instituição, são enormes em situações onde as práticas de corrupção e outras más governanças são a norma como sugerem Richardson e Cashmore (2011). Neste caso, o poder (das instituições) tem uma influência positiva ou negativa muito significativa sobre a avaliação a ser realizada (CASHMORE; AXELSSON, 2013). Talvez, um instrumento deste tipo deva ser visto como parte de um modelo idealizado de governança que a corporação acredita e, assim, reproduzir este modelo torna-se um objetivo importante, independentemente de ser realmente implementado ou não (RICHARDSON; CASHMORE, 2011).

As AMDs atuam em diversos contextos cujas especificidades influenciam a busca pela boa governança. Slunge e Loayza (2012) apontam fatores sociais, falta de vontade política, falta de apropriação da ferramenta como elementos que limitam a influência da AAE. Para 
Axelsson et al. (2012), os contextos sociopolíticos e culturais são diferentes e podem influenciar a prática de AAE. Percebe-se a relevância da AAE e o seu papel no âmbito das AMDs. Assim sendo, todos os fatores contextuais devem ser levado em consideração para um melhor aproveitamento de benefícios proporcionados por este instrumento.

\subsection{A influência do contexto na aplicação da Avaliação Ambiental Estratégica}

De acordo com Hilding-Rydevik e Bjarnadóttir (2007), o contexto no âmbito da Avaliação Ambiental Estratégica é: "Um conjunto de fatos ou circunstâncias que têm um impacto sobre as abordagens ${ }^{4}$ escolhidas para a AAE. O contexto também é o conjunto de fatos e condições que têm um impacto sobre os resultados ${ }^{5}$ da implementação da Avaliação Ambiental Estratégica".

Atualmente, a literatura concorda sobre o fato de que a AAE é um instrumento que deve variar de acordo com o seu contexto de aplicação. No entanto, exatamente como esta ferramenta deve ser adaptada é uma questão em aberto, principalmente em relação às decisões de política (AXELSSON et al., 2012).

Mclauchlan e João (2010) analisaram a questão de "Justiça Ambiental" na Escócia ressaltando o caráter utópico da resolução deste aspecto pela AAE e, portanto a necessidade de adaptar a política ambiental escocesa; Fischer e Gazzola (2006) sugeriram que a AAE se adapte ao contexto italiano para que seja mais efetiva neste país; Therivel e Minas (2002) discutiram como o tempo, os recursos, os responsáveis pela condução e a documentação influenciam na efetividade da AAE. Axelsson et al. (2012) analisaram desafios de profissionais de avaliação de impacto refletindo sobre as lições aprendidas a partir da aplicação de uma abordagem inovadora (desenvolvida pelo Banco Mundial) de AAE aplicada a política; Silva et al. (2014) apontam o exercício da vontade política e o compromisso de integrar as questões ambientais e de sustentabilidade na tomada de decisão como um dos principais desafios da AAE no Brasil; Margato e Sánchez (2014) apontam que a AAE no Brasil (assim como em outras jurisdições em que ela não é obrigatória) deve ser

\footnotetext{
${ }^{4}$ Segundo os autores, "as abordagens se referem à meta e objetivos ligados a AAE, as expectativas colocadas sobre a implementação de $\mathrm{AAE}$, as etapas escolhidas na sua implementação e seu método de aplicação na prática."

${ }_{5}^{5}$ De acordo com os autores, "os resultados se referem os impactos e efeitos que a implementação da AAE tem sobre o conteúdo de um plano, tomada de decisão, participantes no processo de planejamento, modo de funcionamento das organizações que participam do processo de planejamento, tanto a curto como a longo prazo."
} 
satisfatoriamente relacionada ao contexto de tomada de decisão de tal modo que o seu valor possa ser discernível.

Os elementos que contribuem para a influência da AAE sobre a ação estratégica podem ser explicados, para alguns, pelas especificidades encontradas na operação do instrumento, uma vez que nem todos os fatores são importantes dependendo do contexto de tomada de decisão (DOREN et al., 2013; RUNHAAR; DRIESSEN, 2007; CHANCHITPRICHA; BOND, 2013). Jiliberto (2011) enfatiza que a eficácia de uma AAE invariavelmente difere de acordo com o contexto em que é aplicada. Os processos de tomada de decisão variam de acordo com a estrutura de poder e suas regras, com a estrutura institucional e as suas prioridades, com a tradição de planejamento e, além disso, com PPP específicos, influenciados por questões ambientais, sociais, culturais e políticas.

De acordo com Grindle (2007), sem uma compreensão completa destas limitações contextuais, corre-se o risco de atribuir expectativas irrealistas sobre aquilo que a AAE pode oferecer, estabelecendo-se referências de boas práticas não compatíveis com o contexto de aplicação, e há um risco de investir recursos escassos de forma não optimizada. Em vez de adaptar os procedimentos de $\mathrm{AAE}$ ao contexto encontrado, há um risco de introdução de uma abordagem demasiado ambiciosa, baseada nas melhores práticas internacionais desenvolvidas em outros contextos.

Por outro lado, a integração da AAE ao processo de planejamento contribui para a estruturação do processo decisório (EALES; SHEATE, 2011), e nesse caso a orientação pelas melhores práticas internacionais pode ser salutar. Seja como for, percebe-se que o contexto é crucial. É preciso entendê-lo para uma boa compreensão do valor da AAE (HILDINGRYDEVIK; BJARNADÓTTIR, 2007; NOBLE, 2009) e, consequentemente, um melhor aproveitamento de seus benefícios. 


\section{MATERIAS E MÉTODOS}

Tendo em vista os objetivos da pesquisa, foram adotados procedimentos metodológicos voltados para: (i) o estabelecimento do contexto de aplicação das AAEs pelas AMDs, fundamentado em suas políticas de salvaguarda e no perfil de aplicação do instrumento em países em desenvolvimento; (ii) a identificação dos aspectos estratégicos dos objetos avaliados, bem como seus respectivos termos de referência (TRs) e avaliações ambientais; (iii) a revisão da qualidade dos relatórios de Avaliação Ambiental Estratégica.

As informações coletadas referem-se à atuação de quatro agências, a saber: o Banco Mundial, Banco Interamericano de Desenvolvimento, Banco Africano de Desenvolvimento e Banco Asiático de Desenvolvimento. Esta delimitação se justifica pelo fato de que estas corporações concedem seus financiamentos a todos os países em desenvolvimento, são agências com maior volume de recursos negociados, além de frequentemente apontadas na literatura (CASHMORE; RICHARDSON; AXELSSON, 2014; PELLIN et al., 2011; REES, 1999).

Para fins de realização dos levantamentos foi estabelecido o ano de 1999 como marco temporal, tendo em vista a adoção da AAE pelo Banco Mundial como instrumento de política ambiental (tendo sido seguido pelas demais agências) e mudança na política de financiamento adotada pelas AMDs (que passam a conceder empréstimos para o desenvolvimento de poíticas, planos e programas, além de projetos).

A análise dos exercícios financeiros disponíveis ${ }^{6}$ para os anos de $2000^{7}$ a 2012 permitiu identificar os setores que foram contemplados com maior aporte de recursos mediante acordos de financiamento junto às AMDs (Quadro 1).

Tendo em vista a presença do setor energético como um dos principais beneficiados pelos recursos, e sendo este setor o que apresenta o segundo maior número de AAEs (ver resultados do levantamento das AAEs solicitadas pelas AMDs) elaboradas ao longo do período estabelecido, optou-se por direcionar as análises de casos para este setor.

\footnotetext{
6 Os Exercícios Financeiros de 2000, 2001, 2002, 2003, 2004, 2005, 2006 e 2007 do Banco Africano de Desenvolvimento não foram encontrados.

7 O Exercício Financeiro de um ano inicia-se no mês de julho do ano anterior. Portanto, o Exercício Financeiro de 2000 iniciou-se em julho 1999.
} 
Quadro 1 - Distribuição por setor dos três maiores empréstimos das Agências Multilaterais de Desenvolvimento (em milhões de dólares dos EUA)

\begin{tabular}{|c|c|c|c|c|c|c|c|c|c|c|c|}
\hline \multicolumn{3}{|c|}{$\begin{array}{c}\text { Banco Mundial } \\
\text { (Média dos exercícios financeiros } \\
\text { de 2000-2012) }\end{array}$} & \multicolumn{3}{|c|}{$\begin{array}{l}\text { Banco Interamericano de } \\
\text { Desenvolvimento } \\
\text { (Média dos exercícios } \\
\text { financeiros de 2000-2012) }\end{array}$} & \multicolumn{3}{|c|}{$\begin{array}{l}\text { Banco Africano de } \\
\text { Desenvolvimento } \\
\text { (Média dos exercícios } \\
\text { financeiros de 2007-2012) }\end{array}$} & \multicolumn{3}{|c|}{$\begin{array}{c}\text { Banco Asiático de } \\
\text { Desenvolvimento } \\
\text { (Média dos exercícios } \\
\text { financeiros de } 2000 \text { - 2011) }\end{array}$} \\
\hline Setor & Valor & $\%$ & Setor & Valor & $\%$ & Setor & Valor & $\%$ & Setor & Valor & $\%$ \\
\hline Transportes & 4476,6 & $16 \%$ & $\begin{array}{l}\text { Transportes e } \\
\text { comunicações }\end{array}$ & 1141,6 & $16 \%$ & Transportes & 923,3 & $19 \%$ & Energia & 1597,6 & $19 \%$ \\
\hline $\begin{array}{l}\text { Energia e } \\
\text { mineração }\end{array}$ & 3457,7 & $12 \%$ & Energia & 876,2 & $12 \%$ & Multisetor & 777,8 & $16 \%$ & Multisetor & 1009,1 & $12 \%$ \\
\hline
\end{tabular}

Fonte: Elaborado pelo autor 
Os procedimentos metodológicos empregados no desenvolvimento da pesquisa são descritos a seguir.

\subsection{Contexto de Aplicação da AAE pelas AMDs}

\subsubsection{Caracterização das diretrizes operacionais estabelecidas para a AAE}

Esta etapa envolve a sistematização das diretrizes estabelecidas pelas AMDs para a aplicação da AAE, a fim de se estabelecer o contexto de aplicação do instrumento no âmbito dos acordos de cooperação para o desenvolvimento. Buscou-se verificar como a Avaliação Ambiental Estratégica é circunscrita na estrutura operacional das Agências Multilaterais de Desenvolvimento, bem como as abordagens empregadas por cada agência. As boas práticas internacionais para a prática da AAE (de LEMOS, 2009), tendo como base os princípios apontados na literatura, foram confrontadas às diretrizes operacionais das AMDs, a fim de verificar o seu alinhamento.

\subsubsection{Levantamento do perfil de aplicação das AAEs nos países em desenvolvimento}

O levantamento do perfil de utilização da AAE pelas AMDs no âmbito de acordos de financiamento com países em desenvolvimento foi realizado a partir das informações disponíveis nos sítios eletrônicos de cada instituição, complementados por pesquisa bibliográfica e, no caso do Banco Mundial e Banco Africano de Desenvolvimento, contato com seus representantes.

As informações de aplicações de AAE foram organizadas quanto à distribuição geográfica, setor de aplicação, data e organização financiadora.

\subsection{Verificação de Aspectos Estratégicos Associados às AAEs - Estudo de Casos Selecionados}

Nessa etapa foram adotadas três categorias de caracterização: (i) caráter estratégico das ações estratégicas; (ii) adaptação/adequação ao contexto de termos de referências e Avaliações Ambientais; e (iii) revisão de qualidade de relatórios. A escolha feita se justifica 
pela importância e relevância dessas categorias para a Avaliação Ambiental Estratégica. Estudos têm discutido a efetividade da AAE nos países em desenvolvimento (MALVESTIO; MONTAÑO, 2013; WANG et al, 2012; ZU; RU, 2008) destacando pontos importantes em relação a: (i) o nível estratégico - as boas práticas recomendam que a Avaliação Ambiental Estratégica se aplique nos altos níveis estratégicos. Há necessidade que a AAE seja de fato estratégica (HERRERA, 2007; LEE; WALSH, 1992; PARTIDÁRIO, 2007; VERHEEM; TONK, 2000; TETLOW; HANUSCH, 2012); (ii) adaptação ao contexto de aplicação do instrumento (DALAL-CLAYTON; SADLER 2005; JOÃO; MCLAUCHLAN, 2014; LOBOS; PARTIDÁRIO, 2014; VERHEEM; TONK, 2000); (iii) Revisão de qualidade de relatório como mecanismo de promoção de efetividade (BONDE; CHERP, 2000; FISCHER, 2010; SADLER, 1996).

\subsubsection{Seleção de casos para estudo de contexto}

Tendo em vista a necessidade de informações que permitam identificar os elementos contextuais associados à aplicação da AAE pelas AMDs (abordagem, aspectos estratégicos das ações avaliadas, alinhamento entre termos de referência e avaliações efetuadas, qualidade dos relatórios), verifica-se que a disponibilidade dos documentos a serem analisados constitui um elemento essencial para a definição dos casos a serem estudados.

No caso específico do presente trabalho, entende-se haver necessidade de analisar os documentos que descrevem a ação estratégica, os Termos de Referência para a AAE e seus respectivos relatórios de avaliação ambiental. Neste sentido, verificou-se não haver necessidade de estabelecimento de critérios para seleção dos casos, uma vez que os documentos necessários para as análises pretendidas só estavam disponíveis para seis dentre as 27 aplicações de AAEs identificadas no setor energético (Quadro 2).

Quadro 2 - Casos analisados

(Continua)

\begin{tabular}{|c|c|c|c|c|}
\hline Ação Estratégica & $\begin{array}{c}\text { Tipo de Avaliação } \\
\text { Ambiental }\end{array}$ & País & AMD & ANO \\
\hline $\begin{array}{l}\text { Projeto Energia } \\
\text { Manantali }\end{array}$ & $\begin{array}{c}\text { Avaliação Ambiental } \\
\text { Regional }\end{array}$ & $\begin{array}{c}\text { Mali, Mauritânia, } \\
\text { Senegal }\end{array}$ & $\begin{array}{c}\text { Banco Mundial e } \\
\text { Banco Africano } \\
\text { de } \\
\text { Desenvolvimento }\end{array}$ & 1995 \\
\hline
\end{tabular}


(Conclusão)

\begin{tabular}{|c|c|c|c|c|}
\hline Ação Estratégica & $\begin{array}{c}\text { Tipo de Avaliação } \\
\text { Ambiental }\end{array}$ & País & AMD & ANO \\
\hline $\begin{array}{l}\text { Projeto Hidrelétrico } \\
\text { Kabeli «A» }\end{array}$ & $\begin{array}{l}\text { Avaliação de Impacto } \\
\text { Cumulativo }\end{array}$ & Nepal & Banco Mundial & 2011 \\
\hline $\begin{array}{l}\text { Projeto Energia Gasosa } \\
\text { Kribi }\end{array}$ & $\begin{array}{c}\text { Avaliação Ambiental } \\
\text { Regional }\end{array}$ & Camarões & Banco Mundial & 2008 \\
\hline $\begin{array}{l}\text { Projeto de } \\
\text { Desenvolvimento de } \\
\text { Energia Nepal }\end{array}$ & $\begin{array}{c}\text { Avaliação Ambiental } \\
\text { Setorial }\end{array}$ & Nepal & Banco Mundial & 1997 \\
\hline Projeto Nam Theun 2 & $\begin{array}{c}\text { Avaliação de Impacto } \\
\text { Cumulativo }\end{array}$ & Laos & Banco Mundial & 2004 \\
\hline $\begin{array}{l}\text { Projeto Hidrelétrico } \\
\text { Rampur }\end{array}$ & $\begin{array}{l}\text { Avaliação de Impacto } \\
\text { Cumulativo }\end{array}$ & Índia & Banco Mundial & 2006 \\
\hline
\end{tabular}

Fonte: Elaborado pelo autor

\subsubsection{Levantamento de dimensões características de PPPs}

A bibliografia consultada (ver Quadro 3) permitiu estabelecer, para fins de referência, os elementos característicos das ações estratégicas que as diferenciam de projetos. Esses elementos foram denominados Dimensões Estratégicas ${ }^{8}$ para diferenciá-los de elementos não estratégicos, isto é, elementos característicos de projetos. Nesse sentido, foram identificados os seguintes elementos: objetivo, tempo, espaço, abrangência, nível de detalhes e alternativas.

Por objetivo entende-se a expressão da intencionalidade da ação planejada, apontando para algo a ser alcançada. O tempo é o período de duração entre a concepção da ação e a sua execução futura em forma de projetos, implicando a elaboração dos prazos para o seu alcance. Por espaço, entende-se a área delimitada espacialmente (BAPTISTA, 2007). A alternativa se refere a propostas concretas ou caminhos que podem ser percorridos para alcançar objetivos e metas da ação (BAPTISTA, 1981). A abrangência designa atividades, aspectos e componentes de uma determinada ação. Por nível de detalhes, entende-se a pormenorização e descrição das atividades, aspectos e componentes da ação. A dimensão volume designa recursos humanos, físicos e materias concretos (BAPTISTA, 2007). Devido à dificuldade de

\footnotetext{
${ }^{8}$ O termo "dimensão" é utilizado no planejamento para designar elementos essencias da organização de uma ação (BAPTISTA, 2007). A denominação "Dimensão Estratégica” não é utilizada no campo do planejamento. Ela é empregada exclusivamente neste trabalho para facilitar o entendimento.
} 
encontrar informações a seu respeito, a dimensão volume não foi considerada nesta dissertação.

Quadro 3 - Dimensões características de Instrumentos de Planejamento

\begin{tabular}{|c|c|c|}
\hline Dimensão & Estratégica (PPP) & Não estratégica (Projeto) \\
\hline Objetivo & $\begin{array}{l}\text { Os objetivos são amplos, } \\
\text { Expressam as grandes linhas, valores } \\
\text { principais e a intencionalidade da } \\
\text { organização. Indicam a natureza do } \\
\text { conjunto dos resultados pretendidos pelo } \\
\text { planejamento que está sendo } \\
\text { desenvolvido (BAPTISTA, 1981, 2007; } \\
\text { KITCHELL, 1967). }\end{array}$ & $\begin{array}{l}\text { Os objetivos são específicos. Expressam } \\
\text { uma decomposição do objetivo geral, que } \\
\text { aponta resultados a serem alcançados em } \\
\text { determinadas áreas. Devem ser } \\
\text { explicitados em metas concretas que } \\
\text { definam a dimensão de seus resultados (em } \\
\text { termos de abrangência e extensão) em um } \\
\text { tempo determinado (BAPTISTA, 1981, } \\
\text { 2007; KITCHELL, 1967). }\end{array}$ \\
\hline
\end{tabular}

A ação aponta o sentido/direção (norte, sul, leste, oeste) do desenvolvimento Espaço podendo apresentar eventuais opções de desenvolvimento espacial. Pode se referir a uma região (cidade, estado, etc.), porém o local exato é incerto (FISCHER, 2007).
A ação apresenta limitação espacial. O local de implementação é definido com exatidão (BAPTISTA, 1981，2007; FISCHER, 2007).
A ação encontra-se distante da sua execução em forma de projeto. Entre a concepção da ação e sua execução, há um período de aguarda das providências Tempo necessárias para tornar efetiva a execução. As providências consistem em viabilizar a ação estratégica em forma de planos, programas e/ou projeto (KITCHELL, 1967).
A ação encontra-se mais perto da execução; apresenta limitação temporal. $\mathrm{O}$ período entre a concepção da ação e sua execução é curto. Não é preciso um período de aguardo das providências necessárias para tornar efetiva a execução (BAPTISTA, 1981, 2007; KITCHELL, 1967).

A ação pode envolver mais de um setor; se dedicar a um setor, área ou região; ou envolver grupos de projetos vinculados entre si ou a plano(s) maiore(s). O seu âmbito é maior (BAPTISTA, 1981, 2007).

A ação apresenta poucos detalhes referidos e especificações. O grau de

Nível de detalhamento é pequeno (BAPTISTA, Detalhes 1981, 2007)
O foco é o projeto. O seu âmbito é menor. A ação deve se referir de forma exaustiva a todos os aspectos da estrutura da questão a que se destina, isto é, da única atividade planejada (BAPTISTA, 1981, 2007).
A ação detalha as atividades a serem desenvolvidas. Há estabelecimento de prazos; objetividade e exatidão nas informações, na terminologia e nas especificações técnicas. Cada operação é descrita com detalhes (BAPTISTA, 1981, 2007).

Trata-se de alternativas singulares de localização específica, operação, design e/ou construção (BAPTISTA, 1981, 2007).
As alternativas envolvem uma ampla área; podem ser fiscal e/ou envolver outra procedência/fonte (intermodal, outras fontes energéticas, etc.) com base em critérios socioeconômicos, ambientais e/ou espaciais (FISCHER, 2007). 
Foi verificado o caráter estratégico de ações estratégicas selecionadas através do levantamento de dimensões estratégicas apresentadas por estas. A consideração de uma dimensão como estratégica ou não estratégica foi feita de acordo com os critérios (ver quadro 3) levantados na bibliografia.

\subsubsection{Alinhamento de Termos de Referência e Avaliações Ambientais em relação a aspectos-chave da $\mathrm{AAE}$}

Os Termos de Referência e Avaliações Ambientais analisados são oriundos de diferentes contextos de aplicação. Ainda que as diretrizes operacionais para aplicação da AAE estabelecidas pelas agências tenham forte influência dos requisitos definidos pelo Banco Mundial, verifica-se uma grande variação na nomenclatura e abordagens empregadas. Os TRs e as AAs foram analisados a partir do referencial estabelecido para a AAE, considerando seus elementos essenciais (ou 'aspectos-chave') conforme descritos por Therivel (2004):

- Identificação dos indicadores ambientais/de sustentabilidade: a AAE deve ter parâmetros ambientais-chave.

- Identificação de áreas problemáticas: a AAE deve focar nos elementos-chave.

- Avaliação de impactos dos objetivos e/ou alternativas da ação estratégica

- Documentação dos resultados da avaliação.

Os aspectos-chave mencionados orientaram a análise de conteúdo realizada sobre os Termos de Referência e os relatórios das Avaliações Ambientais. Em seguida, para os mesmos aspectos-chave, verificou-se o alinhamento entre os documentos que orientam o escopo das avaliações (TRs padrões estabelecidos pelas AMDs e os TRs específicos emitidos para cada avaliação) e os relatórios das avaliações ambientais. 


\subsection{Revisão de qualidade de relatórios de Avaliações Ambientais}

Os critérios de revisão de qualidade são orientados pelas boas práticas sendo estabelecidos a partir dos critérios apontados por Chanchitpricha e Bond (2013), Doren et al (2013), Fischer (2007) ${ }^{9}$, Sadler (1996) e Therivel (2004).

Em relação aos critérios de consulta pública, como será visto nos resultados da primeira parte dessa dissertação, as AMDs têm recomendações diferentes dependendo dos impactos causados pelos diferentes financiamentos. Para operações com impactos que vão além do local sujeito ao trabalho físico, as partes afetadas e interessadas serão consultadas pelo menos duas vezes durante a preparação do projeto, durante a fase de definição do escopo da avaliação ambiental ou processos de verificação, e durante a revisão do relatório de avaliação. Para operações com impactos restritos ao local de trabalho físico, as partes afetadas devem ser consultadas pelo menos uma vez, de preferência durante a elaboração ou revisão do Plano de Gestão Ambiental e Social, conforme acordado com o mutuário (ASIAN DEVELOPMENT BANK, 2003b; BANQUE AFRICAINE DE DÉVELOPPEMENT, 2001; INTER-AMERICAN DEVELOPMENT BANK, 2006; WORLD BANK, 2013b). Por outro lado, as boas práticas recomendam que seja dado às autoridades e ao público a oportunidade, dentro de prazos adequados, de expressar a sua opinião (CHANCHITPRICHA; BOND, 2013; DOREN et al., 2013; FISCHER, 2007; SADLER, 1996; THERIVEL, 2004).

Há também diferenças em relação à analise de alternativas. No âmbito das AMDs as recomendações sobre alternativas diferem. Enquanto o Banco Asiático de Desenvolvimento apenas recomenda que alternativas de desenvolvimento sejam consideradas, o Banco Africano de Desenvolvimento, o Banco Interamericano de Desenvolvimento e o Banco Mundial solicitam que as alternativas sejam realizáveis e incluem o cenário "sem a ação estratégica". Por outro lado, as boas práticas recomendam que haja pelo menos três alternativas: "não fazer nada", "fazer o mínimo" e "mais benéfico ao ambiente" (THERIVEL, 2004). Assim sendo, optou-se por considerar critérios de boas práticas.

$\mathrm{Na}$ análise foi verificado se cada critério foi atendido de forma muito satisfatória (sem importantes omissões), satisfatória (bem atendida com poucas omissões), simplesmente satisfatória (algumas omissões e inadequações), simplesmente insatisfatória (importantes omissões com poucas partes bem atendidas), insatisfatória (omissões e inadequações

\footnotetext{
${ }^{9}$ Os critérios propostos por Fischer (2007) se baseam na Diretiva Europeia 2001/42/CE. Optou-se por considerar estes critérios como boas práticas, pois são diretrizes amplamente discutidas e aplicadas a um grande conjunto de países conforme salientado por Therivel (2004). São critérios consolidados frutos do acordo de vários países de adotar um único quadro para seus sistemas de AAE.
} 
significantes), muito insatisfatória (muitas inadequações e omissões. Partes importantes não atendidas), não atendida (não realizado) ou não se aplica (quando o critério não se aplica ao contexto), correspondendo respectivamente às notas A, B, C, D, E, F, G e n/a.

Os critérios fazem parte de seções correspondentes às etapas da AAE que também foram avaliadas seguindo os mesmos parâmetros. Uma nota geral foi atribuída ao relatório considerando todos os critérios avaliados. O quadro 4 apresenta os critérios sintetizados. 
Quadro 4 - Critérios de avaliação para revisão de qualidade de relatório

(Continua)

\begin{tabular}{|c|c|c|c|}
\hline & Seção 1 - Objetivos & & \\
\hline 1 & Descreve o conteúdo e os objetivos principais da ação estratégica. & A,B & \\
\hline 2 & Os objetivos da AAE são apresentados, relacionados aos indicadores e metas, se for o caso. & A & \\
\hline 3 & Avaliação da Seção 1 & & \\
\hline 4 & $\begin{array}{l}\text { Autoridades competentes e apropriadas são consultadas para a determinação do alcance e nível de } \\
\text { informações que devem ser incluídas no relatório AAE. }\end{array}$ & A,C & \\
\hline 5 & $\begin{array}{l}\text { A AAE se concentra em questões importantes e desconsidera as menos significativas. As razões de } \\
\text { desconsideração devem ser documentadas. }\end{array}$ & $\mathrm{A}, \mathrm{C}$ & \\
\hline 6 & Alternativas razoáveis estabelecidas. & A & \\
\hline 7 & $\begin{array}{l}\text { Técnicas, dificuldades processuais e outros problemas (tais como deficiências técnicas ou falta de } \\
\text { know-how) são discutidos. Suposições e incertezas são explicitadas. }\end{array}$ & A,B & \\
\hline
\end{tabular}


(Continuação)

\begin{tabular}{|c|c|c|c|}
\hline & Critério & Autores & Nota \\
\hline & \multicolumn{3}{|l|}{ Avaliação da Seção 2} \\
\hline & Seção 3 - Baseline & Autores & Nota \\
\hline 8 & $\begin{array}{l}\text { Aspectos pertinentes do estado atual do ambiente receptor da ação estratégica e a sua provável } \\
\text { evolução, sem a ação estratégica são descritos. Características ambientais das zonas susceptíveis de } \\
\text { serem significativamente afetadas são descritas com mais detalhes. }\end{array}$ & $\mathrm{A}, \mathrm{B}, \mathrm{C}$ & \\
\hline 9 & Os objetivos de AAE e dados de coleta da baseline se reforçam mutuamente. & A & \\
\hline \multirow[t]{3}{*}{10} & $\begin{array}{l}\text { Os métodos utilizados para levantar a baseline são adequados à abrangência e complexidade da } \\
\text { avaliação. }\end{array}$ & $\mathrm{A}, \mathrm{C}$ & \\
\hline & Avaliação da Seção3 & & \\
\hline & Seção 4 - Links para outras ações estratégicas & Autores & Nota \\
\hline 11 & $\begin{array}{l}\text { As relações entre a ação estratégica e os níveis anteriores e posteriores (na cadeia de tomada de } \\
\text { decisão) são identificadas e explicadas. }\end{array}$ & $\mathrm{A}, \mathrm{B}$ & \\
\hline 12 & $\begin{array}{l}\text { Aspectos que geram conflitos entre as ações estratégicas são claramente documentados; e são feitas } \\
\text { recomendações sobre como conciliar as ações estratégicas, de modo a promover a sustentabilidade. }\end{array}$ & A & \\
\hline
\end{tabular}


(Continuação)

\begin{tabular}{c|lcl}
\hline & Seção 5 - Alternativas & Autores & Nota \\
\hline 13 & $\begin{array}{l}\text { As alternativas consideradas são apropriadas para a escala (internacional, nacional, etc.) e o nível } \\
\text { (Política, Plano, Programa) da tomada de decisão. }\end{array}$ & A, B \\
\hline 14 & $\begin{array}{l}\text { As alternativas consideradas lidam com as questões identificadas na baseline e/ou buscam alcançar } \\
\text { metas de sustentabilidade. }\end{array}$ & A, B & A, B \\
\hline 15 & $\begin{array}{l}\text { As alternativas incluem o “não fazer nada”, "fazer o mínimo” e “alternativas mais benéficas ao } \\
\text { ambiente". }\end{array}$ & A, B, D \\
\hline 16 & As razões para descartar alternativas de maiores considerações são apresentadas. & A \\
\hline 17 & Os efeitos ambientais e de sustentabilidade de cada alternativa são identificados e comparados & \\
\hline & Avaliação da Seção 5 & Autores \\
\hline 18 & Os prováveis impactos significativos sobre o meio ambiente são identificados e avaliados. & A, B, C \\
\hline 19 & Prováveis impactos indiretos, cumulativos, sinérgicos e secundários são identificados e avaliados. & A, B, C \\
\hline 20 & $\begin{array}{l}\text { Foram utilizadas adequadas técnicas de previsão de impacto e de avaliação. A avaliação do } \\
\text { impacto condiz com as normas e regulamentos aceitos internacionalmente. }\end{array}$ & A, B \\
\hline & Avaliação da Seção 6 & \\
\hline
\end{tabular}


(Continuação)

\begin{tabular}{|c|c|c|c|}
\hline & Seção 7 - Mitigação e monitoramento & Autores & Nota \\
\hline 21 & $\begin{array}{l}\text { As medidas previstas para evitar, reduzir, compensar e/ou melhorar quaisquer impactos } \\
\text { significativos da ação estratégica são indicadas. }\end{array}$ & $\mathrm{A}, \mathrm{B}, \mathrm{C}, \mathrm{E}$ & \\
\hline 22 & Medidas de monitoramento dos impactos são explicitadas. & $\mathrm{A}, \mathrm{B}, \mathrm{C}, \mathrm{E}$ & \\
\hline \multirow[t]{3}{*}{23} & Referências à AIA de projeto e outras AAE são explicitadas. & $\mathrm{A}, \mathrm{B}, \mathrm{D}$ & \\
\hline & Avaliação da Seção 7 & & \\
\hline & Seção 8 - Consulta & Autores & Nota \\
\hline 24 & $\begin{array}{l}\text { Às autoridades ambientais e outras, e o público é dada a oportunidade, dentro de um prazo } \\
\text { adequado, de expressar a sua opinião sobre a AAE antes da adoção da ação estratégica. }\end{array}$ & $\mathrm{A}, \mathrm{B}, \mathrm{C}, \mathrm{D}, \mathrm{E}$ & \\
\hline \multirow[t]{3}{*}{25} & Os órgãos públicos e relevantes tiveram uma resposta sobre suas colocações. & $\mathrm{A}, \mathrm{B}, \mathrm{C}, \mathrm{D}$ & \\
\hline & Avaliação da Seção 8 & & \\
\hline & Seção 9 - Relatório de AAE & Autores & Nota \\
\hline 26 & O relatório descreve como a AAE foi realizada. & $\mathrm{B}, \mathrm{E}$ & \\
\hline 27 & O relatório identifica o tomador de decisão e a entidade que realizou a AAE. & A & \\
\hline
\end{tabular}


(Conclusão)

\begin{tabular}{|c|c|c|c|}
\hline & Seção 9 - Relatório de AAE & Autores & Nota \\
\hline 28 & $\begin{array}{l}\text { O relatório é claro e conciso em seu layout e apresentação, É apresentado como um todo integrado, } \\
\text { e usa mapas e outras ilustrações quando necessário. }\end{array}$ & A & \\
\hline 29 & No relatório, a linguagem usada é simples e clara. & A & \\
\hline 30 & O relatório descreve a metodologia utilizada na AAE, inclusive quem foi consultado e como. & $\mathrm{A}, \mathrm{C}, \mathrm{E}$ & \\
\hline 31 & O relatório se concentra nas grandes questões. & A & \\
\hline \multirow[t]{3}{*}{32} & O relatório está escrito, sem viés de forma imparcial. & A & \\
\hline & \multicolumn{3}{|l|}{ Avaliação da Seção 9} \\
\hline & \multicolumn{3}{|l|}{ Nota geral } \\
\hline \multicolumn{4}{|c|}{ Autores } \\
\hline \multicolumn{4}{|c|}{ A = Therivel (2004); B= Fischer (2007); C= Sadler (1996), D = Doren et al (2013); E = Chanchitpricha e Bond (2013). } \\
\hline
\end{tabular}

Fonte: Elaborado pelo autor 


\section{RESULTADOS E DISCUSSÕES}

\subsection{Contexto de Aplicação da AAE pelas AMDs}

\subsubsection{Caracterização das políticas ambientais voltadas para $A A E$}

A Avaliação Ambiental Estratégica no âmbito das Agências Multilaterais de Desenvolvimento é um envelope que envolve: a Avaliação Ambiental Estratégica propriamente dita, Avaliação Ambiental Regional (AAR), Avaliação Ambiental Setorial (AAS), Avaliação Ambiental de Política (AAP) e o Estudo de Impactos Ambientais de Programa (EIAP) (ANNANDALE et al., 2001; LOYZA, 2012), bem como a Avaliação de Impactos Cumulativos, Análise Ambiental do País, Análise Ambiental Estratégica, Avaliação de Impacto Estratégico e Avaliação Ambiental. Algumas dessas ferramentas são restritas a algumas AMDs. Os níveis e as categorias de aplicação de cada uma são apresentados nos itens a seguir.

\subsubsection{Processamento Ambiental dos pedidos de financiamento}

As Agências Multilaterais de Desenvolvimento apresentam similaridades entre si no que diz respeito ao processamento ambiental dos pedidos dos financiamentos. A primeira etapa do ciclo do projeto é o Pré-design. Nesse estágio, as solicitações são analisadas pelo banco que as classifica de acordo com seus potenciais impactos ambientais. As AMDs dispõem de categorias predefinidas que são atribuídas às diferentes operações (Quadro 5). A categoria $\mathrm{A} / 1^{10}$ é atribuída aos financiamentos cujas ações causarão prováveis impactos ambientais adversos que são sensíveis, diversos e sem precedente. Podem afetar áreas além das que serão sujeitas ao trabalho físico. A categoria B/2 corresponde às solicitações suscetíveis de gerar impactos ambientais e/ou sociais prejudiciais e específicos ao local da operação. A categoria $\mathrm{C} / 3$ é atribuída aos pedidos de financiamento que causarão pouquíssimos ou nenhum impacto ambiental e, consequentemente não necessitam de uma Avaliação Ambiental. Após a categorização das operações, a AMD emite um Termo de Referência no qual consta além da classe atribuída, a Avaliação Ambiental recomendada para

10 A denominação "Categoria + letra (A, B ou C)" é utilizada pelo Banco Mundial, Banco Asiático de Desenvolvimento e Banco Interamericano de Desenvolvimento. O Banco Africano de Desenvolvimento usa a designação "Categoria + número (1, 2 ou 3)". 
tal grupo assim como o seu escopo. As AMD obrigam que a consulta pública seja feita na definição do escopo e/ou após a avaliação de impactos, de acordo com a categoria.

No design do projeto, segunda etapa do ciclo do projeto, avaliou-se os impactos. Em seguida, documentam-se os resultados da avaliação em um relatório. O relatório de avaliação passará pela análise do Banco antes da aprovação do financiamento. A análise do Banco e a aprovação correspondem à etapa de processamento do empréstimo do ciclo do projeto (Figura 1) (ASIAN DEVELOPEMENT BANK, 2003b; BANQUE AFRICAINE DE DÉVELOPPEMENT, 2001; INTER-AMERICAN DEVELOPEMENT BANK，2007; WORLD BANK, 2012; 2013a; 2013b). 
Quadro 5 - Categorização Ambiental das Agências Multilaterais de Desenvolvimento

\begin{tabular}{|c|c|c|c|c|}
\hline & Banco Mundial & $\begin{array}{l}\text { Banco Africano de } \\
\text { Desenvolvimento }\end{array}$ & $\begin{array}{l}\text { Banco Interamericano de } \\
\text { Desenvolvimento }\end{array}$ & $\begin{array}{l}\text { Banco Asiático de } \\
\text { Desenvolvimento }\end{array}$ \\
\hline $\begin{array}{l}\text { Categoria } \\
\text { A/1 }\end{array}$ & $\begin{array}{l}\text { Prováveis impactos ambientais ad- } \\
\text { versos que são sensíveis, diversos e } \\
\text { sem precedente. Podem afetar áreas } \\
\text { além das que serão sujeitas ao trabalho } \\
\text { físico. }\end{array}$ & $\begin{array}{l}\text { Prováveis impactos ambientais e/ou } \\
\text { sociais negativos e irreversíveis } \\
\text { suscetíveis de afetar significati- } \\
\text { vamente componentes ambientais e } \\
\text { sociais sensíveis. }\end{array}$ & $\begin{array}{l}\text { Prováveis impactos ambientais, sociais e } \\
\text { culturais significativamente negativos } \\
\text { (numa grande área, permanente, de } \\
\text { grande magnitude e intensidade) podendo } \\
\text { ser diretos, indiretos, cumulativos ou } \\
\text { regionais. }\end{array}$ & $\begin{array}{l}\text { Prováveis impactos ambientais } \\
\text { significativos e adversos. }\end{array}$ \\
\hline $\begin{array}{l}\text { Categoria } \\
\text { B/2 }\end{array}$ & $\begin{array}{l}\text { Prováveis impactos ambientais ad- } \\
\text { versos sobre humanos ou áreas } \\
\text { ambientais importantes. Porém, estes } \\
\text { impactos são menos adversos que os da } \\
\text { categoria A e são restritos ao local. } \\
\text { Poucos impactos são irreversíveis. }\end{array}$ & $\begin{array}{l}\text { Prováveis impactos ambientais e/ou } \\
\text { sociais prejudiciais e específicos ao } \\
\text { local da operação. }\end{array}$ & $\begin{array}{l}\text { Prováveis impactos ambientais, sociais e } \\
\text { culturais temporários e restritos ao local } \\
\text { de magnitude e intensidade moderadas. }\end{array}$ & $\begin{array}{l}\text { Alguns prováveis impactos } \\
\text { ambientais adversos, mas de } \\
\text { menor grau e/ou significância } \\
\text { que os da categoria } \mathrm{A} \text {. }\end{array}$ \\
\hline $\begin{array}{l}\text { Categoria } \\
\mathrm{C} / 3\end{array}$ & $\begin{array}{l}\text { Pouquíssimo ou nenhum potencial } \\
\text { impacto ambiental. }\end{array}$ & $\begin{array}{l}\text { Nenhum potencial impacto ambien- } \\
\text { tal ou social negativo. }\end{array}$ & $\begin{array}{l}\text { Pouquíssimo ou nenhum potencial } \\
\text { impacto negativo ambiental, social e } \\
\text { cultural. }\end{array}$ & $\begin{array}{l}\text { Improváveis impactos ambien- } \\
\text { tais adversos }\end{array}$ \\
\hline
\end{tabular}

Fonte: Elaborado pelo autor 
Figura 1 - Processamento Ambiental das Agências Multilaterais de Desenvolvimento

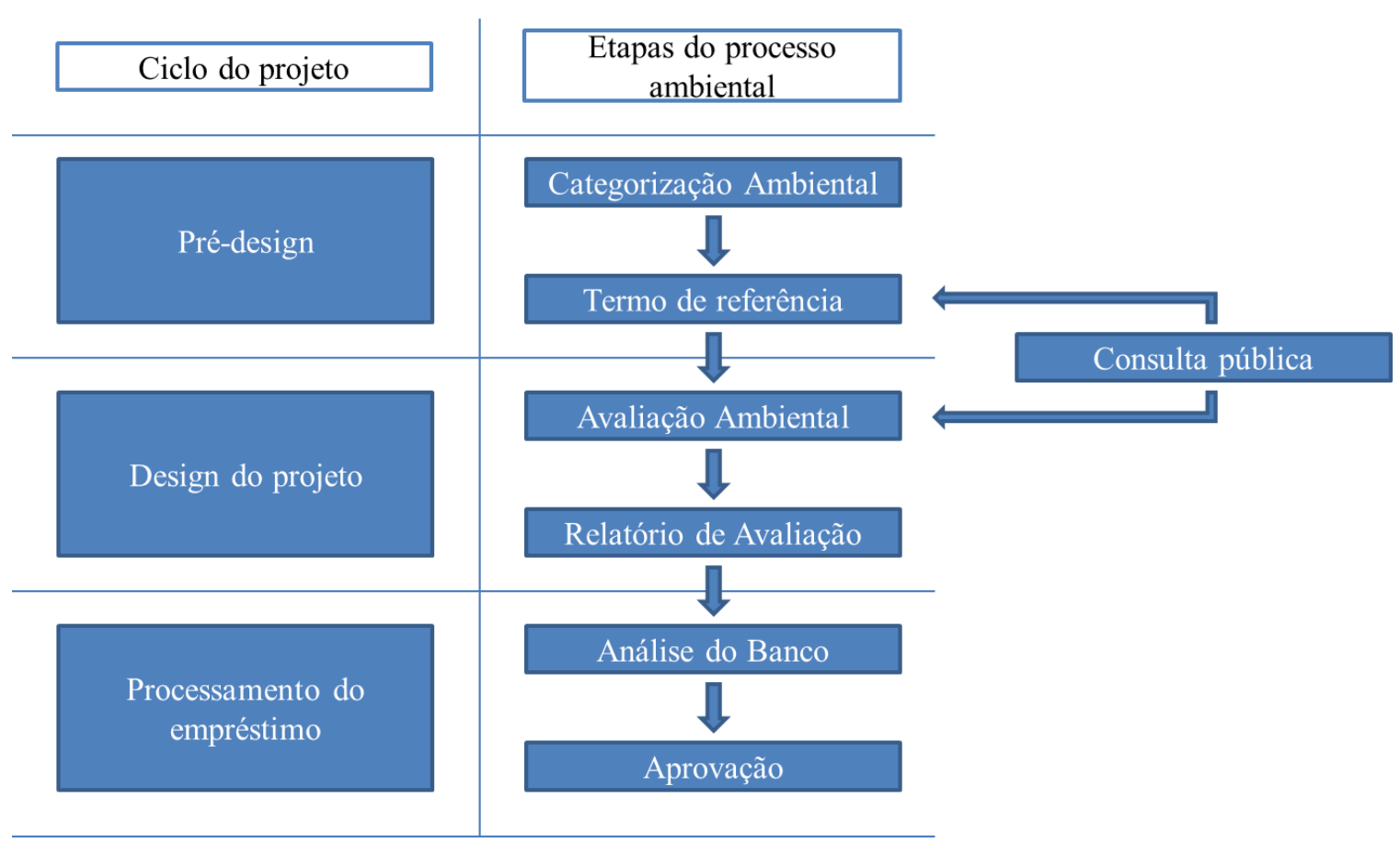

Fonte: Elaborado pelo autor

\subsubsection{Banco Mundial}

O Grupo Banco Mundial (GBM) é composto pelo Banco Internacional de Reconstrução e Desenvolvimento (BIRD) e a Associação Internacional de Desenvolvimento (AID), ambas apoiam projetos de desenvolvimento no mundo inteiro e, em conjunto, formam o Banco Mundial (BM). O BIRD, coorporativa global pertencente a 188 países, tem por objetivo a redução da pobreza dos países de renda média e baixa promovendo, por meio de empréstimos, um desenvolvimento econômico equitativo e sustentável. A AID, afiliada do Grupo Banco Mundial e o maior canal multilateral de financiamento concessionário no mundo, permite ao Banco Mundial financiar sem juros e subsídios projetos dos 81 países mais pobres do mundo (BANCO MUNDIAL, 2005; BANCO MUNDIAL, 2012).

Para alcançar as suas metas, o Banco Mundial segue diretrizes, entre outros, o Bank Procedure (BP 4.01) e Operational Procedure 4.01 (OP 4.01) de 1999. Estes regem o processo ambiental voltado para AA nessa instituição e, desta forma, estipulam que um empréstimo deve ser precedido por uma avaliação ambiental que assegura e informa os tomadores de decisão da viabilidade ambiental do financiamento. 
A Avaliação Ambiental Estratégica ${ }^{11}$ é um dos instrumentos impostos no Operational Procedure 4.01 e é definida pelo BM como sendo uma ferramenta que, pela sua abordagem participativa e analítica, objetiva integrar considerações ambientais e sociais nos PPPs e avaliar suas ligações com considerações econômicas (WORLD BANK, 2013a). Este instrumento se aplica a PPP da categoria A. Quando se trata de Políticas, Planos ou Programas regionais ou setoriais, a AAE é denominada respectivamente Avaliação Ambiental Regional (AAR) ou Avaliação Ambiental Setorial (AAS). Os financiamentos da categoria B requerem uma Análise Ambiental Inicial (AAI), antes de determinar necessidade de aplicação de uma AAE (Quadro 6). A Avaliação Ambiental Estratégica pode ser aplicada junto com outro(s) instrumento(s). Esta exigência assim como o escopo e o conteúdo do relatório de AAE devem constar no TR emitido pela Assessoria Regional do Banco Mundial (WORLD BANK, 2013b).

\begin{tabular}{|c|c|c|}
\hline Níveis & Categoria A & Categoria B \\
\hline Programa & AAE & A definir após uma Análise Inicial \\
\hline Plano & AAE & A definir após uma Análise Inicial \\
\hline Política & AAE & A definir após uma Análise Inicial \\
\hline PPP Regionais & $\mathrm{AAR}^{1}$ & A definir após uma Análise Inicial \\
\hline PPP Setoriais & $\mathrm{AAS}^{2}$ & A definir após uma Análise Inicial \\
\hline
\end{tabular}

Ao confrontar as políticas ambientais voltadas para AAE do Banco Mundial com as boas práticas, percebe-se que as primeiras seguem as segundas em todos os pontos exceto na etapa de alternativa (Quadro 7). Enquanto as boas práticas recomendam a consideração do cenário "sem ação" além da alternativa mais benéfica ao meio ambiente e "fazer o mínimo", as diretrizes de AAE do BM solicitam a consideração de alternativas viáveis além do cenário sem a ação estratégica. Também foram constatadas diferenças no que diz respeito a consulta

\footnotetext{
${ }^{11}$ No momento da análise do manual operacional do Banco Mundial (setembro de 2013), essa AMD só usava a designação Avaliação Ambiental Estratégica. No entanto, na fase final de elaboração da presente dissertação (agosto de 2014), fez-se uma leitura do manual operacional disponibilizado no site da instituição para fins de conferência de dados. Percebeu-se que o Banco Mundial adotou a designação Avaliação Ambiental e Social Estratégica.
} 
pública. O BM recomenda duas consultas para ações estratégicas da categoria A. Por sua vez, as boas práticas apenas preconizam a disponibiliação do relatório final para consulta.

Quadro 7 - Alinhamento da política ambiental de AAE do BM com boas práticas

\begin{tabular}{|c|c|c|}
\hline Etapas de AAE & Manual Operacional do Banco Mundial & Boas práticas \\
\hline Triagem & $\begin{array}{l}\text { - } \quad \text { Exame do tipo, localização, } \\
\text { sensibilidade e escala da ação } \\
\text { estratégica projeto proposta } \\
\text { - } \quad \text { Atribuição da categoria ambiental } \\
\text { de acordo com os potenciais riscos } \\
\text { ambientais associados ao projeto }\end{array}$ & $\begin{array}{l}\text { Determinar a necessidade de } \\
\text { AAE e o nível de detalhes }\end{array}$ \\
\hline Escopo & $\begin{array}{l}\text { - } \quad \text { Quadro político, legal e } \\
\text { administrativo } \\
\text { - } \quad \text { Descrição da ação estratégica } \\
\text { - } \quad \text { Determinação de principais } \\
\text { questões ambientais }\end{array}$ & $\begin{array}{l}\text { Identificação de questões- } \\
\text { chaves, abrangência do } \\
\text { estudo e impactos a serem } \\
\text { analisados }\end{array}$ \\
\hline $\begin{array}{l}\text { Estudos e Análise } \\
\text { de Base Ambiental }\end{array}$ & - Descrever dados de baseline & $\begin{array}{l}\text { Reunir, coletar e produzir } \\
\text { informações de maneira } \\
\text { crítica e lógica }\end{array}$ \\
\hline $\begin{array}{l}\text { Descrição e Análise } \\
\text { de cenários e } \\
\text { alternativas }\end{array}$ & $\begin{array}{l}\text { Comparar alternativas viáveis incluindo o } \\
\text { cenário "sem ação estratégica" }\end{array}$ & $\begin{array}{l}\text { Identificação de uma série de } \\
\text { alternativas e opções (incluir } \\
\text { os cenários "não fazer nada", } \\
\text { "fazer o mínimo" e "mais } \\
\text { benéfico ao ambiente"). }\end{array}$ \\
\hline $\begin{array}{l}\text { Avaliação de } \\
\text { Impacto das } \\
\text { alternativas }\end{array}$ & $\begin{array}{l}\text { Prever e avaliar os prováveis impactos } \\
\text { positivos e negativo de cada alternativa. }\end{array}$ & $\begin{array}{l}\text { Identificar prever e avaliar os } \\
\text { impactos e significância das } \\
\text { alternativas }\end{array}$ \\
\hline $\begin{array}{l}\text { Descrição das } \\
\text { medidas de } \\
\text { mitigação e } \\
\text { monitoramento }\end{array}$ & $\begin{array}{l}\text { Identificar medidas de mitigação e } \\
\text { explorar oportunidades para melhoria } \\
\text { ambiental }\end{array}$ & $\begin{array}{l}\text { Identificar as medidas para } \\
\text { evitar, reduzir e compensar } \\
\text { os impactos identificados }\end{array}$ \\
\hline $\begin{array}{l}\text { Relatório / } \\
\text { Documentação }\end{array}$ & Relatório/Documentação & Relatório/Documentação \\
\hline Consulta pública & $\begin{array}{l}\text { - Para financiamentos da categoria A, } \\
\text { realiazar no mínimo duas consultas sendo } \\
\text { a primeira na etapa de definição de escopo } \\
\text { e a segunda após a elaboração do relatório } \\
\text { final. } \\
\text { - Para financiamentos da categoria B, } \\
\text { realiazar no mínimo uma consulta. }\end{array}$ & $\begin{array}{l}\text { Disponibilizar o relatório } \\
\text { final para consulta pública }\end{array}$ \\
\hline
\end{tabular}

Fonte: Boas práticas de Lemos (2011), baseado em Sadler (2000), Therivel (2004) e Grunn e Noble (2009) 


\subsubsection{Banco Africano de Desenvolvimento}

O Banco Africano de Desenvolvimento (BAD) é uma Agência Multilateral de Desenvolvimento que tem como acionistas os 53 países africanos e 24 países não africanos. Fundado em 1964, o Grupo Banco Africano de Desenvolvimento tem por principal objetivo contribuir para o desenvolvimento econômico sustentável e o progresso social dos seus membros individuais e regionais. Os recursos do BAD, que são obtidos em geral por meio da contração de empréstimos nos mercados de capitais, são utilizados para conceder créditos não concessionais aos seus países membros. Os fundos desta linha de crédito são utilizados para financiar um elevado número de projetos e programas de desenvolvimento através de: créditos ao setor público, privado e investimento de capital; prestação de assistência técnica a projetos e programas de apoio institucionais; investimento de capitais privados e públicos, etc. (BANCO AFRICANO DE DESENVOLVIMENTO, 2011).

Dentre os seus requisitos para concessão de empréstimos, o BAD exige conformidade com os Novos Procedimentos de Avaliação Ambiental e Social (de 2001) tendo como um dos objetivos assegurar que os PPP sejam viáveis do ponto de vista ambiental e social. Para este fim, o banco indica na sua política de salvaguarda instrumentos susceptíveis de serem aplicados, entre outros, a Avaliação Ambiental e Social Estratégica (AASE) que é definida como sendo

uma ferramenta que avalia os efeitos ambientais e sociais associados a uma proposição de Política, estratégia, plano, ou programa, em particular as proposições visando uma região específica (Avaliação Ambiental e Social Regional) ou um setor (Avaliação Ambiental e Social Setorial) (BANQUE AFRICAINE DE DÉVELOPPEMENT, 2001).

A AASE apenas se aplica aos planos e programas da categoria 1 (Quadro 8) e pode ser requisitada junto com outro(s) instrumento(s). O escopo da avaliação é definido pelo Complexe Opérationnel do Banco Africano de Desenvolvimento e deve constar no Termo de Referência (BANQUE AFRICAINE DE DÉVELOPPEMENT, 2001). Ao contrário da política ambiental voltada para Avaliação Ambiental Estratégica do Banco Mundial que solicita uma análise ambiental inicial antes de exigir a aplicação desse instrumento para a categoria 2, o BAD, de imediato, define o Plano de Gestão Ambiental e Social como instrumento desta classe. 
Quadro 8 - Categorias e Níveis de aplicação da Avaliação Ambiental e Social Estratégica no Banco Africano de Desenvolvimento

\begin{tabular}{l|cc}
\multicolumn{1}{c|}{ Níveis } & Categoria 1 & Categoria 2 \\
\hline Programa & AASE & PGAS $^{3}$ \\
\hline Plano & AASE & PGAS \\
\hline PP Regionais & AASR ${ }^{1}$ & PGAS \\
\hline PP Setoriais & AASS ${ }^{2}$ & PGAS \\
\hline \multicolumn{2}{c}{${ }^{1}$ Avaliação Ambiental e Social Regional; ${ }^{2}$ Avaliação Ambiental e Social Setorial; } \\
\end{tabular}

Fonte: Elaborado pelo autor.

Ao comparar a política ambiental do Banco Africano de Desenvolvimento com as boas práticas, percebe-se que há diferenças no que diz respeito à ênfase da avaliação e consulta pública (Quadro 9). As diretrizes de AAE do BAD realçam a consideração da dimensão social juntamente à dimensão ambiental. Ademais elas solicitam a realização de pelo menos duas consultas ao público para os financiamentos de categoria 1. As boas práticas, por outro lado, não estabelecem um número mínimo de consultas com base nos tipos de impactos esperados.

Quadro 9 - Alinhamento da política ambiental de AAE do BAD com boas práticas

(Continua)

\begin{tabular}{|c|c|c|}
\hline Etapas de AAE & Manual Operacional do BAD & Boas práticas \\
\hline Triagem & $\begin{array}{l}\text { Determinar a categoria social e ambiental } \\
\text { atribuída à ação estratégica }\end{array}$ & $\begin{array}{l}\text { Determinar a necessidade de } \\
\text { AAE e o nível de detalhes }\end{array}$ \\
\hline Escopo & $\begin{array}{l}\text { Identificar as dimensões ambientais e } \\
\text { sociais que devem ser levados em } \\
\text { consideração durante o processo de } \\
\text { avaliação }\end{array}$ & $\begin{array}{l}\text { Identificação de questões- } \\
\text { chaves, abrangência do estudo e } \\
\text { impactos a serem analisados }\end{array}$ \\
\hline $\begin{array}{l}\text { Estudos e Análise de } \\
\text { Base Ambiental }\end{array}$ & Descrever dados de baseline & $\begin{array}{l}\text { Reunir, coletar e produzir } \\
\text { informações de maneira crítica e } \\
\text { lógica }\end{array}$ \\
\hline $\begin{array}{l}\text { Descrição e Análise } \\
\text { de cenários e } \\
\text { alternativas }\end{array}$ & $\begin{array}{l}\text { Identificar alternativas realizáveis } \\
\text { (incluindo o cenário "sem ação } \\
\text { estratégica") }\end{array}$ & $\begin{array}{l}\text { Identificação de uma série de } \\
\text { alternativas e opções }\end{array}$ \\
\hline
\end{tabular}


(Conclusão)

\begin{tabular}{|c|c|c|}
\hline Etapas de AAE & Manual Operacional do BAD & Boas práticas \\
\hline $\begin{array}{l}\text { Avaliação de Impacto } \\
\text { das alternativas }\end{array}$ & $\begin{array}{l}\text { Examinar os potenciais impactos } \\
\text { positivos e negativos e compara-los aos } \\
\text { impactos de outras alternativas }\end{array}$ & $\begin{array}{l}\text { Identificar prever e avaliar os } \\
\text { impactos e significância das } \\
\text { alternativas }\end{array}$ \\
\hline $\begin{array}{l}\text { Descrição das } \\
\text { medidas de mitigação } \\
\text { e monitoramento }\end{array}$ & $\begin{array}{l}\text { Recomenda que medidas necessárias para } \\
\text { prevenir, minimizar, mitigar ou } \\
\text { compensar impactos adversos e aumentar } \\
\text { os benefícios ambientais e sociais. }\end{array}$ & $\begin{array}{l}\text { Identificar as medidas para } \\
\text { evitar, reduzir e compensar os } \\
\text { impactos identificados }\end{array}$ \\
\hline $\begin{array}{l}\text { Relatório / } \\
\text { Documentação }\end{array}$ & Relatório/Documentação & Relatório/Documentação \\
\hline Consulta pública & $\begin{array}{l}\text { - Para financiamentos da categoria } 1 \text {, } \\
\text { realiazar no mínimo duas consultas sendo } \\
\text { a primeira na etapa de definição de escopo } \\
\text { e a segunda após a elaboração do relatório } \\
\text { final. } \\
\text { - Para financiamentos da categoria } 2 \text {, } \\
\text { realiazar no mínimo uma consulta. }\end{array}$ & $\begin{array}{l}\text { Disponibilizar o relatório final } \\
\text { para consulta pública }\end{array}$ \\
\hline
\end{tabular}

Fonte: Boas práticas de Lemos (2011), baseado em Sadler (2000), Therivel (2004) e Grunn e Noble (2009)

\subsubsection{Banco Interamericano de Desenvolvimento}

O Grupo Banco Interamericano de Desenvolvimento é composto pelo Fundo Multilateral de Investimentos (Fumin), a Corporação Interamericana de Investimentos (CII) e o Banco Interamericano de Desenvolvimento (BID). O Fumin, administrado pelo BID, estimula o crescimento do setor privado com investimentos e doações enquanto a CII apoia empresas de pequeno e médio porte. Fundado em dezembro de 1959, o BID é a maior e mais antiga Agência Multilateral de Desenvolvimento regional do mundo e a principal fonte de financiamento multilateral para o desenvolvimento econômico, social e institucional na América Latina e no Caribe. Os seus recursos provêm de seus 48 países membros, mercados financeiros e fundos fiduciários e de operações de cofinanciamento (BANCO INTERAMERICANO DE DESENVOLVIMENTO, 2000; 2013).

O Banco Interamericano de Desenvolvimento foi a primeira AMD a adotar uma política ambiental (em 1979) no intuito de assegurar a qualidade ambiental de suas operações e apoiar projetos ambientais da região (BANCO INTERAMERICANO DE DESENVOLVIMENTO, 2006). No entanto, o BID foi a última AMD a incorporar a Avaliação Ambiental Estratégica em sua política ambiental. O banco segue as diretrizes 
ambientais adotadas em 2007. Estas diretrizes requerem a aplicação de AAE para Políticas, Planos e Programas da categoria A. Para a categoria B, o BID solicita uma Análise Ambiental e Social como também um Plano de Gestão Ambiental e Social (Quadro 10).

\section{Quadro 10 - Categorias e Níveis de aplicação da Avaliação Ambiental Estratégica no Banco interamericano de Desenvolvimento}

\begin{tabular}{l|cc}
\hline Níveis & Categoria A & Categoria B \\
\hline Programa & AAE & AnAS $^{1}+$ PGAS $^{2}$ \\
\hline Plano & AAE & AnAS + PGAS \\
\hline Política & AAE & AnAS + PGAS \\
\hline $\begin{array}{l}\text { Atividades Setoriais e } \\
\text { Regionais }\end{array}$ & AAE & AnAS + PGAS \\
\hline
\end{tabular}

${ }^{1}$ Análise Ambiental e Social; ${ }^{2}$ Plano de Gestão Ambiental e Social

Fonte: Elaborado pelo autor.

A Avaliação Ambiental Estratégica é definida pela política ambiental do BID como sendo o instrumento que insere variáveis sociais e ambientais no planejamento do desenvolvimento, processos de implementação e tomada de decisão em nível estratégico antes que compromissos e decisões em nível de projeto sejam tomados. Essa ferramenta apresenta, no âmbito do banco, algumas características singulares. A triagem é realizada pela AMD na sua análise preliminar enquanto o escopo é feito juntamente com o mutuário. A aplicação da AAE deve respeitar a legislação em vigor no país mutuário e considerar aportes de partes envolvidas (INTER-AMERICAN DEVELOPMENT BANK, 2007).

Quanto verificação do alinhamento da política ambiental de AAE do BID com as boas práticas, constata-se que as diretrizes de AAE do Banco Interamericano de Desenvolvimento condizem com a literatura exceto no tocante às alternativas e consultas públicas como pode ser visto do Quadro 11. 
Quadro 11 - Alinhamento da política ambiental de AAE do BID com boas práticas

\begin{tabular}{|c|c|c|}
\hline Etapas de AAE & Manual Operacional do Banco Mundial & Boas práticas \\
\hline Triagem & $\begin{array}{l}\text { - Auxiliar na categorização } \\
\text { ambiental da ação estratégica } \\
\text { - Identificar potenciais fatores de } \\
\text { risco ambientais }\end{array}$ & $\begin{array}{l}\text { Determinar a necessidade de } \\
\text { AAE e o nível de detalhes }\end{array}$ \\
\hline Escopo & $\begin{array}{l}\text { Indicar a finalidade daAAE e fornecer } \\
\text { uma breve descrição do projeto }\end{array}$ & $\begin{array}{l}\text { Identificação de questões- } \\
\text { chaves, abrangência do estudo e } \\
\text { impactos a serem analisados }\end{array}$ \\
\hline $\begin{array}{l}\text { Estudos e Análise de } \\
\text { Base Ambiental }\end{array}$ & $\begin{array}{l}\text { Coletar informações/dados relevantes } \\
\text { para a tomada de decisão a respeito do } \\
\text { objeto a ser avaliado }\end{array}$ & $\begin{array}{l}\text { Reunir, coletar e produzir } \\
\text { informações de maneira crítica e } \\
\text { lógica }\end{array}$ \\
\hline $\begin{array}{l}\text { Descrição e Análise } \\
\text { de cenários e } \\
\text { alternativas }\end{array}$ & $\begin{array}{l}\text { Identificar possíveis alternativas da ação } \\
\text { estratégica (incluir a alternativa "nenhuma } \\
\text { ação"). }\end{array}$ & $\begin{array}{l}\text { Identificação de uma série de } \\
\text { alternativas e opções (incluir os } \\
\text { cenários "não fazer nada" e } \\
\text { "mais benéfico ao ambiente"). }\end{array}$ \\
\hline $\begin{array}{l}\text { Avaliação de Impacto } \\
\text { das alternativas }\end{array}$ & $\begin{array}{l}\text { Identificar mudanças no meio ambiente } \\
\text { resultantes de cada alternativa }\end{array}$ & $\begin{array}{l}\text { Identificar prever e avaliar os } \\
\text { impactos e significância das } \\
\text { alternativas }\end{array}$ \\
\hline $\begin{array}{l}\text { Descrição das } \\
\text { medidas de mitigação } \\
\text { e monitoramento }\end{array}$ & $\begin{array}{l}\text { Descrever medidas de mitigação e } \\
\text { monitoramento }\end{array}$ & $\begin{array}{l}\text { Identificar as medidas para } \\
\text { evitar, reduzir e compensar os } \\
\text { impactos identificados }\end{array}$ \\
\hline $\begin{array}{l}\text { Relatório / } \\
\text { Documentação }\end{array}$ & Relatório/Documentação & Relatório/Documentação \\
\hline Consulta pública & $\begin{array}{l}\text { - Para financiamentos da categoria } 1 \text {, } \\
\text { realiazar no mínimo duas consultas sendo } \\
\text { a primeira na etapa de definição de escopo } \\
\text { e a segunda após a elaboração do relatório } \\
\text { final. } \\
\text { - } \quad \text { Para financiamentos da categoria } 2 \text {, } \\
\text { realiazar no mínimo uma consulta. }\end{array}$ & $\begin{array}{l}\text { Disponibilizar o relatório final } \\
\text { para consulta pública }\end{array}$ \\
\hline
\end{tabular}

Fonte: Boas práticas de Lemos (2011), baseado em Sadler (2000), Therivel (2004) e Grunn e Noble (2009)

\subsubsection{Banco Asiático de Desenvolvimento}

O Banco Asiático de Desenvolvimento (ADB) foi criado em 1966 através de um acordo multilateral ratificado por 31 países. Ele tem 61 membros, dos quais 44 estão na Ásia e no Pacífico. O objetivo desta instituição é tornar a Ásia um continente livre da pobreza através de seu auxílio aos países membros. Esta assistência visa reduzir a pobreza e melhorar a qualidade e as condições de vida da população. Para alcançar as suas metas, o ADB segue uma agenda estratégica de crescimento econômico sustentável, desenvolvimento social e 
governança política e institucional eficaz, baseando-se em três temas transversais: desenvolvimento do setor privado, a cooperação regional e integração para o desenvolvimento e sustentabilidade ambiental. Os principais instrumentos utilizados na prestação de ajuda aos países membros são diálogos políticos, empréstimos, assistências técnicas, doações, garantias e investimentos de capital. O Banco os consegue através de seus recursos ordinários de capital entre outros aplicações privadas, mercados de capitais, capital integralizado dos acionistas e acúmulo de lucros (ASIAN DEVELOPMENT BANK, 2003a).

Na sua Política Ambiental de salvaguarda, o ADB recomenda ferramentas que poderão ser aplicadas para avaliar os impactos ambientais de seus financiamentos. A Avaliação Ambiental Estratégica, recomendada desde 2003, é a ferramenta indicada para programas e operações setoriais da categoria A (Quadro 12). Para a categoria B, uma Avaliação Ambiental Inicial é requisitada antes de determinar necessidade de aplicação de uma AAE.

Quadro 12 - Categorias e Níveis de aplicação da Avaliação Ambiental Estratégica no Banco Asiático de Desenvolvimento

\begin{tabular}{l|cc}
\hline Níveis & Categoria A & Categoria B \\
\hline Programa & AAE ou AAMP & A definir após a AAI ${ }^{2}$ \\
\hline Atividades Setoriais & AAE ou AAS & A definir após a AAI \\
\hline
\end{tabular}

${ }^{1}$ Avaliação Ambiental da Matriz de Política; ${ }^{2}$ Avaliação Ambiental Inicial

Fonte: Elaborado pelo autor.

Uma das particularidades da AAE no âmbito do ADB é que, além de definir o escopo junto com o mutuário, o Banco asiático recomenda que o processo de avaliação estabeleça diretrizes para projetos e subprojetos e seja muito participativo, envolvendo a população durante o processo.

O Quadro 13 mostra as diferenças entre as boas práticas e as diretrizes ambientais do Banco Asiático de Desenvolvimento voltadas para AAE. Observa-se diferenças no que tange às consultas públicas e alternativas. Enquanto a AMD solicita um mínimo de duas consultas para financiamentos de catogoria $\mathrm{A}$, as boas práticas apenas consideram a realizaçao de uma consulta como satisfatória. Quanto às alternativas, a literatura recomenda a consideração de três alternativas especificadas enquanto as diretrizes ambientais de AAE do banco solicitam a consideração de possíveis alternativas sem mencionar tipos de cenários a serem levados em consideração. 
Quadro 13 - Alinhamento da política ambiental de AAE do ADB com boas práticas

\begin{tabular}{|c|c|c|}
\hline Etapas de AAE & Manual Operacional do Banco Mundial & Boas práticas \\
\hline Triagem & Verificar a necessidade de AAE & $\begin{array}{l}\text { Determinar a necessidade de } \\
\text { AAE e o nível de detalhes }\end{array}$ \\
\hline Escopo & $\begin{array}{l}\text { - } \quad \text { Delimitar da(s) área(s) a ser } \\
\text { coberta(s) pela avaliação e descrever } \\
\text { condições de baseline da área de estudo } \\
\text { - } \quad \text { Garantir que todas as questões } \\
\text { prioritárias e relevantes para a decisão } \\
\text { sejam abordadas } \\
\text { - } \quad \text { Definir indicadores }\end{array}$ & $\begin{array}{l}\text { Identificação de questões- } \\
\text { chaves, abrangência do estudo e } \\
\text { impactos a serem analisados }\end{array}$ \\
\hline $\begin{array}{l}\text { Estudos e Análise de } \\
\text { Base Ambiental }\end{array}$ & $\begin{array}{l}\text { Descrever o ambiente afetado com foco } \\
\text { em áreas sensíveis e ameaçadas }\end{array}$ & $\begin{array}{l}\text { Reunir, coletar e produzir } \\
\text { informações de maneira crítica e } \\
\text { lógica }\end{array}$ \\
\hline $\begin{array}{l}\text { Descrição e Análise } \\
\text { de cenários e } \\
\text { alternativas }\end{array}$ & Descrição de possíveis alternativas & $\begin{array}{l}\text { Identificação de uma série de } \\
\text { alternativas e opções (incluir os } \\
\text { cenários "não fazer nada" e } \\
\text { "mais benéfico ao ambiente"). }\end{array}$ \\
\hline $\begin{array}{l}\text { Avaliação de Impacto } \\
\text { das alternativas }\end{array}$ & $\begin{array}{l}\text { - Identificação, previsão e avaliação } \\
\text { de impactos ambientais de alternativas } \\
\text { - Integração dos efeitos ambientais, } \\
\text { sociais e econômicos devem ser parte da } \\
\text { previsão do impacto e do processo de } \\
\text { avaliação. }\end{array}$ & $\begin{array}{l}\text { Identificar prever e avaliar os } \\
\text { impactos e significância das } \\
\text { alternativas }\end{array}$ \\
\hline $\begin{array}{l}\text { Descrição das } \\
\text { medidas de mitigação } \\
\text { e monitoramento }\end{array}$ & $\begin{array}{l}\text { - } \quad \text { Medidas de eliminação, redução ou } \\
\text { compensação de efeitos ambientais } \\
\text { - } \quad \text { Incluir plano de monitoramento }\end{array}$ & $\begin{array}{l}\text { Identificar as medidas para } \\
\text { evitar, reduzir e compensar os } \\
\text { impactos identificados }\end{array}$ \\
\hline $\begin{array}{l}\text { Relatório / } \\
\text { Documentação }\end{array}$ & Relatório/Documentação & Relatório/Documentação \\
\hline Consulta pública & $\begin{array}{l}\text { - Para financiamentos da categoria A, } \\
\text { realizar no mínimo duas consultas sendo a } \\
\text { primeira na etapa de definição de escopo e } \\
\text { a segunda após a elaboração do relatório } \\
\text { final. } \\
\text { - Para financiamentos da categoria B, } \\
\text { realizar no mínimo uma consulta. }\end{array}$ & $\begin{array}{l}\text { Disponibilizar o relatório final } \\
\text { para consulta pública }\end{array}$ \\
\hline
\end{tabular}

Fonte: Boas práticas de Lemos (2011), baseado em Sadler (2000), Therivel (2004) e Grunn e Noble (2009)

A Avaliação Ambiental Estratégica é uma ferramenta que apresenta inúmeros benefícios. Porém, ela deve ser adaptada ao contexto para que possa desempenhar o seu papel adequadamente. Uma das formas de adequar a AAE ao contexto de aplicação é a adoção de 
leis regulamentadoras que levam em conta o cenário de aplicação. Este tipo de adequação tem se verificado no âmbito das Agências Multilaterais de Desenvolvimento.

Todas as instituições analisadas dispõem de políticas ambientais voltadas para Avaliação Ambiental Estratégica que servem de guias assegurando a viabilidade ambiental dos financiamentos. Os resultados demostram que essas diretrizes condizem com a literatura em todos os aspectos salvo no que se refere ao processos de participação pública e alternativas. Enquanto as AMDs vão além das boas práticas no que diz respeito às consultadas à população, elas ficam aquém em relação às alternativas a serem consideradas pela avaliação. Os requerimentos de consulta pública adotados pelas Agências Multilaterais de Desenvolvimento merecem ser destacados como aspectos positivos que encorajam o envolvimento das partes afetadas ao longo do processo de Avaliação Ambiental Estratégica. Ao contrário, constata-se a necessidade de aproximar as políticas ambientais de AAE das boas práticas para garantir a consideração de alternativas adequadas no processo de avaliação.

Constatou-se o uso de diferentes denominações para AAE no âmbito das AMDs. O Banco Mundial recentemente passou a adotar a denominação Avaliação Ambiental e Social Estratégica que já era usada pelo Banco Africano de Desenvolvimento. Por outro lado, a ADB e o BID usam a denominação Avaliação Ambiental Estratégica. Embora a designação não sirva de parâmetro para mensurar o caráter estratégico de uma Avaliação Ambiental, ela constitui um importante referencial. De todo modo, é importante destacar a essência da ferramenta - ponto de vista partilhado por Connelly e Richardson (2005), e Mclauchlan e João (2011).

Em relação ao conteúdo das políticas ambientais voltadas para Avaliação Ambiental Estratégica das AMDs, os resultados mostram que no âmbito do Banco Mundial e Banco Interamericano de Desenvolvimento, a AAE se aplica a todos os níveis estratégicos do planejamento, isto é, Políticas, Planos e Programas, além de ações estratégicas regionais e setoriais. Esses escalões são apontados na literatura como níveis em que a Avaliação Ambiental Estratégica também pode ser aplicada (FISCHER, 2007; LEE; WALSH, 1992; PARTIDÁRIO, 2000; THERIVEL, 2004). De maneira oposta, a AAE no âmbito do Banco Asiático de Desenvolvimento e Banco Africano de Desenvolvimento não se aplica a todos os níveis estratégicos, como o nível de políticas. Especialmente no ADB, os planos também são isentos de Avaliação Ambiental Estratégica. Percebe-se que esta ferramenta não se aplica a certos níveis estratégicos superiores (na cadeia decisória) que estabelecem um quadro para níveis subsequentes. Assim sendo, a AAE avalia ações estratégicas cujas precursoras não passaram pela mesma avaliação, fato que pode gerar conflitos e inconsistências. Constata-se 
que esse instrumento vê-se limitado a certos níveis sendo que pode se adequar a todos os escalões estratégicos e cumprir seu papel. A Diretiva Europeia 2001/42/EC tem sido criticado por Therivel (2004), por apresentar a mesma limitação.

No que diz respeito às categorias atribuídas pelas AMDs às solicitações de financiamentos, para a categoria $\mathrm{A} / 1$ todos os financiamentos devem passar por uma Avaliação Ambiental Estratégica. No entanto, para a categoria $B / 2$ há divergências entre as Agências Multilaterais de Desenvolvimento. O Banco Mundial e o Banco Asiático de Desenvolvimento solicitam uma análise inicial para essa categoria no intuito de verificar a necessidade de uma Avaliação Ambiental Estratégica. Já, o Banco Africano de Desenvolvimento e o Banco Interamericano de Desenvolvimento requerem outro tipo de avaliação para a categoria $\mathrm{B} / 2$. Nessas duas últimas $\mathrm{AMDs}$, a $\mathrm{AAE}$ é restrita à categoria $\mathrm{A} / 1$ enquanto ela também pode se aplicar à categoria $\mathrm{B} / 2$.

\subsubsection{Levantamento das AAEs solicitadas pelas AMDs}

As políticas adotadas pelas AMDs dificultam a aplicação da AAE no momento de concepção da ação estratégica como preconiza a literatura (ver THERIVEL, 2004). Para obter um financiamento, deve-se fazer um pedido formal ao banco que irá analisar a ação estratégica antes de solicitar a AAE. No momento do pedido, a ação estratégica deve ser minimamente estruturada, pois a avaliação do banco precisa de informações para verificar a viabilidade do financiamento e elaborar o Termo de Referência. Sendo assim, a aplicação da $\mathrm{AAE}$ no início do planejamento é dificultada quando o país mutuário não tem a $\mathrm{AAE}$ regulamentada.

Foi feito um levantamento de todas as aplicações de Avaliações Ambientais Estratégicas solicitadas pelo Banco Interamericano de Desenvolvimento, pelo Banco Africano de Desenvolvimento, pelo Banco Asiático de Desenvolvimento e pelo Banco Mundial do ano de 1993 até o ano de 2014 (Apêndice 1). Obteve-se um total de 214 AAEs aplicadas nos países em desenvolvimento.

O levantamento feito permite observar determinados agrupamentos de interesse para a

caracterização. É possível verificar que os setores de Transporte, Energia, Água, Agricultura e Turismo foram aqueles que tiveram o maior número de AAEs elaboradas (Figura 2). 
Figura 2 - Número de AAEs requisitadas pelas AMDs, por setor de aplicação (1993-2014)

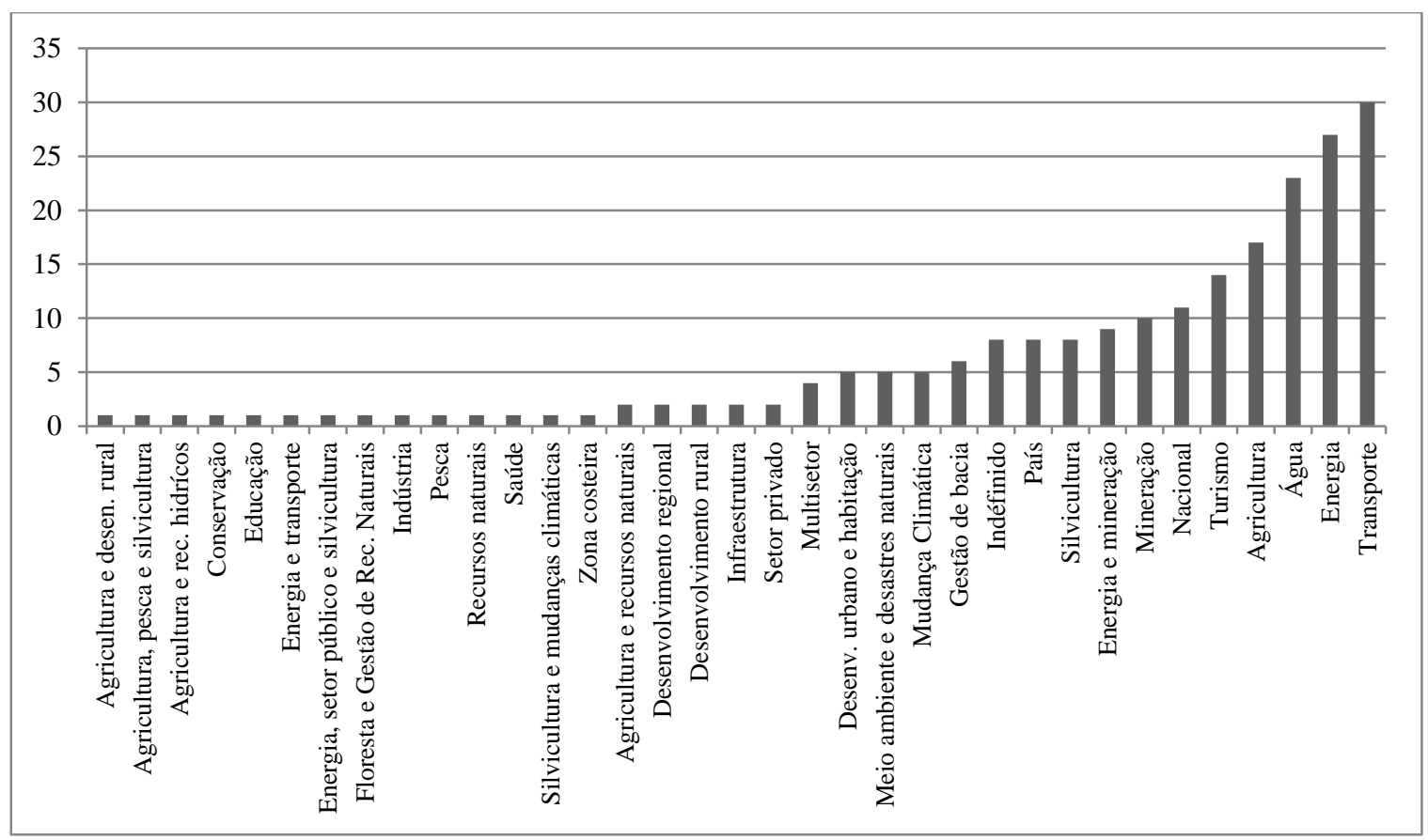

Fonte: Elaborado pelo autor

Considerando o número total de aplicações de AAE por ano, percebe-se que há uma tendência de aumento ao longo dos anos (Figura 3). Observa-se também que as primeiras aplicações se deram antes das AMDs adotarem a Avaliação Ambiental Estratégica nas suas Políticas Ambientais ${ }^{12}$. Portanto, pode-se inferir que as primeiras aplicações eram voluntárias, ainda assim aceitas pelas Agências Multilaterais de Desenvolvimento. ano de 1999. 
Figura 3 - Evolução do número de aplicações ao longo do período analisado

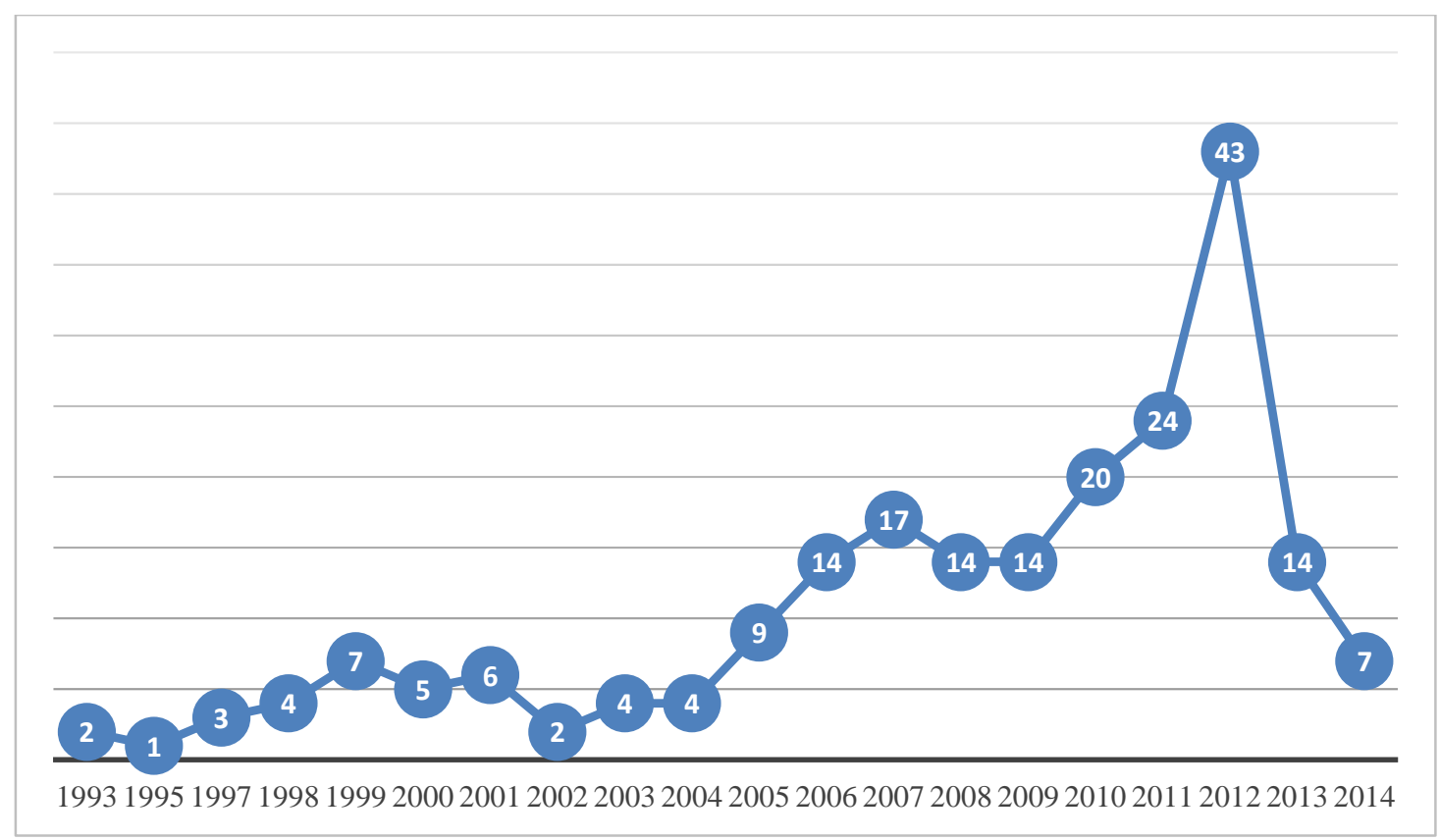

Fonte: Elaborado pelo autor

Olhando para a distribuição geográfica das aplicações de AAE solicitadas pelas AMD nos países em desenvolvimento, percebe-se que a Ásia (Figura 4) e África (Figura 5) são os continentes com o maior número de AAEs (77 cada um). A América Latina e Caribe (Figura 6) e Eurásia vêm em segunda e terceira posição com, respectivamente, 58 e 2 aplicações. Contudo, embora a África e a Ásia sejam os continentes com o maior número de aplicações, a África é o continente com o maior número de países que receberam aplicações de AAE.

Com relação aos países, a Índia se destaca por apresentar o maior número (26) de aplicações em nível continental e mundial. O Brasil vem em segundo lugar com 12 aplicações. O México e a Argentina tiveram 9 aplicações cada um. Por outro lado, países tais como Venezuela, Honduras, Republica Centro-africana, Afeganistão, Mongólia, entre outros, só tiveram uma aplicação cada um. A Turquia e o Kosovo, únicos países da Eurásia no levantamento, também tiveram uma aplicação cada um. As aplicações regionais são as que envolvem mais de um país. A Ásia ${ }^{13}$ conta três aplicações regionais enquanto que a África ${ }^{14} \mathrm{e}$

\footnotetext{
${ }^{13}$ Região Mekong com duas aplicações. O Grande Mekong é composto por Laos, Tailândia, Vietnã, Camboja, Mianmar e da província de Yunnan da China (BANCO MUNDIAL, 2004). A aplicação regional mencionada na figura 5 se refere à AAE aplicada ao setor energético do Paquistão, Tajaquistão e Afeganistão.

${ }^{14}$ Ruanda, Burundi e Tanzânia (uma AAE); Guiné, Libéria e Serra Leoa (1); Guiné, Mali, Mauritânia e Senegal (1); Mali, Mauritânia e Senegal (1); Moçambique e África do Sul (1); Bacia do Níger (1); Países da Bacia do Congo (2); Gana, Mali e Senegal (2); Bacia do Nilo (8); Burkina Faso, Gâmbia, Mali, Mauritânia, Níger, Senegal e Chad (1); Djibouti, Etiópia e Quénia (1); Etiópia, Eritreia, Somália (1); Buruni e Ruanda (1).
} 
a América Latina e Caribe ${ }^{15}$ têm, respectivamente, 22 e 4 Avaliações Ambientais Estratégicas regionais.

Figura 4 - Número de aplicações de AAEs requisitadas pelas AMDs em países asiáticos (1993-2014)

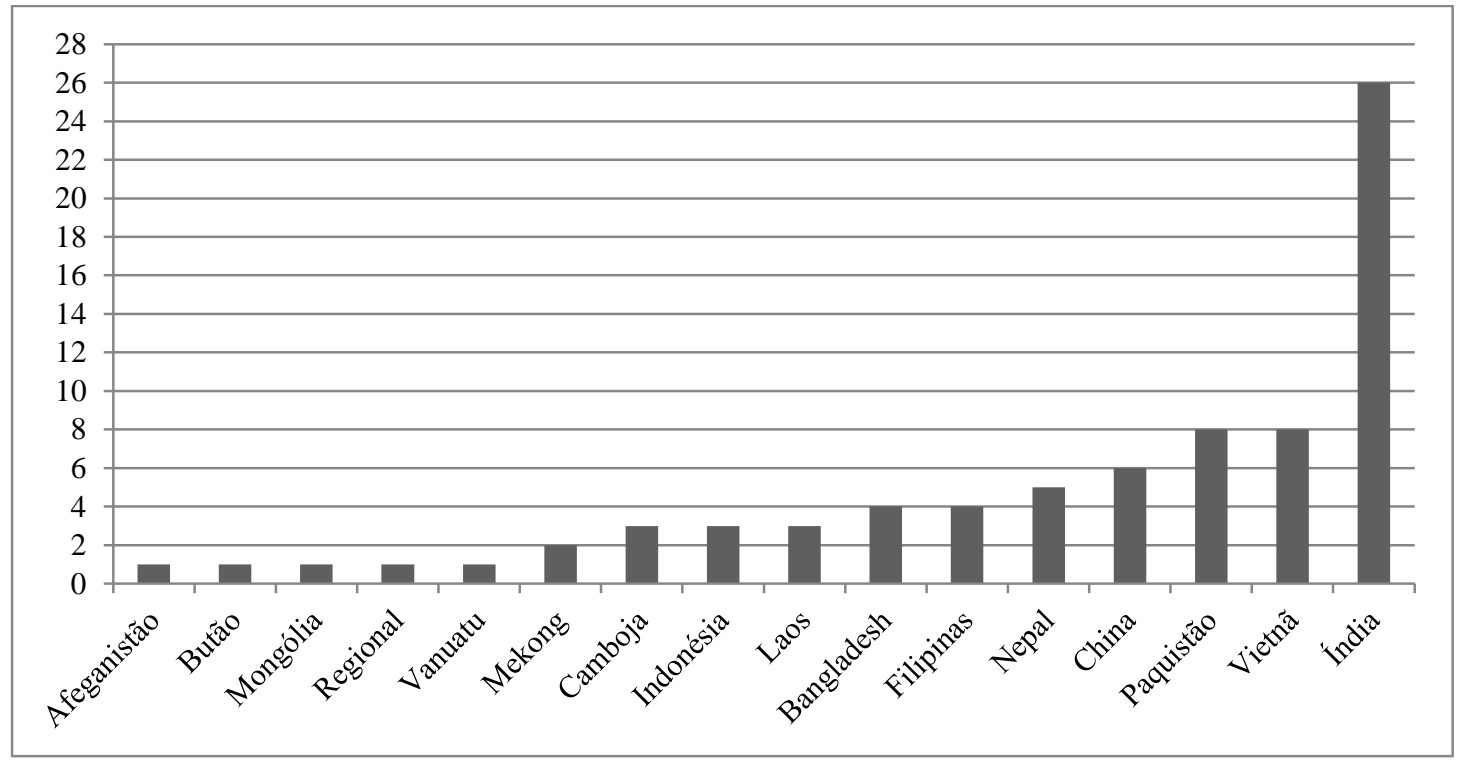

Fonte: Elaborado pelo autor

Figura 5 - Número de aplicações de AAEs requisitadas pelas AMDs em países africanos (1993-2014)

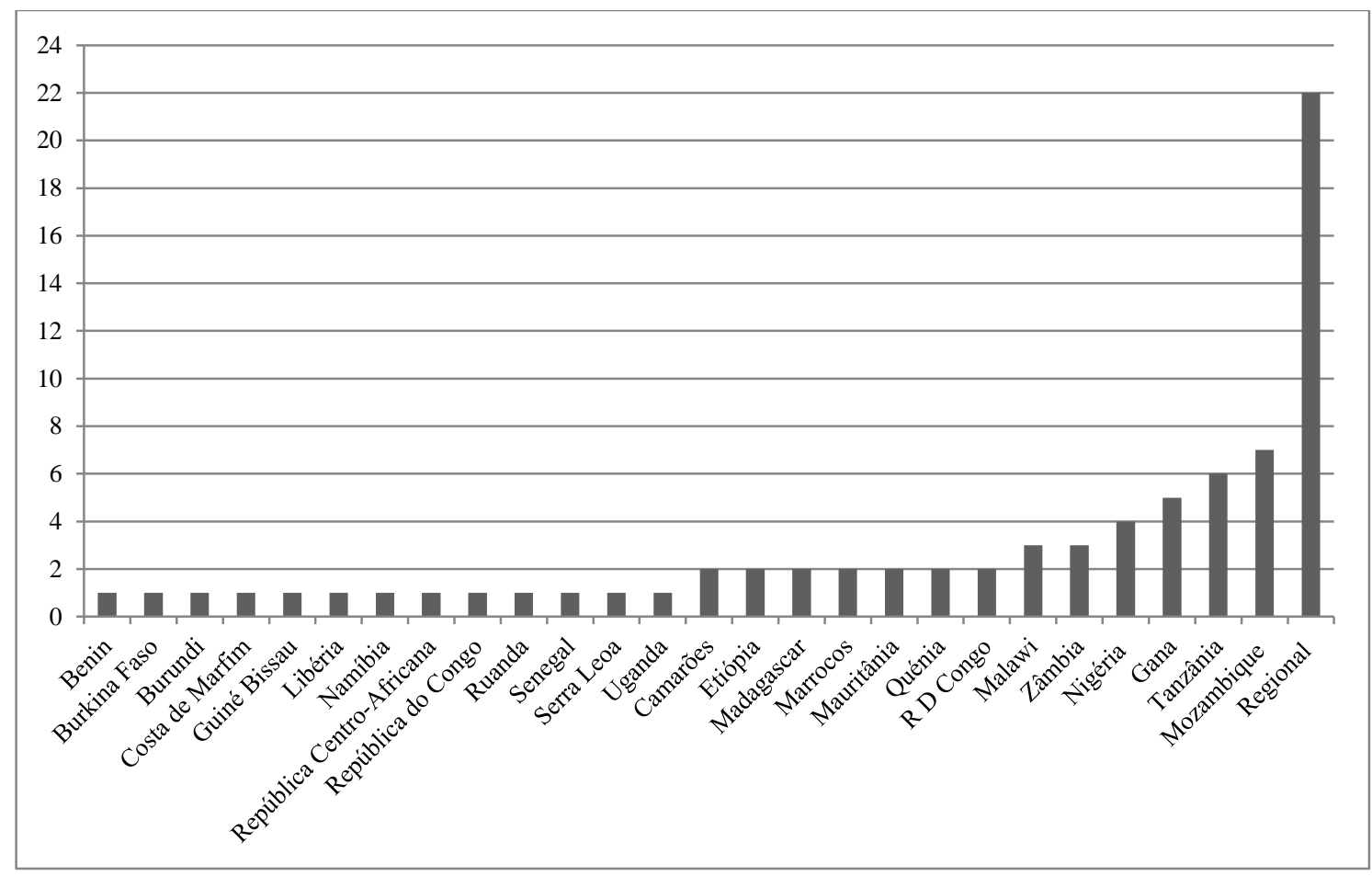

Fonte: Elaborado pelo autor

${ }^{15}$ Bolívia e Brasil (uma AAE); Colômbia, Costa Rica, El Salvador, México e Nicarágua (1); Guiana e Suriname (1); Apoio regional Holandês (1). 
Figura 6 - Número de aplicações de AAEs requisitadas pelas AMDs em países da América Latina e Caribe (1993-2014)

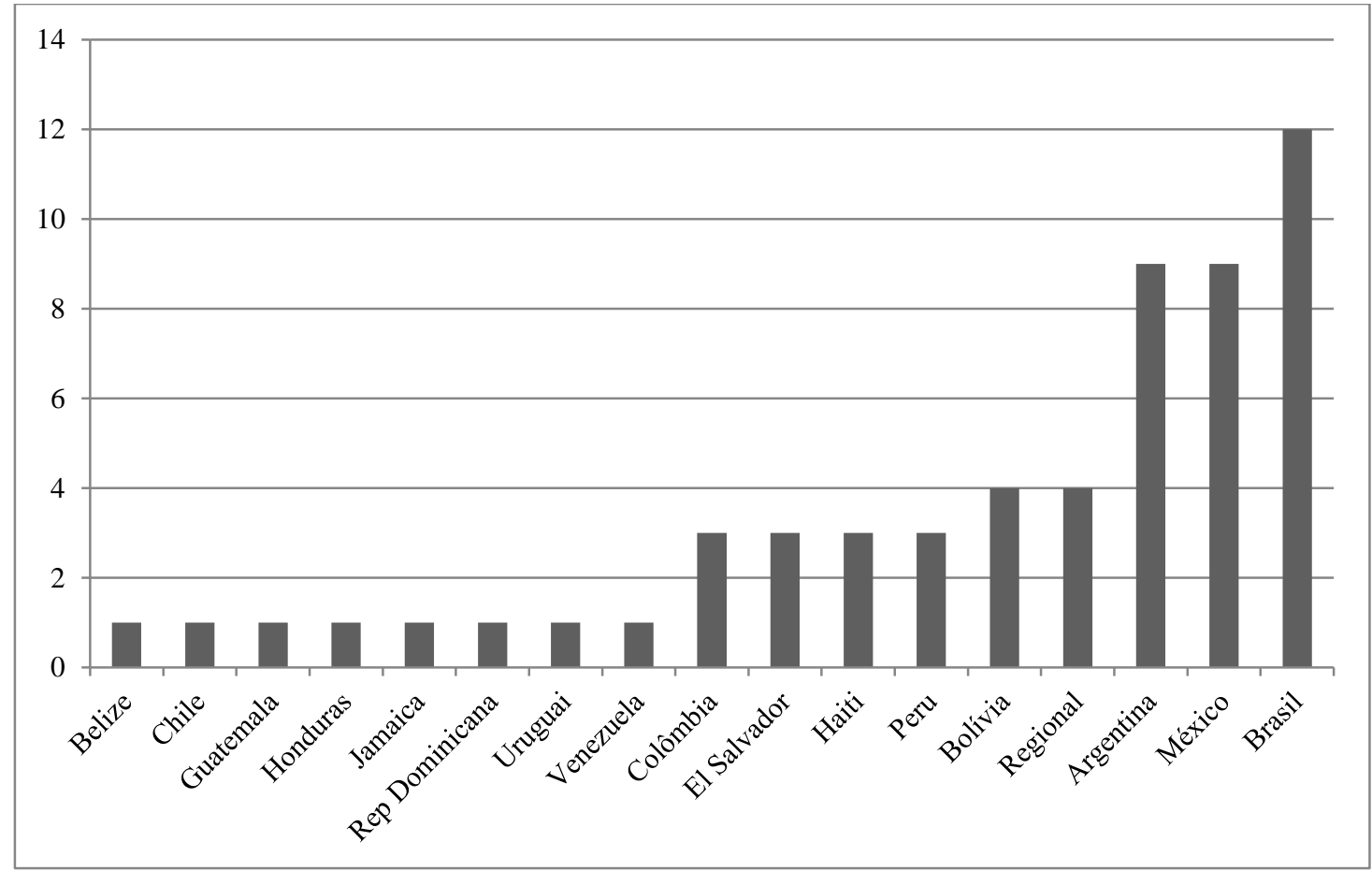

Fonte: Elaborado pelo autor 
5.2 Verificação de Aspectos Estratégicos associados às AAEs - Estudo de Casos Selecionados

\subsubsection{Projeto Energia Manantali}

\subsubsection{Contexto de inserção do projeto}

\section{(i) Background}

A Organização para o Desenvolvimento do Rio Senegal (Organisation pour la Mise en Valeur du Fleuve Senegal) foi criado em 1972 pelo Mali, Mauritânia e Senegal no intuito de promover o desenvolvimento econômico da bacia do Rio Senegal para fins de irrigação, navegação e produção de energia elétrica. O rio Senegal tem $1800 \mathrm{~km}$ de extensão, sendo um dos maiores rios de África. Ele começa na Guiné, flui para o norte em direção à parte ocidental do Mali, em seguida, vira para o noroeste estabelecendo a fronteira entre o Senegal e a Mauritânia, até atingir o Oceano Atlântico em Saint Louis (Figura 7). A área total da Bacia do Rio Senegal é de aproximadamente $290000 \mathrm{~km}^{2}$ e, no ano de 1996, suportava cerca de $10 \%$ da população dos três países. A bacia é constituída de três principais regiões: a bacia superior, o vale e o delta. As fortes chuvas na bacia superior fornecem quase todo o fluxo do rio Senegal, que traz água e vida a jusante para o deserto e as regiões secas da Mauritânia e do Senegal (WORLD BANK, 1997a).

Essas precipitações ocorrem de abril a outubro, causando um grande aumento do volume do rio por cerca de dois meses a cada ano. A agricultura no vale tradicionalmente dependia do aumento anual do volume do rio. A enxurrada também permite criação de gado, a recarga de aquíferos rasos que, por sua vez, permitem manter as ativitades de criação de gado e peixes e agricultura praticadas nas aldeias. Nas décadas de 1970 e 1980, no entanto, todas essas atividades foram severamente prejudicadas devido à seca vivenciada no vale (WORLD BANK, 1997a).

É em parte como resposta à esta aridez que a criação da Organização para o Desenvolvimento do Rio Senegal foi acelerada tendo como principais objetivos desenvolver a irrigação controlada permitindo o cultivo de cerca de 375000 há; aprimorar o tráfego de barcaças de Saint-Louis para Kayes; e viabilizar a produção de energia elétrica (WORLD BANK, 1997a). 
Em 1981, foram construídas duas represas - uma em Diama, no delta do rio, para evitar a intrusão de água salgada para o vale inferior, e uma segunda em Manantali no Mali Ocidental, para o armazenamento de água, regulação do fluxo do rio e geração de energia. A barragem em Diama tornou a agricultura irrigada possível durante todo o ano e permitiu o abastecimento de água para as populações a montante de Diama e para a cidade de Dakar. Por outro lado, o armazenamento das águas de enchentes pela barragem Manantali permitiu manter o reservatório Diama a nível pleno e estável e aumentar os níveis de dois lagos (Guiers e Rkiz), reduzindo consideravelmente os custos para os sistemas de irrigação bombeada em torno destes corpos d'água. Devido a essas melhorias, a agricultura irrigada se tornou uma grande força econômica no vale (WORLD BANK, 1997a).

No entanto, os componentes de navegação do plano de desenvolvimento integrado para o vale mostraram pouca perspectiva, concomitantemente havia uma demanda significativa de energia nas capitais Bamako (Mali), Nouakchott (Mauritânia), e Dakar (Senegal) e no Vale Senegal, justificando o desenvolvimento de instalações de geração de energia no Manantali. As instalações de energia ajudariam a minimizar o custo em longo prazo do fornecimento de energia elétrica para os três países e melhorariam a situação financeira dos serviços públicos locais (WORLD BANK, 1997a).

A vertente energética do projeto foi especialmente importante para o Mali, uma vez que a energia gerada foi projetada para representar cerca de $50 \%$ de sua demanda total para além de 2001 (WORLD BANK, 2006). Ademais, o Mali sofria por não ter terras litorâneas e pelo pobre estado de suas infraestruturas rodoviárias que dificultavam o transporte do combustível a partir dos portos atlânticos de seus países vizinhos. Todavia, em todos os três países, os sistemas de fornecimento de energia elétrica eram predominantemente térmicos de pequeno porte com uma capacidade total instalada de menos de 400 Megawatts (MW) tornando a eletricidade um produto de alto custo (WORLD BANK, 1997a). O projeto proposto foi uma alternativa substancialmente mais barata em relação à geração de energia térmica, dado o alto custo de combustíveis de petróleo particularmente nas regiões sem litoral do Mali (WORLD BANK, 2006).

Com efeito, este projeto tem amplos objetivos envolvendo três setores. Na agricultura, desejava-se conter as grandes inundações e viabilizar as culturas de cereais, legumes e cana de açúcar. No setor de transporte e comunicação, o projeto visava regular a descarga do Rio Senegal com cerca de $300 \mathrm{~m}^{3} / \mathrm{s}$ para subsidiar a estiagem do rio garantindo um fluxo mínimo para navegação. No setor energético, projetava-se produzir energia elétrica por uma outra usina hidroelétrica de 200 MW localizada no pé da já existente represa Manantali. O projeto 
também previa a instalação de $1000 \mathrm{~km}$ em linhas de transmissão (LTs) para distribuição de energia nos três países (WORLD BANK, 2006).

Os principais objetivos do projeto eram: (a) instalar uma usina de geração de energia para trazer benefícios econômicos e financeiros a partir da já construída barragem Manantali, e incentivar a cooperação e os intercâmbios de energia entre os três países membros; (b) ajudar a minimizar o custo de fornecimento de energia elétrica para os três países; (c) fornecer energia hidrelétrica para ajudar a atender o aumento da demanda por energia elétrica e reduzir os custos de combustível; (d) fortalecer a Organização para o Desenvolvimento do Rio Senegal e as entidades do setor de energia nos três países e estabelecer uma organização eficaz para gerenciar e operar a barragem Manantali e as instalações do projeto de modo satisfatório, levando em consideração a segurança, saúde e meio ambiente; e (e) contribuir para o desenvolvimento da agricultura tradicional a jusante, através da gestão racional do reservatório Manantali (WORLD BANK, 1997b).

\section{(ii) Descrição do Projeto}

O Projeto Energia Manantali previa desenvolver um extenso sistema de energia que atingiria as áreas urbanas de Mali, Mauritânia e Senegal alimentando-os com energia elétrica gerada a partir de uma usina a ser construída na já existente barragem Manantali. Esta última dispunha de um reservatório cuja capacidade é de 11,3 bilhões $\mathrm{m}^{3}$. A usina proposta teria 200 MW de capacidade instalada repartidos em cinco unidades de 40 MW, sendo a produção média de energia estimada em $804 \mathrm{GWh}$ (com base em dados de hidrologia para o período 1950-1994) (WORLD BANK, 1997a).

O projeto Energia Manantali era constituído de cinco componentes (Figura 7):

Componente A - Usina: este componente incluiria (a) as obras civis para a usina e o centro de despacho em Manantali; (b) instalações eletromecânicas (5 unidades de 40 MW cada); (c) uma subestação de elevação; e (d) reforços para a já existente barragem Manantali.

Componente B - Sistema de Transmissão e Despacho de carga: o sistema de transmissão de Manantali consistiria em um Sistema Leste com uma LT de 225 quilowatts $(\mathrm{kW})$ de $306 \mathrm{Km}$ em circuito único em direção a Bamako e um Sistema Oeste com LT de 225 quilovolts $(\mathrm{kV})$ circuito único de $945 \mathrm{~km}$ para Dakar.

Componente C - Supervisão: um consórcio de três consultores experientes foi recrutado para: (a) avaliar a proposta de apoio e contrato de concessão dos componentes do 
projeto; (b) supervisionar a construção de todos os componentes do projeto e execução do contrato; (c) realizar o treinamento do pessoal.

Componente D - Fortalecimento Institucional: este componente incluiria o apoio à implementação de duas agências de: (a) Assistência ao recrutamento de um operador privado; (b) Apoio à implementação do plano de mitigação e monitoramento ambiental; (c) Apoio à criação/revisão dos princípios tarifários e dos mecanismos e acordos de compra de energia; (d) Estudos relativos ao programa de otimização de gestão do reservatório, medidas de mitigação, promoção da eletrificação do vale Senegal e desenvolvimento de potenciais locais para produção de hidrelétricidade; (e) Formação de pessoal; (f) Aquisição de equipamentos, materiais e veículos; e (g) Custos de operação durante a construção do projeto.

Componente $\mathbf{E}$ - Avaliação Técnica: consiste na avaliação dos componentes físicos do projeto e inspeç̃̃es dos equipamentos.

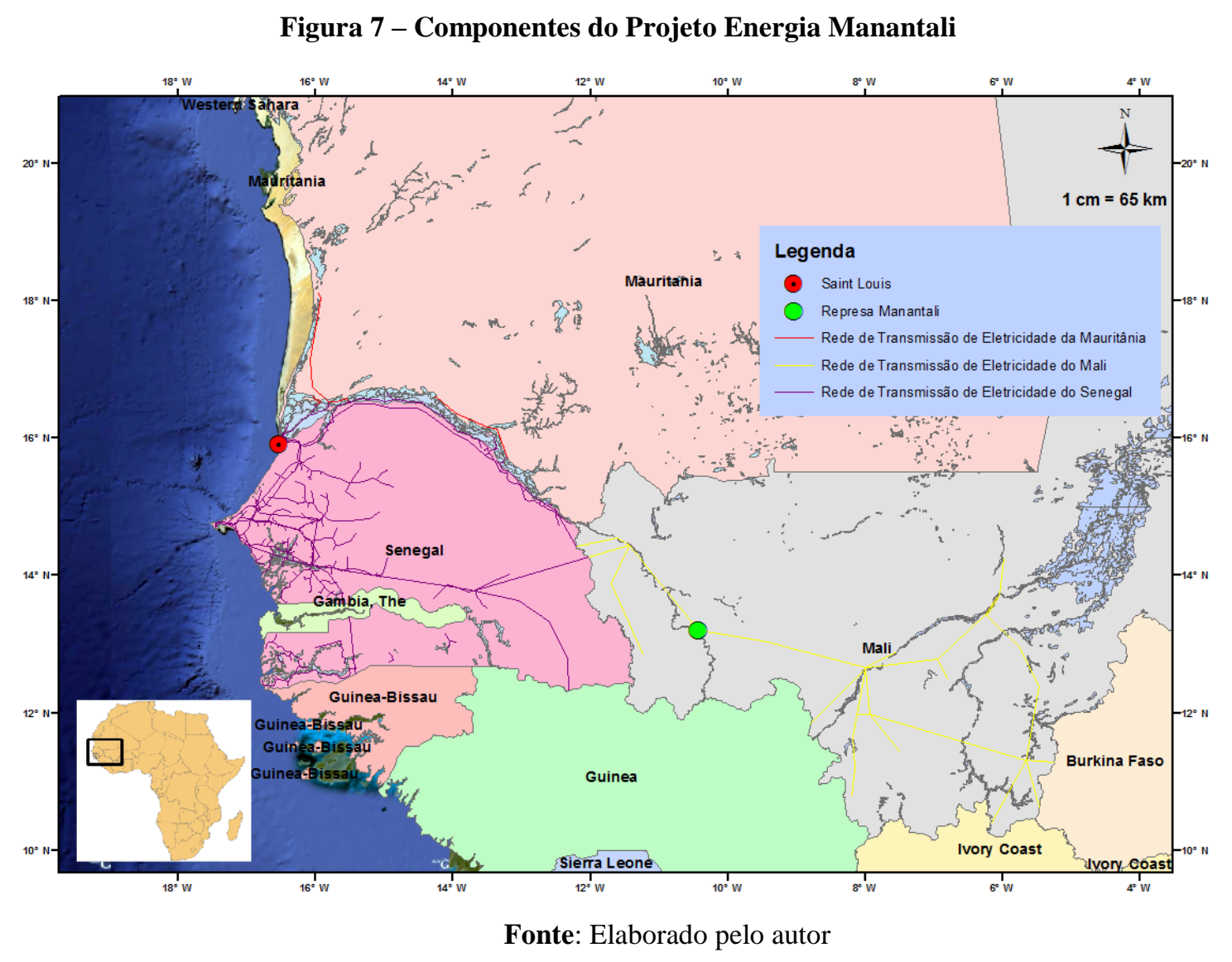

\subsubsection{Caracterização do nível estratégico do Projeto Energia Manantali}

O Projeto Energia Manantali apresenta as seguintes dimensões estratégicas:

Nível de Detalhes, abrangência e alternativas (Figura 8). 
A dimensão nível de detalhes é considerada como estratégica, pois a descrição do projeto apresenta poucos detalhes referidos assim como falta objetividade e exatidão nas informações e especificações. Nem todas as operações são descritas detadalhamente. A segunda dimensão, abrangência, é considerada estratégica, pois o projeto envolve mais de um setor (energia, transporte e agricultura). A dimensão alternativa também é considerada estratégica, uma vez que o background do projeto aponta também a consideração de alternativas térmicas na concepção do projeto.

Figura 8 - Dimensões Estratégicas do Projeto Energia Manantali

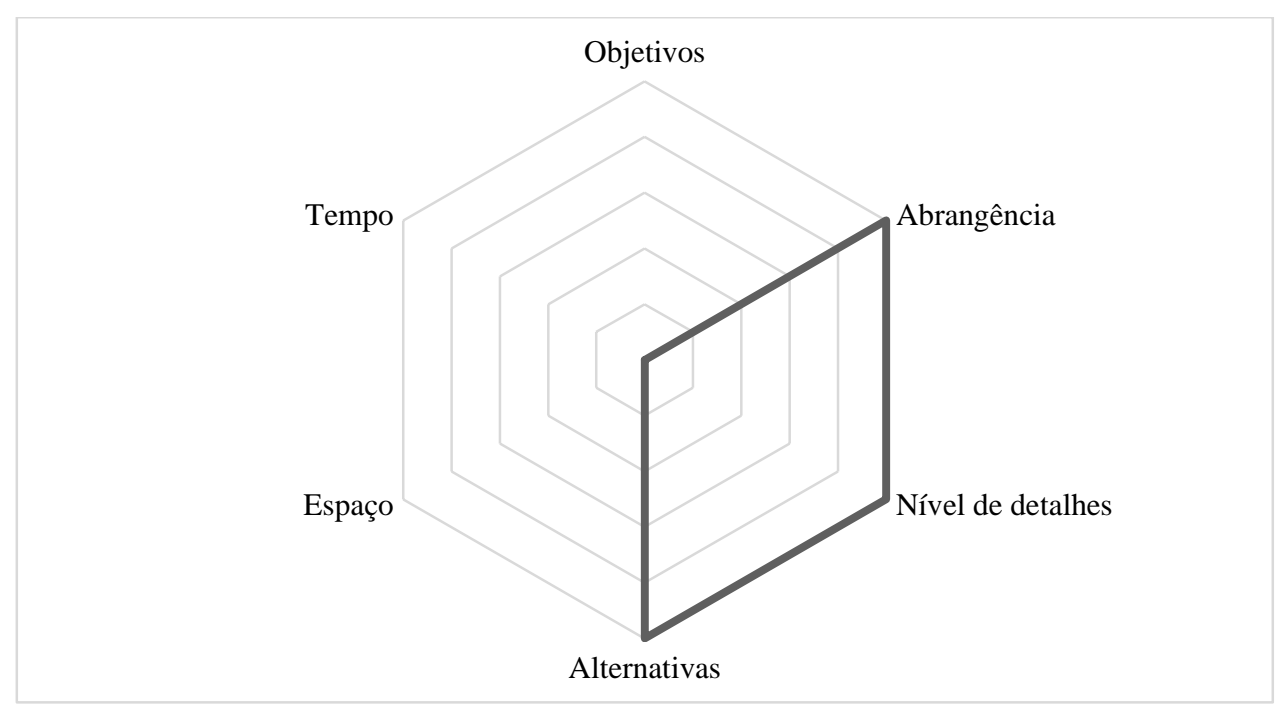

Fonte: Elaborado pelo autor

As dimensões objetivo, tempo e espaço não foram consideradas estratégicas na análise realizada. A dimensão objetivo não é estratégica, pois os objetivos expressam uma decomposição do objetivo geral sendo explicitados em metas concretas que definam a dimensão dos resultados a ser alcançados. A dimensão tempo não é considerada estratégica porque o projeto se encontra relativamente perto de sua execução. O período entre a concepção do projeto e sua execução é curto. Não foram levantados indícios de que é preciso um período de aguarda das providências necessárias para tornar efetiva a execução. A dimensão espaço também não é considerada estratégica, uma vez que o local de instalação dos componentes do projeto é definido com exatidão. A usina e as linhas de transmissão, entre outros, já têm os seus locais de implantação conhecidos. 


\subsubsection{Caracterização do Termo de Referência da Avaliação Ambiental}

O Termo de referência define os objetivos da Avaliação Ambiental como sendo: (a) analisar os impactos ambientais do projeto durante as fases de construção e exploração, e (b) caso necessário propor um plano de monitoramento assim como opções e medidas concretas para evitar ou mitigar os eventuais danos causados durante a construção e exploração. $\mathrm{O}$ Termo de Referência também fixa a abordagem a ser seguida pela AA, estipulando que o estudo deve ser realizado em duas fases:

- Avaliação de impactos ambientais

Esta etapa deve incluir os seguintes elementos:

- A descrição do ambiente receptor da barragem Manantali e de seus potenciais impactos ambientais a montante e a jusante. Considerar impactos sobre a saúde das comunidades vizinhas e sobre o regime de água;

- A descrição e avaliação dos vários elementos presentes nos corredores das Linhas de Transmissão considerando os estudos técnicos previamente realizados e Avaliação de Impactos Ambientais;

- A identificação de áreas críticas e ambientalmente sensíveis, isto é, locais onde as atividades terão um efeito significante sobre o meio ambiente e zonas onde a implementação das atividades e obras requer disposições para proteger o meio ambiente;

- A avaliação do impacto ambiental de alternativas térmicas.

- Preparação de um plano e de medidas de mitigação dos impactos

- Nesta segunda fase, a Avaliação Ambiental deve preparar um plano com medidas de mitigação e monitoramento.

O TR também solicita que seja feita uma consulta pública com participação ativa das partes interessadas (incluir, sobretudo a Organização para o Desenvolvimento do Rio Senegal e as pessoas que podem ser afetadas pelo projeto) e que os resultados seja documentados. 


\subsubsection{Alinhamento do TR e AA em relação a aspectos-chave da $A A E$}

(i) Verificação de aspectos-chave associados às AAEs no Termo de Referência e na Avaliação Ambiental

Dos quatro elementos essencias apontados por Therivel (2004), o Termo do referência solicita a realização de três etapas a saber, identificação de áreas problemáticas, avaliação de alternativas e a documentação do estudo.

Quanto à Avaliação Ambiental, ela tem sido solicitada no intuito de esclarecer a tomada de decisão a respeito de aspectos ambientais do projeto. A Avaliação Ambiental do Projeto Manantali apresenta as seguintes etapas: Escopo, Avaliação de Impacto, Relatório, Participação Pública, Mitigação e Monitoramento.

No entanto, no que diz respeito às etapas mínimas de uma AAE, a análise evidenciou que a Avaliação Ambiental não apresenta uma das quatro etapas mínimas (Figura 9). De um lado, a AA identifica indicadores e áreas problemáticas, avalia os impactos e documenta os resultados de avaliação. Por outro lado, porém, a avaliação não avalia impacto de alternativas salvo impactos do cenário com o projeto. A Avaliação Ambiental não considerou nenhuma alternativa de caráter estratégico. Os cenários levados em conta envolvem localizações das LT LTs e lançamentos de água pela represa.

Figura 9 - Alinhamento do TR e AA do Projeto Energia Manantali em relação a aspectos-chave da AAE

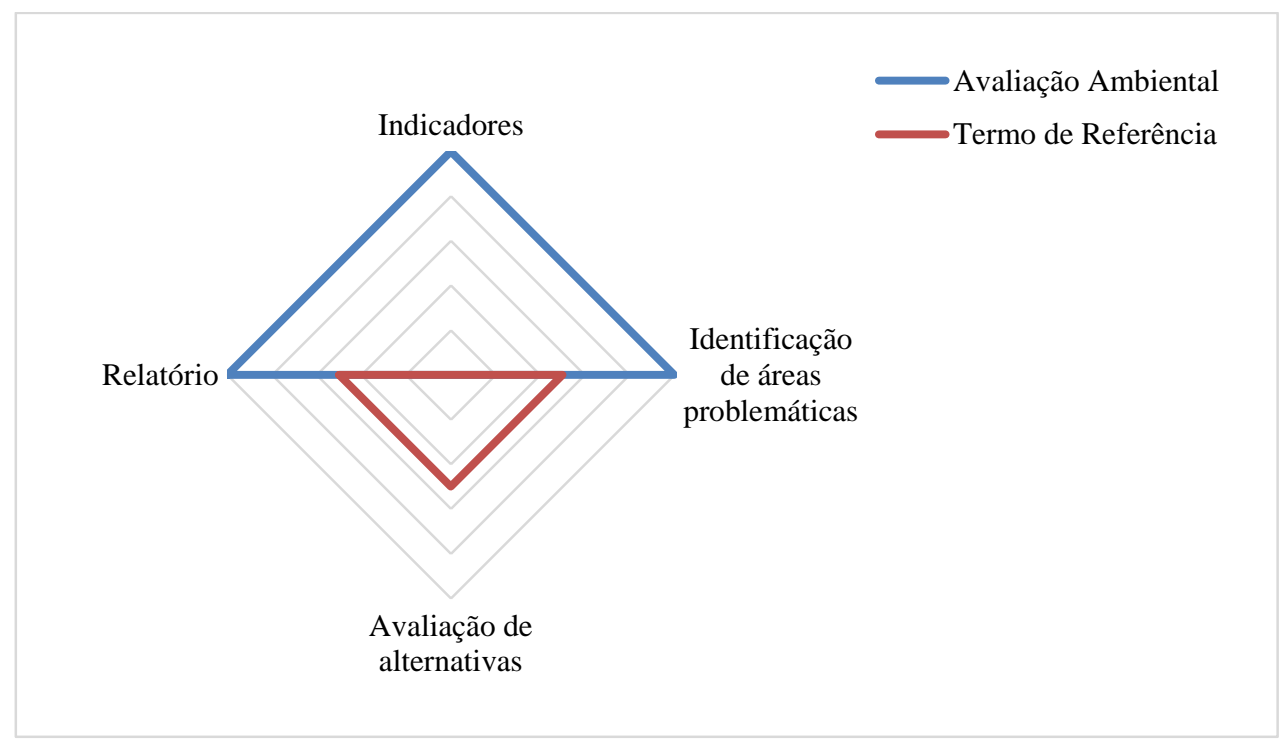

Fonte: Elaborado pelo autor 
(ii) Distanciamento entre TR padrão e TR específico do Projeto Energia Manantali

O Termo de Referência padrão aponta de forma genérica que devem ser adaptados aos diferentes contextos de aplicação. O quadro 14 mostra a relação de tarefas consideradas no Termo de Referência no qual constata-se que as tarefas não selecionadas dizem respeito ao contexto de inserção da ação estratégica e Avaliação Ambiental.

Quadro 14 - Relação TR padrão e TR específico do Projeto Energia Manantali

Tarefas apontadas pelo Termo de Referência padrão

Atendimento

Discussão do enquadramento de políticas no âmbito dos quais se efetua a AA. Explicação dos requisitos ambientais e identificação de acordos ambientais internacionais relevantes.

Descrição da ação estratégica proposta (o seu contexto geográfico, ecológico, social e temporal) incluindo quaisquer investimentos fora do local que possam ser necessários (por exemplo, dutos exclusivos, estradas de acesso, usinas geradoras de energia). Indicação da necessidade ou não de planos de reassentamento ou de ações de desenvolvimento para povos indígenas.

Previsão e avaliação dos prováveis impactos positivos e negativos da ação estratégica.

Avaliação das dimensões da área de estudo e descrição das condições físicas, biológicas e socioeconómicas relevantes, incluindo quaisquer alterações previstas para antes do início da ação estratégica. Também levar em consideração atividades de desenvolvimento em curso e propostas dentro da área da ação estratégica, mas não diretamente ligadas à mesma.

Identificação das medidas mitigadoras e quaisquer impactos residuais negativos que não possam ser mitigados. Exploração de oportunidades para melhoria ambiental.

Especificação do plano de monitoramento e de reforço institucional.

Avaliação de impactos ambientais de cada alternativa. Comparação de alternativas viáveis (incluindo a situação sem o projeto) em termos de potenciais impactos ambientais.

Justificativa da escolha de cada alternativa.

Consulta pública: Fazer registo das reuniões ocorridas entre os vários organismos e para obtenção de opiniões das pessoas afetadas pela ação estratégica projeto e de organizações não governamentais (ONG).

Documentação dos resultados

Fonte: Elaborado pelo autor 
(iii) Atendimento de apontamentos do Termo de Referência pela Avaliação Ambiental

Verificou-se que a AA não atende a todos os elementos solicitados pelo Termo de Referência. Com efeito, o estudo não identifica áreas ambientais críticas e não considera alternativas térmicas. Por outro lado, a avaliação descreve a baseline como solicitado no TR, avalia os elementos presentes nos corredores das LT e avalia os impactos ambientais.

\subsubsection{Projeto de Energia Gasosa Kribi}

\subsubsection{Contexto de inserção do projeto}

\section{(i) Background}

A República dos Camarões é um país da região ocidental da África Central que faz fronteira com a Nigéria a oeste; República Centro-Africana a leste; Chade a nordeste; e Guiné Equatorial, Gabão e República do Congo, ao sul. O litoral dos Camarões encontra-se no Golfo do Biafra, parte do Golfo da Guiné e do Oceano Atlântico (Figura 10). 
Figura 10 - Localização da República dos Camarões

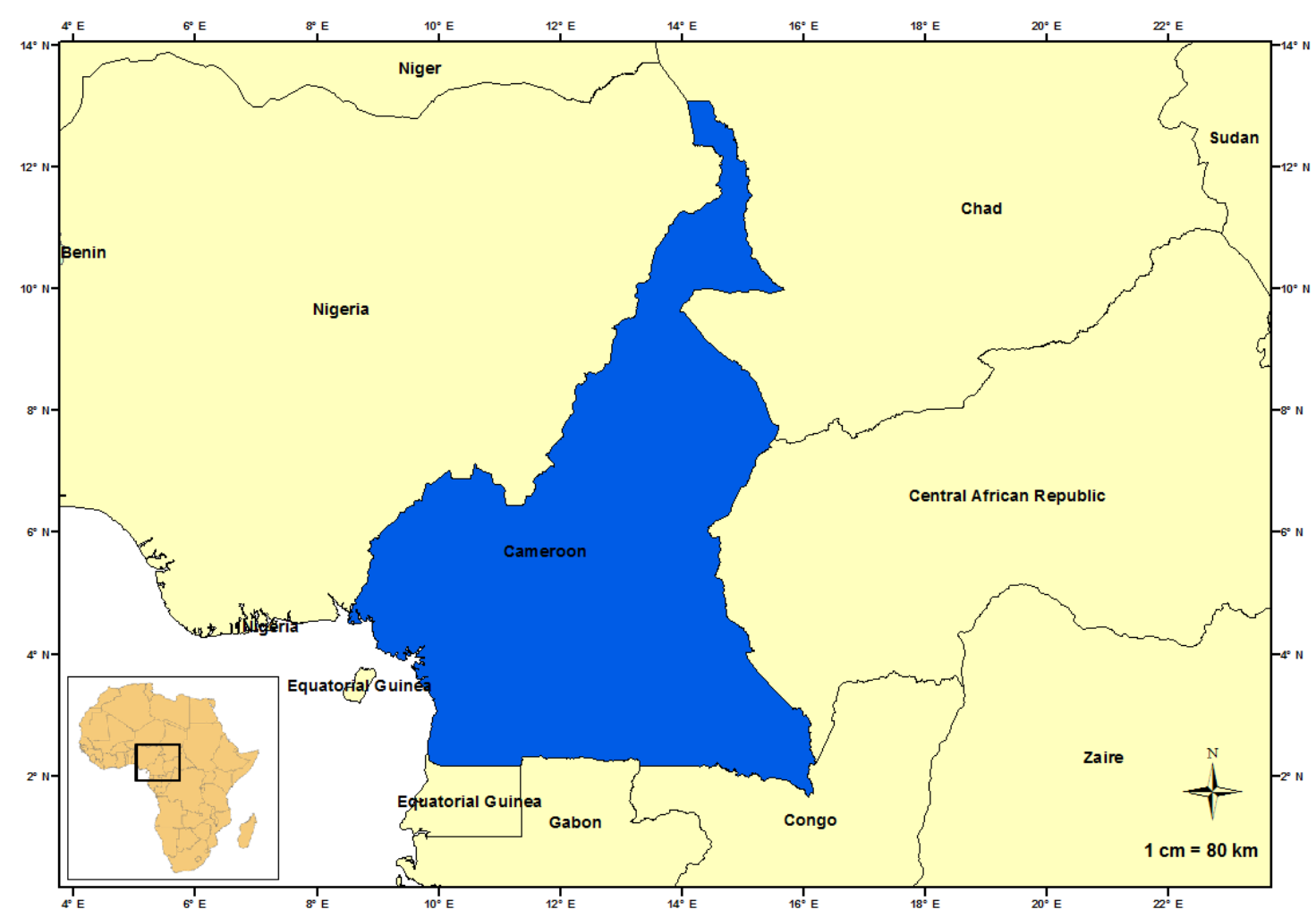

Fonte: Elaborado pelo autor

Apesar de Camarões ser rico em recursos naturais, a economia do país cresceu pouco e os níveis de pobreza permanecem inalterados. O crescimento econômico que foi de $2,7 \%$ em média do ano de 2005 a 2009, era estimado em 3,2\% para 2010 e projetada para 3,8\% em 2011. Entre os anos de 2001 e 2007, o aumento médio do Produto Interno Bruto (PIB) de 3,4\% ficou aquém dos 7\% necessários para alcançar os Objetivos de Desenvolvimento do Milênio até 2015 (THE WORLD BANK, 2011).

A crise econômica de 2009 evidenciou a vulnerabilidade da economia camaronesa a choques exógenos. As autoridades responderam à crise protegendo gastos prioritários e apoiando setores em perigo, entre outros, o energético. A pequena quantidade e má qualidade de infraestruturas deste setor vêm retardando o crescimento econômico do país nos últimos anos. Apesar de Camarões ter um potencial de 12000 MW (sendo apenas 1000 MW produzidos) a eletricidade, o gás e a água contribuíam para apenas 1\% do PIB não petrolífero. Potências hidrelétricas importantes, gases e reservas minerais (tais como bauxita, ferro, urânio, platina e ouro) não eram explorados, em parte devido à falta de fornecimento de energia elétrica confiável. A demanda por eletricidade em Camarões excedia a oferta e 
requeria investimentos no curto e médio prazo (THE WORLD BANK, 2011; WORLD BANK, 2011c).

O fornecimento incerto e o alto custo da eletricidade têm sido citados entre os cinco maiores constrangimentos para fazer negócios em Camarões suscetíveis de causar um prejuízo equivalente a $5 \%$ da receita da empresa e $2 \%$ de perda de crescimento do PIB. Ademais, os altos custos de energia elétrica tornavam esta inacessível para a maioria da população tendo efeitos negativos sobre a renda familiar (THE WORLD BANK, 2011).

Ciente desse cenário, grandes recursos hidrelétricos são apontados como soluções para aumentar a oferta de energia de menor custo em médio prazo, mas esses empreendimentos levam tempo para ser construídos. Futuras hidrelétricas projetadas no rio Sanaga levarão vários anos para ser operadas. Assim sendo, são necessárias soluções emergenciais de energia térmica de menor custo para preencher a lacuna de oferta até a construção de novas hidrelétricas. Além disso, existem complementaridades entre energia hidrelétrica e gasosa em Camarões, uma vez que a segunda oferece a custo acessível um seguro contra o risco de baixa hidrologia. Em 2009, em caráter de urgência, a energia térmica foi produzida a partir de combustível oleoso pesado para suprir a falta de eletricidade. Em 2011, outras quatro usinas de energia térmica foram construídas em caráter de urgência para alimentar em eletricidade as cidades Bamenda, Ebolowa, Mbalmayo e a Capital Yaoundé (THE WORLD BANK, 2011).

Considerado um dos investimentos de menor custo, o Projeto de Energia Gasosa Kribi (PEGK) se inseria nesse contexto sendo o empreendimento que desencadearia o uso de reservas gasosas que não tinham sido exploradas até então e alimentaria em eletricidade 163000 domicílios (THE WORLD BANK, 2011). Previsto para entrar em operação em 2012/2013 com capacidade de 216 MW, o PEGK objetivava principalmente (i) aumentar a capacidade e viabilidade do fornecimento de eletricidade na República dos Camarões, contribuindo desta forma para o crescimento e a redução da pobreza no país; e (ii) melhorar o acesso ao financiamento privado para o desenvolvimento do setor de energia elétrica dos Camarões (WORLD BANK, 2008, 2011a, 2011c).

\section{(ii) Descrição do Projeto}

O Projeto tem os seguintes componentes:

(i) construção de uma infraestrutura na jazida de gás no sul da cidade de Sanaga;

(ii) construção de uma Unidade Central de Processamento de gás; 
(iii) construção de gasodutos marinhos e terrestres, incluindo ao gasoduto offshore de 14 $\mathrm{km}$ da jazida de Sanaga para a unidade Central de processamento de gás; de um oleoduto offshore para injeção de glicol de 14 km entre a jazida e a Unidade Central de Processamento de gás; e de uma adutora offshore de condensação/processo da Unidade Central de Processamento de gás para o poço KB-4 de onde será conectado à plataforma de armazenamento para as exportações;

(iv) construção de um gasoduto onshore de $18 \mathrm{~km}$ da Unidade Central de Processamento de gás para a usina Kribi em Mpolongwe;

(v) construção e operação de uma nova usina de produção de energia elétrica a base de gás natural localizada no vilarejo Mpolongwe a $9 \mathrm{~km}$ ao norte na cidade litorânea Kribi na província sul do país; e

(vi) construção de uma Linha de Transmissão de circuito duplo $225 \mathrm{kV}$ de $100 \mathrm{~km}$ entre a usina de Kribi e a existente subestação Mangombe $(225 / 90 \mathrm{kV})$ em Édea na província litorânea (THE WORLD BANK, 2011; WORLD BANK, 2008, 2011a, 2011c). Como pode ser visto na figura 11, atualmente o projeto conta com mais uma linha de transmissão de circuito único indo em direção ao sul da província.

Figura 11 - Componentes do Projeto Energia Gasosa Kribi

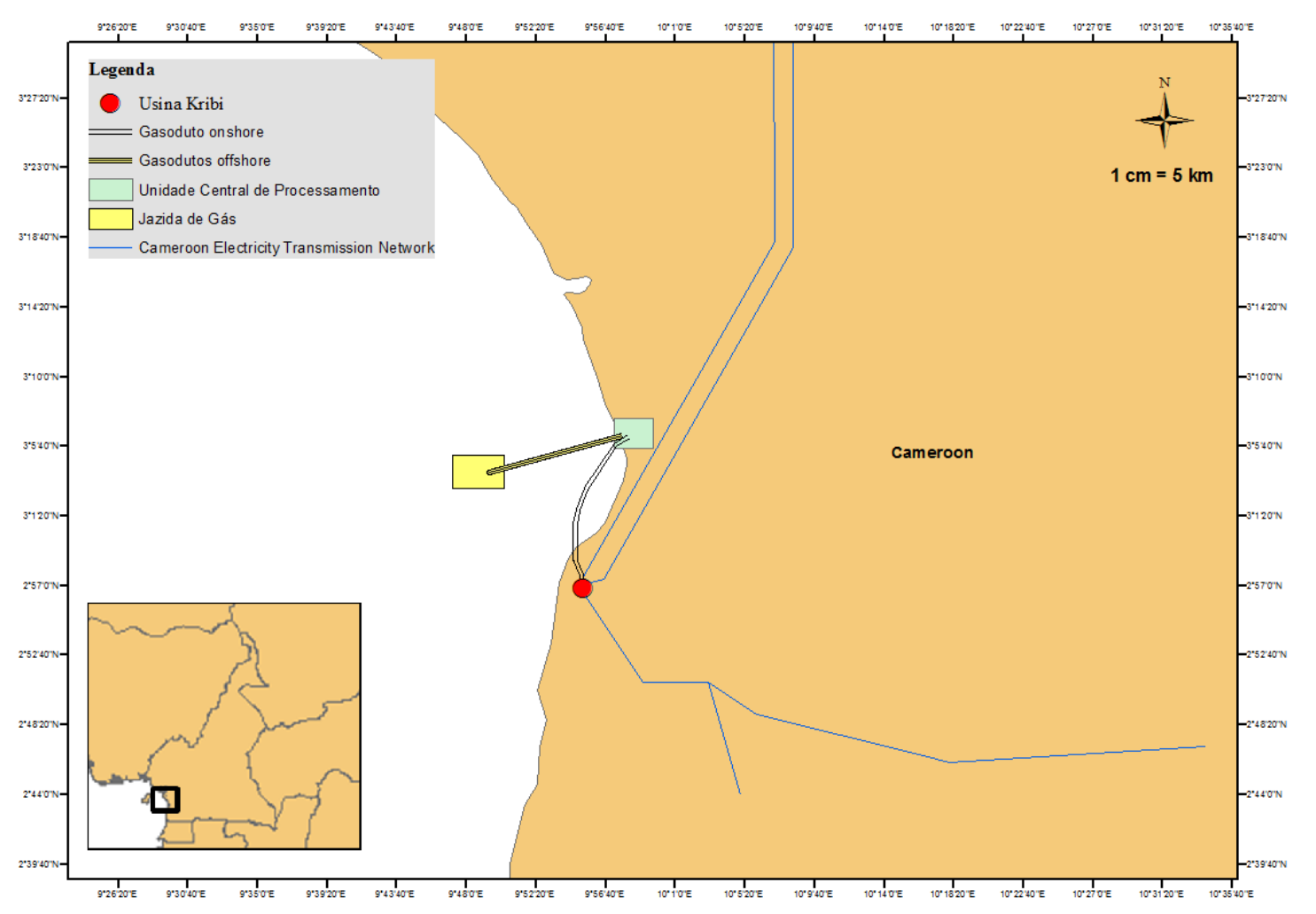

Fonte: Elaborado pelo autor 
A análise económica global realizada pela consultoria francesa Sogreah, com base em uma atualização do Plano de Desenvolvimento de Longo Prazo do Setor de Eletricidade Horizonte 2030 (Plan de Développement à Long Terme du Secteur de l' Electricité Horizon 2030), confirmou que o projeto foi o segundo investimento de menor custo no setor elétrico, após o Projeto emergencial de Energia Térmica Dibamba de $88 \mathrm{MW}$, que foi desenvolvido para enfrentar a escassez de energia nos horários de pico em 2009. Mais de 80 cenários foram analisados considerando vários critérios de demanda e oferta para avaliar possibilidades de expansão de geração de energia de menor custo em Camarões, incluindo diferentes projeções de preços de petróleo e gás. Dado o período de gestação relativamente longo de investimentos hidroelétricos, potenciais alternativas para o projeto que poderiam fornecer a energia necessária a partir de 2012 são as unidades adicionais de óleo combustível pesado que podem ser adicionadas às usinas existentes. O plano de desenvolvimento resultante é nitidamente mais caro do que o plano envolvendo gás natural. Por isso, as usinas de óleo combustível pesado não foram consideradas como alternativa viável para o desenvolvimento do Projeto. Ademais, as reservas de gás na jazida de Sanaga do sul eram estimadas a 32,66 bilhões de metros cúbicos os quais eram muito superiores às necessidades contratuais do projeto limitadas a 0,283 bilhões de metros cúbicos por ano.

Quanto às potenciais alternativas tecnológicas ao Projeto, o estudo do plano de expansão de menor custo da Rede de Interconexão Sul resultou na proposição de uma usina tecnológica de motores a gás com uma capacidade máxima de $300 \mathrm{MW}$. No que diz respeito às alternativas tecnológicas, motores a gás foram comparados com turbinas a gás. Os primeiros com capacidade de 16,6 MW por unidade foram escolhidos como investimentos de menor custo. Além disso, a instalação do motor a gás em várias etapas é viável no local da instalação da usina, permitindo que a capacidade de geração potencialmente aumente de 216 MW para 330 MW no futuro (THE WORLD BANK, 2011).

\subsubsection{Caracterização do nível estratégico do Projeto Energia Gasosa Kribi}

Foram identificados quatro dimensões estratégicas: objetivo, abrangência, nível de detalhes e alternativa (Figura 12).

Os objetivos do projeto foram considerados estratégicos, pois são amplos e gerais apresentando as grandes linhas, ou seja, o conjunto de resultados pretendidos. Com efeito, o projeto Kribi objetiva aumentar a capacidade e viabilidade do fornecimento de eletricidade, reduzir a pobreza e melhorar o acesso ao financiamento privado. A segunda dimensão 
levantada é a abrangência. O projeto envolve seis ações (componentes) vinculadas entre si sendo que algumas (tais como a construção de gasodutos marinhos e terrestres, como também a usina e as linhas de transmissão) podem ser consideradas como projetos. A terceira dimensão identificada é o nível de detalhes. Pode-se ver que o projeto apresenta poucos detalhes referidos. Não há objetividade e exatidão nas informações, na terminologia e nas especificações técnicas. A quarta dimensão identificada é a consideração de alternativas. O planejamento do projeto considerou mais de 80 cenários envolvendo outras fontes de produção de energia elétrica (combustível, por exemplo) antes de chegar à escolha de energia gasosa para o Kribi. Também foram consideradas alternativas envolvendo motores a gás em vez de turbinas a gás. Contudo, esses cenários não são considerados estratégicos, pois se trata de alternativas singulares tecnológicas.

Figura 12 - Dimensões Estratégicas do Projeto Energia Gasosa Kribi

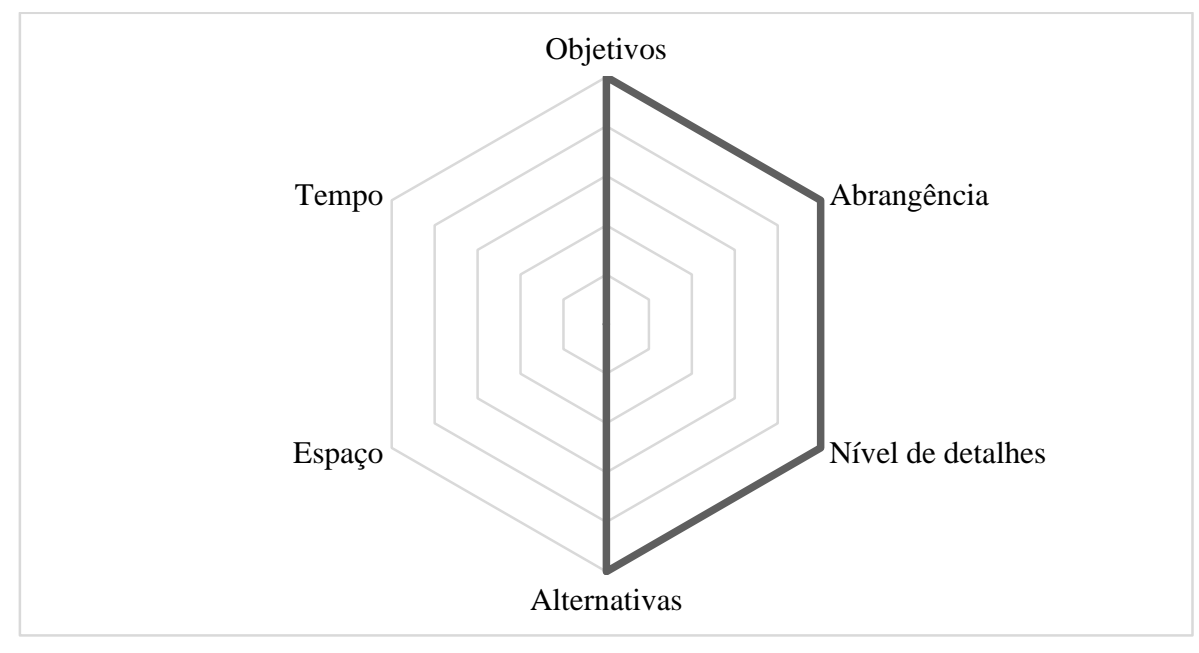

Fonte: Elaborado pelo autor

As dimensões tempo e espaço não foram consideradas estratégicas pela análise realizada. Em relação ao tempo, identificou-se que o projeto encontra muito perto de sua execução. A descrição do projeto revela que alguns componentes já estavam sendo implantados no momento da solicitação de financiamento. No tocante à dimensão espaço, notou-se que o local de implantação dos componentes do projeto é definido com exatidão. As localizações da usina, gasodutos, linhas de transmissão já são conhecidas. 


\subsubsection{Caracterização do Termo de Referência da Avaliação Ambiental Regional}

As entidades energéticas camaronesas têm feito duas Avaliações Ambientais que analisaram os efeitos diretos dos componentes do projeto, mas não consideraram os impactos sociais e ambientais indiretos, induzidos e cumulativos em escala regional, levando em conta as atividades econômicas que já existem. Sendo assim, o Banco Mundial, através do Termo de Referência solicitou uma Avaliação Ambiental Regional que consideraria estes impactos como também as questões de desenvolvimento na região de Kribi.

Os elementos solicitados pelo Termo de Referência eram os seguintes:

- Considerar os planos de desenvolvimento da área (offshore e onshore) norte de Kribi. Analisar em grandes linhas os impactos sociais e ambientais indiretos, induzidos e cumulativos sobre os ecossistemas terrestres e marinhos; impactos sobre a população: poluição; e aspectos relativos à segurança dos projetos existentes, projetos em andamento e projetos planejados ou atividades de desenvolvimento econômico (turismo, minas, portos, hidrelétricas, etc.) em um período de 10 a 15 anos. Dar uma atenção especial aos impactos sobre as espécies marinhas e terrestres ameaçadas de extinção e biodiversidade de florestas de mangue e Floresta do litoral atlântico.

- Analisar os gases de efeito estufa para o projeto inteiro. Abordar questões de mudanças climáticas.

- Abordar capacitação em gestão e monitoramento ambiental e social no que diz respeito às alterações na região de Kribi. Analisar a necessidade de capacitação em gestão ambiental e social no âmbito da Empresa Nacional de Hidrocarboneto ${ }^{16}$ e outras instituições responsáveis pelo setor de petróleo e gás.

- Conceber um Plano de Desenvolvimento Social e Programa de Ligação da Comunidade. Incluir um registro de queixa na AAR.

- Discutir a AAR numa consulta pública com stakeholders, pessoas afetadas, ONGs nacionais e partes interessadas.

- Documentar os resultados.

16 Traduzido do francês "Société National des Hydrocarbures". 


\subsubsection{Alinhamento do TR e AAR em relação a aspectos-chave da AAE}

(i) Verificação de aspectos-chave associados às AAEs no Termo de Referência e na Avaliação Ambiental Regional

Dos quatro elementos-chave, o Termo de Referência apenas aponta a identificação de aspectos-chaves a serem considerados na avaliação e a documentação de resultados. Em relação às alternativas, o TR só faz menção do cenário com o projeto.

Quanto à Avaliação Ambiental Regional, esta foi solicitada para paliar as deficiências das duas AIA de projeto previamente realizadas que não consideraram os gasodutos do Projeto Energia Gasosa Kribi. Desta forma, a AAR foi requisitada no intuito de avaliar os impactos cumulativos do todos os componentes do projeto uma vez que os efeitos indiretos não podem ser negligenciados, considerando a abrangência do projeto e a sua grande ocupação territorial. Todavia, a AAR não se limitou ao Projeto Energia Gasosa Kribi, ela também considerou os outros projetos previstos na região de Kribi e seus arredores tendo em vista a sua importância na avaliação de impactos cumulativos que eles podem originar.

Ao verificar se esta avaliação atende aos requisitos mínimos de uma Avaliação Ambiental Estratégica, nota-se que três das quatros etapas indispensáveis são realizadas (Figura 13). Com efeito, a AAR estabelece indicadores ambientais (aspectos abordados) que orientaram a avaliação. Na definição do alcance geográfico, a AAR identifica as áreas problemáticasNo entanto, em relação à avaliação de impacto de alternativas, notou-se que a AAR apenas avalia o cenário com os projetos, em seguida sugere alternativas que poderiam ter sido consideradas sem as avaliar. 
Figura 13 - Alinhamento do TR e AAR do Projeto Energia Gasosa Kribi em relação a aspectos-chave de uma AAE

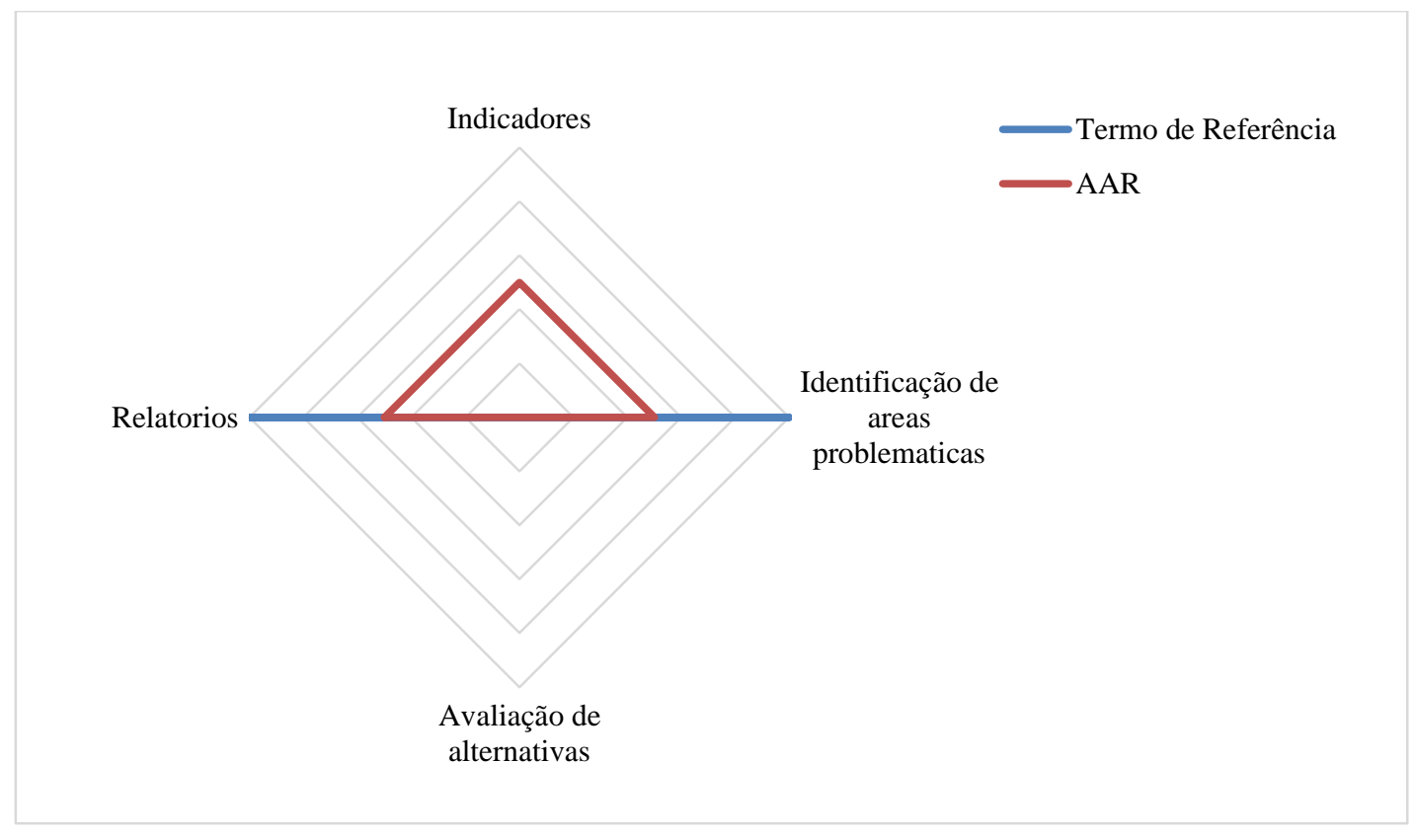

Fonte: Elaborado pelo autor

(ii) Distanciamento entre TR padrão e TR específico do Projeto Energia Gasosa Kribi

O quadro 15 mostra tarefas apontadas pelo Termo de Referência padrão e solicitadas pelo TR específico após adaptação. Observa-se a ausência de recomendações relacionadas ao contexto de inserção do projeto Kribi e da AAR, como também a falta de prescrições relativas a alternativas.

Quadro 15 - Relação TR padrão e TR específico do Projeto Energia Gasosa Kribi

(Continua)

Tarefas apontadas pelo Termo de Referência padrão

Atendimento

Discussão do enquadramento de políticas no âmbito dos quais se efetua a AA. Explicação dos requisitos ambientais e identificação de acordos ambientais internacionais relevantes.

Descrição da ação estratégica proposta (o seu contexto geográfico, ecológico, social e temporal) incluindo quaisquer investimentos fora do local que possam ser necessários (por exemplo, dutos exclusivos, estradas de acesso, usinas geradoras de energia). Indicação da necessidade ou não de planos de reassentamento ou de ações de desenvolvimento para povos indígenas. 
(Conclusão)

Tarefas apontadas pelo Termo de Referência padrão

Atendimento

Previsão e avaliação dos prováveis impactos positivos e negativos da ação estratégica.

Avaliação das dimensões da área de estudo e descrição das condições físicas, biológicas e socioeconómicas relevantes, incluindo quaisquer alterações previstas para antes do início da ação estratégica. Também levar em consideração atividades de desenvolvimento em curso e propostas dentro da área da ação estratégica, mas não diretamente ligadas à mesma.

Identificação das medidas mitigadoras e quaisquer impactos residuais negativos que não possam ser mitigados. Exploração de oportunidades para melhoria ambiental.

Especificação do plano de monitoramento e de reforço institucional.

Avaliação de impactos ambientais de cada alternativa. Comparação de alternativas viáveis (incluindo a situação sem o projeto) em termos de potenciais impactos ambientais.

Justificativa da escolha de cada alternativa.

Consulta pública: Fazer registo das reuniões ocorridas entre os vários organismos e para obtenção de opiniões das pessoas afetadas pela ação estratégica projeto e de organizações não governamentais (ONG).

Documentação dos resultados

Fonte: Elaborado pelo autor

\section{(iii) Atendimento de apontamentos do Termo de Referência pela $A A R$}

Foi observado que todos os requisitos do TR foram cumpridos exceto a realização de um plano de desenvolvimento social. A avaliação considera os planos de desenvolvimento da região; avalia os impactos sociais e ambientais: analisa as implicações do projeto para com as mudanças climáticas; examina a questão de capacitação em gestão ambiental; e submete a AAR a uma consulta pública. Porém, a avaliação não prevê um Plano de Desenvolvimento Social e um Programa de Ligação da Comunidade tampouco inclui um registro de queixa na AAR como solicita o TR. 


\subsubsection{Projeto de Desenvolvimento de Energia Nepal}

\subsubsection{Contexto de inserção do projeto}

\section{(i) Background}

O Nepal é um país asiático dos Himalaias, limitado ao norte pela China e ao leste, sul e oeste pela Índia. É um país sem costa marítima, tendo como capital Catmandu. A sua superfície é de $147181 \mathrm{~km}^{2}$.

O Reino de Nepal tem vastos recursos hídricos que representam uma potencial fonte de riqueza. Comercialmente explorável, o potencial de energia hidrelétrica é estimado em cerca de 43000 MW, sendo apenas 522 MW explorados, e outros 119 MW em implementação (no momento da elaboração do projeto). O censo de 2001 revelou que $40 \%$ de domicílios do Nepal têm acesso à eletricidade. Isto corresponde a $90 \%$ da população urbana e, aproximadamente, $30 \%$ da população rural.

Embora menos da metade da população tivesse acesso à eletricidade, o setor energético de Nepal tinha um bom desempenho em comparação com os outros setores públicos que atuavam em prol ao desenvolvimento da energia no sul da Ásia, especialmente. No entanto, o setor estava afetado por problemas institucionais que limitavam seu desenvolvimento e a mobilização de capital privado tendo consequências refletidas na pobre quantidade e qualidade da oferta, grandes perdas nos sistemas, mínimas trocas energéticas com a Índia e alto custo da energia elétrica.

Reconhecendo a necessidade de tratar estas questões, o Reino de Nepal apontou o desenvolvimento de seu potencial hídrico como uma prioridade para atender às necessidades de energia da grande maioria da população que tinha pouco ou nenhum acesso à eletricidade, e para reduzir a pobreza. Desta forma, o Nono Plano do Governo (1998-2002) para o setor energético tinha destacado a necessidade de (i) produzir hidroeletricidade confiável para atender a demanda interna e a exportação; (ii) reduzir as disparidades rural/urbana e regional na oferta de eletricidade. e (iii) vincular a eletrificação rural às atividades econômicas rurais. O Décimo Plano manteve a mesma racionalidade tendo como objetivo principal aumentar a capacidade de geração de 800 MW até 2008.

Esta ênfase no desenvolvimento energético seguia a adoção da Política de Desenvolvimento Hidrelétrico de 1990 que, juntamente com mudanças na legislação de energia elétrica e a abertura do setor de energia para os investimentos privados nacionais e 
estrangeiros, pretendia fazer as instituições operar em um setor energético eficiente e digno de crédito, bem como aumentar a participação do setor privado na prestação de serviços de energia elétrica. Enquanto sob este enquadramento político, o Nepal tem sido capaz de atrair alguns investimentos privados, houve o reconhecimento de que mais precisava ser feito para atrair mais capital privado e melhorar a eficiência e credibilidade da Autoridade Energética.

A revisada Política de Desenvolvimento Hidrelétrico, de 2001, abordou muitos dos problemas do setor. Ela previa um aumento da participação de investidores privados na produção, distribuição e gerenciamento de energia elétrica reconhecendo, contudo, a necessidade de mudanças institucionais e estruturais para alcançar os objetivos de desenvolvimento do setor energético. A política revisada pediu a criação de um ambiente mais competitivo para a participação do setor privado, como também a introdução de procedimentos transparentes e amigáveis de investimento. A política chamou a atenção para a necessidade de considerar os aspectos sociais e ambientais de hidrelétrica no intuito de assegurar que os efeitos adversos sobre o meio ambiente e comunidades estejam reduzidos (THE WORLD BANK GROUP, 2003a; WORLD BANK, 2003).

Enquanto houve progresso em várias frentes, ainda outras ações eram necessárias. $\mathrm{O}$ Projeto de Desenvolvimento de Energia Nepal surgiu neste contexto sendo condizentes com as metas desenvolvimento e de redução da pobreza do país, e tendo como objetivos: (i) desenvolver o potencial hidrelétrico de Nepal de uma maneira ambientalmente e socialmente sustentável, de modo a ajudar a atender a demanda de eletricidade doméstica; (ii) melhorar o acesso de zonas rurais aos serviços de energia elétrica; e (iii) promover a participação privada no setor energético, como forma de melhorar a eficiência do setor e mobilizar financiamento para as necessidades de investimento do setor (THE WORLD BANK GROUP, 2003b).

\section{(ii) Descrição do Projeto}

O projeto de Desenvolvimento de Energia Nepal cuja implementação levaria 6 anos era constituído de três componentes:

Componente A: Criação de Fundo de Desenvolvimento Energético (FDE) para financiar o investimento privado de hidrelétricas de pequeno e médio porte

O Fundo de Desenvolvimento de Energia seria um mecanismo de financiamento do setor privado que iria fornecer financiamentos para empreendimentos hidrelétricos de pequeno e médio porte no intuito de superar: (i) a falta financiamento para projetos hidrelétricos do setor privado; (ii) a imaturidade no que diz respeito ao financiamento 
de dívida; e (iii) a necessidade de proporcionar conforto aos investidores privados que desejariam envolver-se em projetos pela primeira vez.

Os primeiros créditos para projetos de investimento através do fundo seriam fornecidos pela AID. Com o tempo, previa-se que os recursos de outras instituições financeiras internacionais e domésticas seriam mobilizados para aumentar os fundos de investimento acessíveis. Com esse crédito, o fundo iria financiar pequenos sistemas hidrelétricos com uma capacidade total de aproximadamente $10 \mathrm{MW}$ e um sistema hidrelétrico médio de cerca de $30 \mathrm{MW}$.

Componente B: Eletrificação de comunidades de aldeias através da construção de micro usinas hidrelétricas (até $10 \mathrm{MW}$ )

Este componente apoiaria a ampliação da eletrificação de aldeias através do desenvolvimento de novas micro usinas hidrelétricas (de 2,5 - $3 \mathrm{MW}$ ) para servir cerca de 30000 novos consumidores. Seria construída uma micro usina hidrelétrica em cada comunidade participante. Este componente levaria em consideração os sucessos alcançados no âmbito do já implantado Programa de Desenvolvimento de Energia Rural e abrangeria além dos 15 distritos atualmente atendidos pelo programa, outros 10 distritos.

Cada aldeia contaria com uma micro hidrelétrica e um sistema de distribuição de baixa tensão. A tecnologia para tais sistemas era standard e comprovada. As micro usinas hidrelétricas geralmente envolveriam um sistema de captação de água, canal de sedimentação, canal de alvenaria revestido, reservatório, conduto forçado, casa de força e curto canal de fuga. Os canais teriam menos de $15 \mathrm{~m}$ de diâmetro e uma capacidade de armazenamento negligenciável. A construção de grandes barragens, com volumes significativos de armazenamento não foi cogitada. Os fluxos desviados seriam normalmente de menos de 200 litros/segundo e capacidades instaladas normalmente variariam de menos de $10 \mathrm{~kW}$ até cerca de $60 \mathrm{~kW}$. Assim as estruturas de obras civis, compreendendo estes esquemas eram pequenas, sendo as comunidades locais capazes de construi-los usando métodos de construção manuais. As micro hidrelétricas seriam localizadas em áreas não atendidas por extensão de rede (da rede nacional, ou sistemas de rede isolados), pelo menos nos próximos cinco anos. Assim, áreas suscetíveis ou locais atualmente designados para extensões de rede nacional seriam evitados.

Componente C: Rede de transmissão e distribuição. 
Esse componente envolvia o investimento para a construção de uma LT (de $75 \mathrm{~km}$ ) de $220 \mathrm{kV}$ em circuito duplo (com um circuito amarrado inicialmente) da usina Khimti até a já existente subestação de 132 kV Dhalkebar. Outras linhas de transmissão e subtransmissão poderiam ser selecionadas e incorporadas a esse componente do projeto. Foram apontadas, entre outras, a linha de transmissão (de $45 \mathrm{~km}$ ) $132 \mathrm{kV}$ da subestação de Dhalkebar para Bhittamod no lado nepalês da fronteira com a Índia (que se juntaria a rede indiana facilitando o comércio transfronteiriço de energia), e a extensão de linha de $132 \mathrm{kV}$ a partir da subestação Dhalkebar. Esse componente também envolvia o fornecimento e instalação de equipamentos e materiais, e obras civis para a ampliação dos sistemas de sub-transmissão e distribuição para as áreas rurais e cidades não eletrificadas, reabilitação e reforço dos sistemas de distribuição existentes em áreas urbanas e semi-centros industriais (THE WORLD BANK GROUP, 2003a; 2003b).

O projeto de Desenvolvimento de Energia Nepal cobria essencialmente todo o Reino de Nepal sendo qualquer domicílio rural um potencial beneficiário. Foi feito uma triagem no intuito de identificar os potenciais locais receptores de micro usinas hidrelétricas. O processo de triagem e classificação realizada excluiu os locais que necessitariam, para receber a micro hidrelétrica, de uma remoção significativa de águas dos rios por grandes desvios de fluxo, bem como locais cuja micro hidrelétrica interferiria na biodiversidade protegida, áreas de patrimônio natural e/ou cultural. Como todas as hidrelétricas são executadas de acordo com o tipo de rio, e os projetos de transmissão e distribuição não resultariam em reassentamento de pessoas. Previa-se que não haveria nenhum segmento da população que seria afetada adversamente (THE WORLD BANK GROUP, 2003b).

O projeto de Desenvolvimento de Energia Nepal foi uma das estratégias tradicionais de empréstimo da AID associada a recursos públicos para apoiar grandes projetos hidrelétricos e instalações de transmissão e distribuição alimentando em energia as zonas rurais, desta forma, ampliando a rede nacional. No entanto, dada a dificuldade de mobilizar financiamento para grandes projetos hidrelétricos que envolvem grandes custos iniciais, e problemas ambientais e sociais associados a tais projetos; dado o custo alto e dificuldade técnica de se chegar às comunidades remotas através da extensão da rede nacional, a alternativa estratégica que visa a mobilização de fundos privados e comerciais para as pequenas e médias hidrelétricas prevaleceu. A experiência dolorosa do Nepal com a construção de grandes hidrelétricas levou à adoção de uma estratégia alternativa com foco 
inicial em uma busca acelerada de projetos hidrelétricos de menor porte para atender aos requisitos de energia do reino.

A criação de Fundo de Desenvolvimento Energético tinha vantagens sobre o financiamento convencional de projetos, uma vez que podia contribuir para uma série de projetos de pequeno e médio porte no setor privado, que de outra forma seriam muito pequenos e caros como operação separada para a AID. Um grande investimento inicial do FDE foi descartado, pois se estima que a exigência de desembolso a curto e médio prazo seria modesta até a expansão das linhas de investimento e a demonstração do forte apetite do mercado para o Fundo (WORLD BANK, 2003).

\subsubsection{Caracterização do nível estratégico do Projeto de Desenvolvimento de Energia Nepal}

O Projeto de Desenvolvimento de Energia Nepal apresenta todas as seis dimensões estratégicas: objetivo, espaço, abrangência, nível de detalhes, alternativa e tempo (Figura 14).

Com efeito, o projeto objetivava desenvolver o potencial hidrelétrico de Nepal, melhorar o acesso à energia elétrica e promover a participação do setor privado no setor energético. Trata-se de objetivos amplos que apresentam em grandes linhas a intencionalidade do projeto. A dimensão "espaço" é considerada estratégica, pois o local exato de implantação dos componentes do projeto ainda é incerto. O projeto de Desenvolvimento de Energia Nepal cobre essencialmente o Reino de Nepal sendo que qualquer domicílio rural é um potencial beneficiário. Quanto à dimensão abrangência, o projeto envolvia essencialmente dois setores: energético e econômico. Ademais, o projeto envolvia o país inteiro dedicando-se, portanto a uma área muito abrangente. A dimensão "nível de detalhes” é considerada estratégica, pois o projeto apresentava poucos detalhes referidos. Embora o projeto se refira aos componentes dos sistemas de micro hidrelétrica (sistema de captação, casa de força, etc.), não há exatidão nas informações, terminologias e especificações técnicas. A dimensão "alternativa" também é considerada estratégica, pois o cenário retido (como apresentado acima na descrição do projeto) foi escolhido com base em critérios econômicos em detrimento do cenário envolvendo grandes projetos hidrelétricos. A dimensão "tempo" também é considerada estratégica, uma vez que o projeto se encontrava distante de sua execução. Há indícios de que precisava de um tempo de aguarda para que providências necessárias sejam tomadas no intuito de tornar efetiva a execução/implantação do projeto. 
Figura 14 - Dimensões Estratégicas do Projeto de Desenvolvimento de Energia Nepal

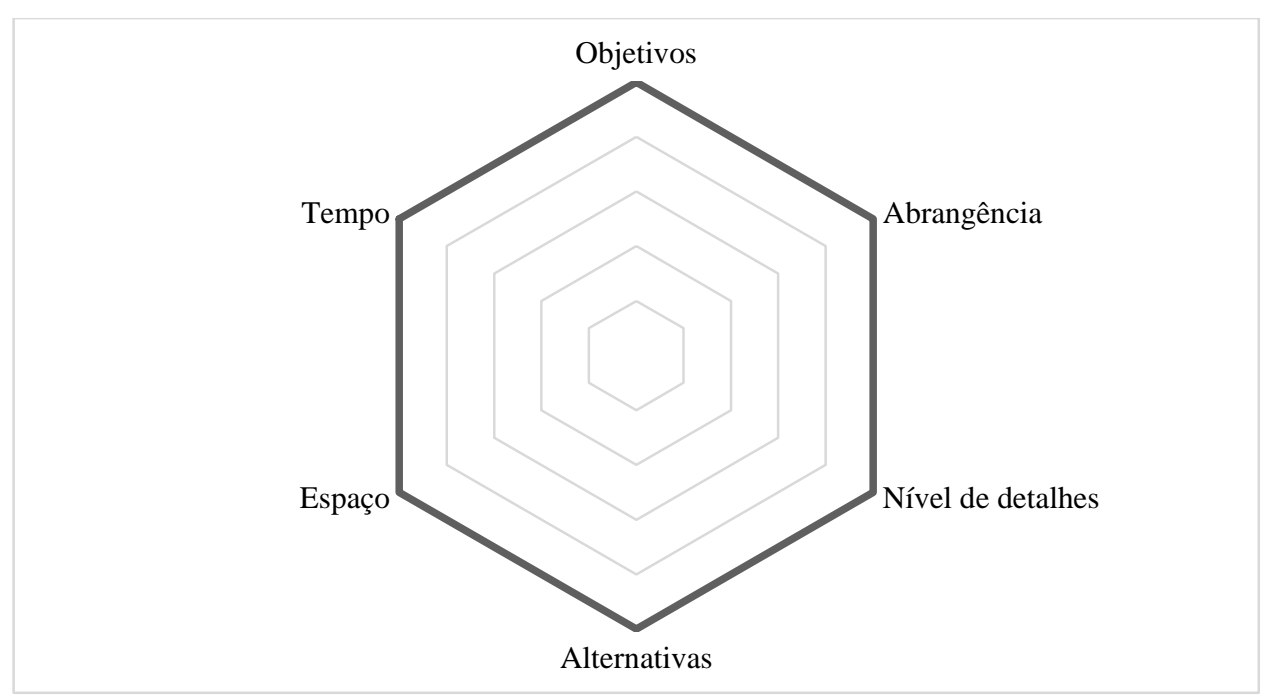

Fonte: Elaborado pelo autor

\subsubsection{Caracterização do Termo de referência da Avaliação Ambiental Setorial}

Com efeito, uma Avaliação Ambiental Setorial foi aplicada ao setor energético do Nepal, em 1997, no intuito de examinar os impactos cumulativos dos múltiplos projetos previstos para o setor no médio e longo prazo. Esta avaliação foi conduzida de forma voluntária baseando-se em um Termo de Referência padrão (MINISTRY OF WATER RESOURCES, 1997).

Assim sendo, na ausência do TR específico, analisou-se a Política Operacional 4.01 e o anexo $\mathrm{B}^{17}$ dos Procedimentos Operacionais 4.01 do Banco Mundial (Agência financiadora do Projeto) que define o conteúdo esperado de uma Avaliação Ambiental de um projeto categoria $\mathrm{A}^{18}$ e o Termo de Referência padrão disponibilizado pela AMD. Estas diretrizes do Manual Operacional do Banco Mundial orientam a elaboração dos Termos de Referência no âmbito dessa AMD. É importante mencionar que a estrutura apresentada por estas diretrizes é semelhante a dos Termos de Referência previamente analisados.

Nestas diretrizes são apontados os seguintes pontos:

\footnotetext{
${ }^{17} \mathrm{O}$ anexo B refere-se à aplicação de Avaliação Ambiental para Projetos de Barragens e Reservatórios

18 Banco Mundial tem classificado o Projeto de Desenvolvimento de Energia como "A" considerando os potenciais impactos ambientais que poderão resultar da construção da hidrelétrica de médio porte de aproximadamente $30 \mathrm{MW}$ e das mini hidrelétricas com capacidade total de $10 \mathrm{MW}$ (THE WORLD BANK GROUP, 2003a)
} 
- Discussão do enquadramento de políticas no âmbito dos quais se efetua a AA. Explicação dos requisitos ambientais de co-financiadores. Identificação de acordos ambientais internacionais relevantes dos quais o país faz parte.

- Descrição do projeto proposto (o seu contexto geográfico, ecológico, social e temporal) incluindo quaisquer investimentos fora do local que possam ser necessários (por exemplo, dutos exclusivos, estradas de acesso, usinas geradoras de energia). Indicação da necessidade ou não de planos de reassentamento ou de ações de desenvolvimento para povos indígenas.

- Avaliação das dimensões da área de estudo e descrição das condições físicas, biológicas e socioeconómicas relevantes, incluindo quaisquer alterações previstas para antes do início do projeto. Também levar em consideração as atividades de desenvolvimento em curso e propostas dentro da área do projeto, mas não diretamente ligadas ao mesmo.

- Previsão e avaliação dos prováveis impactos positivos e negativos do projeto, em termos quantitativos na medida do possível. Identificação das medidas mitigadoras e quaisquer impactos residuais negativos que não possam ser mitigados. Exploração de oportunidades para melhoria ambiental.

- Avaliação de impactos ambientais de cada alternativa. Comparação de alternativas viáveis (incluindo a situação sem o projeto) em termos de potenciais impactos ambientais. Justificativa da escolha de cada alternativa.

- Especificação das medidas mitigadoras, plano de monitoramento e de reforço institucional.

- Consulta pública: Fazer registo das reuniões ocorridas entre os vários organismos e para obtenção de opiniões das pessoas afetadas pelo projeto e de organizações não governamentais (ONG).

- Documentação dos resultados 


\subsubsection{Alinhamento do TR e AAS em relação a aspectos-chave da AAE}

(i) Verificação de aspectos-chave associados às AAEs no Termo de Referência e na Avaliação Ambiental Setorial

Observou-se que o Termo de Referência padrão atende a todos os requisitos de uma AAE à exceção de estabelecimento de indicadores ambientais. Não foi encontrado tarefas que se reportam claramente à identificação de indicadores.

Quanto à Avaliação Ambiental Setorial cujo principal objetivo era incorporar critérios ambientais e sociais na escolha de opções de fornecimento de energia elétrica, foi verificado que uma das quatros etapas não foi realizada (Figura 15). A avaliação não identifica áreas problemáticas. No entanto, a falta dessa etapa é devidamente justificada, pois essa etapa já tinha sido feita pelo estudo ambiental inicial realizada antes da AAS.

Figura 15 - Alinhamento do TR e AAR do Projeto de Desenvolvimento de Energia Nepal

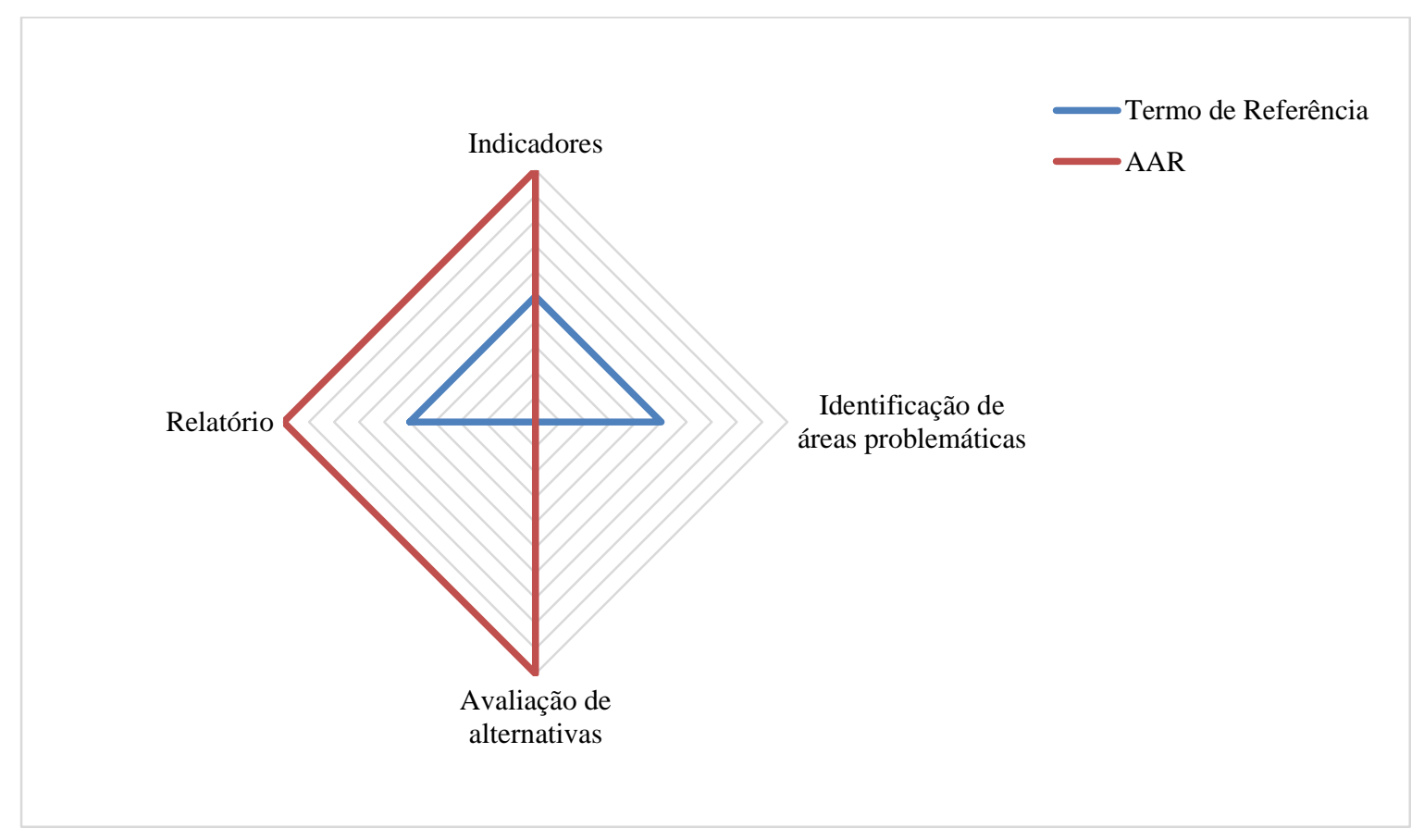

Fonte: Elaborado pelo autor 
(ii) Distanciamento entre $T R$ padrão e TR específico do Projeto de Desenvolvivemento de Energia Nepal

Esta verificação não foi realizada, uma vez que o Avaliação Ambiental Setorial se baseou em um TR padrão

(iii) Atendimento de apontamentos do Termo de Referência pela AAS

Avaliação Ambiental Setorial apresenta o enquadramento de políticas no âmbito dos quais se efetua a AA. A avaliação também descreve o projeto proposto atendendo, desta forma, ao segundo ponto do Termo de Referência. No entanto, a avaliação não fez nenhuma avaliação de impactos do projeto. Em relação às alternativas, a avaliação aponta alternativas viáveis, apresenta as vantagens e desvantagens e justifica a escolha de cada uma. No que diz respeito às medidas de mitigação e monitoramento, a avaliação não as aponta. Ao contrário, ela se refere ao quadro político (em processo de aprovação pelo BM no momento da aplicação da AAS) que estabelece diretrizes a serem consideradas como medidas de mitigação e monitoramento pelos subprojetos. Todavia, a avaliação aborda o reforço institucional destacando reformas a serem incorporadas pelos órgãos de licenciamento e o setor energético de Nepal. No processo de Avaliação Ambiental Setorial não foi feita consulta pública. Entretanto, a avaliação demostra a necessidade e importância da participação do público e aponta os passos a seguir para realizar a consulta pública de subprojetos.

\subsubsection{Projeto Hidrelétrico Kabeli “ $A$ ”}

\subsubsection{Contexto de inserção do projeto}

\section{(i) Background}

O nível de desenvolvimento energético de Nepal é baixo comparado aos padrões globais e regionais do sul asiático. Em 2010, estimava-se que $88 \%$ da demanda total de energia primária eram fornecidas pelas formas tradicionais de energia, refletindo a distribuição da população predominantemente rural no Nepal e a ausência de energia limpa comercializada fora das áreas urbanas. Essa forte dependência energética de fontes 
tradicionais trazia consigo problemas bem conhecidos, entre outros, oportunidades limitadas para o desenvolvimento econômico rural, degradação ambiental e ineficiência energética.

No mesmo ano, aproximadamente $27 \%$ da população rural e $87 \%$ da população urbana tinham acesso à eletricidade por meio de conexões fora da rede ou através da rede nacional. No entanto, o consumo de energia elétrica permaneceu muito baixo, mesmo para as áreas urbanas de Nepal, porque a capacidade de oferta era altamente restrita e não acompanhou o aumento da demanda.

Esse baixo nível de desenvolvimento tem sido agravado pela crise energética que se vivenciou no inverno de 2008/2009. O racionamento de energia elétrica para os consumidores ligados à rede tem sido revelador da faceta do sistema energético nepalês hidro dependente cujos conflitos prolongados e as instituições e finanças fracas têm desencorajado investimentos prejudicando o aumento da capacidade de geração de energia. A diferença entre oferta e demanda tem crescido acentuadamente nos últimos anos. Sendo a capacidade de armazenamento do Nepal extremamente limitada. O excesso de água disponível durante o período das monções, que poderia ser usada para aumentar os fluxos do rio naturalmente baixos na estação seca, não é armazenado (WORLD BANK, 2010).

O governo nepalês de 1996-1997 conduziu uma análise exaustiva e um processo de classificação de 138 projetos candidatos $^{19}$. A Autoridade Energética de Nepal elaborou estudos de viabilidade para cinco corredores de transmissão, pelas quais o Ministério de Energia emitiu um grande número de licenças de pesquisa. Um desses cinco corredores prioritários é o corredor Rio Kabeli.

Além do Kabeli "A", vários outros projetos hidrelétricos estavam em desenvolvimento na bacia do rio Kabeli. Esses empreendimentos exigiam linhas de transmissão para distribuir a energia produzida. No total, previa-se que eventualmente os projetos poderiam gerar cerca de 170 MW que seriam uma importante contribuição para o sistema que dispunha de menos de 700 MW instalados (WORLD BANK, 2010).

No que diz respeito ao Projeto Kabeli "A", vale ressaltar que os seus objetivos mudaram ao longo do tempo. Em 2010, os objetivos de desenvolvimento do projeto eram apoiar a construção de novas linhas de transmissão para distribuir cerca de 170 MW no corredor Rio Kabeli na primeira fase e mais $30 \mathrm{MW}$ na segunda fase do projeto. Dependendo da disponibilidade de recursos e da necessidade, o projeto teria como objetivo o fornecimento de eletricidade aos moradores da área que naquele momento não tinham acesso à energia

\footnotetext{
${ }^{19}$ Essa análise é o estudo de triagem e classificação feito para o Projeto de Desenvolvimento de Energia Nepal
} 
elétrica (WORLD BANK, 2010). Em 2011, os objetivos do projeto passaram a ser contribuir para o desenvolvimento econômico do Nepal assim como contribuir para o desenvolvimento da área de projeto. Como objetivos específicos, o projeto visou: (i) contribuir para o Sistema Integrado de Energia Nepalês com 37,6 MW e uma produção anual de energia estimada a 190 GWh; e (ii) demonstrar um modelo de parceria público-privada na geração de energia hidrelétrica (WORLD BANK, 2010, 2013b).

\section{(ii) Descrição do Projeto}

Assim como os objetivos, o projeto em si foi ligeiramente alterado do ano de 2010 para 2011. Em 2010, o projeto era composto por dois componentes e podia incluir um terceiro componente. Era previsto (i) fase 1: construção de uma LT circuito duplo $132 \mathrm{kV}$ de aproximadamente $90 \mathrm{~km}$ de Kabeli "A" para a subestação Damak; (ii) fase 2: construção da usina hidrelétrica Kabeli "A" com capacidade de produção de $30 \mathrm{MW}$; (iii) fase 3: eletrificação e distribuição rural: grandes partes da área do projeto, em especial, ao longo do corredor de transmissão proposto, naquele momento não eletrificadas. Propunha-se financiar o acesso à energia elétrica para as famílias que viviam nas proximidades da linha de transmissão (WORLD BANK, 2010).

Em 2011, a fase 3 foi descartada sendo o projeto constituído apenas dos dois primeiros componentes. O Projeto Hidrelétrico Kabeli "A" seria localizado no distrito Panchthar na fronteira dos distritos Panchthar e Taplejung, dois distritos da região de desenvolvimento leste de Nepal. O projeto planejou ocupar mais de $15 \mathrm{~km}$ de comprimento do laço formado pelos rios Kabeli e Tamor. As primeiras obras deveriam ser localizadas em Dhuseni, no vilarejo Amarpur (no distrito Panchthar) a cerca de $2,5 \mathrm{~km}$ a montante da pequena vila de mercado Kabeli Bazaar. Previram-se dois pontos de captação na margem esquerda que iriam alimentar duas bacias de sedimentação subterrânea. A água, então, seria passada através de um túnel de 4326 m de comprimento para o rio Tamor, no vilarejo Amarpur. A usina semi-subterrânea seria construída na margem esquerda do rio Tamor. A queda bruta e vazão do projeto foram estimadas em 116,80 m e 37,73 m³/s, respectivamente (WORLD BANK, 2011b, 2012).

\subsubsection{Caracterização do nível estratégico do Projeto Hidrelétrico Kabeli “A”}

Foram levantadas as seguintes dimensões estratégicas: alternativas e abrangência (Figura 16). O primeiro elemento é considerado como estratégico, pois o projeto passou por 
uma triagem e classificação da autoridade nepalesa. Nessa seleção, foram desconsiderados projetos envolvendo outras formas de energia (térmica e eólica entre outros) com base em critérios socioeconômicos e ambientais. Portanto, as alternativas não são singulares de operação. A abrangência também é considerada estratégica, pois o Kabeli “A” envolve duas operações (usina e linha de transmissão) vinculadas entre si e a um plano maior.

As dimensões objetivo, espaço, tempo e nível de detalhes não foram consideradas estratégicas. Os objetivos gerais do projeto expressam a decomposição de um objetivo geral que é de estimular investimentos privados no setor energético de Nepal. Ademais, ao se referir ao desenvolvimento da área de projeto, o objetivo aponta os resultados a serem alcançados em áreas determinadas. Os objetivos específicos explicitam metas concretas, portanto não são estratégicos. A dimensão espaço também não foi considerada estratégica, pois o local receptor do projeto é definido com exatidão. Entre outros, os locais de captação de água e a implantação da usina hidrelétrica já são definidos, fato que ilustra quão definido é o projeto. O "tempo" não foi considerado como dimensão estratégica, pois o projeto encontrase muito perto da execução apresentando, portanto uma limitação temporal. Com efeito, na descrição do projeto não foram encontrados indícios de que providências precisam ser tomadas antes da implantação do projeto. O elemento "nível de detalhes" também não foi considerado estratégico, uma vez que o projeto apresenta certa objetividade na exatidão das informações e especificações técnicas. Ademais, cada operação (usina semi-subterrênea, linha de transmissão) é descrita adequadamente.

Figura 16 - Dimensões Estratégicas do Projeto hidrelétrico Kabeli « A »

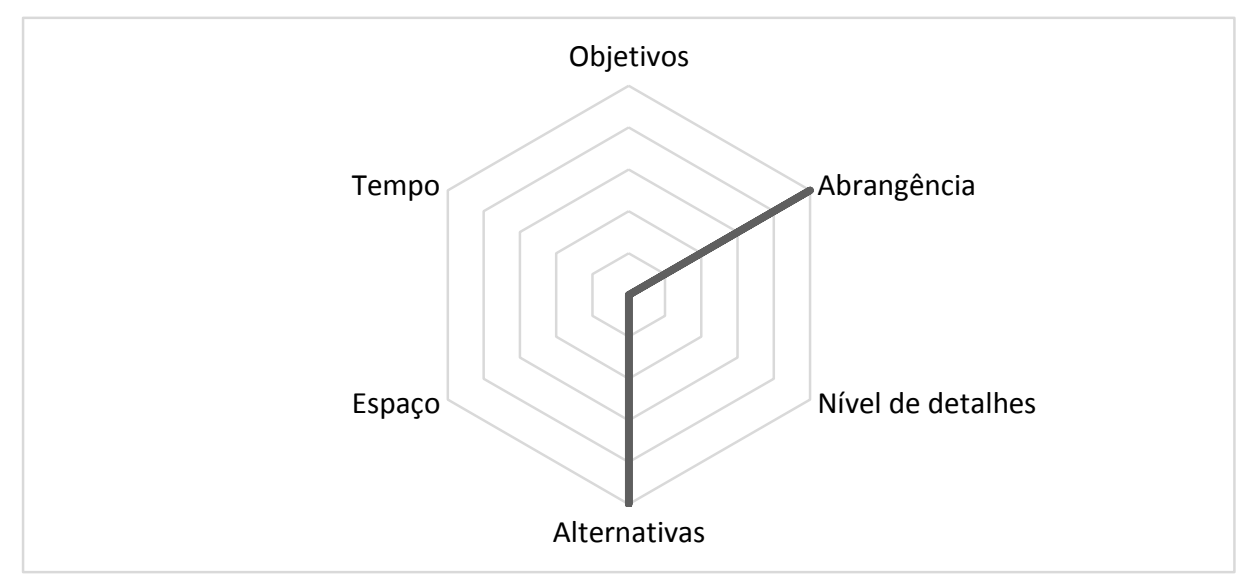

Fonte: Elaborado pelo autor 


\subsubsection{Caracterização do Termo de referência da Avaliação de Impacto Cumulativo}

A Avaliação de Impacto Cumulativo (AIC) foi conduzida a pedido dos responsáveis pelo projeto hidrelétrico Kabeli “A”. Diferentemente de outros casos, neste projeto o TR não foi emitido pela Agência Multilateral de Desenvolvimento financiadora, mas pelas autoridades nepalesas.

Com efeito, o Termo de Referência da Avaliação de Impacto Cumulativo do Projeto Hidrelétrico Kabeli "A" não foi encontrado. Contudo, o relatório fornece algumas informações relevantes e suficiente para a análise. Esse projeto foi mantido na amostra analisada uma vez que revela um caso incomum onde o TR não é a ponte direta entre a avaliação e o projeto, pois a avaliação tem como objeto de estudo a bacia Kabeli. A Avaliação de Impacto Cumulativo foi solicitada após a realização da AIA de projeto para ajudar na escolha da melhor combinação de projetos e locais para um maior aproveitamento da bacia com menos impacto. No entanto, a AIC pouco avalia os impactos da bacia. O foco maior foi dado para o projeto hidrelétrico Kabeli “A”. (NEPAL ENVIRONMENTAL \& SCIENTIFIC SERVICES, 2011).

Levantou-se as questões-chave que constituem a base para o Termo de Referência. Esses aspectos constituiram o TR da AIA de projeto que não tratou satisfatoriamente todas as questões. Sendo assim, uma Avaliação de Impacto Cumulativo foi solicitada no intuito de paliar as defiências das avaliações anteriores e avaliar os impactos de todos os projetos sobre a bacia inteira. As questões-chave que serviram de base para a AIC são as seguintes:

- Descrever todas as questões de salvaguarda e impactos associados aos projetos da bacia. Identificar e descrever qualquer potencial impacto de grande escala, significativos e/ou irreversíveis.

- Descrever os potenciais impactos indiretos e/ou de longo prazo decorrente das actividades futuras previstas na bacia.

- Descrever todas as alternativas (relevantes) consideradas para ajudar a evitar ou minimizar os impactos negativos.

- Descrever as medidas tomadas pelo mutuário para resolver questões políticas de salvaguarda. Providenciar uma avaliação da capacidade do mutuário de planejar e implementar as medidas descritas. 
- Identificar os principais interessados e descrever os mecanismos de consulta e divulgação de políticas de salvaguarda, com ênfase nas pessoas potencialmente afetadas.

- Documentar os resultados.

\subsubsection{Alinhamento do TR e AIC em relação a aspectos-chave da AAE}

(i) Verificação de aspectos-chave associados às AAEs no Termo de Referência e na Avaliação de Impacto Cumulativo

Foi verificado que o Termo de Referência não atende a todos os aspectos-chave de uma AAE. O documento não se refere à identificação de indicadores e áreas problemáticas. Por outro lado, a avaliação de impactos de alternativas e a documentação dos resultados foram apontadas.

Em relação à Avaliação de Impacto Cumulativo do Projeto Hidrelétrico Kabeli “A”, foi verificado que a avaliação atende a todas as etapas mínimas exceto a avaliação de alternativas (Figura 17). Com efeito, a avaliação identifica indicadores, áreas problemáticas e documenta os resultados. No entanto, a AIC só avalia a alternativa com o projeto. Nos requisitos mínimos de uma AAE, devem ser avaliadas no mínimo duas alternativas.

Figura 17- Alinhamento do TR e AIC do Projeto hidrelétrico Kabeli « A »

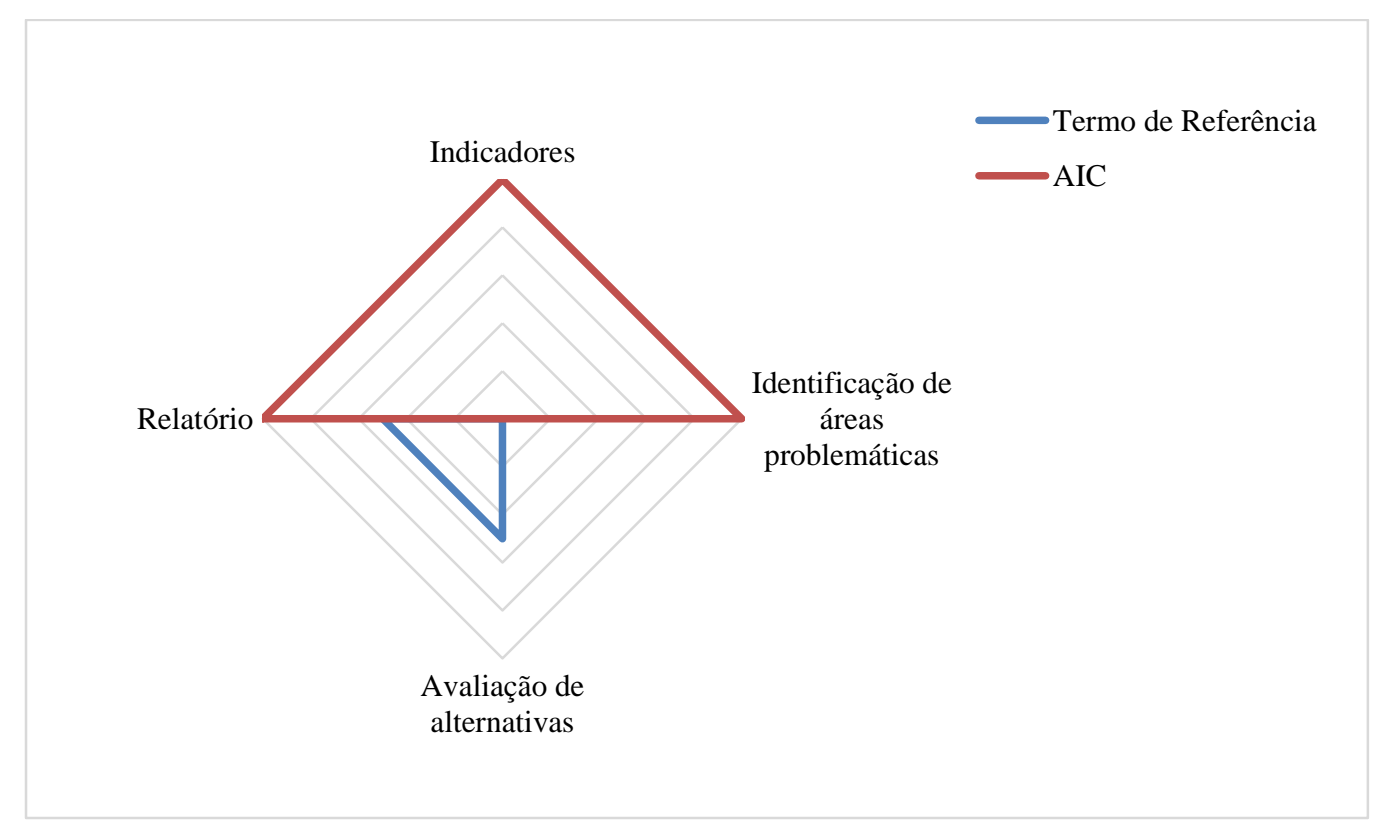

Fonte: Elaborado pelo autor 
(ii) Distanciamento entre TR padrão e TR específico do Projeto hidrelétrico Kabeli“ $A$ ”

Ao comparar o termo de referência padrão e específico, percebe-se que apenas co contexto de inserção da ação estratégica não foi retomado pelo TR específico (Quadro 16). Os outros aspectos foram solicitados sendo adaptados ao contexto de aplicação da Avaliação de Impacto Cumulativo.

Quadro 16 - Relação TR padrão e TR específico do Projeto hidrelétrico Kabeli « A »

Discussão do enquadramento de políticas no âmbito dos quais se efetua a AA. Explicação dos requisitos ambientais e identificação de acordos ambientais internacionais relevantes.

Descrição da ação estratégica proposta (o seu contexto geográfico, ecológico, social e temporal) incluindo quaisquer investimentos fora do local que possam ser necessários (por exemplo, dutos exclusivos, estradas de acesso, usinas geradoras de energia). Indicação da necessidade ou não de planos de reassentamento ou de ações de desenvolvimento para povos indígenas.

Previsão e avaliação dos prováveis impactos positivos e negativos da ação estratégica.

Avaliação das dimensões da área de estudo e descrição das condições físicas, biológicas e socioeconómicas relevantes, incluindo quaisquer alterações previstas para antes do início da ação estratégica. Também levar em consideração atividades de desenvolvimento em curso e propostas dentro da área da ação estratégica, mas não diretamente ligadas à mesma.

Identificação das medidas mitigadoras e quaisquer impactos residuais negativos que não possam ser mitigados. Exploração de oportunidades para melhoria ambiental.

Especificação do plano de monitoramento e de reforço institucional.

Avaliação de impactos ambientais de cada alternativa. Comparação de alternativas viáveis (incluindo a situação sem o projeto) em termos de potenciais impactos ambientais.

Justificativa da escolha de cada alternativa.

Consulta pública: Fazer registo das reuniões ocorridas entre os vários organismos e para obtenção de opiniões das pessoas afetadas pela ação estratégica projeto e de organizações não governamentais (ONG). 


\section{(iii) Atendimento de apontamentos do Termo de Referência pela AIC}

Observou-se que apenas a descrição de todas as questões de salvaguarda e impactos associados aos projetos da bacia foi realizada pela Avaliação de Impacto Cumulativo. Há justificativas para o não cumprimento das outras tarefas.

A avaliação ambiental foi solicitada pelos responsáveis do projeto denominando-se Avaliação de Impacto Cumulativo do Projeto Hidrelétrico Kabeli "A" (Cumulative Impact Assessment of Kabeli "A" Hydroeletric Project) (NEPAL ENVIRONMENTAL \& SCIENTIFIC SERVICES, 2011). De início, percebe-se que a avaliação, que deveria analisar impactos cumulativos dos projetos da bacia tem o nome de um dos projetos. Ela avalia a bacia dando maior ênfase para o Projeto Hidrelétrico Kabeli “A”, justificando esta mudança pelo fato de esse projeto ser o único empreendimento com dados disponíveis.

\subsubsection{Projeto Hidrelétrico Nam Theun 2}

\subsubsection{Contexto de inserção do projeto}

\section{(i) Background}

A República Democrática Popular Lau (Laos) é o país mais pobre e menos desenvolvido da região do leste da Ásia. Os indicadores sociais estão entre os mais baixos da região (WORLD BANK, 1988, 2004) e a renda per capita anual, estimada em 2003, foi de US\$ 320. Ao longo das últimas duas décadas, a economia de Laos foi gradualmente se movendo em direção a um sistema orientado para o mercado; mais recentemente, a sua perspectiva econômica tem melhorado e o crescimento tem sido em torno de $6 \%$ ao ano.

Com seus vastos recursos naturais e a sua posição central na crescente sub-região do Grande Mekong ${ }^{20}$, Laos é bem localizado para acelerar o crescimento e reduzir a pobreza, desde que aumente a contribuição dos recursos naturais para o desenvolvimento sustentável, promova um ambiente propício para atrair investimentos privados e faça progressos em reformas abrangentes para melhorar a qualidade da governança, gestão das finanças públicas, e prestação de serviços.

${ }^{20}$ O Grande Mekong é composto de Laos, Tailândia, Vietnã, Camboja, Myanmar e a província chinesa de Yunnan (WORLD BANK, 2004). 
A energia hidrelétrica poderia cumprir um papel especial como um dos setores estratégicos de crescimento, baseando-se nos recursos hídricos abundantes do país. O exercício de planejamento estratégico do setor identificou o Projeto Nam Theun 2 (NT2) como a melhor opção hidrelétrica disponível para atender os mercados domésticos e regionais (WORLD BANK, 2004).

O Projeto era economicamente e tecnicamente sólido, proporcionando retornos satisfatórios para Laos e oferecendo uma importante fonte alternativa de energia para a Tailândia. A demanda de energia neste último estava crescendo em cerca de 6,5\% ao ano e esperava-se que precisaria da energia fornecida por NT2 quando este entraria em operação (em 2009/2010). Em termos comerciais, o custo de produção de energia para a Tailândia era competitivo considerando os preços do gás natural, o custo das recentes usinas do sudeste asiático e o custo atual do projeto. Além disso, a hidrelétrica NT2 forneceria ao nordeste tailandês uma diversificação útil de abastecimento. Por estas razões, o governo do Laos atribuía a mais alta prioridade ao desenvolvimento do projeto NT2, que vinha sendo planejado desde o final da década de 1980 (WORLD BANK, 2004).

Várias alternativas ao NT2 foram consideradas. Em 1998, foram examinados 19 projetos energéticos em um estudo de alternativas baseando-se em critérios técnicos, econômicos, financeiros, ambientais e sociais. De acordo com os resultados obtidos, incorporando características adicionais ao projeto NT2, poderia se conseguir a redução significativa dos impactos ambientais que os outros projetos ofereciam. Em 2000, uma atualização parcial do Estudo de Estratégia de Desenvolvimento Hidrelétrico foi realizada reavaliando os projetos hidrelétricos em termos de abastecimento interno e exportação. $\mathrm{O}$ projeto NT2 recebeu a maior pontuação em relação à viabilidade de projetos hidrelétricos. Em 2004, o projeto obteve novamente a maior pontuação ao ser comparado com 19 outros projetos hidrelétricos considerando os aspectos técnicos, econômicos, sociais e ambientais. Alternativas levando em conta os componentes do projeto (reservatório, localização da barragem, sistema de regulação, etc.) foram analisadas antes de chegar-se ao design final. Também foram estudados cenários de produção de energia na Tailândia que incluiu alternativas de energia hidrelétrica. No entanto, opções hidrelétricas nesse país são muito limitadas devido à falta de locais adequados. Outras energias renováveis como solar e eólica foram estudadas e julgadas inviáveis. Em Laos, foi feita uma análise de produção de energia considerando opções térmicas (petróleo, gás, carvão), nuclear (urânio), solar, eólica, geotérmica e de biomassa) que permitiriam honrar o compromisso do governo de fornecer 3000 MW para a Tailândia. Concluiu-se que nenhuma contribuição significativa poderia ser 
esperada a partir de fontes alternativas de combustível disponíveis em Laos. Os únicos recursos importantes que poderiam contribuir para o cumprimento dos compromissos seriam a energia hidrelétrica e térmica a base de carvão. Também foi considerado um cenário sem o projeto. Neste caso, havia probabilidade de desenvolvimento de outras atividades (tal como mineração) no local (THE WORLD BANK; MIGA, 2005).

O objetivo de desenvolvimento do projeto é gerar receitas, através de uma exploração ambientalmente e socialmente sustentável do potencial hidroelétrico do NT2, que seria usado para financiar os gastos de redução da pobreza e programas de gestão ambiental. Atingir essa meta exigiria compromisso do Governo para reformar a gestão da despesa pública e promover a conservação do meio ambiente, bem como a implementação efetiva do projeto em si (THE WORLD BANK; MIGA, 2005; WORLD BANK, 2004).

\section{(ii) Descrição do Projeto}

O Projeto Hidrelétrico Nam Theun 2 seria construído no rio Nam Theun, um afluente do rio Mekong, na província Bolikhamsay no centro de Laos. A área de adução de água (de $4013 \mathrm{~km}^{2}$ ) localiza-se nas montanhas Annamite ao longo da fronteira com o Vietnã. Trata-se de um projeto de desvio inter-bacia do rio que transporia as águas do rio Nam Theun para o rio Xe Bang Fai, um afluente do rio Mekong, que se junta a este a cerca de $150 \mathrm{~km}$ ao sul do rio Nam Theun.

A usina teria uma capacidade instalada de 1070 MW. A água descarregada a partir da usina seria levada a um reservatório de regulação, de onde fluiria para o rio Xe Bang Fai através de um canal aberto de $27 \mathrm{~km}$ construído para este propósito e para reconstituição do rio Nam Phit (THE WORLD BANK; MIGA, 2005).

O Projeto hidrelétrico Nam Theun 2 tem três componentes:

- Componente 1: Usina hidrelétrica. O projeto NT2 teria uma capacidade instalada de $1070 \mathrm{MW}$ dos quais $75 \mathrm{MW}$ seriam consumidos localmente e $995 \mathrm{MW}$ exportados para a Tailândia (WORLD BANK, 2004). Os principais elementos da usina hidrelétrica seriam:

- (i) uma barragem de 48 metros de altura no rio Nam Theun a uma altitude de 540,4 m acima do nível do mar;

- (ii) um vertedouro fechado seria construído integralmente junto à barragem;

- (iii) fluxo de saída - uma conduta de saída seria construída ao lado do vertedouro para soltar a água a jusante; 
- (iv) um reservatório - em máximo suprimento, a uma altitude de $538 \mathrm{~m}$, o reservatório teria uma área de $450 \mathrm{~km}^{2}$ e seguraria 3910 milhões de metros cúbicos de água;

- (v) Canal de adução de água e estruturas de adução;

- (vi) Túnel condutor, eixo de onda, eixo de pressão e túnel de pressão. Este sistema transmitiria a água do canal de adução para a usina;

- (vii) uma usina hidrelétrica (de onde a água fluiria para o rio Xe Bang Fai, também um afluente do Mekong). A usina ficaria em um único edifício que abrigaria quatro turbinas (eixo vertical Francis) de $252 \mathrm{MW}$ e duas unidades de turbinas geradoras (eixo vertical Pelton) de $40 \mathrm{MW}$;

- (viii) uma LT circuito duplo $500 \mathrm{kV}$ de $138 \mathrm{~km}$ para a rede tailandesa;

- (ix) uma LT circuito único $115 \mathrm{kV}$ de $70 \mathrm{~km}$ para a rede nacional de Laos;

- (x) Canal de fuga e regulação da represa. A água descartada das turbinas seria conduzida através de um canal de fuga para a lagoa de regulação;

- (xi) Canal a jusante. Um canal escavado de diferentes larguras (1,8 m a 8,5 m) levaria a água da barragem de regulação para o rio Xe Bang Fai (27 km de distância);

- (xii) Estradas e pontes. As seguintes estradas e pontes seriam construídas/melhoradas no âmbito do projeto: (a) Thakek para Gnommalath; (b) Gnommalath para Nakai; (c) Nakai para Ban Nam Nian.; (d) estrada de acesso ao local da barragem; (e) local da barragem - O trecho da estrada 8B seria reformado; e (f) estradas nos locais de reassentamento;

- (xii) Operadores. Seria estabelecida uma aldeia para os operadores (e suas famílias) perto da barragem de regulação. O local seria equipado com as seguintes facilidades: (a) 48 habitações; (b) uma pousada; (c) serviços de manutenção (estação de tratamento de água e esgoto, unidades de combate a incêndio, instalações de recolha de lixo, guardas e cercas); (d) recreação e lazer (piscina, playground, quadra de tênis, auditório e biblioteca); (e) um posto de saúde; (f) escola e templo.

- Componente 2: Gestão de impactos ambientais e sociais. O projeto se concentraria no desenvolvimento de um quadro regulamentário que facilitaria a gestão baseando-se na ciência e na supervisão de intervenções de conservação na Área de Proteção Nacional Nakai Nam Theun e nos dois corredores adjacentes. O projeto capacitaria o pessoal para a conservação e implementação de planos transparentes de gestão no intuito de proteger e conservar áreas afetadas. 
- Componente 3: Monitoramento e avaliação. Este componente do projeto consistia em atividades internas e externas, incluindo: (i) supervisionar a implementação física do projeto hidrelétrico; (ii) monitorar impactos e medidas de mitigação; (iii) monitorar sistematicamente os componentes técnicos e de salvaguardas; (iv) assessorar a alta administração do Banco Mundial sobre a implementação do projeto; (v) monitorar independentemente a bacia do NT2 e os mecanismos de gestão de receitas; e (vi) supervisionar (WORLD BANK, 2004).

\subsubsection{Caracterização do nível estratégico do Projeto Hidrelétrico Nam Theun 2}

Foram identificdas três dimensões estratégicas: objetivo, abrangência e alternativa (Figura 18). Os objetivos do projeto são considerados como estratégicos, pois são amplos, gerais e expressam as grandes linhas. Com efeito, o objetivo do projeto é gerar receitas, através de uma exploração ambientalmente e socialmente sustentável do potencial hidroelétrico do Nam Theun 2, que será usado para financiar os gastos de redução da pobreza e programas de gestão ambiental. Percebe-se que há uma indicação da natureza do conjunto de resultados pretendidos. A segunda dimensão estratégica é a abrangência. Constatou-se que o projeto envolve uma hidrelétrica, LTs, operações de gestão ambiental e social assim como monitoramento e avaliação, portanto, grupos de projetos vinculados entre si.

A terceira dimensão, "alternativa" é considerada estratégica, pois o projeto Nam Theun 2 foi selecionado após uma série de avaliações (em 1998 e 2004) baseadas em critérios econômicos, financeiros, ambientais e sociais. Ademais, as opções energéticas de Tailândia consideraram energias eólica e solar. Em Laos, foram levados em conta cenários de produção de energia a base de petróleo, gás, etc. Nos dois casos, tratam-se de alternativas envolvendo outras fontes de energia. O cenário sem o projeto também foi considerado. No entanto, algumas alternativas, entre outras as locacionais e operacionais, foram levadas em conta no planejamento do projeto, mas não consideradas estratégicas pela análise realizada.

As dimensões espaço, tempo e nível de detalhes também não foram consideradas estratégicas. O espaço é definido com exatidão, uma vez que o Nam Theun 2 já tem o seu local de implantação conhecido. Em relação ao tempo, não foram encontrados indícios que indicam que é preciso um período de aguarda das providências necessárias para tornar efetiva a execução do projeto. Esse último encontra-se muito perto de sua execução. A dimensão nível de detalhes também não foi considerada estratégica, pois as informações dos componentes do Nam Theun 2 são apresentados com objetividade e exatidão. 
Figura 18 - Dimensões Estratégicas do Projeto Nam Theun 2

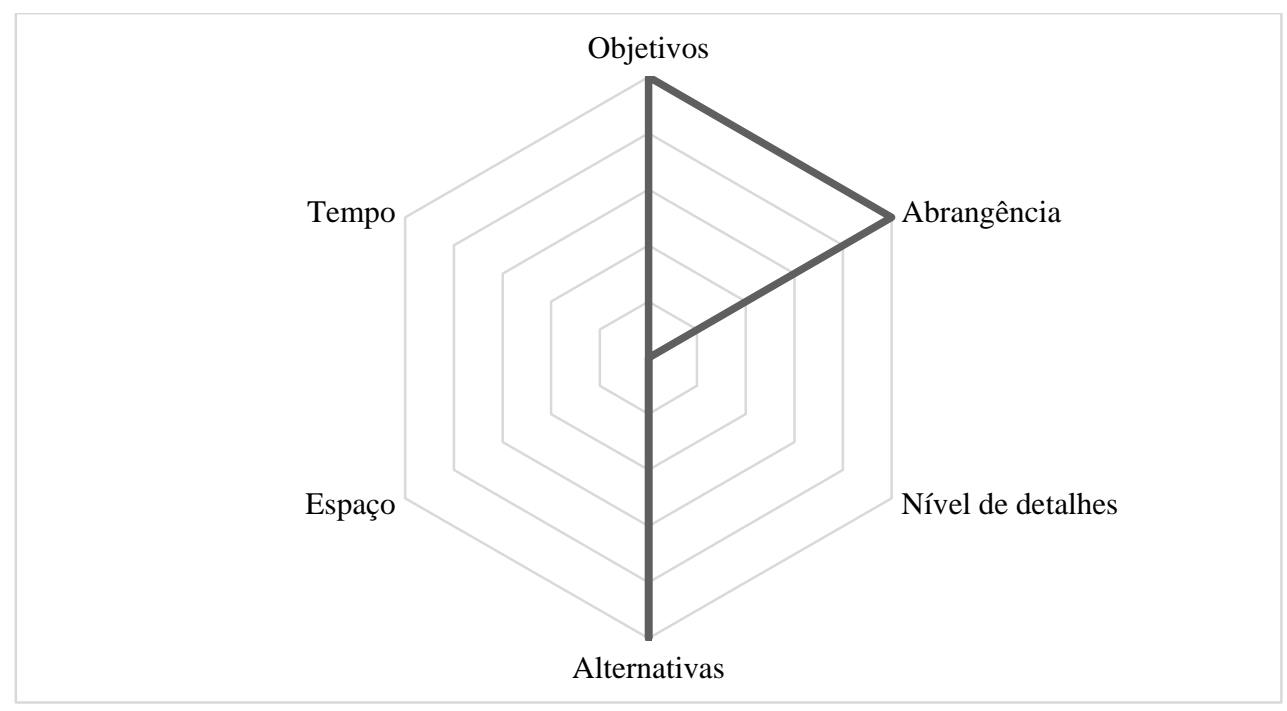

Fonte: Elaborado pelo autor

\subsubsection{Caracterização do Termo de referência da Análise de Impacto Cumulativo}

O TR solicitou a elaboração de um estudo de Avaliação de Impacto Cumulativo, que iria analisar os impactos agregados a partir de: (a) construção e operação do projeto e, (b) potenciais cenários de desenvolvimento que também poderiam afetar as dimensões ambientais e sociais impactadas pelo projeto.

Com o passar do tempo, o Projeto Hidrelétrico NT2 causaria impactos ambientais e sociais diretos e indiretos dentro e fora de sua área de influência imediata. Ao mesmo tempo, haveria um desenvolvimento regional em diversos setores envolvendo navegação, estradas, hidrelétricas, irrigação, desenvolvimento urbano, silvicultura, pesca, mineração e conservação. Os impactos do NT2 combinados com os impactos potenciais de projetos já existentes e/ou planejados na sua área e na região do Grande Mekong precisavam ser levados em conta para reduzir os impactos e garantir que Laos e os outros países da sub-região tirassem benefícios de tais projetos.

De acordo com o TR, o escopo do estudo deveria cobrir as dimensões espaciais e temporais relevantes para os impactos cumulativos e considerar o planejamento estratégico a médio e longo prazo na área do projeto e na região do Grande Mekong. Os cenários de desenvolvimento avaliados deveriam incluir todos os setores relevantes e questões-chave que possam ser confrontados sob esses cenários. 
Referente à cobertura espacial, a avaliação devia avaliar os potencias impactos cumulativos que o projeto causaria, dentro das seguintes principais áreas: (a) Bacia do rio Mekong; (b) Bacias dos rios Nam Kading e Xe Bang Fai; e (c) zona de desenvolvimento associada às linhas de transmissão. Esta cobertura espacial permitia que o projeto: (a) fosse avaliado considerando os desenvolvimentos atuais e planejados na bacia do rio Mekong; (b) examinasse os impactos cumulativos das atividades atuais e projetadas nas duas bacias hidrográficas em que o projeto seria localizado; e (c) analisasse os impactos nos locais que seriam influenciados pelo corredor das linhas de transmissão.

Em relação à cobertura temporal, o TR estipulou que o estudo avaliasse os potenciais impactos cumulativos nos seguintes prazos: (a) planejamento horizonte 5 anos; (b) planejamento horizonte 20 anos. Esses prazos foram selecionados, a fim de cobrir os estudos de planejamento realizados em níveis regionais, nacionais e/ou setoriais por parte da Comissão do Rio Mekong, os governos nacionais e outras organizações que utilizavam esses horizontes em seus trabalhos. Além disso, o estudo iria, sempre que possível, fornecer previsões quantitativas em longo prazo de dados impactos com base em análises de tendências.

Referente a cenários de desenvolvimento, o estudo deveria analisar os impactos induzidos e indiretos do projeto em cenários de desenvolvimento futuro, no contexto da cobertura espacial e temporal descrito anteriormente. Cenários deveriam ser representativos de alternativas de desenvolvimento alternativo para Laos, com base em planos de desenvolvimento existentes nos diversos setores. Os cenários de desenvolvimento deveriam considerar as atividades previstas/propostas pelas principais agências de desenvolvimento e pelo governo de Laos. Dois cenários de desenvolvimento deveriam necessariamente ser contemplados: (a) cenário "business as usual" dando a visão global de todos os desenvolvimentos propostos dentro de um horizonte de planejamento de 20 anos, e (b) cenário que refletisse as "boas práticas", com ênfase nas dimensões ambiental e social. Uma abordagem de avaliação de risco deveria ser utilizada na análise dos dois cenários, considerando o normal e o nível de desenvolvimento que levaria a efeitos cumulativos significativos ou aceitavelmente insignificantes.

O TR apontou os principais resultados do estudo, a saber: (a) compreender de forma abrangente os impactos cumulativos do Projeto Nam Theun 2 em um contexto regional, tanto na área do projeto, quanto nos países ribeirinhos a jusante ao longo do rio Mekong; (b) recomendar aos stakeholders uma melhor avaliação dos impactos cumulativos identificados e uma melhoria de seus planejamentos e programas. 
O Termo de Referência estabelece as seguintes tarefas que deveriam ser respeitados pelos consultores que conduziriam a Avaliação de Impacto Cumulativo:

Reunião de Iniciação do Projeto: nesta reunião deveriam ser discutidos os seguintes aspectos: metodologia a ser utilizada para o estudo; plano de trabalho do projeto e cronograma; resultados esperados; identificação de todos os documentos relevantes a serem revistos como parte da baseline do estudo; escopo de avaliação de impacto cumulativo; problemas ou constrangimentos associados ao estudo; e abordagem da consulta pública com os stakeholders.

D Baseline: uma linha de base ambiental e social deveria ser preparada baseada na consolidação das informações disponíveis. O consultor deveria apresentar a melhor informação disponível na forma de mapas, imagens, e resumos de avaliações de uso da terra. Os mapas deveriam ser produzidos usando SIG. O desenvolvimento da linha de base devia incluir análises documentais e avaliação dos estudos existentes que tinham abordado os impactos ambientais e sociais e questões de planejamento de desenvolvimento estratégico.

Refinar o estudo do escopo: após a identificação de aspectos chaves, o escopo deveria ser revisado através de um processo interativo de consulta. O consultor identificaria questões de interesse regional; componentes de ecossistemas que eram meritórios para os stakeholders; coberturas espacial e temporal do estudo; outras atividades que poderiam afetar o ecossistema; e possíveis impactos. O escopo deveria basear-se numa abordagem participativa, solicitando comentários de grupos afetados e outros stakeholders, e realizando uma oficina de planejamento e discussões em grupo com, entre outros, autoridades provinciais e nacionais. O escopo final do estudo deveria ser apresentado em termos de: questões de impacto cumulativo a serem avaliados; horizonte de planejamento ou período de tempo da avaliação; cobertura espacial; elementos a serem incluídos no cenário de desenvolvimento; e indicadores propostos para avaliar os impactos cumulativos.

$>\quad$ Preparação e desenvolvimento prévio de cenários: elaboração de no mínimo dois cenários, "business as usual" e boas práticas.

$>\quad$ Relatório inicial e reunião: um relatório inicial deveria ser preparado baseando-se nos resultados preliminares. $\mathrm{O}$ documento seria apresentado numa reunião com $\mathrm{O}$ Banco Mundial e o Banco Asiático de Desenvolvimento.

Avaliação de Impacto: 
- Avaliar as tendências econômica, ecológica e social, incluindo aquelas potencialmente induzidas pelo NT2 ou outros projetos regionais.

- Avaliar todos os impactos (positivos e negativos) sociais e ambientais relevantes dos prováveis projetos de desenvolvimento regional e as tendências socioeconômicas, incluindo os impactos indiretos, cumulativos de longo prazo. Essa análise devera incluir, mas não se limitar ao:

* Regime de fluxo esperado nos sistemas fluviais afetados e seus efeitos;

* Efeito de qualquer aumento da irrigação, pesca e desenvolvimento do turismo;

* Efeito da ausência de projetos susceptíveis de serem anulados devido ao NT2;

* Efeitos de mudanças nas interações sociais e econômicas transfronteiriças com o Vietnã e a Tailândia;

Efeitos do desenvolvimento induzido;

* Impacto sobre os diferentes grupos sociais, tais como minorias étnicas, mulheres, jovens, idosos e outros grupos vulneráveis ou marginalizados;

* Papel de questões de governança, como a corrupção, a identificação de elite e desigualdade que poderiam restringir os esforços de desenvolvimento ou poderiam ser agravadas por esforços de desenvolvimento;

* Identificação de instituições susceptíveis de melhorar ou restringir os esforços de desenvolvimento particularmente a respeito de oportunidades equitativas e sustentabilidade;

* Impacto sobre a posse da terra e práticas de uso da terra, incluindo aqueles específicos a minorias étnicas;

* Avaliação dos diversos interesses de stakeholders (a nível nacional, regional e local), sua influência e implicações na seleção e implementação de projetos e políticas regionais.

* Potencial de efeitos sinérgicos dentre as tendências regionais e os projetos regionais, incluindo o NT2 .

- Identificar os principais riscos sociais e ambientais e desafios de desenvolvimento em longo prazo na zona de influência. 
- Avaliar alternativas estratégicas para o desenvolvimento em longo prazo na região, especificando: benefícios (incluindo a atribuição entre os grupos e áreas geográficas), restrições; opções de implementação e financiamento; e custos.

- Avaliar a adequação e limitações do quadro jurídico e institucional em Laos para tratar efeitos induzidos e cumulativos.

Relatório intermediário e reunião: um relatório intermediário deveria ser preparado com base na análise de impacto. Recomendações para atividades relacionadas ao NT2 para melhor avaliar os impactos cumulativos do projeto, se houvesse, deveriam ser incluídas no relatório intermediário. Além de descrever os potenciais impactos cumulativos, no relatório deveria constar a avaliação das implicações para o desenvolvimento futuro. Oficinas de consulta deveriam ser realizadas neste momento, a fim de solicitar comentários de grupos afetados e stakeholders.

Conclusões e recomendações: o relatório final deveria considerar os seguintes aspectos nas conclusões e recomendações:

- Os principais impactos cumulativos do projeto Nam Theun 2 em um contexto regional, tanto na área do projeto e nos países ribeirinhos a jusante ao longo do rio Mekong;

- Recomendações para atividades relacionadas ao projeto NT2 para melhor atender os impactos cumulativos do projeto;

- Recomendações aos órgãos governamentais competentes, incluindo as agências setoriais, distrito e governos provinciais;

- Recomendações para os países ribeirinhos e a Comissão do Rio Mekong sobre as atividades atuais e futuras nas áreas afetadas da bacia do rio Mekong. Relatório final: o relatório da avaliação deveria incorporar os resultados da consulta e os comentários do ADB e BM. O consultor deveria:

- fornecer a documentação sobre os resultados da consulta com os grupos afetados e stakeholders;

- rever o relatório com base na tabela acordada de conteúdo e os resultados da consulta;

- incluir como parte do relatório final, a maneira como o documento foi influenciado pelo processo de consulta, incluindo exemplos específicos;

- fornecer o relatório final para o $\mathrm{ADB}$ e o Grupo Banco Mundial para análise e; 
- incorporar comentários do $\mathrm{ADB}$ e $\mathrm{BM}$ no relatório e fornecer documentação sobre a forma como o relatório final respondia a estes comentários. Auxiliar o Governo de Laos no Programa de Consulta Pública, incluindo a divulgação de documentos relacionados ao projeto e, especialmente, a Avaliação de Impacto Cumulativo.

Resumidamente, o Termo de Referência apontou as seguintes grandes linhas:

$>$ Avaliar impactos cumulativos nas principais áreas (cobertura espacial)

> Avaliar potenciais impactos cumulativos nos horizontes de 5 e 20 anos (cobertura Temporal)

Consultas públicas

$>$ Preparação de baseline

$>$ Avaliação de alternativas estratégicas. Analisar os impactos induzidos e indiretos do projeto em cenários de desenvolvimento futuro.

$>$ Avaliação de impacto de tendências (i) econômica, (ii) ecológica e (iii) social: avaliar todos os impactos sociais e ambientais relevantes dos prováveis projetos de desenvolvimento regional. Considerar (i) o regime de fluxo esperado nos sistemas fluviais; (ii) efeito de aumento de irrigação, pesca e turismo; (iii) efeito de ausência de projetos; (iv) efeitos transfronteiriços; (v) efeito de desenvolvimento induzido; (vi) impactos sobre grupos sociais; (vii) governança; (viii) instituições; (ix) uso de terra; (x) efeitos sinergéticos. Identificação dos principais riscos sociais e ambientais e desafios de desenvolvimento. Avaliação da adequação e limitações do quadro jurídico e institucional.

\subsubsection{Alinhamento do TR e AIC em relação a aspectos-chave da AAE}

(i) Verificação de aspectos-chave associados às AAEs no Termo de Referência e na Avaliação de Impacto Cumulativo

Foi observado que o Termo de Referência e a Avaliação de Impacto Cumulativo atendem a todos os elementos referindo-se a identificação de indicadores e as áreas problemáticas, avaliação de alternativas e documentação de resultados (Figura 19). 
Figura 19 - Alinhamento do TR e AIC do Projeto Nam Theun 2

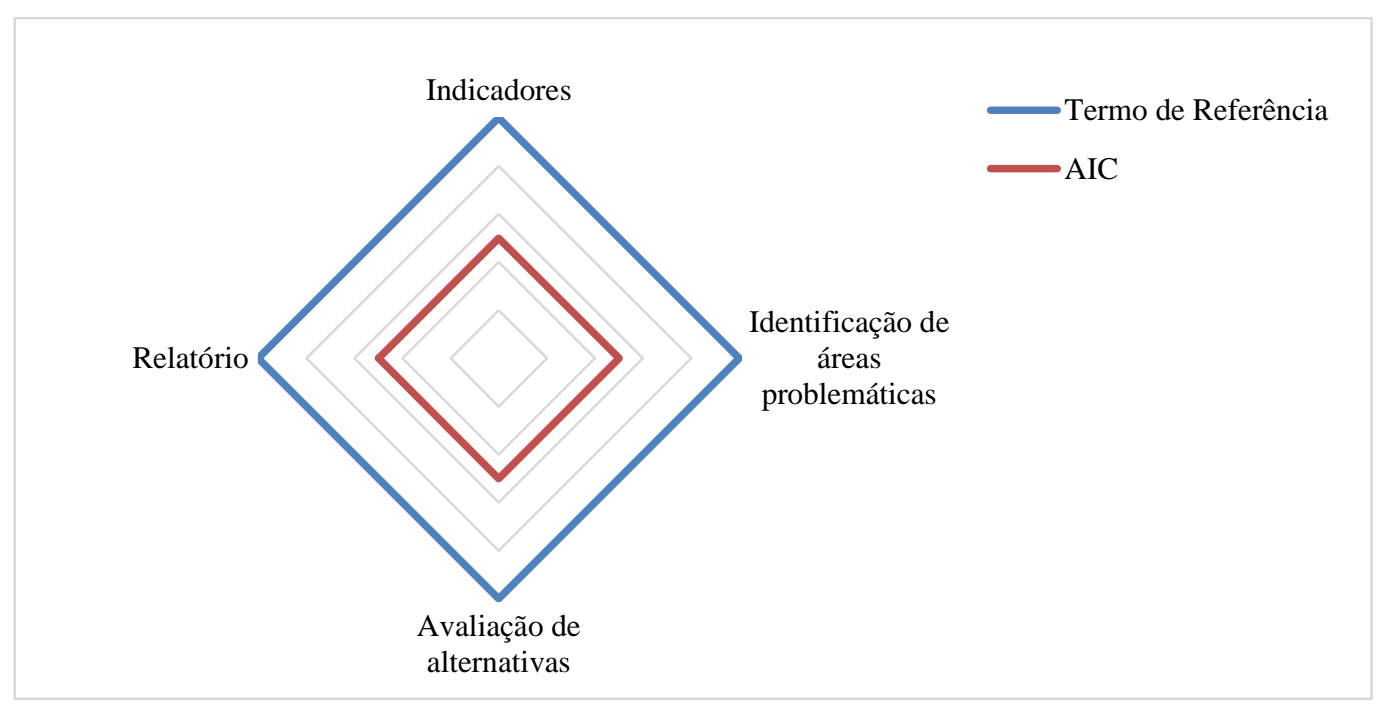

Fonte: Elaborado pelo autor

(ii) Distanciamento entre TR padrão e TR específico do Projeto hidrelétrico Nam

Theun 2

Como pode ser visto no quadro 17 , foi verificado que todos os apontamentos do Termo de Referência padrão foram adaptados e solicitados no TR específico.

Quadro 17 - Relação TR padrão e TR específico do Projeto hidrelétrico Nam Theun 2

(Continua)

Tarefas apontadas pelo Termo de Referência padrão

Atendimento

Discussão do enquadramento de políticas no âmbito dos quais se efetua a AA. Explicação dos requisitos ambientais e identificação de acordos ambientais internacionais relevantes.

Descrição da ação estratégica proposta (o seu contexto geográfico, ecológico, social e temporal) incluindo quaisquer investimentos fora do local que possam ser necessários (por exemplo, dutos exclusivos, estradas de acesso, usinas geradoras de energia). Indicação da necessidade ou não de planos de reassentamento ou de ações de desenvolvimento para povos indígenas.

Previsão e avaliação dos prováveis impactos positivos e negativos da ação estratégica.

Avaliação das dimensões da área de estudo e descrição das condições físicas, biológicas e socioeconómicas relevantes, incluindo quaisquer alterações previstas para antes do início da ação estratégica. Também levar em consideração atividades de desenvolvimento em curso e propostas dentro da área da ação estratégica, mas não diretamente ligadas à mesma. 
(Conclusão)

\section{Tarefas apontadas pelo Termo de Referência padrão}

Atendimento

Identificação das medidas mitigadoras e quaisquer impactos residuais negativos que não possam ser mitigados. Exploração de oportunidades para melhoria ambiental.

Especificação do plano de monitoramento e de reforço institucional.

Avaliação de impactos ambientais de cada alternativa. Comparação de alternativas viáveis (incluindo a situação sem o projeto) em termos de potenciais impactos ambientais.

Justificativa da escolha de cada alternativa.

Consulta pública: Fazer registo das reuniões ocorridas entre os vários organismos e para obtenção de opiniões das pessoas afetadas pela ação estratégica projeto e de organizações não governamentais (ONG).

Documentação dos resultados

Fonte: Elaborado pelo autor

\section{(iii) Atendimento de apontamentos do Termo de Referência pela AIC}

Foi observado que todos os elementos solicitados no Termo de Referência, foram atendidos pela Avaliação de Impacto Cumulativo. O estudo realizou a baseline, avaliação de impacto (em uma abordagem temporal e espacial) de alternativa e consultas públicas. É importante ressaltar que, em relação à baseline, a avaliação atende à solicitação do TR. Contudo, com base na revisão de qualidade do relatório que será apresentada a seguir, não considerou-se o levantamento feito como baseline, uma vez que esta se refere a tendências de desenvolvimento. 


\subsubsection{Projeto Hidrelétrico Rampur}

\subsubsection{Contexto de inserção do projeto}

\section{(i) Background}

A Índia é um país da Ásia Meridional. É o segundo país mais populoso e o sétimo maior em área geográfica. O país faz fronteira com Paquistão a oeste; República Popular da China, Nepal e Butão ao norte e Bangladesh e Mianmar a leste.

O governo indiano vem tentando alcançar altos níveis de expansão econômica, com 8\% de crescimento projetado para os anos de 2002 até 2007 a fim de atingir suas metas de redução da pobreza e avanço das regiões rurais. A melhoria de infraestrutura, permitindo o acesso às fontes de eletricidade, é um dos pré-requisitos para alcançar estas metas (WORLD BANK, 2005a). Assim sendo, o Governo tomou certas medidas políticas para melhorar a eficiência e qualidade dos serviços de distribuição de energia elétrica; melhorar a confiabilidade de antigas usinas térmicas; estimular o investimento em energia renovável; e ampliar o acesso rural. O governo tem adotado estas metas como prioritárias, e tem se empenhado em incentivar a construção de instalações elétricas adicionais para atender a crescente demanda por energia (WORLD BANK, 2007a).

No entanto, a Índia, por muitos anos, enfrentou racionamentos no fornecimento de energia. Análises mostraram que estas carências só poderiam ser sanadas pela redução de perdas e aumento da eficiência nos ganhos. O governo estimava que a Índia precisasse de mais 100000 MW até 2012 para que o país atingisse a meta de crescimento anual de 8\% e forneçesse energia para todos os domicílios (WORLD BANK, 2005a). Além dos problemas de falta de energia, havia outros desafios tais como baixo nível de conectividade e infraestrutura limitada. (WORLD BANK, 2007a).

O Governo indiano planejava aumentar a capacidade energética do país considerando a redução de emissão de carbono como um dos elementos-chave para enfrentar os desafios ambientais. Apesar de ser reconhecido internacionalmente como um pequeno emissor de $\mathrm{CO}_{2}$, o país emitia o equivalente a 4\% da emissão mundial em 2007. Em 2031, mantendo a taxa de crescimento de $8 \%$ ao ano, a Índia emitirá 5,5 bilhões de toneladas de $\mathrm{CO}_{2}$ por ano, o que equivalerá a $13 \%$ do total do mundo. Sob este cenário, a Índia continuará a depender fortemente de recursos de carvão. Para alcançar um caminho de desenvolvimento de baixa 
emissão carbônica, julgou-se importante que opções mais limpas de produção de energia fossem ampliadas (THE WORLD BANK, 2007).

No entanto, a participação da energia hidrelétrica no mix de geração total vem diminuindo nos últimos anos. Em 2005, a energia hidrelétrica representou apenas $25 \%$ da capacidade total de geração do país. Essa deficiência tem contribuído para a incapacidade da Índia de atender às demandas de energia nos horários de pico, e tem originado problemas técnicos e económicos relacionados ao funcionamento da rede. Dada a disponibilidade abundante de carvão, era provável que usinas térmicas continuassem a ser a geração alternativa preferida para os próximos anos. No entanto, essas usinas constituíam uma fonte significativa de emissão de dióxido de carbono e material particulado em suspensão. Por outro lado, quando desenvolvido de acordo com as boas práticas ambientais e sociais, a hidrelétricidade representa uma fonte de energia relativamente limpa e barata (WORLD BANK, 2005a, 2007a).

Através da construção de Rampur, a Índia adiaria a necessidade da construção de usinas térmica (movidas a carvão ou petróleo) de mesma capacidade e, desta forma, reduziria as emissões de gases de efeito estufa e, consequentemente, o seu impacto sobre o aquecimento global. A hidrelétrica Rampur iria evitar a emissão de aproximadamente 12000 toneladas de $\mathrm{SO}_{\mathrm{x}}, 6000$ toneladas de $\mathrm{NO}_{\mathrm{x}}$ e cerca de 2 milhões de toneladas de $\mathrm{CO}_{2}$ na atmosfera a cada ano (WORLD BANK, 2005a).

A construção eficiente e a tempo do Projeto Hidrelétrico Rampur, incorporando boas práticas, melhoraria a imagem da energia hidrelétrica como uma alternativa limpa e de baixo custo em um cenário "business-as-usual" em relação a usinas térmicas a carvão ou óleo que emitem gases de efeito estufa e também agravam a dependência do país de combustíveis importados. A par disto o governo pretendia candidatar-se a financiamento de créditos de carbono para este projeto e as estimativas preliminares mostram que poderá render cerca US\$ 8 milhões por ano (THE WORLD BANK, 2007).

\section{(ii) Descrição do Projeto}

O objetivo de desenvolvimento do projeto Hidrelétrico Rampur era tornar a autoridade indiana capaz de preparar e implementar projetos hidrelétricos de forma econômica, ambiental e socialmente sustentável (WORLD BANK, 2005a, 2005b); e melhorar a rede norte através da adição de energia renovável e menos poluente (WORLD BANK, 2007a, 2007b). 
O Projeto Hidrelétrico Rampur era constituído de três elementos:

- Componente 1: Usina hidrelétrica a fio d’água de $412 \mathrm{MW}$ - O projeto hidrelétrico Rampur seria localizado a jusante da hidrelétrica Nathpa Jhakri no rio Sutlej no estado de Himachal Pradesh.

A construção de mais uma usina energética em cascata utilizando a água desassoreada do canal de fuga de Nathpa Jhakri tem sido considerada na concepção do projeto Nathpa Jhakri cuja construção incluiu os trabalhos iniciais de Rampur. Este último usaria a água que sairia do canal de fuga do Nathpa Jhakri e, assim, a sua construção e operação não exigiria uma represa nem seria necessário qualquer novo reservatório ou inundação de terras. A hidrelétrica Rampur seria um projeto a fio d'água operando em cascata com o projeto Nathpa Jhakri (THE WORLD BANK, 2007).

Foram avaliados seis projetos alternativos para a usina, cada qual envolvia a estrutura de adução de água do Rampur. Os estudos levaram em conta as condições geológicas que poderiam, eventualmente, ser afetadas na construção de várias vias subterrâneas do túnel de adução de água. Os locais e as dificuldades de encontrar a melhor localização da usina e condutos forçados foram também considerados nos estudos (DHI WATER AND ENVIRONMENT, 2007).

- Componente 2: implementar medidas para garantir a disponibilidade do projeto hidrelétrico a montante Nathpa Jhakri - o Projeto Nathpa Jhakri tem sido afetado por níveis mais elevados de silte do que o esperado no Rio Sutlej resultando no desligamento da usina por períodos mais longos do que o previsto na sua concepção. O apoio ao investimento no âmbito desse componente seria composto por: (i) aquisição de peças de reposição; (ii) a disponibilização de placas de acabamento na captação; (iii) a dragagem pesada com bombas para manter a captação livre de sedimentos; e (iv) um túnel para desviar a água carregada de silte para fora da área das obras de captação a jusante da barragem.

- Componente 3: Assistência técnica para a reforma institucional e capacitação para auxiliar o mutuário a alcançar as boas práticas internacionais no desenvolvimento e operações da hidrelétrica e melhoria na preparação de projetos futuros.

Esse componente do projeto exigiria estudos, treinamento e suporte técnico nas áreas de (i) planejamento e gestão de questões ambientais e sociais; (ii) gestão de contratos; (iii) segurança e saúde; e (iv) prestação de contas financeiras e governança corporativa. Uma parte desse componente de assistência técnica foi mantida suficientemente flexível, de modo que as 
medidas referentes a questões e problemas de implementação possam ser incorporadas (THE WORLD BANK, 2007).

\subsubsection{Caracterização do nível estratégico do Projeto Hidrelétrico Rampur}

Analisando o Projeto Hidrelétrico Rampur, foram identificadas duas dimensões estratégicas: abrangência e alternativa (Figura 20). Em relação à abrangência, analisando o projeto, constata-se que este envolve uma hidrelétrica a ser construída e em cascata com uma hidrelétrica já instalada. Ademais o projeto envolve a capacitação institucional. O Rampur envolve, portanto, componentes que podem ser considerados como grupos de projetos vinculados entre si. A segunda dimensão, "alternativas" é considerada estratégica, pois o projeto Rampur foi selecionado após estudos que consideraram outras fontes alternativas de energia. O projeto hidrelétrico Rampur foi confrontado a projeto de usinas térmicas movidas a carvão ou petróleo. Na fase de concepção do projeto Rampur também foram consideradas alternativas de localização da usina e do túnel de captação de água, mas estas alternativas não são consideradas estratégicas, uma vez que se trata de alternativas singulares de localização.

As dimensões espaço, tempo, nível de detalhes e objetivos não foram consideradas estratégicas. Em relação ao espaço, o local de implantação dos componentes do projeto é definido com exatidão. O Rampur já tem o seu local receptor definido. No que diz respeito ao tempo, não foram encontrados indícios de que providências precisam ser tomadas para tornar a execução do projeto viável. O Projeto Rampur se encontra muito perto de sua execução, apresentando, portanto uma limitação temporal. No tocante à dimensão nível de detalhes, percebe-se que a descrição do projeto apresenta muitos detalhes. Apresenta-se com objetividade e exatidão as informações e especificações das atividades a serem desenvolvidas. Os objetivos do projeto não foram considerados estratégicos, pois explicita metas concretas que definam a dimensão e apontam os resultados a serem alcançados em uma determinada área. 
Figura 20 - Dimensões Estratégicas do Projeto Hidrelétrico Rampur

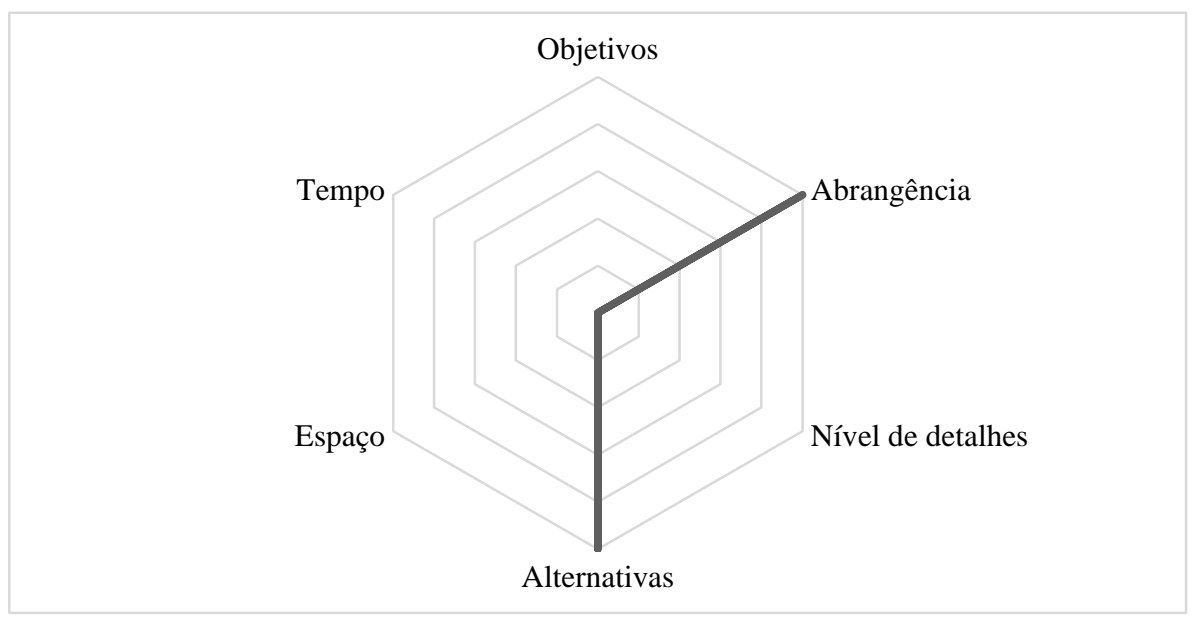

Fonte: Elaborado pelo autor

\subsubsection{Caracterização do Termo de referência da Avaliação de impacto cumulativo e induzido}

O Termo de Referência elaborado pela agência financiadora desse projeto não foi encontrado entre os documentos disponibilizados pela AMD. As informações abaixo apresentadas baseiam-se no resumo do TR contido no relatório da Avaliação de Impacto Cumulativo. O resumo comporta dados suficientes para os fins deste trabalho, todavia podem faltar alguns aspectos, uma vez que algumas informações podem ser omitidas em um resumo.

O objetivo geral da avaliação de impacto cumulativo e induzido é o planejamento para que os projetos de desenvolvimento na área do Projeto Hidrelétrico Rampur bem como na bacia do rio Satluj sejam sustentáveis.

Os objetivos específicos da avaliação são:

- Examinar e compreender os impactos agregados de: (a) construção e funcionamento de todos os projetos atuais e futuros da Bacia Satluj e (b) potencial cenários de desenvolvimento que possam afetar as dimensões ambiental e social impactadas pelos projetos propostos.

- Examinar e compreender os impactos agregados do desenvolvimento da energia hidrelétrica na bacia diretamente atribuíveis ao Projeto Hidrelétrico Rampur. É particularmente importante compreender a natureza e a magnitude dos impactos do Projeto Hidrelétrico Rampur, sobre e além, dos impactos dos projetos já em vigor. 
- Realizar consultas públicas iniciais sobre os resultados da avaliação, e registrar os pontos de vista das comunidades locais e outros "stakeholders".

- Recomendar medidas específicas a serem implementadas pelo Projeto Rampur como também por outros projetos futuros e abordar as questões de impactos cumulativos para além da mitigação e/ou medidas de gestão de impactos específicos do projeto.

O Termo de Referência estipula que a avaliação deveria realizar as seguintes tarefas:

- Consultar os stakeholders e a população afetada.

- Identificar as questões-chave para avaliar os impactos dos projetos hidrelétricos em curso e propostos na bacia do rio Satluj. Os aspectos-chave deveriam incluir o fluxo e qualidade de água, contaminação da água, perda da cobertura florestal, perda da biodiversidade e dos habitats, mudanças climáticas, perda da horticultura, secagem de pequenas fontes de água, etc.

- Avaliar os impactos cumulativos dos projetos na Bacia Satluj inteira (na parte indiana da Bacia Satluj) assim como na área de Influência dos projetos hidrelétricos Rampur e Nathpa Khakri que poderiam ser considerados como zonas de desenvolvimento lineares associadas ao desenvolvimento.

- Avaliar os riscos dos cenários de desenvolvimento considerando como padrão o cenário "business as usual". Considerar também o cenário "boas práticas" que deveria refletir a adoção das melhores práticas disponíveis com amplo apoio político para o desenvolvimento social e ambiental.

- Avaliar a cobertura das dimensões espaciais e temporais dos projetos (em andamento e propostos) sobre o meio ambiente e a ecologia da bacia levando em conta o planejamento estratégico de médio e longo prazo na área do projeto e na bacia Satluj inteira.

- Documentar os resultados. 
5.2.6.4 Alinhamento do TR e da Avaliação de Impacto Cumulativo e Induzido em relação a aspectos-chave da $A A E$

(i) Verificação de aspectos-chave associados às AAEs no Termo de Referência e na Avaliação de Impacto Cumulativo e Induzido

Foi observado que o Termo de Referência atende a todos os aspectos-chave fazendo referência e identificação de indicadores, áreas problemáticas, avaliação de alternativas e documentação dos resultados.

Em relação à Avaliação de Impacto Cumulativo e Induzido do Projeto Hidrelétrico Rampur, foi verificado que a avaliação atendeu as todas as etapas mínimas exceto a avaliação de alternativas (Figura 21). A avaliação identificou as questões-chave (indicadores), as áreas problemáticas e documentou os resultados, todavia, apenas foi avaliada a alternativa com o projeto.

Figura 21 - Alinhamento do TR e AICI do Projeto Hidréletrico Rampur

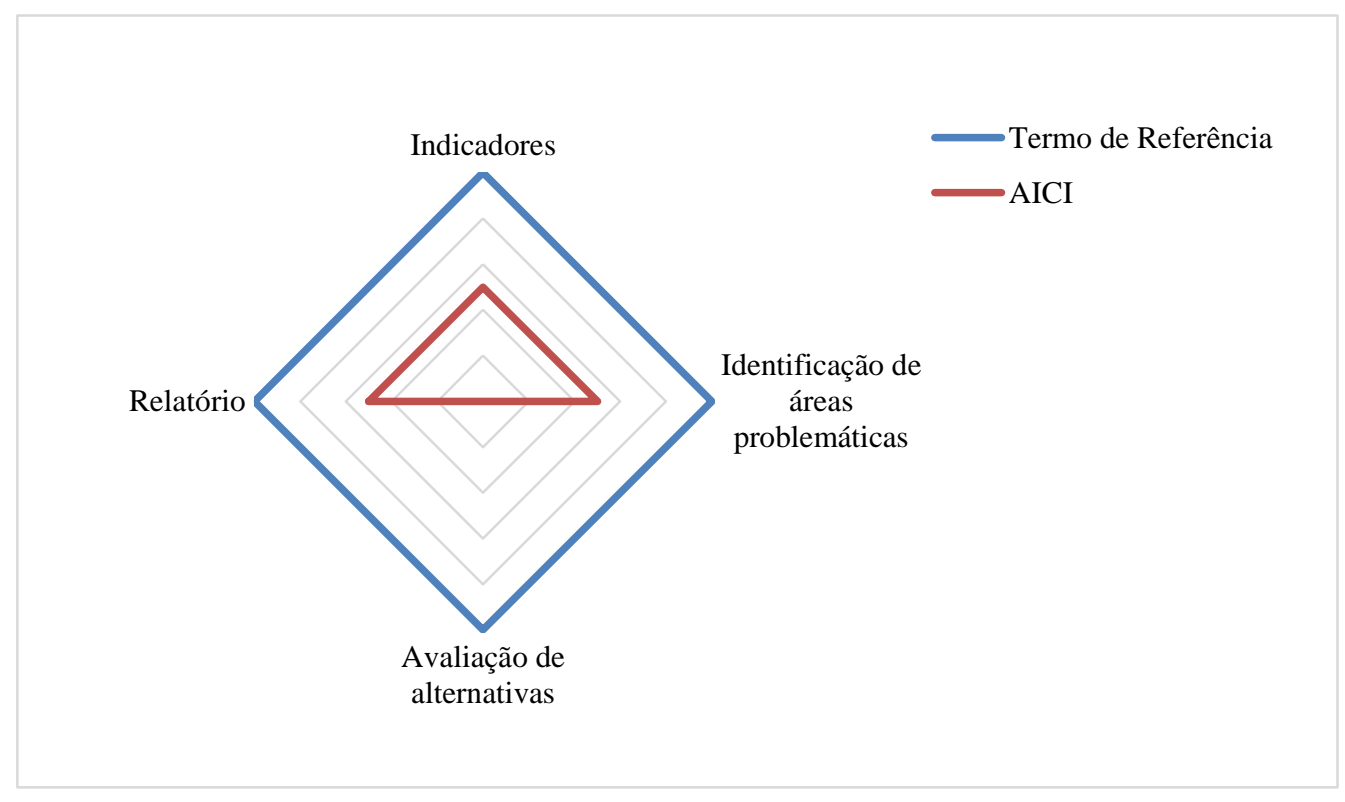

Fonte: Elaborado pelo autor 
(ii) Distanciamento entre TR padrão e TR específico do Projeto hidrelétrico Rampur

Foi observado que todas as tarefas do Termo de Referência padrão foram de alguma forma solicitadas pelo TR específico, exceto requisitos referentes ao contexto de inserção da ação estratégica e ao enquadramento da Avaliação de Impacto Cumulativo e Induzido (Quadro 18).

Quadro 18 - Relação TR padrão e TR específico do Projeto hidrelétrico Rampur

\author{
Tarefas apontadas pelo Termo de Referência padrão
}

Atendimento

Discussão do enquadramento de políticas no âmbito dos quais se efetua a AA. Explicação dos requisitos ambientais e identificação de acordos ambientais internacionais relevantes.

Descrição da ação estratégica proposta (o seu contexto geográfico, ecológico, social e temporal) incluindo quaisquer investimentos fora do local que possam ser necessários (por exemplo, dutos exclusivos, estradas de acesso, usinas geradoras de energia). Indicação da necessidade ou não de planos de reassentamento ou de ações de desenvolvimento para povos indígenas.

Previsão e avaliação dos prováveis impactos positivos e negativos da ação estratégica.

Avaliação das dimensões da área de estudo e descrição das condições físicas, biológicas e socioeconómicas relevantes, incluindo quaisquer alterações previstas para antes do início da ação estratégica. Também levar em consideração atividades de desenvolvimento em curso e propostas dentro da área da ação estratégica, mas não diretamente ligadas à mesma.

Identificação das medidas mitigadoras e quaisquer impactos residuais negativos que não possam ser mitigados. Exploração de oportunidades para melhoria ambiental.

Especificação do plano de monitoramento e de reforço institucional.

Avaliação de impactos ambientais de cada alternativa. Comparação de alternativas viáveis (incluindo a situação sem o projeto) em termos de potenciais impactos ambientais.

Justificativa da escolha de cada alternativa.

Consulta pública: Fazer registo das reuniões ocorridas entre os vários organismos e para obtenção de opiniões das pessoas afetadas pela ação estratégica projeto e de organizações não governamentais (ONG).

Documentação dos resultados

Fonte: Elaborado pelo autor 
(iii) Atendimento de apontamentos do Termo de Referência pela AICI

Foi notado que apenas não foram atendidos elementos referentes a avaliação de cenário e a cobertura temporal. Com efeito, a AICI não avalia o cenário de boas práticas nem o "business as usual" como solicitado no TR. Em relação à cobertura temporal, a Avaliação de Impacto Cumulativo e Induzido não avalia os impactos em uma perspectiva de médio e longo prazo como requerido no Termo de Referência.

\subsubsection{Síntese dos Resultados}

Ao analisar os seis casos analisados (Quadro 19), percebe-se que duas Avaliações Ambientais (do Projeto Energia Manantali e Projeto de Desenvolvimento de Energia Nepal) foram aplicadas antes da adoção formal da AAE na política Ambiental do Banco Mundial.

Em relação ao momento de aplicação da AAE, nota-se que em todos os casos a Avaliação foi aplicada depois da concepção do projeto. Em nenhum caso, a avaliação foi aplicada simultaneamente à concepção do projeto como preconiza as boas práticas da literatura. Também observa-se que todas as avaliações foram aplicadas após os Estudos de Impactos Ambientais em decorrência da percepção das limitações deste instrumento.

Quadro 19 - Informações sobre Avaliações Ambientais analisadas

(Continua)

\begin{tabular}{l|c|c|c|c}
\hline Denominação & $\begin{array}{c}\text { Ano de } \\
\text { aplicação }\end{array}$ & $\begin{array}{c}\text { Momento de } \\
\text { aplicação }\end{array}$ & $\begin{array}{c}\text { Momento de } \\
\text { aplicação em relação } \\
\text { à AIA de projetos }\end{array}$ \\
\hline $\begin{array}{l}\text { Projeto Energia } \\
\text { Manantali }\end{array}$ & $\begin{array}{c}\text { Avaliação } \\
\text { Ambiental } \\
\text { (Categoria A) }\end{array}$ & 1995 & $\begin{array}{c}\text { Após a concepção } \\
\text { do projeto }\end{array}$ & Após duas AIA \\
\hline $\begin{array}{l}\text { Projeto Energia } \\
\text { Gasosa Kribi }\end{array}$ & $\begin{array}{c}\text { Avaliação } \\
\text { Ambiental } \\
\text { Regional } \\
\text { (Categoria A) }\end{array}$ & 2008 & $\begin{array}{c}\text { Após a concepção } \\
\text { do projeto }\end{array}$ & $\begin{array}{c}\text { Após duas AIA } \\
\begin{array}{l}\text { Projeto de } \\
\text { Desenvolvimento } \\
\text { de Energia Nepal }\end{array}\end{array}$ \\
$\begin{array}{l}\text { Avaliação } \\
\text { Ambiental Setorial } \\
\text { (Categoria A) }\end{array}$ & 1997 & $\begin{array}{c}\text { Após a concepção } \\
\text { do projeto }\end{array}$ & $\begin{array}{c}\text { Após um Estudo de } \\
\text { Triagem ambiental } \\
\text { (antes da AIA) }\end{array}$
\end{tabular}


(Conclusão)

\begin{tabular}{l|c|c|c|c}
\hline & Denominação & $\begin{array}{c}\text { Ano de } \\
\text { aplicação }\end{array}$ & $\begin{array}{c}\text { Momento de } \\
\text { aplicação }\end{array}$ & $\begin{array}{c}\text { Momento de } \\
\text { aplicação em relação } \\
\text { à AIA de projetos }\end{array}$ \\
\hline $\begin{array}{l}\text { Projeto } \\
\text { Hidrelétrico } \\
\text { Kabeli « A » }\end{array}$ & $\begin{array}{c}\text { Avaliação de } \\
\text { Impacto } \\
\text { Cumulativo } \\
\text { (Categoria A) }\end{array}$ & 2011 & $\begin{array}{c}\text { Após a concepção } \\
\text { do projeto }\end{array}$ & $\begin{array}{c}\text { Simultaneamente à } \\
\text { AIA } \\
\text { (AIC concluída dois } \\
\text { meses após a AIA) }\end{array}$ \\
\hline $\begin{array}{l}\text { Projeto } \\
\text { Hidrelétrico Nam } \\
\text { Theun 2 }\end{array}$ & $\begin{array}{c}\text { Análise de Impacto } \\
\text { Cumulativo } \\
\text { (Categoria A) }\end{array}$ & 2004 & $\begin{array}{c}\text { Após a concepção } \\
\text { do projeto }\end{array}$ & $\begin{array}{c}\text { Após uma série de } \\
\text { estudos ambientais e } \\
\text { sociais }\end{array}$ \\
\hline $\begin{array}{l}\text { Projeto } \\
\text { Hidrelétrico } \\
\text { Rampur }\end{array}$ & $\begin{array}{c}\text { Avaliação de } \\
\text { Impacto } \\
\text { Cumulativo e } \\
\text { Induzido } \\
\text { (Categoria A) }\end{array}$ & 2006 & $\begin{array}{c}\text { Após a concepção } \\
\text { do projeto }\end{array}$ & Após a AIA \\
\hline
\end{tabular}

Fonte: Elaborado pelo autor

Ao olhar para as Dimensões estratégicas apresentadas pelos projetos (Figura 22), notase que apenas o Projeto de Desenvolvimento de Energia Nepal apresenta todas as dimensões estratégicas de uma ação estratégica. Portanto, pode se afirmar que, sem dúvida, este projeto é uma ação estratégica. Para o restante dos casos, o número de dimensões nos dá indícios da proximidade dos casos com as ações estratégicas ou projetos. Ao observar a figura 22, percebe-se que todos os projetos analisados apresentam a dimensão estratégica "abrangência" e "alternativa". As dimensões "objetivo" e "nível de detalhes" são consideradas em metades dos casos. As dimensões "espaço" e "tempo" são presentes em apenas um caso, o Projeto de Desenvolvimento de Energia Nepal. 
Figura 22 - Dimensões estratégicas apresentadas pelos projetos analisados

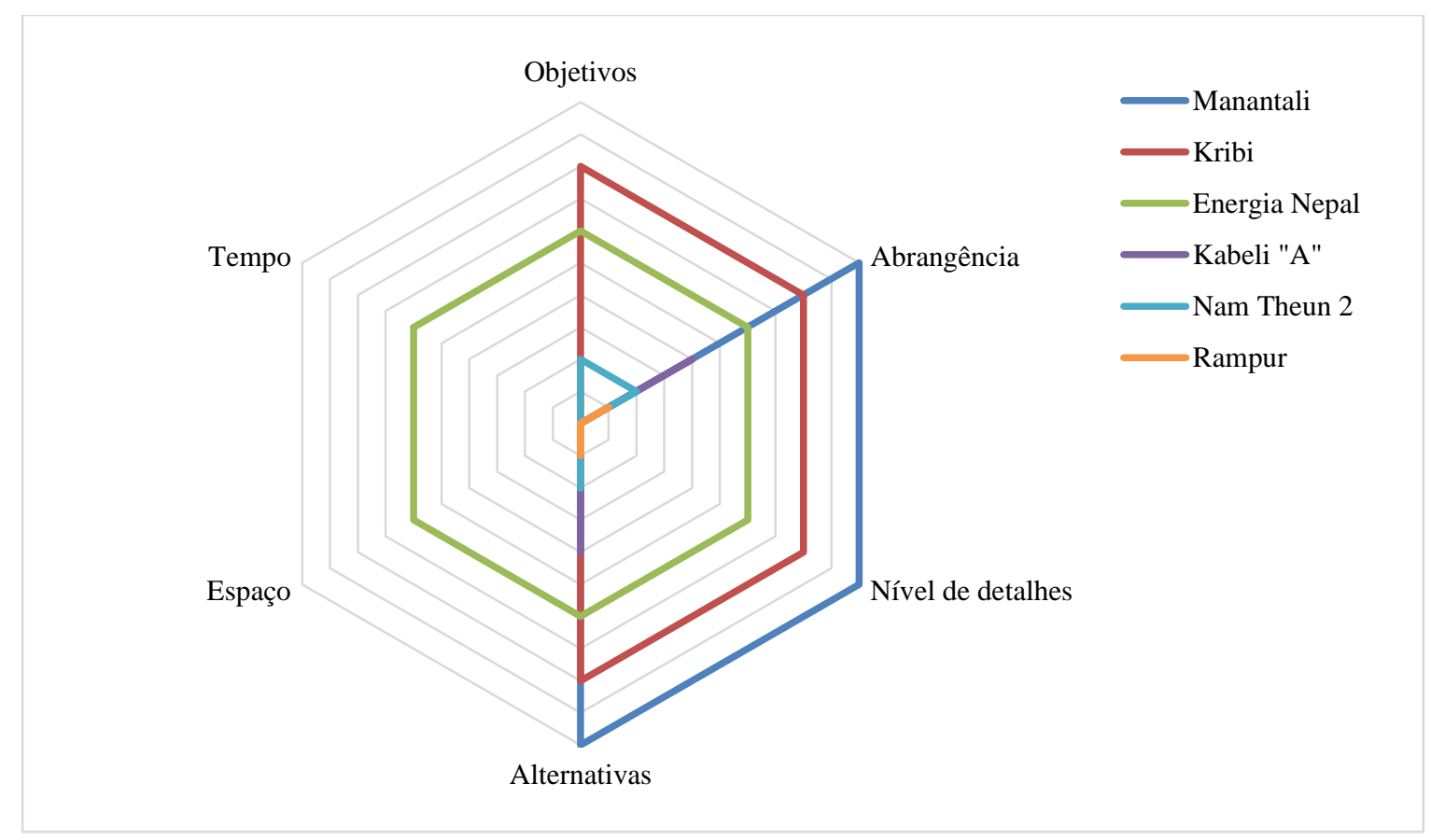

Fonte: Elaborado pelo autor

Em relação ao alinhamento dos termos de referência, percebe-se que a solicitação de documentação dos resultados e a identificação de impactos foram requisitados por todos os TRs. Por outro lado, a identificação de indicadores foi a tarefa menos solicitada sendo apontados em três casos apenas (Figura 23) 
Figura 23 - Alinhamento dos TRs em relação a aspectos-chave da AAE

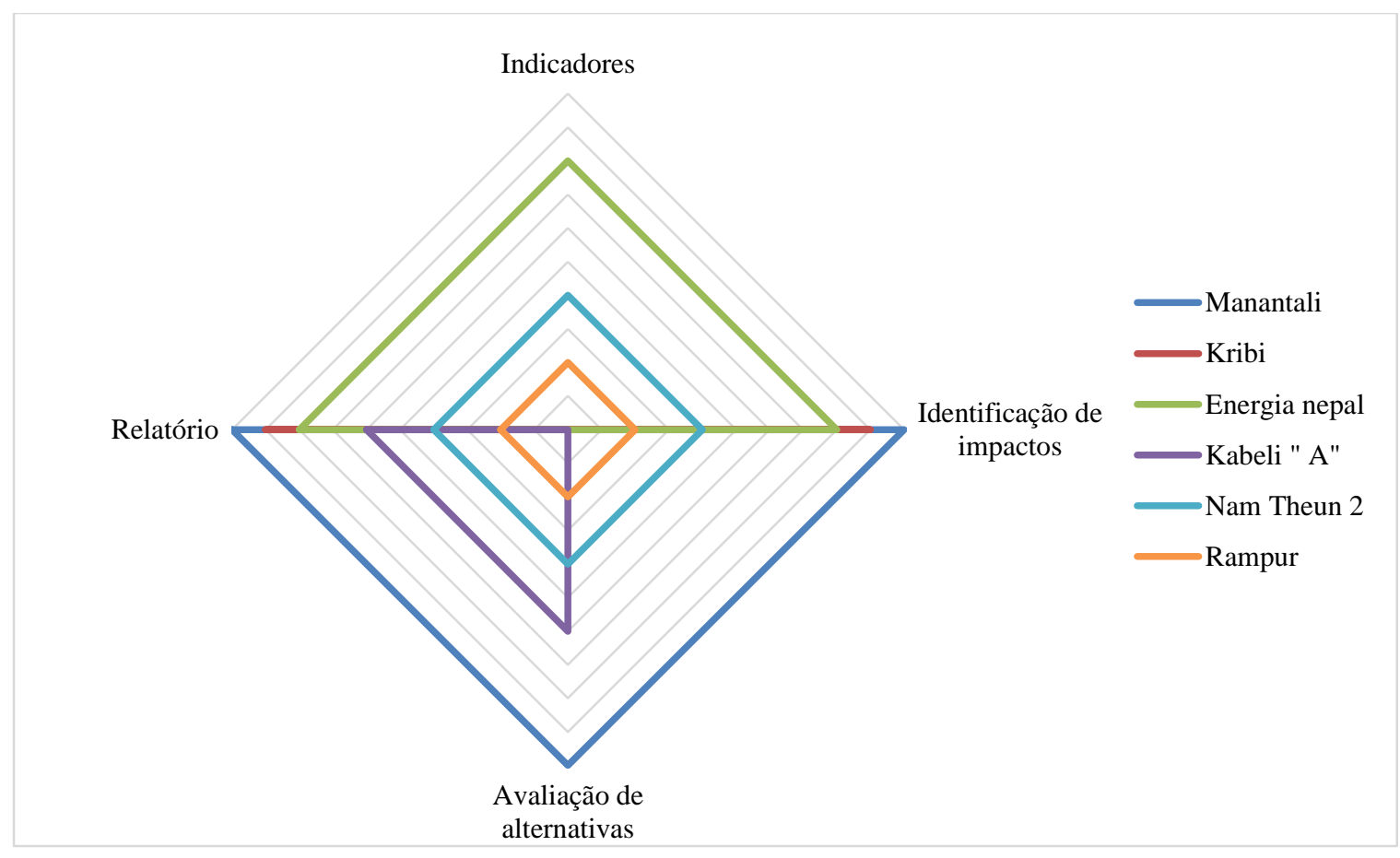

Fonte: Elaborado pelo autor

Ao analisar os resultados gerais relativos ao alinhamento com o que orienta uma AAE (Figura 24), percebe-se que em todos os casos duas etapas foram atendidas (i) identificação de indicadores e (ii) relatório. Também constata-se que a avaliação de alternativas é a etapa que mais foi omitida, seguida da identificação de impactos/áreas problemáticas. A figura 24 evidencia que apenas uma das seis Avaliações Ambientais analisadas atende a todos os requisitos mínimos que orientam uma Avaliação Ambiental Estratégica. 
Figura 24 - Alinhamento das Avaliações Ambientais em relação a aspectos-chave da AAE

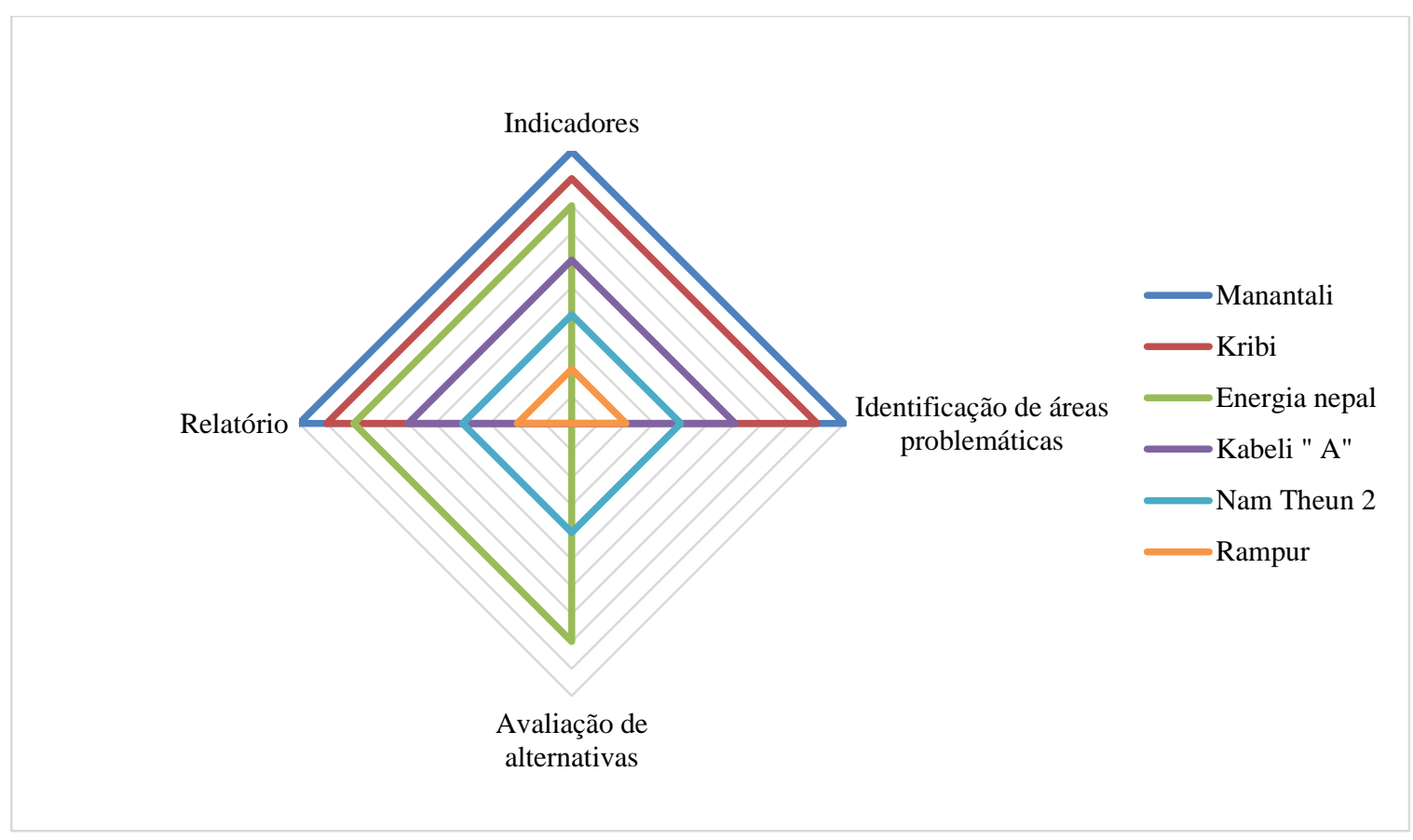

Fonte: Elaborado pelo autor

Quanto ao distanciamento entre o termo de referência padrão e os termos de referência específicos, observou-se que a maioria das tarefas não solicitadas dizem respeito ao enquadramento das Avaliações Ambientais e ao contexto de inserção das ações estratégicas (Quadro 20).

O Quadro 21 mostra os elementos solicitados por cada Termo de Referência. A cor verde representa os elementos atendidos pelas avaliações enquanto os elementos em vermelho mostram elementos não atendidos. A apresentação dos elementos no quadro abaixo não seguem um parâmetro. Os elementos foram organizados por similaridade buscando colocar as mesmas solicitações nas mesmas linhas.

Ao analisar o conjunto dos resultados, percebe-se que em nenhum caso a Avaliação Ambiental atendeu a todos os elementos solicitados pelos Termos de Referência. Todavia, exceto para o Projeto de Desenvolvimento de Energia Nepal e Kabeli "A" nos quais as AA só atenderam a duas das solicitações, para o restante a maioria das solicitações foram atendidas. No caso do Projeto Hidrelétrico Kabeli "A", vale ressaltar que há uma divergência entre o recorte territorial solicitado no TR (bacia inteira) e o recorte devidamente utilizado na avaliação (área sujeita ao trabalho físico) que foi justificada pela inexistência de dados para toda a bacia. 
Quadro 20 - Termo de Referência padrão e Termos de Referência específicos

\begin{tabular}{|c|c|c|c|c|c|c|}
\hline Tarefas apontadas pelo Termo de Referência padrão & Manantali & Kribi & Nepal & Kabeli "A" & $\begin{array}{l}\text { Nam } \\
\text { Theun2 }\end{array}$ & Rampur \\
\hline $\begin{array}{l}\text { Discussão do enquadramento de políticas no âmbito dos quais se efetua a AA. } \\
\text { Explicação dos requisitos ambientais e identificação de acordos ambientais } \\
\text { internacionais relevantes. }\end{array}$ & x & $\boldsymbol{x}$ & & $\mathbf{v}$ & $\sqrt{ }$ & $\mathbf{x}$ \\
\hline $\begin{array}{l}\text { Descrição da ação estratégica proposta (o seu contexto geográfico, ecológico, social e } \\
\text { temporal) incluindo quaisquer investimentos fora do local que possam ser necessários } \\
\text { (por exemplo, dutos exclusivos, estradas de acesso, usinas geradoras de energia). } \\
\text { Indicação da necessidade ou não de planos de reassentamento ou de ações de } \\
\text { desenvolvimento para povos indígenas. }\end{array}$ & x & $\boldsymbol{x}$ & $\checkmark$ & $\boldsymbol{x}$ & & $\boldsymbol{x}$ \\
\hline Previsão e avaliação dos prováveis impactos positivos e negativos da ação estratégica. & $v$ & $\boldsymbol{V}$ & $v$ & & & 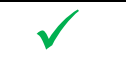 \\
\hline $\begin{array}{l}\text { Avaliação das dimensões da área de estudo e descrição das condições físicas, } \\
\text { biológicas e socioeconómicas relevantes, incluindo quaisquer alterações previstas para } \\
\text { antes do início da ação estratégica. Também levar em consideração atividades de } \\
\text { desenvolvimento em curso e propostas dentro da área da ação estratégica, mas não } \\
\text { diretamente ligadas à mesma. }\end{array}$ & & & & & & 1 \\
\hline $\begin{array}{l}\text { Identificação das medidas mitigadoras e quaisquer impactos residuais negativos que } \\
\text { não possam ser mitigados. Exploração de oportunidades para melhoria ambiental. } \\
\text { Especificação do plano de monitoramento e de reforço institucional. }\end{array}$ & & $\mathbf{v}$ & $\mathbf{v}$ & & $\checkmark$ & $\boldsymbol{v}$ \\
\hline $\begin{array}{l}\text { Avaliação de impactos ambientais de cada alternativa. Comparação de alternativas } \\
\text { viáveis (incluindo a situação sem o projeto) em termos de potenciais impactos } \\
\text { ambientais. Justificativa da escolha de cada alternativa. }\end{array}$ & & $\boldsymbol{x}$ & & $\sqrt{ }$ & $\boldsymbol{v}$ & $\sqrt{ }$ \\
\hline $\begin{array}{l}\text { Consulta pública: Fazer registo das reuniões ocorridas entre os vários organismos e } \\
\text { para obtenção de opiniões das pessoas afetadas pela ação estratégica projeto e de } \\
\text { organizações não governamentais (ONG). }\end{array}$ & & 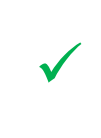 & & 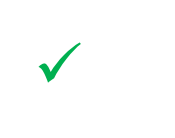 & $\checkmark$ & $\sqrt{ }$ \\
\hline Documentação dos resultados & & $\sqrt{ }$ & 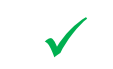 & $\sqrt{ }$ & $\sqrt{ }$ & $\sqrt{ }$ \\
\hline
\end{tabular}


Quadro 21- Elementos solicitados nos Termos de Referência e atendidos pelas Avaliações Ambientais

\begin{tabular}{|c|c|c|c|c|c|}
\hline \multicolumn{6}{|c|}{ Termos de Referência } \\
\hline Manantali & Kribi & Energia Nepal & Kabeli « A » & Nam Theun 2 & Rampur \\
\hline \multirow{3}{*}{ Descrição da baseline } & \multirow{3}{*}{-} & \multirow{3}{*}{-} & \multirow{3}{*}{$\begin{array}{l}\text { Descrever questões de } \\
\text { salvaguarda }\end{array}$} & Preparação de baseline & Cobertura espacial \\
\hline & & & & Cobertura temporal & \multirow{2}{*}{ Cobertura temporal } \\
\hline & & & & Cobertura espacial & \\
\hline $\begin{array}{l}\text { Descrição de elementos } \\
\text { presentes nos corredores }\end{array}$ & - & Avaliação da área de estudo & $\begin{array}{l}\text { Identificar e descrever } \\
\text { impactos }\end{array}$ & - & - \\
\hline $\begin{array}{l}\text { Identificação de áreas } \\
\text { críticas }\end{array}$ & $\begin{array}{c}\text { Análise de efeito estufa e } \\
\text { mudanças climáticas }\end{array}$ & Avaliação de impacto & - & Avaliação de impacto & $\begin{array}{l}\text { Identificação de } \\
\text { questões-chave }\end{array}$ \\
\hline $\begin{array}{l}\text { Avaliação de } \\
\text { alternativas }\end{array}$ & - & Avaliação de alternativas & Descrever alternativas & $\begin{array}{l}\text { Avaliação de } \\
\text { alternativas }\end{array}$ & $\begin{array}{l}\text { Avaliação de } \\
\text { alternativas }\end{array}$ \\
\hline Participação Pública & Participação Pública & Participação Pública & Consulta pública & Consulta pública & Consulta pública \\
\hline $\begin{array}{l}\text { Mitigação e } \\
\text { Monitoramento }\end{array}$ & - & Mitigação e Monitoramento & $\begin{array}{l}\text { Mitigação e } \\
\text { monitoramento }\end{array}$ & - & - \\
\hline- & $\begin{array}{c}\text { Plano de } \\
\text { Desenvolvimento }\end{array}$ & $\begin{array}{l}\text { Enquadramento Político e } \\
\text { descrição do projeto }\end{array}$ & - & - & - \\
\hline
\end{tabular}

Elemento solicitado pelo TR e atendido pela AA

Fonte: Elaborado pelo autor

Elemento Solicitado pelo TR, mas não atendido pela AA 


\subsubsection{Discussão}

Para o conjunto de casos selecionados, verificou-se que os anos de aplicações das avaliações são bem distribuídos ao longo do tempo. Encontram-se aplicações realizadas antes e depois da adoção da AAE nas políticas ambientais das agências de fomento. Em relação aos locais de aplicação, temos dois casos no continente africano e quatro casos na Ásia.

Em relação ao momento de aplicação da avaliação, nenhum caso seguiu as boas práticas recomendadas na literatura. O ideal é iniciar o processo de Avaliação Ambiental Estratégica no começo do processo de tomada de decisão, isto é, na identificação dos objetivos da ação estratégica (THERIVEL, 2004). Todos os casos analisados pecaram neste quesito. Também não foi respeitado o momento de aplicação da AAE em relação à Avaliação de Impacto Ambiental de projetos. Apenas em um caso, Projeto de Desenvolvimento de Energia Nepal, a Avaliação Ambiental Setorial foi aplicada antes da AIA de projetos. Constata-se que a maioria dos casos não respeita, nesta questão, as boas práticas preconizadas na literatura. Idealmente, a AAE e a AIA de projeto devem ser aplicadas em sequência (BINA, 2007; VERHEEM; TONK, 2000), sendo que a AAE examina proativamente uma gama de alternativas e escolhe o melhor curso de ação. A avaliação de projeto é então iniciada para determinar com mais detalhes os potenciais impactos e opções de implementação da "melhor" alternativa (NOBLE, 2009; PARTIDÁRIO, 2007). Pellin et al. (2011) destacam essa falha ao apontar as limitações gerais do estudo de Avaliação Ambiental Estratégica do Complexo do Rio Madeira. Para esse empreendimento, no momento de elaboração da AAE, decisões sobre o planejamento setorial já tinham sido tomadas, e o processo de licenciamento já estava em andamento.

É preciso ressaltar que em todos os casos, exceto o Projeto de Desenvolvimento de Energia Nepal, as Avaliações Ambientais Estratégicas foram solicitadas para paliar as limitações das AIAs de projetos previamente aplicadas. De fato, a AAE pode preencher as lacunas da AIA de projeto (ALSHUWAIKHAT, 2005; FISCHER, 2003; LEE; WALSH, 1992; PARTIDÁRIO, 1996). No entanto, para isso, esse instrumento deve preceder a AIA de projeto. A aplicação tardia é uma oportunidade perdida de usufruir dos benefícios proporcionados por esta ferramenta. Para Pellin et al. (2011), a AAE é solicitada por AMD como requisito para aprovação ou não de concessão de financiamento e é realizada muito tarde quando decisões estratégicas já são tomadas. Assim sendo, estas práticas têm atribuído a essas avaliações um caráter estratégico do qual não estão revestidos, contribuindo para a 
disseminação de um conceito equivocado de AAE. Contudo, vale ressaltar que o fato de recorrer à Avaliação Ambiental Estratégica após as AIA de projetos mostra um reconhecimento por parte dos responsáveis da importância de tipo de avaliação. Lições aprendidas poderão levar a uma futura inserção da AAE no momento adequado no processo de planejamento.

\subsubsection{Caracterização do Nível estratégico de Projetos Analisados}

Ao olhar para as dimensões estratégicas apresentadas pelos projetos analisados (Figura 22), nota-se que as dimensões abrangência e alternativas são consideradas em todos os projetos analisados. Em relação à dimensão alternativa, os resultados obtidos mostram que o planejamento de projetos analisados não envolvem apenas alternativas estratégicas. Essas últimas, muitas vezes, apresentaram também elementos não estratégicos. Isso pode ser visto no caso do projeto hidrelétrico Nam Theun 2 e Rampur nos quais algumas alternativas são estratégicas (envolvendo outras fontes energéticas entre outros), ao mesmo tempo também foram consideradas alternativas locacionais e operacionais não estratégicas.

Os resultados obtidos mostram também que as dimensões nível de detalhes e objetivo foram consideradas em metade dos casos analisados. No entanto, as dimensões espaço e tempo só são levadas em consideração em um caso. Analisando individualmente os projetos, verifica-se que apenas o Projeto de Desenvolvimento de Energia Nepal apresenta todas as dimensões estratégicas de uma ação estratégica. Para o restante dos casos, o número de dimensões nos dá indícios da proximidade dos casos com as ações estratégicos e/ou projetos. Segundo Baptista (2007), todos os Programas, Planos e Políticas devem apresentar todas as dimensões estratégicas. Contudo, a ausência de determinadas dimensões caracteriza o instrumento como de baixo alcance estratégico. Assim sendo, pode se afirmar que o Projeto Hidrelétrico Rampur e Projeto Hidrelétrico Kabeli «A » ao estabelecerem com enfoque estratégico somente as dimensões 'Abrangência' e 'Alternativas', constituem objetos de alcance estratégico restrito. Por outro lado, o modo como foram descritas as quatro dimensões estratégicas identificadas para o Projeto Energia Gasosa Kribi sinaliza para um objeto de maior alcance estratégico. 


\subsubsection{Alinhamento dos TRs e das AAs em relação a aspectos-chave da AAE}

\section{(i) Verificação de aspectos-chave associados às AAEs nos Termos de Referência e nas Avaliações Ambientais}

Ao analisar os resultados gerais relativos aos requisitos mínimos de uma AAE (Figura 23 e 24), constata-se que apenas uma das seis Avaliações Ambientais analisadas apresenta todos os requisítos mínimos de uma Avaliação Ambiental Estratégica. Percebe-se que em todos os casos duas etapas foram atendidas: (a) identificação de indicadores e (b) relatório. Também nota-se que a avaliação de alternativas é a etapa que mais foi omitida, seguida da identificação de impactos/áreas problemáticas. No tocante aos termos de referência, estes solicitam os requisitos mínimos na maioria dos casos.

A falta de consideração de alternativas nos processos de Avaliação Ambiental Estratégica não é exclusiva aos países em desenvolvimento. A revisão da qualidade de relatórios feita por Fischer (2011) revela deficiências no que diz respeito à identificação e consideração de alternativas pelas Avaliações Ambientais Estratégicas de planos ingleses de ordenamento territorial. Ao analisar AAEs de planejamento de recursos minerais na Dinamarca, Bidstrup e Hansen (2014) também constataram falhas na consideração de alternativas. Segundo os autores, a documentação e a má interpretação da legislação dinamarquês são barreiras que dificultam o alinhamento da prática com as recomendações de boas práticas sobre alternativas. Para Alshuwaikhat (2005), a falta de discussões sobre alternativas pelos tomadores de decisão dificulta a boa aplicação da AAE em muitos países em desenvolvimento. Para Lobos e Partidário (2014), a inserção tardia da AAE na arena de tomada de decisões limita a sua constribuição para decisões estratégicas, limitando a avaliação a se debruçar sobre alternativas de desenvolvimento. Percebe-se a necessidade de olhar com mais atenção para alternativas no âmbito das AAEs, a fim de superar as suas limitações alinhando, desta forma, as aplicações com as boas práticas.

Ao contrário de alternativas que não foram atendidas, a identificação de indicadores e a documentação de resultados se destacaram positivamente. Para Fischer (2007) e Therivel (2004), indicadores são importantes para descrição e monitoramento de baseline assim como para previsão de impactos. Quanto ao relatório, eles são importantes, pois documentam os resultados obtidos e constituem fontes de consulta para os tomadores de decisão (THERIVEL, 2004). 
(ii) Distanciamento entre o TR padrão e TRs específicos

Constatou-se que na maioria dos casos analisados, as tarefas do termo de referência padrão são adaptadas aos contextos de aplicação. Isso demostra uma boa prática uma vez que as aplicações devem ser voltadas para as especificidades encontradas. IAIA (1999) recomenda que o processo de AAE seja adaptado às realidades, assuntos e circunstâncias do objeto avaliado. Dalal-Clayton e Sadler (2005), João e Mclauchlan (2014), Lobos e Partidário (2014) e Verheem e Tonk (2000) também têm realçado a necessidade de adaptar a AAE aos diferentes contextos, a fim de que ela contribua para a tomada de decisão e, a longo prazo, mude valores, condutas e comportamentos de atores e instituições.

Considerando os TRs como elementos de mediação entre os objetos avaliados e as avaliações ambientais, cabe a eles orientar as avaliações. As adaptações constatadas em algumas situações é um aspecto encorajador, uma vez que é compatível com as boas práticas preconizadas na literatura. Contudo, vale ressaltar que uma adaptação extrema pode levar a AAE a perder a sua essência, isto é, o seu caráter estratégico. Portanto, a adaptação ao contexto deve ter limites. Isso é importante, pois supostamente o termo de referência irá influenciar de modo intenso a Avaliação Ambiental.

\section{(iii) Atendimento de apontamentos do Termo de Referência pela AA}

No quadro 21, verifica-se que nenhum caso seguiu todas as recomendações do TR específico. O fato de não atender a todas as aplicações pode revelar uma adaptação às situações enfrentadas. Os termos de referência específicos nem sempre levam em consideração todas as minúcias do contexto no qual se insere o objeto avaliado. Como observado no caso do Projeto Energia Gasosa Kribi, as dificuldades encontradas ao aplicar a AA levaram os consultores a se adaptarem aos obstáculos enfrentados deixando de atender a certos requisitos do TR.

O projeto hidrelétrico Kabeli "A" é um caso atípico que merece uma atenção particular. O TR da Avaliação de Impacto Cumulativo do projeto não foi emitido pela AMD, mas pelas autoridades nepalesas responsáveis pelo projeto. Como mostrado nos resultados, a AIC não atendeu a solicitação do TR de avaliar exclusivamente a bacia do rio Kabeli "A". Ao invés disso, devido a indisponibilidade de dados a avaliação se debruçou pouco sobre a bacia dando maior ênfase para o projeto, ao ponto da avaliação denominar-se Avaliação de Impacto Cumulativo do Projeto Hidrelétrico Kabeli “A”. Percebe-se que os consultores tiveram mais 
liberdade em relação à condução da avaliação ambiental, optando pela melhor abordagem em função da disponibilidade de dados. Embora, isso possa ser visto como uma perda de oportunidade da AIC paliar as limitações das AIA previamente realizadas, essa situação revela uma adaptação ao contexto encontrado uma vez que os consultores adequaram a aplicação aos problemas enfrentados. Isto ilustra uma initiativa no sentido de adaptar a AA ao contexto como preconiza a literatura adaptação ao contexto de aplicação (ver JOÃO; MCLAUCHLAN, 2014; LOBOS; PARTIDÁRIO, 2014; VERHEEM; TONK, 2000).

\subsection{Revisão de qualidade de relatórios de Avaliações Ambientais}

\subsubsection{Revisão de qualidade do relatório da Avaliação Ambiental do Projeto Energia Manantali}

A análise de qualidade do relatório (Quadro 22) mostra que de modo geral esse último apresenta informações de maneira estritamente suficiente para a tomada de decisão. Com efeito, a primeira seção apresenta informações de forma insatisfatória (nota F). A avaliação menciona os objetivos da ação estratégica, no entanto não apresenta os seus próprios objetivos. Isto é uma grande omissão que se percebe de imediato.

Na seção 2 (nota $\mathrm{C}$ ), as informações apresentam algumas omissões, entre outros, a consulta aos atores-chave na definição do escopo que não foi feita. A terceira seção (nota $F$ ) tem importantes critérios mal atendidos. Os métodos utilizados para levantamento de baseline não são mencionados. Além disso, não foi apresentado o ambiente onde seria construído a represa, mas sim apenas a fauna, flora e população dos locais de implantação das Linhas de Transmissão.

$\mathrm{Na}$ seção 4 (nota B), as informações são apresentadas de forma adequada sem importantes omissões. A avaliação relaciona os objetivos do Projeto Manantali aos do projeto Diama, uma vez que os dois tem a mesma perspectiva de promover o desenvolvimento na região do Rio Senegal.

Na seção 5 (nota B) há algumas omissões. A avaliação não considera a alternativa sem o projeto. O estudo só considera alternativas locacionais das LTs. Não houve consideração de alternativa com energia térmica embora esta tenha sido considerada na concepção do projeto e sua avaliação solicitada no TR. 
Nas seções 6 (nota B) e 7 (nota A), as informações são adequadamente apresentadas de forma geral. As avaliações condizem com a literatura sendo as suas informações assim como as das medidas de mitigação e monitoramento satisfatoriamente apresentadas.

Na seção 8 (nota F), destacam-se deficiências na consulta pública. Com efeito, o público foi consultado antes da avaliação para que fique sabendo das características do projeto e opine sobre este. Uma segunda consulta não foi feita para que a população opine sobre os impactos do projeto.

Na seção 9 (nota B), as informações são adequadamente apresentadas. O relatório é bem estruturado e não contem importantes omissões. 


\section{Quadro 22 - Revisão de qualidade do relatório da Avaliação Ambiental do Projeto Energia Manantali}

(Continua)

\begin{tabular}{|c|c|c|c|}
\hline & Critério & Nota & Comentários \\
\hline & Seção 1 - Objetivos & & \\
\hline 1 & Descreve o conteúdo e os objetivos principais da ação estratégica. & A & $\begin{array}{l}\text { Os objetivos são apresentados na pg } 18 \text { e são de acordo com os } \\
\text { objetivos elencados no Project Information Document. }\end{array}$ \\
\hline 2 & $\begin{array}{l}\text { Os objetivos da AAE são apresentados, relacionados aos } \\
\text { indicadores e metas se for o caso. }\end{array}$ & G & $\begin{array}{l}\text { O relatório se refere ao TR (que define os objetivos da } \\
\text { avaliação) (pg 12-17), porém não menciona o objetivo da } \\
\text { Avaliação Ambiental. }\end{array}$ \\
\hline \multirow[t]{3}{*}{3} & $\begin{array}{l}\text { Os objetivos e indicadores da AAE cobrem uma gama adequada de } \\
\text { temas ambientais/de sustentabilidade, incluindo a biodiversidade, } \\
\text { população, saúde humana, fauna, flora, solo, água, ar, fatores } \\
\text { climáticos, o património cultural, paisagístico e suas inter-relações. } \\
\text { Eles integram as questões ambientais, sociais e econômicos. }\end{array}$ & G & $\begin{array}{l}\text { Os objetivos da Avaliação Ambiental não são apresentados no } \\
\text { relatório. Porém, o Termo de referência (anexado ao relatório) } \\
\text { sugere alguns objetivos. Estes são genéricos, isto é, focalizados } \\
\text { nos impactos do projeto de forma geral. }\end{array}$ \\
\hline & Avaliação da Seção 1 & $\mathrm{~F}$ & Importantes omissões. \\
\hline & Seção 2 - Escopo & & \\
\hline 4 & $\begin{array}{l}\text { Autoridades competentes e apropriadas são consultadas para a } \\
\text { determinação do alcance e nível de informações que devem ser } \\
\text { incluídas no relatório AAE. }\end{array}$ & G & $\begin{array}{l}\text { Os tomadores de decisão foram envolvidos para apontar } \\
\text { prováveis problemas ambientais. Porém, esse envolvimento não } \\
\text { teve o intuito de definir o escopo da Avaliação Ambiental e } \\
\text { informações do relatório, mas sim esclarecer os consultores } \\
\text { ambientais sobre o escopo e os objetivos do Projeto (pg 27). }\end{array}$ \\
\hline 5 & $\begin{array}{l}\text { A AAE se concentra em questões importantes e desconsidera as } \\
\text { menos significativas. As razões de desconsideração devem ser } \\
\text { documentadas. }\end{array}$ & $\mathrm{B}$ & $\begin{array}{l}\text { A Avaliação Ambiental tem uma abordagem focalizada nos } \\
\text { aspectos relacionados aos impactos relevantes. Os demais } \\
\text { impactos não são abordados. }\end{array}$ \\
\hline
\end{tabular}


(Continuação)

\begin{tabular}{|c|c|c|c|}
\hline & Critério & Nota & Comentários \\
\hline 6 & Alternativas razoáveis estabelecidas. & A & $\begin{array}{l}\text { A Avaliação Ambiental propõe alternativas de rotas diferentes } \\
\text { às sugeridas no projeto no que diz respeito aos traçados das } \\
\text { linhas de Transmissão. A Avaliação Ambiental também propõe } \\
\text { alternativas de gestão da água do reservatório para conciliar } \\
\text { produção de energia elétrica e agricultura (pg 162). }\end{array}$ \\
\hline \multirow[t]{3}{*}{7} & $\begin{array}{l}\text { Técnicas, dificuldades processuais e outros problemas (tais como } \\
\text { deficiências técnicas ou falta de know-how) são discutidos. } \\
\text { Suposições e incertezas são explicitadas. }\end{array}$ & A & $\begin{array}{l}\text { O relatório menciona dificuldades em relação à incerteza de } \\
\text { alguns aspectos tais como colisão de aves com as Linhas de } \\
\text { Transmissão, doença decorrentes da exposição de moradores e } \\
\text { trabalhadores ao campo magnético de Linha de Transmissão, } \\
\text { reação de moradores quando interagirem com a mão de obra } \\
\text { durante a fase de construção, etc. (pg 174). }\end{array}$ \\
\hline & Avaliação da Seção 2 & $\mathrm{C}$ & Simplesmente satisfatória. \\
\hline & Seção 3 - Baseline & & \\
\hline 8 & $\begin{array}{l}\text { Aspectos pertinentes do estado atual do ambiente receptor da ação } \\
\text { estratégica e a sua provável evolução, sem a ação estratégica são } \\
\text { descritos. Características ambientais das zonas susceptíveis de } \\
\text { serem significativamente afetadas são descritas com mais detalhes. }\end{array}$ & B & $\begin{array}{l}\text { As características do ambiente receptor são bem apresentadas. } \\
\text { Porém, não há menção de cenário ambiental futuro sem ação } \\
\text { estratégica. }\end{array}$ \\
\hline 9 & $\begin{array}{l}\text { Os objetivos de AAE e dados de coleta da baseline se reforçam } \\
\text { mutuamente. }\end{array}$ & $\mathrm{G}$ & $\begin{array}{l}\text { Não há menção de objetivos da Avaliação Ambiental. Portanto, } \\
\text { não há correlação da baseline com os objetivos. }\end{array}$ \\
\hline \multirow[t]{2}{*}{10} & $\begin{array}{l}\text { Os métodos utilizados para levantar a baseline são adequados à } \\
\text { abrangência e complexidade da avaliação. }\end{array}$ & $\mathrm{G}$ & $\begin{array}{l}\text { Nenhuma menção de métodos utilizados para levantamento de } \\
\text { dados da Baseline. }\end{array}$ \\
\hline & Avaliação da Seção3 & $\mathrm{F}$ & Importantes omissões. \\
\hline
\end{tabular}


(Continuação)

\begin{tabular}{|c|c|c|c|}
\hline & Seção 4 - Links para outras ações estratégicas & Nota & Comentários \\
\hline 11 & $\begin{array}{l}\text { As relações entre a ação estratégica e os níveis anteriores e } \\
\text { posteriores (na cadeia de tomada de decisão) são identificadas e } \\
\text { explicadas. }\end{array}$ & B & $\begin{array}{l}\text { O relatório menciona o projeto da represa Diama (Senegal). Este } \\
\text { é mencionado apenas para ressaltar os objetivos comuns que } \\
\text { tem com o Projeto Energia Manantali. A relação entre os dois } \\
\text { projetos poderia ser melhor explicada (pg 131). }\end{array}$ \\
\hline \multirow[t]{3}{*}{12} & $\begin{array}{l}\text { Aspectos que geram conflitos entre as ações estratégicas são } \\
\text { claramente documentados; e são feitas recomendações sobre como } \\
\text { conciliar as ações estratégicas, de modo a promover a } \\
\text { sustentabilidade. }\end{array}$ & $\mathrm{n} / \mathrm{a}$ & Não se aplica. \\
\hline & Avaliação da Seção 4 & B & Bem apresentado de maneira geral. \\
\hline & Seção 5 - Alternativas & & \\
\hline 13 & $\begin{array}{l}\text { As alternativas consideradas são apropriadas para a escala } \\
\text { (internacional, nacional, etc.) e o nível (Política, Plano, Programa) } \\
\text { da tomada de decisão. }\end{array}$ & $\mathrm{C}$ & $\begin{array}{l}\text { A descrição do projeto menciona a consideração de energia } \\
\text { térmica como alternativa ao projeto. No entanto, essa alternativa } \\
\text { não foi avaliada pela Avaliação Ambiental. Esta última também } \\
\text { não avalia alternativa sem o projeto. Os cenários avaliados se } \\
\text { referem aos traçados das Linhas de Transmissão e à gestão de } \\
\text { lançamento da água do reservatório (pg 162) }\end{array}$ \\
\hline 14 & $\begin{array}{l}\text { As alternativas consideradas lidam com as questões identificadas na } \\
\text { baseline e / ou buscam alcançar metas de sustentabilidade. }\end{array}$ & A & $\begin{array}{l}\text { As alternativas propostas pela Avaliação Ambiental consideram } \\
\text { a Baseline. As rotas sugeridas levam em consideração a flora e } \\
\text { fauna. }\end{array}$ \\
\hline 15 & $\begin{array}{l}\text { As alternativas incluem o "não fazer nada", "fazer o mínimo" e } \\
\text { "alternativas mais benéficas ao ambiente". }\end{array}$ & G & Alternativa sem o projeto não considerada. \\
\hline
\end{tabular}


(Continuação)

\begin{tabular}{|c|c|c|c|}
\hline & Critério & Nota & Comentários \\
\hline 16 & $\begin{array}{l}\text { As razões para descartar alternativas de maiores considerações são } \\
\text { apresentadas. }\end{array}$ & B & $\begin{array}{l}\text { A Avaliação Ambiental não elimina alternativas, mas menciona } \\
\text { os seus pontos negativos e os contrapõe aos pontos positivos da } \\
\text { alternativa mais favorável (pg 162). }\end{array}$ \\
\hline \multirow[t]{3}{*}{17} & $\begin{array}{l}\text { Os efeitos ambientais e de sustentabilidade de cada alternativa são } \\
\text { identificados e comparados. }\end{array}$ & A & $\begin{array}{l}\text { Os impactos das diferentes alternativas são devidamente } \\
\text { identificados, avaliados e comparados aos impactos de outras } \\
\text { alternativas. }\end{array}$ \\
\hline & Avaliação da Seção 5 & $\mathrm{C}$ & Alternativas bem apresentadas de forma geral. \\
\hline & Seção 6 - Identificação e avaliação de Impactos & & \\
\hline 18 & $\begin{array}{l}\text { Os prováveis impactos significativos sobre o meio ambiente são } \\
\text { identificados e avaliados. }\end{array}$ & B & $\begin{array}{l}\text { Os impactos são identificados e avaliados. As suas } \\
\text { probabilidades são apontados. Os impactos são relacionados às } \\
\text { fases que ocorrerão. Os pontos positivos e negativos dos } \\
\text { cenários são ressaltados. }\end{array}$ \\
\hline 19 & $\begin{array}{l}\text { Prováveis impactos indiretos, cumulativos, sinérgicos e secundários } \\
\text { são identificados e avaliados. }\end{array}$ & B & $\begin{array}{l}\text { Efeitos indiretos são pouco mencionados. Impactos } \\
\text { cumulativos, sinergéticos e secundários não são avaliados. } \\
\text { Embora o projeto envolva três países, os impactos de cada uma } \\
\text { das três linhas de transmissão são restritos aos respectivos países } \\
\text { receptores. Portanto, o relatório não menciona impactos } \\
\text { ambientais Transfronteiriços. }\end{array}$ \\
\hline 20 & $\begin{array}{l}\text { Foram utilizadas adequadas técnicas de previsão de impacto e de } \\
\text { avaliação. A avaliação do impacto condiz com as normas e } \\
\text { regulamentos aceitos internacionalmente. }\end{array}$ & B & $\begin{array}{l}\text { Métodos utilizados não mencionados. Porém, a avaliação de } \\
\text { impactos está de acordo com a literatura que é mencionada ao } \\
\text { longo do relatório. }\end{array}$ \\
\hline & Avaliação da Seção 6 & B & Bem apresentado de maneira geral. \\
\hline
\end{tabular}


(Continuação)

\begin{tabular}{|c|c|c|c|}
\hline & Seção 7 - Mitigação e monitoramento & Nota & Comentários \\
\hline 21 & $\begin{array}{l}\text { As medidas previstas para evitar, reduzir, compensar e/ou melhorar } \\
\text { quaisquer impactos significativos da ação estratégica são indicadas. }\end{array}$ & A & $\begin{array}{l}\text { A Avaliação Ambiental apresenta um plano de gestão ambiental } \\
\text { com medidas de mitigação (pg 125). }\end{array}$ \\
\hline 22 & Medidas de monitoramento dos impactos são explicitadas. & A & $\begin{array}{l}\text { Medidas de monitoramento se encontram no plano de gestão } \\
\text { ambiental e são relacionadas ao levantamento de dados da } \\
\text { baseline, uma vez que esses dados são importantes para a gestão } \\
\text { do reservatório. }\end{array}$ \\
\hline \multirow[t]{3}{*}{23} & Links para AIA de projetos e outras AAE são explicitados. & $\mathrm{n} / \mathrm{a}$ & $\begin{array}{l}\text { Não há nenhuma menção de posteriores AIA de projetos ou } \\
\text { AAE. }\end{array}$ \\
\hline & Avaliação da Seção 7 & A & Satisfatório. \\
\hline & Seção 8 - Consulta & & \\
\hline 24 & $\begin{array}{l}\text { As autoridades ambientais e outras e o público é dada a } \\
\text { oportunidade, dentro de um prazo adequado, de expressar a sua } \\
\text { opinião sobre a AAE antes da adoção da ação estratégica. }\end{array}$ & $\mathrm{E}$ & $\begin{array}{l}\text { O público foi consultado para que fique sabendo das } \\
\text { características do projeto (pg 28). Uma segunda consulta não foi } \\
\text { feita para que a população opine sobre a avaliação dos impactos } \\
\text { do projeto. }\end{array}$ \\
\hline \multirow[t]{3}{*}{25} & $\begin{array}{l}\text { Os órgãos públicos e relevantes tiveram uma resposta sobre suas } \\
\text { colocações. }\end{array}$ & $\mathrm{G}$ & $\begin{array}{l}\text { Não realizado. O público foi consultado para opinar a respeito } \\
\text { do projeto. Porém, as suas preocupações não foram respondidas. }\end{array}$ \\
\hline & Avaliação da Seção 8 & $\mathrm{~F}$ & Processo de consulta insatisfatório. \\
\hline & Seção 9 - Relatório de AAE & & \\
\hline 26 & O relatório descreve como a AAE foi realizada. & A & $\begin{array}{l}\text { O relatório descreve satisfatoriamente como a Avaliação } \\
\text { Ambiental foi conduzida. }\end{array}$ \\
\hline
\end{tabular}


(Conclusão)

\begin{tabular}{|c|c|c|c|}
\hline & Critério & Nota & Comentários \\
\hline 27 & $\begin{array}{l}\text { O relatório identifica o tomador de decisão e a entidade que } \\
\text { realizou a AAE. }\end{array}$ & $\mathrm{B}$ & $\begin{array}{l}\text { A Avaliação Ambiental foi solicitada pelo Banco Mundial como } \\
\text { requisito para concessão de financiamento. O mutuário é a } \\
\text { Organização para o Desenvolvimento do Rio Senegal. Porém, } \\
\text { não ha menção da consultoria/instituição que realizou a } \\
\text { avaliação. }\end{array}$ \\
\hline 28 & $\begin{array}{l}\text { O relatório é claro e conciso em seu layout e apresentação, É } \\
\text { apresentado como um todo integrado, e usa mapas e outras } \\
\text { ilustrações quando necessário. }\end{array}$ & $\mathrm{B}$ & $\begin{array}{l}\text { Relatório claro e conciso. No entanto, há pouco uso de mapa na } \\
\text { seção de avaliação de impactos. O texto é muito descritivo. O } \\
\text { uso de mapa ajudaria principalmente na visualização da } \\
\text { localização exata das linhas de transmissão. }\end{array}$ \\
\hline 29 & No relatório, a linguagem usada é simples e clara. & A & Linguagem boa e clara. \\
\hline 30 & $\begin{array}{l}\text { O relatório descreve a metodologia utilizada na AAE, inclusive } \\
\text { quem foi consultado e como. }\end{array}$ & G & $\begin{array}{l}\text { Não ha menção de metodologia usada para levantamento de } \\
\text { dados da Baseline nem para avaliação de impactos. }\end{array}$ \\
\hline 31 & O relatório se concentra nas grandes questões. & A & A Avaliação Ambiental é focalizada em aspectos relevantes. \\
\hline \multirow[t]{2}{*}{32} & O relatório está escrito, sem viés de forma imparcial. & A & Bem escrito. \\
\hline & Avaliação da Seção 9 & $\mathrm{~B}$ & Bem apresentado de maneira geral. \\
\hline \multicolumn{2}{|r|}{ Nota geral } & $\mathbf{C}$ & Simplesmente satisfatório. \\
\hline
\end{tabular}

Fonte: Elaborado pelo autor 
Contudo, alguns aspectos se destacaram na revisão de qualidade do relatório. Constata-se que a participação ativa de atores-chave apresenta importantes omissões. Os tomadores de decisão foram envolvidos na definição de eventuais problemas ambientais. Porém, este envolvimento não teve o intuito de definir o escopo da Avaliação Ambiental nem informações do relatório, mas sim esclarecer os consultores ambientais sobre o escopo e os objetivos do Projeto. Embora o público tenha sido consultado para opinar a respeito do projeto, as suas preocupações não foram respondidas. A Avaliação de alternativas também apresenta algumas irregularidades. Como anteriormente mencionado, a descrição do projeto trata a consideração de energia térmica como alternativa. No entanto, ela não foi avaliada pela Avaliação Ambiental que somente analisou cenários referentes aos traçados das Linhas de Transmissão e à gestão de lançamento da água do reservatório. $\mathrm{Na}$ descrição da baseline, avaliação de impactos, medidas de mitigação e monitoramento, a Avaliação Ambiental apresentou poucas omissões.

\subsubsection{Revisão de Qualidade do Relatório da Avaliação Ambiental Regional do Projeto de Energia Gasosa Kribi}

A revisão de qualidade do relatório (Quadro 23) evidencia omissões e inadequações. $\mathrm{Na}$ primeira seção (nota $\mathrm{C}$ ), o projeto é superficialmente apresentado e não há relação evidente entre os objetivos da avaliação e os indicadores. Os critérios da segunda seção (nota E) não obtiveram notas satisfatórias na revisão feita. Embora as dificuldades encontradas sejam mencionadas na avaliação e a sugestão de alternativas seja condizente com as fases dos projetos, não houve envolvimento de atores na definição do escopo (como estipula a política ambiental do Banco Mundial, agência financiadora deste projeto) e não há explicação sobre a definição de questões prioritárias e relevantes.

Na terceira seção (nota $\mathrm{C}$ ), a análise feita mostra que as informações da baseline são apresentadas de modo estritamente satisfatório. A quarta seção teve a maior nota (A), pois a avaliação se refere ao plano de investimento regional e faz recomendações para que este seja um plano sustentável. A quinta seção (nota F) de alternativas apresenta muitas inadequações e importantes omissões. Com efeito, embora as alternativas condigam com o objeto de avaliação, elas são sugeridas apenas para alguns projetos. Ademais, não foram consideradas alternativas sem os projetos. No caso do Projeto Energia Gasosa Kribi, alternativas (envolvendo outros tipos de energia) levadas em conta durante o planejamento não foram 
consideradas na avaliação ambiental de impactos. Nenhuma alternativa foi avaliada; elas foram somente apresentadas.

Os critérios da seção 6 (nota F) foram todos mal atendidos. A avaliação de impactos é muito descritiva. Os métodos de avaliação utilizados na análise não são mencionados. Alguns indicadores tais como bem estar, herança cultural e herança arqueológica são mencionados no scoping, mas não avaliados. A abordagem cumulativa, razão de solicitação da AAR, é mal feita. Os impactos são identificados e relacionados às suas atividades causadoras. Porém, não há menção de efeitos sinergéticos nem indiretos.

Na seção 7 (nota E) de critérios de mitigação e monitoramento, a AAR se refere às ações que devem ser avaliadas nas AIA posteriores. Porém, as medidas de mitigação são superficialmente apresentadas. Quanto ao monitoramento, os seus indicadores são apresentados. No entanto, não há nenhuma menção dos passos seguidos para a sua identificação nem da maneira como o monitoramento deve ser feito. É importante ressaltar que os indicadores de monitoramento diferem dos da avaliação de impacto.

$\mathrm{Na}$ seção 8 (nota $\mathrm{B}$ ) de consulta pública, a análise revela que houve um tempo suficiente para que as partes envolvidas e interessadas dessem a sua opinião. No entanto, a lista de presença fornecida em anexo revela a falta da população local nesta consulta. Apenas cinco pessoas (chefes de vilarejos) representaram a população local. Grupos importantes como pigmeus não foram representados.

$\mathrm{Na}$ última seção (nota B) de apresentação do relatório, a análise mostra que os critérios foram satisfatoriamente atendidos de forma geral. A linguagem do relatório é simples. As ilustrações e mapas são empregados para facilitar o entendimento. A nota geral E do relatório se justifica pela presença de importantes omissões no documento. Portanto, o relatório não apresenta informações necessárias para a tomada de decisão.

É fundamental mencionar que a avaliação se autojulga desnecessária uma vez que no momento em que entra na cena decisões já foram tomadas. O projeto Energia Gasosa Kribi já se encontrava definido. Desta forma, a avaliação não poderia cumprir o seu papel. 
Quadro 23 - Revisão de qualidade do relatório da Avaliação Ambiental Regional do Projeto Energia Gasosa Kribi

(Continua)

\begin{tabular}{|c|c|c|c|}
\hline & Critério & Nota & Comentários \\
\hline & Seção 1 - Objetivos & & \\
\hline 1 & Descreve o conteúdo e os objetivos principais da ação estratégica. & $\mathrm{F}$ & $\begin{array}{l}\text { O relatório apresenta de forma muito superficial o projeto } \\
\text { (pg 13). O estudo muito sucintamente apresenta a } \\
\text { relevância do projeto para o país. }\end{array}$ \\
\hline 2 & $\begin{array}{l}\text { Os objetivos da AAE são apresentados, relacionados aos indicadores e metas se } \\
\text { for o caso. }\end{array}$ & $\mathrm{C}$ & $\begin{array}{l}\text { O relatório apresenta os objetivos da avaliação, porém, não } \\
\text { os relaciona com os indicadores e metas (pg 15). O estudo } \\
\text { não explica satisfatoriamente como os indicadores foram } \\
\text { identificados e selecionados (pg 127). }\end{array}$ \\
\hline \multirow[t]{3}{*}{3} & $\begin{array}{l}\text { Os objetivos e indicadores da AAE cobrem uma gama adequada de temas } \\
\text { ambientais/de sustentabilidade, incluindo a biodiversidade, população, saúde } \\
\text { humana, fauna, flora, solo, água, ar, fatores climáticos, o património cultural, } \\
\text { paisagístico e suas inter-relações. Eles integram as questões ambientais, sociais } \\
\text { e econômicos. }\end{array}$ & A & $\begin{array}{l}\text { Os indicadores se referem a aspectos ambientais, sociais e } \\
\text { econômicos (pg 127-128). }\end{array}$ \\
\hline & Avaliação da Seção 1 & $\mathrm{C}$ & $\begin{array}{l}\text { Satisfatório de modo geral, embora, haja importantes } \\
\text { omissões. }\end{array}$ \\
\hline & Seção 2 - Escopo & & \\
\hline 4 & $\begin{array}{l}\text { Autoridades competentes e apropriadas são consultadas para a determinação do } \\
\text { alcance e nível de informações que devem ser incluídas no relatório AAE. }\end{array}$ & G & $\begin{array}{l}\text { Muito boa identificação de atores envolvidos (pg 26-33). } \\
\text { Porém, os atores não foram envolvidos na definição do } \\
\text { escopo, mas após a avaliação de impacto. }\end{array}$ \\
\hline 5 & $\begin{array}{l}\text { A AAE se concentra em questões importantes e desconsidera as menos } \\
\text { significativas. As razões de desconsideração devem ser documentadas. }\end{array}$ & $\mathrm{G}$ & $\begin{array}{l}\text { A avaliação lista indicadores sem explicar como estes } \\
\text { foram identificados. Não há referência a elementos } \\
\text { descartados. }\end{array}$ \\
\hline
\end{tabular}


(Continuação)

\begin{tabular}{|c|c|c|c|}
\hline & Critério & Nota & Comentários \\
\hline 6 & Alternativas razoáveis estabelecidas. & A & $\begin{array}{l}\text { A avaliação apresenta alternativas para cada um dos } \\
\text { projetos previstos na região Kribi. No entanto, para o } \\
\text { Projeto Energia Gasosa Kribi nenhuma alternativa é } \\
\text { avaliado uma vez que, de acordo com a avaliação, o } \\
\text { projeto já está em andamento e os consultores julgaram } \\
\text { que a avaliação não poderá mudar nada. A AAR deveria } \\
\text { ser conduzida antes para poder cumprir seu papel. } \\
\text { Contudo, alternativas que poderiam ter sido sugeridas } \\
\text { foram apresentadas. (pg 222). }\end{array}$ \\
\hline \multirow[t]{3}{*}{7} & $\begin{array}{l}\text { Técnicas, dificuldades processuais e outros problemas (tais como deficiências } \\
\text { técnicas ou falta de know-how) são discutidos. Suposições e incertezas são } \\
\text { explicitadas. }\end{array}$ & $\mathrm{B}$ & $\begin{array}{l}\text { Falta de dados recentes sobre o censo da população (pg 47; } \\
\text { 167); poucos dados sobre áreas agrárias (pg 64-65); } \\
\text { indisponibilidade de documentos sobre planejamento e } \\
\text { projetos em progresso (pg 177). }\end{array}$ \\
\hline & Avaliação da Seção 2 & $\mathrm{E}$ & Muitas omissões. \\
\hline & Seção 3 - Baseline & & \\
\hline 8 & $\begin{array}{l}\text { Aspectos pertinentes do estado atual do ambiente receptor da ação estratégica e } \\
\text { a sua provável evolução, sem a ação estratégica são descritos. Características } \\
\text { ambientais das zonas susceptíveis de serem significativamente afetadas são } \\
\text { descritas com mais detalhes. }\end{array}$ & A & $\begin{array}{l}\text { Muito boa caracterização da fauna e flora existentes no } \\
\text { local. Apresentação da evolução da biodiversidade ao } \\
\text { longo do tempo. Apresentação da área do centro de } \\
\text { processamento, da usina e das linhas de transmissão. } \\
\text { Omissão da caracterização do local de construção de dutos } \\
\text { (pg 34-46). Boa apresentação de outros aspectos relevantes } \\
\text { (caça, agricultura, pesca) para o projeto. }\end{array}$ \\
\hline 9 & Os objetivos de AAE e dados de coleta da baseline se reforçam mutuamente. & G & Não há relação entre os objetivos e a baseline. \\
\hline
\end{tabular}


(Continuação)

\begin{tabular}{|c|c|c|c|}
\hline & Critério & Nota & Comentários \\
\hline \multirow[t]{3}{*}{10} & $\begin{array}{l}\text { Os métodos utilizados para levantar a baseline são adequados à abrangência e } \\
\text { complexidade da avaliação. }\end{array}$ & A & $\begin{array}{l}\text { Os dados apresentados são secundários, obtidos de outros } \\
\text { trabalhos. }\end{array}$ \\
\hline & Avaliação da Seção3 & $\mathrm{C}$ & Importantes omissões, mas satisfatório de modo geral. \\
\hline & Seção 4 - Links para outras ações estratégicas & & \\
\hline 11 & $\begin{array}{l}\text { As relações entre a ação estratégica e os níveis anteriores e posteriores (na } \\
\text { cadeia de tomada de decisão) são identificadas e explicadas. }\end{array}$ & A & $\begin{array}{l}\text { A Avaliação Ambiental Regional se refere ao plano de } \\
\text { investimento regional e faz recomendações para este seja } \\
\text { um plano sustentável (pg 177-187). }\end{array}$ \\
\hline \multirow[t]{2}{*}{12} & $\begin{array}{l}\text { Aspectos que geram conflitos entre as ações estratégicas são claramente } \\
\text { documentados; e são feitas recomendações sobre como conciliar as ações } \\
\text { estratégicas, de modo a promover a sustentabilidade. }\end{array}$ & $\mathrm{n} / \mathrm{a}$ & \\
\hline & Seção 5 - Alternativas & & \\
\hline 13 & $\begin{array}{l}\text { As alternativas consideradas são apropriadas para a escala (internacional, } \\
\text { nacional, etc.) e o nível (Política, Plano, Programa) da tomada de decisão. }\end{array}$ & $\mathrm{C}$ & $\begin{array}{l}\text { A avaliação apresenta alternativas para cada um dos } \\
\text { projetos previstos na região Kribi. As alternativas } \\
\text { condizem com o objeto de avaliação. Contudo, as } \\
\text { alternativas são sugeridas apenas para alguns projetos. } \\
\text { Ademais, as alternativas, na sua maioria, são } \\
\text { essencialmente locacionais. No caso, do Projeto Energia } \\
\text { Gasosa Kribi, alternativas (envolvendo outros tipos de } \\
\text { energia) consideradas durante o planejamento não foram } \\
\text { consideradas na avaliação. }\end{array}$ \\
\hline
\end{tabular}


(Continuação)

\begin{tabular}{|c|c|c|c|}
\hline & Critério & Nota & Comentários \\
\hline 14 & $\begin{array}{l}\text { As alternativas consideradas lidam com as questões identificadas na baseline e / } \\
\text { ou buscam alcançar metas de sustentabilidade. }\end{array}$ & A & $\begin{array}{l}\text { As alternativas consideram as informações da baseline e } \\
\text { objetivam um desenvolvimento sustentável. }\end{array}$ \\
\hline 15 & $\begin{array}{l}\text { As alternativas incluem o "não fazer nada", "fazer o mínimo" e "alternativas } \\
\text { mais benéficas ao ambiente". }\end{array}$ & $\mathrm{E}$ & $\begin{array}{l}\text { Critério não atendido. Apenas a alternativa } \\
\text { "ambientalmente mais benéfico" foi considerada. }\end{array}$ \\
\hline 16 & $\begin{array}{l}\text { As razões para descartar alternativas de maiores considerações são } \\
\text { apresentadas. }\end{array}$ & $\mathrm{F}$ & $\begin{array}{l}\text { Só foi sugerida uma alternativa por projeto. Exceto o caso } \\
\text { do Projeto Kribi, não foi justificada a não consideração de } \\
\text { outras alternativas. }\end{array}$ \\
\hline \multirow[t]{3}{*}{17} & $\begin{array}{l}\text { Os efeitos ambientais e de sustentabilidade de cada alternativa são identificados } \\
\text { e comparados. }\end{array}$ & G & Critério não atendido. \\
\hline & Avaliação da Seção 5 & $\mathrm{~F}$ & Importantes omissões. \\
\hline & Seção 6 - Identificação e avaliação de Impactos & & \\
\hline 18 & $\begin{array}{l}\text { Os prováveis impactos significativos sobre o meio ambiente são identificados e } \\
\text { avaliados. }\end{array}$ & $\mathrm{F}$ & $\begin{array}{l}\text { Critério muito mal atendido. Os impactos são } \\
\text { identificados. Porém, não são devidamente analisados. } \\
\text { Não há identificação da probabilidade, duração, } \\
\text { frequência, etc. dos impactos. Ademais alguns indicadores } \\
\text { tais como bem estar, herança cultural e herança } \\
\text { arqueológica são mencionados, mas não avaliados }\end{array}$ \\
\hline 19 & $\begin{array}{l}\text { Prováveis impactos indiretos, cumulativos, sinérgicos e secundários são } \\
\text { identificados e avaliados. }\end{array}$ & $\mathrm{F}$ & $\begin{array}{l}\text { Critério muito mal atendido, embora a avaliação tenha sido } \\
\text { solicitada no intuito de avaliar efeitos cumulativos. A } \\
\text { abordagem cumulativa é mal feita. Os impactos são } \\
\text { identificados e relacionados às suas atividades causadoras. } \\
\text { Não há menção de efeitos sinergéticos nem indiretos. }\end{array}$ \\
\hline
\end{tabular}


(Continuação)

\begin{tabular}{|c|c|c|c|}
\hline & Critério & Nota & Comentários \\
\hline \multirow[t]{3}{*}{20} & $\begin{array}{l}\text { Foram utilizadas adequadas técnicas de previsão de impacto e de avaliação. A } \\
\text { avaliação do impacto condiz com as normas e regulamentos aceitos } \\
\text { internacionalmente. }\end{array}$ & $\mathrm{E}$ & $\begin{array}{l}\text { Este critério é mal atendido. A avaliação de impactos é } \\
\text { muito descritiva. Os métodos de avaliação utilizados na } \\
\text { análise não são mencionados. Contudo, há menção de } \\
\text { padrões utilizados (do Banco Mundial). }\end{array}$ \\
\hline & Avaliação da Seção 6 & $\mathrm{~F}$ & Muito insatisfatório. \\
\hline & Seção 7 - Mitigação e monitoramento & & \\
\hline 21 & $\begin{array}{l}\text { As medidas previstas para evitar, reduzir, compensar e/ou melhorar quaisquer } \\
\text { impactos significativos da ação estratégica são indicadas. }\end{array}$ & $\mathrm{D}$ & $\begin{array}{l}\text { As medidas de mitigação são indicadas. Porém, elas são } \\
\text { muito superficiais e apresentadas de modo geral (pg 187). }\end{array}$ \\
\hline 22 & Medidas de monitoramento dos impactos são explicitadas. & $\mathrm{F}$ & $\begin{array}{l}\text { Este critério é mal atendido. Na seção monitoramento, } \\
\text { indicadores a serem monitorados são apresentados. Não há } \\
\text { nenhuma menção de como o monitoramento deve ser feito } \\
\text { nem de como os indicadores foram identificados. É } \\
\text { importante ressaltar que os indicadores de monitoramento } \\
\text { diferem dos da avaliação de impacto (pg 190). }\end{array}$ \\
\hline \multirow[t]{2}{*}{23} & Links para AIA de projetos e outras AAE são explicitados. & B & $\begin{array}{l}\text { A Avaliação Ambiental Regional foi feita após duas AIA } \\
\text { de projetos que avaliaram os componentes do projeto } \\
\text { separadamente exceto os seus gasodutos. Desta forma, a } \\
\text { AAR foi conduzida com a perspectiva de avaliar todos os } \\
\text { componentes do projeto. Portanto, é subsequente às AIA. } \\
\text { Contudo, a AAR se refere a ações que devem ser avaliados } \\
\text { em uma fase posterior. }\end{array}$ \\
\hline & Avaliação da Seção 7 & $\mathrm{E}$ & Insatisfatório. \\
\hline
\end{tabular}


(Continuação)

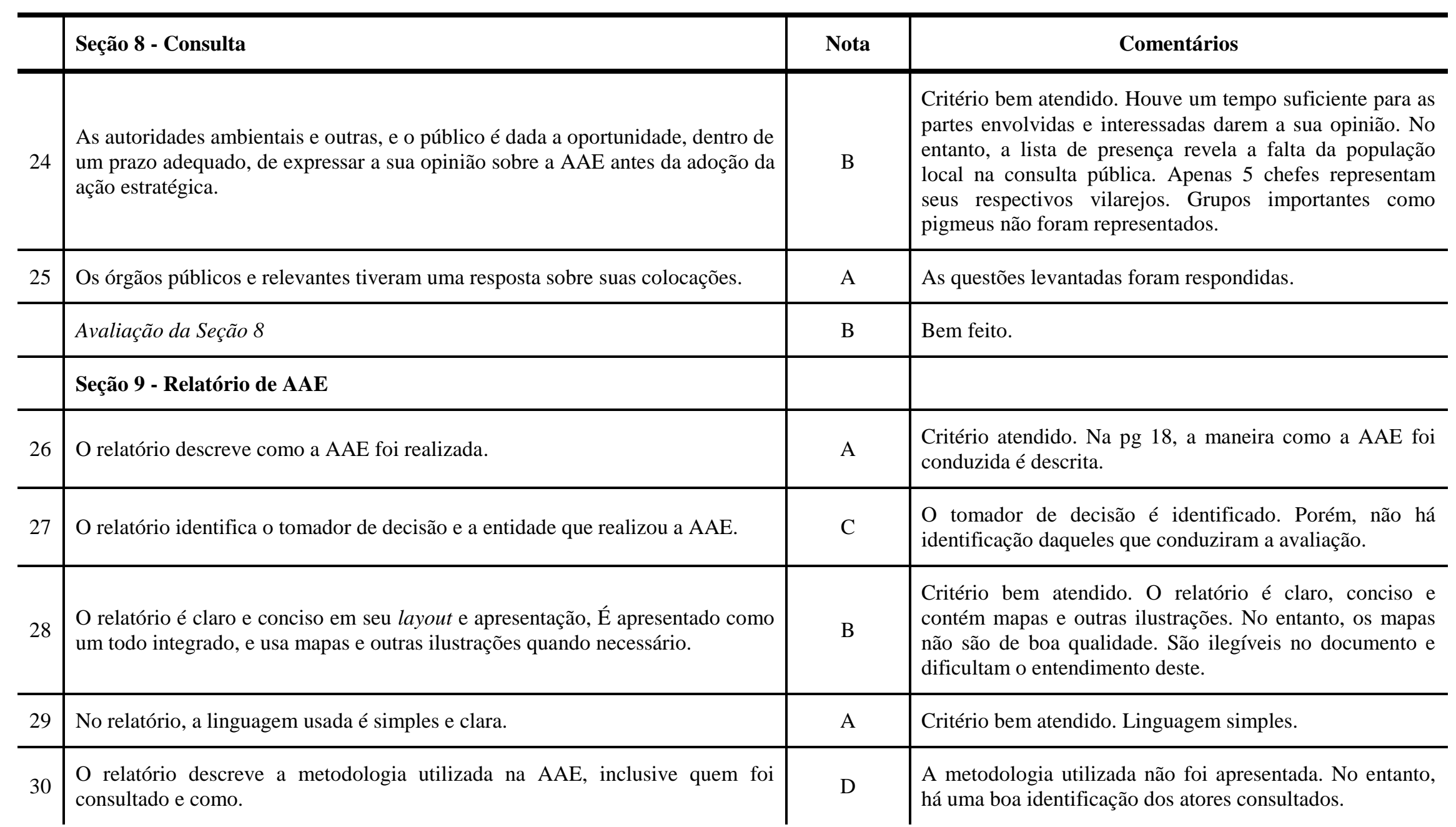


(Conclusão)

\begin{tabular}{l|l|l|l}
\hline & Critério & Nota & Comentários \\
\hline 31 & O relatório se concentra nas grandes questões. & $?$ & $\begin{array}{l}\text { A avaliação não menciona se as questões abordadas são as } \\
\text { mais relevantes. As questões são apresentadas e analisadas } \\
\text { sem explicação. }\end{array}$ \\
\hline 32 & O relatório está escrito, sem viés, de forma imparcial. & A & Critério muito bem atendido. Imparcialidade na avaliação. \\
\hline & Avaliação da Seção 9 & B & Satisfatório. \\
\hline & Nota geral & E & Insatisfatório de forma geral. \\
\hline
\end{tabular}

Fonte: Elaborado pelo autor 


\subsubsection{Revisão de Qualidade do Relatório da Avaliação Ambiental Setorial do Projeto de Desenvolvimento de Energia Nepal}

A revisão de qualidade do relatório revela que a avaliação foi mal conduzida. Apenas as seções 1, 4 e 9 apresentam informações de forma satisfatória. Nestas etapas, o relatório apresenta os objetivos da avaliação que contemplam aspectos de sustentabilidade. A avaliação também menciona satisfatoriamente outras ações estratégicas (seção 4). Ademais, o relatório usa uma linguagem boa e simples (seção 9). Ao contrário, as seções 2, 5 e 7 apresentam importantes omissões, sendo muito insatisfatórias. A etapa do Scoping foi mal feita. Entre outros, não houve envolvimento de atores-chave, não foram mencionadas as dificuldades encontradas nem como os indicadores foram identificados. A alternativa com o projeto não foi avaliada e não há apontamento de medidas de mitigação e monitoramento. As seções 3,6 e 8 não foram atendidas. Entre outros, o levantamento de Baseline, a avaliação de impactos e a consulta pública não foram realizados (Quadro 24).

Considerando a análise realizada, conclui-se que o relatório não apresenta informações necessárias para auxiliar a tomada de decisão (nota F). Com efeito, a avaliação baseia-se e refere-se muito no estudo de Triagem e Classificação realizado pela Autoridade Energética do Nepal e apresenta os resultados deste estudo, mas não faz satisfatoriamente o seu papel de avaliar os impactos do projeto. 
Quadro 24 - Revisão de qualidade do relatório da Avaliação Ambiental Setorial do Projeto de Desenvolvimento de Energia Nepal

\begin{tabular}{|c|c|c|c|}
\hline & Critério & Nota & Comentários \\
\hline & Seção 1 - Objetivos & & \\
\hline 1 & Descreve o conteúdo e os objetivos principais da ação estratégica. & G & A avaliação não apresenta a ação estratégica. \\
\hline 2 & $\begin{array}{l}\text { Os objetivos da AAE são apresentados, relacionados aos indicadores e } \\
\text { metas se for o caso. }\end{array}$ & $\mathrm{C}$ & $\begin{array}{l}\text { A avaliação apresenta os seus objetivos. Porém, estes não são } \\
\text { relacionados aos indicadores. Contudo, os objetivos são } \\
\text { relacionados às metas da ação estratégica (pg 4). }\end{array}$ \\
\hline 3 & $\begin{array}{l}\text { Os objetivos e indicadores da AAE cobrem uma gama adequada de } \\
\text { temas ambientais/de sustentabilidade, incluindo a biodiversidade, } \\
\text { população, saúde humana, fauna, flora, solo, água, ar, fatores climáticos, } \\
\text { o património cultural, paisagístico e suas inter-relações. Eles integram as } \\
\text { questões ambientais, sociais e econômicos. }\end{array}$ & A & $\begin{array}{l}\text { Os objetivos são voltados para sustentabilidade. A avaliação } \\
\text { objetiva integrar o aspecto econômico, ambiental e social (pg } \\
\text { 4). }\end{array}$ \\
\hline & Avaliação da Seção 1 & $\mathrm{C}$ & Satisfatória. \\
\hline & Seção 2 - Escopo & & \\
\hline 4 & $\begin{array}{l}\text { Autoridades competentes e apropriadas são consultadas para a } \\
\text { determinação do alcance e nível de informações que devem ser incluídas } \\
\text { no relatório AAE. }\end{array}$ & G & Não realizado. \\
\hline 5 & $\begin{array}{l}\text { A AAE se concentra em questões importantes e desconsidera as menos } \\
\text { significativas. As razões de desconsideração devem ser documentadas. }\end{array}$ & $\mathrm{F}$ & $\begin{array}{l}\text { Aspectos relevantes são identificados sem justificativa. Não há } \\
\text { explicação sobre a identificação destes aspectos. }\end{array}$ \\
\hline 6 & Alternativas razoáveis estabelecidas. & $\mathrm{C}$ & Satisfatória. \\
\hline
\end{tabular}


(Continuação)

\begin{tabular}{|c|c|c|c|}
\hline & Critério & Nota & Comentários \\
\hline \multirow[t]{3}{*}{7} & $\begin{array}{l}\text { Técnicas, dificuldades processuais e outros problemas (tais como } \\
\text { deficiências técnicas ou falta de know-how) são discutidos. Suposições e } \\
\text { incertezas são explicitadas. }\end{array}$ & G & Não realizado. \\
\hline & Avaliação da Seção 2 & $\mathrm{~F}$ & Muito mal feito. \\
\hline & Seção 3 - Baseline & & \\
\hline 8 & $\begin{array}{l}\text { Aspectos pertinentes do estado atual do ambiente receptor da ação } \\
\text { estratégica e a sua provável evolução, sem a ação estratégica são } \\
\text { descritos. Características ambientais das zonas susceptíveis de serem } \\
\text { significativamente afetadas são descritas com mais detalhes. }\end{array}$ & G & Não realizado. \\
\hline 9 & $\begin{array}{l}\text { Os objetivos de AAE e dados de coleta da baseline se reforçam } \\
\text { mutuamente. }\end{array}$ & G & Não realizado. \\
\hline \multirow[t]{3}{*}{10} & $\begin{array}{l}\text { Os métodos utilizados para levantar a baseline são adequados à } \\
\text { abrangência e complexidade da avaliação. }\end{array}$ & G & Não realizado. \\
\hline & Avaliação da Seção3 & G & Não realizado. \\
\hline & Seção 4 - Links para outras ações estratégicas & & \\
\hline 11 & $\begin{array}{l}\text { As relações entre a ação estratégica e os níveis anteriores e posteriores } \\
\text { (na cadeia de tomada de decisão) são identificadas e explicadas. }\end{array}$ & $\mathrm{B}$ & $\begin{array}{l}\text { A avaliação faz menção de projetos que foram projetados tendo } \\
\text { como base a visão da autoridade de Nepal de atender às } \\
\text { necessidades energéticas da crescente população do país. }\end{array}$ \\
\hline 12 & $\begin{array}{l}\text { Aspectos que geram conflitos entre as ações estratégicas são claramente } \\
\text { documentados; e são feitas recomendações sobre como conciliar as ações } \\
\text { estratégicas, de modo a promover a sustentabilidade. }\end{array}$ & $\mathrm{n} / \mathrm{a}$ & \\
\hline
\end{tabular}


(Continuação)

\begin{tabular}{|c|c|c|c|}
\hline & Critério & Nota & Comentários \\
\hline & Avaliação da Seção 4 & $\mathrm{~B}$ & Seção bem atendida \\
\hline & Seção 5 - Alternativas & Nota & Comentários \\
\hline 13 & $\begin{array}{l}\text { As alternativas consideradas são apropriadas para a escala (internacional, } \\
\text { nacional, etc.) e o nível (Política, Plano, Programa) da tomada de } \\
\text { decisão. }\end{array}$ & $\mathrm{C}$ & $\begin{array}{l}\text { Alternativas envolvendo outros tipos de energia foram } \\
\text { consideradas. }\end{array}$ \\
\hline 14 & $\begin{array}{l}\text { As alternativas consideradas lidam com as questões identificadas na } \\
\text { baseline e/ou buscam alcançar metas de sustentabilidade. }\end{array}$ & $\mathrm{G}$ & $\begin{array}{l}\text { As alternativas não se baseiam na baseline, uma vez que esta } \\
\text { não foi feita. }\end{array}$ \\
\hline 15 & $\begin{array}{l}\text { As alternativas incluem o "não fazer nada", "fazer o mínimo" e } \\
\text { "alternativas mais benéficas ao ambiente". }\end{array}$ & G & Critério não atendido, nenhuma alternativa contemplada. \\
\hline 16 & $\begin{array}{l}\text { As razões para descartar alternativas de maiores considerações são } \\
\text { apresentadas. }\end{array}$ & $\mathrm{B}$ & $\begin{array}{l}\text { Justificativa feita com algumas omissões. A avaliação justifica a } \\
\text { escolha de energia hidrelétrica sugerindo um desenvolvimento } \\
\text { em paralelo de tipos de energias elétricas. }\end{array}$ \\
\hline \multirow[t]{3}{*}{17} & $\begin{array}{l}\text { Os efeitos ambientais e de sustentabilidade de cada alternativa são } \\
\text { identificados e comparados. }\end{array}$ & $\mathrm{G}$ & Critério não atendido. \\
\hline & Avaliação da Seção 5 & $\mathrm{~F}$ & Importantes omissões. \\
\hline & Seção 6 - Identificação e avaliação de Impactos & & \\
\hline 18 & $\begin{array}{l}\text { Os prováveis impactos significativos sobre o meio ambiente são } \\
\text { identificados e avaliados. }\end{array}$ & G & Não realizado. \\
\hline 19 & $\begin{array}{l}\text { Prováveis impactos indiretos, cumulativos, sinérgicos e secundários são } \\
\text { identificados e avaliados. }\end{array}$ & G & Não realizado. \\
\hline
\end{tabular}


(Continuação)

\begin{tabular}{|c|c|c|c|}
\hline & Critério & Nota & Comentários \\
\hline \multirow[t]{3}{*}{20} & $\begin{array}{l}\text { Foram utilizadas adequadas técnicas de previsão de impacto e de } \\
\text { avaliação. A avaliação do impacto condiz com as normas e regulamentos } \\
\text { aceitos internacionalmente. }\end{array}$ & G & Não realizado. \\
\hline & Avaliação da Seção 6 & G & Não realizado. \\
\hline & Seção 7 - Mitigação e monitoramento & & \\
\hline 21 & $\begin{array}{l}\text { As medidas previstas para evitar, reduzir, compensar e/ou melhorar } \\
\text { quaisquer impactos significativos da ação estratégica são indicadas. }\end{array}$ & $\mathrm{F}$ & $\begin{array}{l}\text { A avaliação apenas indica a abordagem de mitigação que as } \\
\text { AIA de projetos deverão seguir. }\end{array}$ \\
\hline 22 & Medidas de monitoramento dos impactos são explicitadas. & $\mathrm{F}$ & $\begin{array}{l}\text { A avaliação apenas indica a abordagem de monitoramento que } \\
\text { as AIA de projetos deverão seguir. }\end{array}$ \\
\hline \multirow[t]{3}{*}{23} & Links para AIA de projetos e outras AAE são explicitados & $\mathrm{C}$ & $\begin{array}{l}\text { A avaliação propõe abordagens que serão seguidas pelas AIA } \\
\text { de projetos. }\end{array}$ \\
\hline & Avaliação da Seção 7 & $\mathrm{~F}$ & Muito mal feito. \\
\hline & Seção 8 - Consulta & & \\
\hline 24 & $\begin{array}{l}\text { As autoridades ambientais e outras e o público é dada a oportunidade, } \\
\text { dentro de um prazo adequado, de expressar a sua opinião sobre a AAE } \\
\text { antes da adoção da ação estratégica. }\end{array}$ & G & Não realizado \\
\hline 25 & $\begin{array}{l}\text { Os órgãos públicos e relevantes tiveram uma resposta sobre suas } \\
\text { colocações. }\end{array}$ & G & Não realizado \\
\hline
\end{tabular}


(Conclusão)

\begin{tabular}{|c|c|c|c|}
\hline & Critério & Nota & Comentários \\
\hline & Avaliação da Seção 8 & G & Não realizado. \\
\hline & Seção 9 - Relatório de AAE & & \\
\hline 26 & O relatório descreve como a AAE foi realizada & $\mathrm{C}$ & Descrição satisfatória. \\
\hline 27 & $\begin{array}{l}\text { O relatório identifica o tomador de decisão e a entidade que realizou a } \\
\text { AAE. }\end{array}$ & $\mathrm{C}$ & $\begin{array}{l}\text { O tomador de decisão e aqueles que conduziram a avaliação são } \\
\text { identificados. }\end{array}$ \\
\hline 28 & $\begin{array}{l}\text { O relatório é claro e conciso em seu layout e apresentação, É apresentado } \\
\text { como um todo integrado, e usa mapas e outras ilustrações quando } \\
\text { necessário. }\end{array}$ & $\mathrm{E}$ & Não há mapas nem tabelas. $\mathrm{O}$ relatório é totalmente descritivo. \\
\hline 29 & No relatório, a linguagem usada é simples e clara. & A & A avaliação usa uma linguagem simples e apropriada. \\
\hline 30 & $\begin{array}{l}\text { O relatório descreve a metodologia utilizada na AAE, inclusive quem foi } \\
\text { consultado e como. }\end{array}$ & G & Não realizado. \\
\hline 31 & O relatório se concentra nas grandes questões & G & Não realizado. \\
\hline \multirow[t]{3}{*}{32} & O relatório está escrito, sem viés, de forma imparcial. & A & Critério bem atendido. \\
\hline & Avaliação da Seção 9 & $\mathrm{C}$ & Importantes omissões, mas satisfatório de forma geral. \\
\hline & Nota geral & $\mathbf{F}$ & Importantes omissões. \\
\hline
\end{tabular}

Fonte: Elaborado pelo autor 


\subsubsection{Revisão de Qualidade do Relatório da Avaliação de Impacto Cumulativo do Projeto Hidrelétrico Kabeli “ $A$ ”}

A revisão de qualidade do relatório (Quadro 25) revela que as duas primeiras seções apresentam informações de modo satisfatório, embora tenham algumas omissões (nota C). A avaliação, entre outros, identifica atores chaves (consultados na definição do escopo de avaliação) e se reporta a dificuldades encontradas na aplicação da avaliação de forma satisfatória. No entanto, o estudo não apresenta os objetivos do projeto; os objetivos da avaliação não são claramente relacionados aos indicadores; não há consideração de outras alternativas a não ser o cenário com o projeto.

Analisando a seção 3 (nota $\mathrm{B}$ ), percebe-se que os dados da baseline são adequadamente apresentados. No entanto, uma das omissões dessa etapa é a não apresentação da metodologia usada na coleta de dados. Contudo, a avaliação menciona que os dados utilizados são oriundos de AIA de projetos previamente realizados.

Na seção 4 (nota $G$ ), os critérios não são atendidos. A avaliação se refere a todos outros projetos da bacia. Estes empreendimentos fazem parte do objeto de avaliação do estudo não sendo considerados, desta forma, ações estratégicas estrangeiros ao alvo da avaliação.

A seção 5 foi avaliada como muito insatisfatória (nota F). Essa parte apresenta importantes omissões. A Avaliação de Impacto Cumulativo apenas considerou a alternativa com o projeto. A razão da não consideração de outras alternativas não foi apresentada.

Na seção 6 (nota C), os critérios são atendidos satisfatoriamente embora haja algumas omissões. A alternativa considerada foi adequadamente avaliada. Os impactos identificados foram analisados com uma abordagem cumulativa. No entanto, a abordagem utilizada apresenta muitas deficiências. Os efeitos cumulativos avaliados são restritos aos indicadores. A avaliação não considera efeitos cumulativos de dois indicadores diferentes.

Na seção 7 (nota $G$ ), nenhum critério foi atendido. A avaliação não apresenta medidas de monitoramento nem de mitigação. Ademais, a avaliação não estabelece diretrizes para subsequentes AIA, uma vez que esses últimos foram realizados antes da avaliação.

Na seção 8 (nota B), as informações contidas são apresentadas de forma satisfatória embora haja algumas omissões. Com efeito, foram feitas duas consultas públicas. A primeira, na definição do scoping, teve o intuito de definir indicadores da avaliação. A segunda, na elaboração do rascunho do relatório, objetivou recolher opiniões públicas sobre os impactos 
levantados. No entanto, o relatório final não menciona como considerou os feedback na versão final do relatório.

Na seção 9 (nota B), os critérios são satisfatoriamente atendidos. A única omissão importante é a falta de descrição da forma como a avaliação foi conduzida e da metodologia utilizada. Ao contrário, o relatório apresenta uma linguagem simples, clara e de fácil compreensão e há uso de mapas e ilustrações para uma melhor compreensão. 
Quadro 25 - Revisão de qualidade do relatório da Avaliação de Impacto Cumulativo do Projeto hidrelétrico Kabeli « A »

(Continua)

\begin{tabular}{|c|c|c|c|}
\hline & Critério & Nota & Comentários \\
\hline & Seção 1 - Objetivos & & \\
\hline 1 & Descreve o conteúdo e os objetivos principais da ação estratégica. & $\mathrm{D}$ & $\begin{array}{l}\text { A avaliação apresenta superficialmente o conteúdo do projeto. Os } \\
\text { componentes e os objetivos do projeto não são apresentados ( } \mathrm{pg} 7) \text {. }\end{array}$ \\
\hline 2 & $\begin{array}{l}\text { Os objetivos da AAE são apresentados, relacionados aos indicadores e } \\
\text { metas, se for o caso. }\end{array}$ & $\mathrm{D}$ & $\begin{array}{l}\text { Os objetivos da avaliação cumulativa de impacto são apresentados. } \\
\text { Porém, eles não são relacionados a indicadores (pg 9). }\end{array}$ \\
\hline \multirow[t]{3}{*}{3} & $\begin{array}{l}\text { Os objetivos e indicadores da AAE cobrem uma gama adequada de } \\
\text { temas ambientais/de sustentabilidade, incluindo a biodiversidade, } \\
\text { população, saúde humana, fauna, flora, solo, água, ar, fatores } \\
\text { climáticos, o património cultural, paisagístico e suas inter-relações. } \\
\text { Eles integram as questões ambientais, sociais e econômicos. }\end{array}$ & $\mathrm{C}$ & $\begin{array}{l}\text { Os indicadores abordam assuntos de sustentabilidade, entre outros, ruído, } \\
\text { herança cultural e ar. No entanto, os objetivos da avaliação não cobrem } \\
\text { satisfatoriamente essas questões. }\end{array}$ \\
\hline & Avaliação da Seção 1 & $\mathrm{C}$ & Satisfatória. \\
\hline & Seção 2 - Escopo & & \\
\hline 4 & $\begin{array}{l}\text { Autoridades competentes e apropriadas são consultadas para a } \\
\text { determinação do alcance e nível de informações que devem ser } \\
\text { incluídas no relatório AAE. }\end{array}$ & $\mathrm{A}$ & $\begin{array}{l}\text { O público, especialistas e representantes de órgãos governamentais } \\
\text { participaram da consulta feita para definir o escopo da avaliação. }\end{array}$ \\
\hline 5 & $\begin{array}{l}\text { A AAE se concentra em questões importantes e desconsidera as menos } \\
\text { significativas. As razões de desconsideração devem ser documentadas. }\end{array}$ & $\mathrm{E}$ & $\begin{array}{l}\text { A avaliação identifica questões prioritárias, porém não as avalia. Apenas } \\
\text { menciona elementos relevantes para o estudo. }\end{array}$ \\
\hline 6 & Alternativas razoáveis estabelecidas. & G & Só foi considerada a alternativa representando o cenário com o projeto. \\
\hline
\end{tabular}


(Continuação)

\begin{tabular}{|c|c|c|c|}
\hline & Critério & Nota & Comentários \\
\hline \multirow[t]{3}{*}{7} & $\begin{array}{l}\text { Técnicas, dificuldades processuais e outros problemas (tais como } \\
\text { deficiências técnicas ou falta de know-how) são discutidos. Suposições } \\
\text { e incertezas são explicitadas. }\end{array}$ & A & $\begin{array}{l}\text { A avaliação encontrou dificuldades para reunir informações sobre os } \\
\text { outros sete projetos da bacia (pg 42). }\end{array}$ \\
\hline & Avaliação da Seção 2 & $\mathrm{C}$ & Satisfatória. \\
\hline & Seção 3 - Baseline & & \\
\hline 8 & $\begin{array}{l}\text { Aspectos pertinentes do estado atual do ambiente receptor da ação } \\
\text { estratégica e a sua provável evolução, sem a ação estratégica são } \\
\text { descritos. Características ambientais das zonas susceptíveis de serem } \\
\text { significativamente afetadas são descritas com mais detalhes. }\end{array}$ & A & Critério atendido satisfatoriamente (pg 10-36). \\
\hline 9 & $\begin{array}{l}\text { Os objetivos de AAE e dados de coleta da baseline se reforçam } \\
\text { mutuamente. }\end{array}$ & $\mathrm{C}$ & $\begin{array}{l}\text { Há uma relação entre a baseline e os objetivos da AAE. Porém, essa } \\
\text { relação poderia ser melhor explicitada. }\end{array}$ \\
\hline \multirow[t]{3}{*}{10} & $\begin{array}{l}\text { Os métodos utilizados para levantar a baseline são adequados à } \\
\text { abrangência e complexidade da avaliação. }\end{array}$ & $\mathrm{B}$ & $\begin{array}{l}\text { Os métodos utilizados na coleta de informações da baseline não são } \\
\text { apresentados. O relatório menciona que os dados obtidos são } \\
\text { provenientes de AIA de projetos e de relatórios de viabilidade do projeto } \\
\text { (pg 9). }\end{array}$ \\
\hline & Avaliação da Seção3 & $\mathrm{B}$ & Satisfatório. \\
\hline & Seção 4 - Links para outras ações estratégicas & & \\
\hline 11 & $\begin{array}{l}\text { As relações entre a ação estratégica e os níveis anteriores e posteriores } \\
\text { (na cadeia de tomada de decisão) são identificadas e explicadas. }\end{array}$ & G & $\begin{array}{l}\text { A avaliação se refere ao Projeto Hidrelétrico Kabeli "A" e aos outros } \\
\text { projetos previstos na bacia. Porém, estes não são considerados como } \\
\text { ações estratégicas relevantes, pois constituem o objeto de estudo da } \\
\text { avaliação. }\end{array}$ \\
\hline
\end{tabular}


(Continuação)

\begin{tabular}{|c|c|c|c|}
\hline & Critério & Nota & Comentários \\
\hline \multirow[t]{3}{*}{12} & $\begin{array}{l}\text { Aspectos que geram conflitos entre as ações estratégicas são } \\
\text { claramente documentados; e são feitas recomendações sobre como } \\
\text { conciliar as ações estratégicas, de modo a promover a sustentabilidade. }\end{array}$ & $\mathrm{n} / \mathrm{a}$ & \\
\hline & Avaliação da Seção 4 & G & Seção não atendida. \\
\hline & Seção 5 - Alternativas & & \\
\hline 13 & $\begin{array}{l}\text { As alternativas consideradas são apropriadas para a escala } \\
\text { (internacional, nacional, etc.) e o nível (Política, Plano, Programa) da } \\
\text { tomada de decisão. }\end{array}$ & G & $\begin{array}{l}\text { A avaliação de impacto cumulativo apenas considerou a alternativa com } \\
\text { o projeto. }\end{array}$ \\
\hline 14 & $\begin{array}{l}\text { As alternativas consideradas lidam com as questões identificadas na } \\
\text { baseline e / ou buscam alcançar metas de sustentabilidade. }\end{array}$ & A & A avaliação da alternativa analisou elementos levantados na baseline \\
\hline 15 & $\begin{array}{l}\text { As alternativas incluem o "não fazer nada', "fazer o mínimo" e } \\
\text { "alternativas mais benéficas ao ambiente". }\end{array}$ & G & Critério não atendido. \\
\hline 16 & $\begin{array}{l}\text { As razões para descartar alternativas de maiores considerações são } \\
\text { apresentadas. }\end{array}$ & G & Critério não atendido. \\
\hline \multirow[t]{2}{*}{17} & $\begin{array}{l}\text { Os efeitos ambientais e de sustentabilidade de cada alternativa são } \\
\text { identificados e comparados. }\end{array}$ & G & Critério não atendido. \\
\hline & Avaliação da Seção 5 & $\mathbf{F}$ & $\begin{array}{l}\text { Muito insatisfatório. Seção com importantes omissões. Mal atendida de } \\
\text { forma geral. Apenas o critério relacionado com baseline foi atendido. }\end{array}$ \\
\hline
\end{tabular}


(Continuação)

\begin{tabular}{|c|c|c|c|}
\hline & Critério & Nota & Comentários \\
\hline & Seção 6 - Identificação e avaliação de Impactos & & \\
\hline 18 & $\begin{array}{l}\text { Os prováveis impactos significativos sobre o meio ambiente são } \\
\text { identificados e avaliados. }\end{array}$ & $\mathrm{B}$ & A alternativa foi bem avaliada de maneira geral. Há poucas omissões. \\
\hline 19 & $\begin{array}{l}\text { Prováveis impactos indiretos, cumulativos, sinérgicos e secundários } \\
\text { são identificados e avaliados. }\end{array}$ & $\mathrm{E}$ & $\begin{array}{l}\text { Os impactos identificados foram analisados com uma abordagem de } \\
\text { avaliação de efeitos cumulativos. No entanto, essa abordagem utilizada } \\
\text { apresenta deficiências importantes. Pois, os efeitos cumulativos } \\
\text { avaliados se restringem a cada um dos indicadores. Na avaliação, não } \\
\text { foram considerados efeitos cumulativos de dois ou mais indicadores } \\
\text { diferentes. }\end{array}$ \\
\hline \multirow[t]{3}{*}{20} & $\begin{array}{l}\text { Foram utilizadas adequadas técnicas de previsão de impacto e de } \\
\text { avaliação. A avaliação do impacto condiz com as normas e } \\
\text { regulamentos aceitos internacionalmente. }\end{array}$ & $\mathrm{B}$ & $\begin{array}{l}\text { A avaliação não menciona as técnicas de previsão de impacto e de } \\
\text { avaliação utilizadas no estudo. Contudo, a avaliação foi conduzida de } \\
\text { forma condizente com as normas e regulamentos aceitos } \\
\text { internacionalmente. }\end{array}$ \\
\hline & Avaliação da Seção 6 & $\mathrm{C}$ & Satisfatória. \\
\hline & Seção 7 - Mitigação e monitoramento & & \\
\hline 21 & $\begin{array}{l}\text { As medidas previstas para evitar, reduzir, compensar e/ou melhorar } \\
\text { quaisquer impactos significativos da ação estratégica são indicadas. }\end{array}$ & G & Critério não atendido. \\
\hline 22 & Medidas de monitoramento dos impactos são explicitadas. & G & Critério não atendido. \\
\hline
\end{tabular}


(Continuação)

\begin{tabular}{|c|c|c|c|}
\hline & Critério & Nota & Comentários \\
\hline \multirow[t]{2}{*}{23} & Links para AIA de projetos e outras AAE são explicitados & G & $\begin{array}{l}\text { A Avaliação de impacto cumulativo foi conduzida após as AIA de } \\
\text { projetos. Assim sendo, a primeira não estabele diretrizes para as últimas. } \\
\text { Contudo, a avaliação de impacto cumulativo aponta alguns } \\
\text { aspectos/diretrizes que deverão ser considerados pelas AIA de outros } \\
\text { projetos da bacia. }\end{array}$ \\
\hline & Avaliação da Seção 7 & $\mathrm{G}$ & Muito mal feito. \\
\hline 24 & $\begin{array}{l}\text { As autoridades ambientais e outras e o público é dada a oportunidade, } \\
\text { dentro de um prazo adequado, de expressar a sua opinião sobre a AAE } \\
\text { antes da adoção da ação estratégica. }\end{array}$ & A & $\begin{array}{l}\text { Foram feitas duas consultas. A primeira na definição do escopo da } \\
\text { avaliação, a segunda durante a preparação do relatório de avaliação (pg } \\
\text { 37). }\end{array}$ \\
\hline \multirow[t]{3}{*}{25} & $\begin{array}{l}\text { Os órgãos públicos e relevantes tiveram uma resposta sobre suas } \\
\text { colocações. }\end{array}$ & $\mathrm{D}$ & $\begin{array}{l}\text { A população foi consultada no intuito de apontar elementos relevantes } \\
\text { sobre o projeto. Esses aspectos foram considerados como indicadores. } \\
\text { No entanto, o relatório não menciona a maneira como os aspectos } \\
\text { levantados na consulta (sobre o rascunho da avaliação) foram } \\
\text { respondidos no relatório final (pg 40). }\end{array}$ \\
\hline & Avaliação da Seção 8 & B & Satisfatório. \\
\hline & Seção 9 - Relatório de AAE & & \\
\hline 26 & O relatório descreve como a AAE foi realizada. & $\mathrm{G}$ & Critério não atendido. \\
\hline 27 & $\begin{array}{l}\text { O relatório identifica o tomador de decisão e a entidade que realizou a } \\
\text { AAE. }\end{array}$ & A & Critério bem atendido (pg 8). \\
\hline 28 & $\begin{array}{l}\text { O relatório é claro e conciso em seu layout e apresentação. É } \\
\text { apresentado como um todo integrado, e usa mapas e outras ilustrações } \\
\text { quando necessário. }\end{array}$ & B & $\begin{array}{l}\text { Critério bem atendido de maneira geral. Contudo, faltou um mapa } \\
\text { ilustrando a espacialização de projetos previstos na bacia. }\end{array}$ \\
\hline
\end{tabular}


(Conclusão)

\begin{tabular}{l|l|c|l}
\hline & Critério & Nota & Comentários \\
\hline 29 & No relatório, a linguagem usada é simples e clara. & A & Critério bem atendido. Linguagem adequada. \\
\hline 30 & $\begin{array}{l}\text { O relatório descreve a metodologia utilizada na AAE, inclusive quem } \\
\text { foi consultado e como. }\end{array}$ & C & $\begin{array}{l}\text { A metodologia utilizada não foi descrita. No entanto, o relatório } \\
\text { mealizados. Quanto à consulta, a avaliação não diz como foi feita a } \\
\text { consulta. Apenas menciona que foi feita. }\end{array}$ \\
\hline 31 & O relatório se concentra nas grandes questões. & B & Satisfatório. \\
\hline 32 & O relatório está escrito, sem viés, de forma imparcial. & B & $\begin{array}{l}\text { A avaliação foca nos indicadores identificados na consulta. No entanto, } \\
\text { estes aspectos não são avaliados na avaliação de alternativa. }\end{array}$ \\
\hline & Avaliação da Seção 9 & B & Critério bem atendido. \\
\hline
\end{tabular}

Fonte: Elaborado pelo autor 


\subsubsection{Revisão de Qualidade do Relatório da Análise de Impacto Cumulativo do Projeto Hidrelétrico Nam Theun 2}

A revisão de qualidade (Quadro 26) evidencia que de modo geral, a avaliação não apresenta informações de maneira satisfatória para uma tomada de decisão (nota D). Com efeito, na primeira seção (nota D), os critérios avaliados revelam que o relatório não apresenta o conteúdo nem os objetivos da ação estratégica. Contudo, os objetivos e indicadores da avaliação são apresentados satisfatoriamente. Na seção 2 (nota E), a análise feita revela muitas omissões na definição do escopo. A Avaliação se debruça sobre indicadores previamente apontados pelo TR. Porém, não há menção de que se trata de elementos relevantes para estudo, tampouco da razão de descarte de outros aspectos. Em relação ao envolvimento das partes na avaliação, foram realizadas duas consultas públicas. No entanto, o relatório não fornece detalhes sobre a maneira como estas foram feitas. Quanto às alternativas, elas condizem com o projeto. No que se refere a dificuldades encontradas, a avaliação reconhece problemas enfrentados na coleta de dados da baseline devido à falta de tempo e recursos financeiros. Assim sendo, apenas foram feitos estudos teóricos (revisão bibliográfica). Também houve dificuldade na previsão e atribuição de impactos, principalmente no que diz respeito à avaliação de impactos oriundos de enchentes na bacia Xe Bang Fai, uma vez que esta dependia do estudo de risco de enchentes que não foi concluído a tempo.

$\mathrm{Na}$ terceira seção (nota $\mathrm{G}$ ), todos os critérios não foram atendidos. A baseline apresentada não foi considerada como tal, posto que apresenta elementos temáticos apontados pelo TR baseando-se em estudos anteriores. Estes não são elementos característicos do meio ambiente, mas tendências de desenvolvimento (hidrelétrica, transporte, irrigação, pesca, indústria, minas, desenvolvimento urbano, etc.).

Os critérios da seção 4 (nota F) foram muito insatisfatoriamente atendidos. A relação com outras ações estratégicas não é adequadamente evidenciada. Na avaliação da bacia do rio Mekong, relaciona-se muito superficialmente o projeto com outros projetos da bacia.

$\mathrm{Na}$ seção 5 (nota $\mathrm{D}$ ), alguns critérios foram satisfatoriamente atendidos, mas o conjunto foi considerado insatisfatório. A avaliação, atendendo aos requisitos do TR, se refere a duas alternativas: "business as usual" e "boas práticas". Estas alternativas não são as únicas apropriadas para o projeto. Poderia se considerar, entre outros, alternativas apontadas na concepção do projeto que levam em conta outras fontes de energia e alternativas sem o 
projeto. Ademais, somente foram avaliados os efeitos da alternativa com o projeto e "business as usual". Para a alternativa "boas práticas", somente foram feitas recomendações.

Os critérios da seção 6 (nota $C$ ) foram atendidos satisfatoriamente embora apresentem algumas omissões. Com efeito, os impactos foram muito adequadamente avaliados utilizandose uma abordagem cumulativa. A avaliação em si foi satisfatoriamente conduzida, no entanto, a abordagem utilizada apresenta muitas deficiências. Ela somente considerou impactos indiretos. Os efeitos cumulativos avaliados são restritos aos indicadores. O estudo não considera efeitos cumulativos de dois indicadores diferentes. Na avaliação da bacia do Mekong, a avaliação considerou impactos dos projetos da bacia que influenciam o fluxo e a qualidade da água. Mesmo assim, a avaliação se restringia a indicadores.

Na seção 7 (nota G), nenhum critério foi atendido. O relatório não apresenta medidas de mitigação e monitoramento. Na seção 8 (nota $\mathrm{F}$ ), os critérios foram muito insatisfatoriamente atendidos. O relatório não fornece detalhes sobre a maneira como a consulta pública foi feita. Não se sabe se as considerações apontadas foram levadas em conta no relatório final.

Na última seção (nota B), a maioria dos critérios foi satisfatoriamente atendida. As únicas omissões foram a não descrição da maneira como a avaliação foi conduzida e a não menção da relevância dos indicadores utilizados na avaliação. 
Quadro 26 - Revisão de qualidade do relatório da Avaliação de Impacto Cumulativo do Projeto Nam Theun 2

(Continua)

\begin{tabular}{|c|c|c|c|}
\hline & Critério & Nota & Comentários \\
\hline & Seção 1 - Objetivos & & \\
\hline 1 & Descreve o conteúdo e os objetivos principais da ação estratégica. & G & A ação estratégica não é apresentada na avaliação. \\
\hline 2 & $\begin{array}{l}\text { Os objetivos da AAE são apresentados, relacionados aos indicadores e } \\
\text { metas, se for o caso. }\end{array}$ & $\mathrm{C}$ & $\begin{array}{l}\text { Os objetivos da avaliação de impacto cumulativo são apresentados } \\
\text { satisfatoriamente (pg 25-26). No entanto, não há relação dos objetivos com } \\
\text { os indicadores. }\end{array}$ \\
\hline \multirow[t]{3}{*}{3} & $\begin{array}{l}\text { Os objetivos e indicadores da AAE cobrem uma gama adequada de } \\
\text { temas ambientais/de sustentabilidade, incluindo a biodiversidade, } \\
\text { população, saúde humana, fauna, flora, solo, água, ar, fatores } \\
\text { climáticos, o património cultural, paisagístico e suas inter-relações. } \\
\text { Eles integram as questões ambientais, sociais e econômicos. }\end{array}$ & $\mathrm{C}$ & $\begin{array}{l}\text { Os indicadores se referem a elementos ambientais satisfatoriamente. Os } \\
\text { objetivos, quanto a eles, não integram todos os aspectos. }\end{array}$ \\
\hline & Avaliação da Seção 1 & $\mathrm{D}$ & Insatisfatório. Importantes omissões. \\
\hline & Seção 2 - Escopo & & \\
\hline 4 & $\begin{array}{l}\text { Autoridades competentes e apropriadas são consultadas para a } \\
\text { determinação do alcance e nível de informações que devem ser } \\
\text { incluídas no relatório AAE. }\end{array}$ & $\mathrm{F}$ & $\begin{array}{l}\text { Foram realizadas duas consultas públicas (pg 26). No entanto, o relatório } \\
\text { não fornece detalhes sobre a maneira como essas foram feitas. }\end{array}$ \\
\hline 5 & $\begin{array}{l}\text { A AAE se concentra em questões importantes e desconsidera as menos } \\
\text { significativas. As razões de desconsideração devem ser documentadas. }\end{array}$ & $\mathrm{E}$ & $\begin{array}{l}\text { A Avaliação de Impacto Cumulativo se debruça sobre indicadores } \\
\text { previamente apontados pelo temo de referência. Não há menção de que se } \\
\text { trata de elementos relevantes para o estudo, tampouco há menção da razão } \\
\text { de descarte de outros aspectos. }\end{array}$ \\
\hline
\end{tabular}


(Continuação)

\begin{tabular}{|c|c|c|c|}
\hline & Critério & Nota & Comentários \\
\hline 6 & Alternativas razoáveis estabelecidas. & $\mathrm{C}$ & $\begin{array}{l}\text { A avaliação apenas considerou a alternativas "boas práticas". Esta } \\
\text { alternativa condiz com o projeto e é razoável. Porém, há outras alternativas } \\
\text { que também são razoáveis, mas não foram consideradas. }\end{array}$ \\
\hline \multirow[t]{3}{*}{7} & $\begin{array}{l}\text { Técnicas, dificuldades processuais e outros problemas (tais como } \\
\text { deficiências técnicas ou falta de know-how) são discutidos. Suposições } \\
\text { e incertezas são explicitadas. }\end{array}$ & A & $\begin{array}{l}\text { (i) Houve dificuldade de coletar dados de baseline pela falta de tempo e } \\
\text { recursos financeiros. Assim sendo, foram feitos estudos teóricos } \\
\text { (bibliografia) (pg 26). (ii) Dificuldade na previsão e atribuição de impactos } \\
\text { (pg 81). (iii) Dificuldade na avaliação de impacto oriundo de enchentes na } \\
\text { bacia Xe Bang Fai antes da conclusão do estudo de risco de enchentes, pois } \\
\text { os dois foram realizados simultaneamente (pg 93). }\end{array}$ \\
\hline & Avaliação da Seção 2 & $\mathrm{E}$ & Muito Insatisfatório. Importantes omissões. \\
\hline & Seção 3 - Baseline & & \\
\hline 8 & $\begin{array}{l}\text { Aspectos pertinentes do estado atual do ambiente receptor da ação } \\
\text { estratégica e a sua provável evolução, sem a ação estratégica são } \\
\text { descritos. Características ambientais das zonas susceptíveis de serem } \\
\text { significativamente afetadas são descritas com mais detalhes. }\end{array}$ & G & $\begin{array}{l}\text { A avaliação não apresenta a linha de base, mas sim elementos temáticos } \\
\text { apontados no TR baseando-se em estudos anteriores (pg 24-77). Estes não } \\
\text { são elementos característicos do meio ambiente. }\end{array}$ \\
\hline 9 & $\begin{array}{l}\text { Os objetivos de AAE e dados de coleta da baseline se reforçam } \\
\text { mutuamente. }\end{array}$ & $\mathrm{n} / \mathrm{a}$ & Não é possível avaliar este critério, uma vez que a baseline não foi feita. \\
\hline \multirow[t]{2}{*}{10} & $\begin{array}{l}\text { Os métodos utilizados para levantar a baseline são adequados à } \\
\text { abrangência e complexidade da avaliação. }\end{array}$ & $\mathrm{n} / \mathrm{a}$ & \\
\hline & Avaliação da Seção3 & G & Não realizado. \\
\hline
\end{tabular}


(Continuação)

\begin{tabular}{|c|c|c|c|}
\hline & Critério & Nota & Comentários \\
\hline & Seção 4 - Links para outras ações estratégicas & & \\
\hline 11 & $\begin{array}{l}\text { As relações entre a ação estratégica e os níveis anteriores e posteriores } \\
\text { (na cadeia de tomada de decisão) são identificadas e explicadas. }\end{array}$ & $\mathrm{F}$ & $\begin{array}{l}\text { A relação com outras ações estratégicas não é bem evidenciada. Na } \\
\text { avaliação da bacia do rio Mekong, relaciona-se superficialmente o projeto } \\
\text { com outros projetos da bacia. }\end{array}$ \\
\hline \multirow[t]{3}{*}{12} & $\begin{array}{l}\text { Aspectos que geram conflitos entre as ações estratégicas são } \\
\text { claramente documentados; e são feitas recomendações sobre como } \\
\text { conciliar as ações estratégicas, de modo a promover a sustentabilidade. }\end{array}$ & $\mathrm{n} / \mathrm{a}$ & \\
\hline & Avaliação da Seção 4 & $\mathrm{~F}$ & Importantes omissões. \\
\hline & Seção 5 - Alternativas & & \\
\hline 13 & $\begin{array}{l}\text { As alternativas consideradas são apropriadas para a escala } \\
\text { (internacional, nacional, etc.) e o nível (Política, Plano, Programa) da } \\
\text { tomada de decisão. }\end{array}$ & $\mathrm{C}$ & $\begin{array}{l}\text { A avaliação, atendendo aos requisitos do TR, se refere a duas alternativas: } \\
\text { "business as usual" e "boas práticas". Estas alternativas não são as únicas } \\
\text { apropriadas para o projeto. Poderia se considerar, entre outros, alternativas } \\
\text { levando em conta outras fontes de energia e alternativas sem o projeto. }\end{array}$ \\
\hline 14 & $\begin{array}{l}\text { As alternativas consideradas lidam com as questões identificadas na } \\
\text { baseline e/ou buscam alcançar metas de sustentabilidade. }\end{array}$ & $\mathrm{E}$ & $\begin{array}{l}\text { Critério atendido com importantes omissões. Com efeito, não foi feito o } \\
\text { levantamento da baseline. As alternativas se basearam em elementos } \\
\text { apontados no TR. }\end{array}$ \\
\hline 15 & $\begin{array}{l}\text { As alternativas incluem o "não fazer nada", "fazer o mínimo" e } \\
\text { "alternativas mais benéficas ao ambiente". }\end{array}$ & $\mathrm{F}$ & $\begin{array}{l}\text { A avaliação somente considerou as alternativas "não fazer nada" e "boas } \\
\text { práticas". O cenário "fazer o mínimo" não tem sido considerado. A } \\
\text { alternativa "boas práticas" apenas foi mencionada. Ela não foi avaliada. }\end{array}$ \\
\hline 16 & $\begin{array}{l}\text { As razões para descartar alternativas de maiores considerações são } \\
\text { apresentadas. }\end{array}$ & G & Critério não atendido. \\
\hline
\end{tabular}


(Continuação)

\begin{tabular}{|c|c|c|c|}
\hline & Seção 6 - Identificação e avaliação de Impactos & Nota & Comentários \\
\hline \multirow[t]{2}{*}{17} & $\begin{array}{l}\text { Os efeitos ambientais e de sustentabilidade de cada alternativa são } \\
\text { identificados e comparados. }\end{array}$ & $\mathrm{D}$ & $\begin{array}{l}\text { Somente foram avaliados os efeitos da alternativa com o projeto e "business } \\
\text { as usual". Para a alternativa "boas práticas", somente foram feitas } \\
\text { recomendações. }\end{array}$ \\
\hline & Avaliação da Seção 6 & $\mathrm{D}$ & Insatisfatório. \\
\hline 18 & $\begin{array}{l}\text { Os prováveis impactos significativos sobre o meio ambiente são } \\
\text { identificados e avaliados. }\end{array}$ & A & Os impactos foram identificados e avaliados satisfatoriamente. \\
\hline 19 & $\begin{array}{l}\text { Prováveis impactos indiretos, cumulativos, sinérgicos e secundários } \\
\text { são identificados e avaliados. }\end{array}$ & $\mathrm{E}$ & $\begin{array}{l}\text { Os impactos identificados foram analisados com uma abordagem } \\
\text { cumulativa. No entanto, a abordagem utilizada apresenta muitas } \\
\text { deficiências. Ela somente considerou impactos indiretos. Os efeitos } \\
\text { cumulativos avaliados são restritos aos indicadores. O estudo não considera } \\
\text { efeitos cumulativos de dois indicadores diferentes. Na avaliação da bacia do } \\
\text { Mekong, a avaliação considerou impactos dos projetos da bacia que } \\
\text { influenciam o fluxo e a qualidade da água (pg 112). Mesmo assim, a } \\
\text { avaliação se restringiu a indicadores. }\end{array}$ \\
\hline \multirow[t]{3}{*}{20} & $\begin{array}{l}\text { Foram utilizadas adequadas técnicas de previsão de impacto e de } \\
\text { avaliação. A avaliação do impacto condiz com as normas e } \\
\text { regulamentos aceitos internacionalmente. }\end{array}$ & $\mathrm{B}$ & Critério bem atendido. Poucas omissões. \\
\hline & Avaliação da Seção 6 & $\mathrm{C}$ & Satisfatório. \\
\hline & Seção 7 - Mitigação e monitoramento & & \\
\hline 21 & $\begin{array}{l}\text { As medidas previstas para evitar, reduzir, compensar e/ou melhorar } \\
\text { quaisquer impactos significativos da ação estratégica são indicadas. }\end{array}$ & G & Critério não atendido. \\
\hline 22 & Medidas de monitoramento dos impactos são explicitadas. & $\mathrm{G}$ & Critério não atendido. \\
\hline
\end{tabular}


(Continuação)

\begin{tabular}{|c|c|c|c|}
\hline & Critério & Nota & Comentários \\
\hline \multirow[t]{3}{*}{23} & Links para AIA de projetos e outras AAE são explicitados & $\mathrm{G}$ & Critério não atendido. \\
\hline & Avaliação da Seção 7 & $\mathrm{G}$ & Seção não atendida. \\
\hline & Seção 8 - Consulta & & \\
\hline 24 & $\begin{array}{l}\text { As autoridades ambientais e outras e o público é dada a oportunidade, } \\
\text { dentro de um prazo adequado, de expressar a sua opinião sobre a AAE } \\
\text { antes da adoção da ação estratégica. }\end{array}$ & $\mathrm{F}$ & $\begin{array}{l}\text { Foram realizadas duas consultas públicas (pg 26). No entanto, o relatório } \\
\text { não fornece detalhes sobre a maneira como esta foi feita. }\end{array}$ \\
\hline \multirow[t]{3}{*}{25} & $\begin{array}{l}\text { Os órgãos públicos e relevantes tiveram uma resposta sobre a suas } \\
\text { colocações. }\end{array}$ & $\mathrm{F}$ & $\begin{array}{l}\text { O relatório não fornece detalhes sobre a maneira como a consulta foi feita. } \\
\text { Não se sabe se as considerações apontadas foram levadas em conta no } \\
\text { relatório final. }\end{array}$ \\
\hline & Avaliação da Seção 8 & $\mathrm{~F}$ & \\
\hline & Seção 9 - Relatório de AAE & & \\
\hline 26 & $\mathrm{O}$ relatório descreve como a $\mathrm{AAE}$ foi realizada. & $\mathrm{F}$ & A avaliação não descreve como todas as etapas foram conduzidas. \\
\hline 27 & $\begin{array}{l}\text { O relatório identifica o tomador de decisão e a entidade que realizou a } \\
\text { AAE. }\end{array}$ & A & $\begin{array}{l}\text { O tomador de decisão (Governo de Laos) e os consultores (consultoria } \\
\text { norueguesa) são devidamente identificados. }\end{array}$ \\
\hline 28 & $\begin{array}{l}\text { O relatório é claro e conciso em seu layout e apresentação. É } \\
\text { apresentado como um todo integrado, e usa mapas e outras ilustrações } \\
\text { quando necessário. }\end{array}$ & A & $\begin{array}{l}\text { Relatório claro, conciso e bem apresentado. Uso de mapa, tabela, ilustrações } \\
\text { quando necessário. }\end{array}$ \\
\hline
\end{tabular}


(Conclusão)

\begin{tabular}{l|l|c|l}
\hline & Critério & Nota & \\
\hline 29 & No relatório, a linguagem usada é simples e clara. & A & Linguagem simples e sem termos muito técnicos. \\
\hline 30 & $\begin{array}{l}\text { O relatório descreve a metodologia utilizada na AAE, inclusive quem } \\
\text { foi consultado e como. }\end{array}$ & B & $\begin{array}{l}\text { A metodologia utilizada apresenta algumas omissões. A Consulta pública } \\
\text { não foidamente descrita. }\end{array}$ \\
\hline 31 & O relatório se concentra nas grandes questões. & E & $\begin{array}{l}\text { A Avaliação se debruça sobre indicadores previamente apontados no TR. } \\
\text { Nãonhuma mençáo de que se trata de elementos relevantes. }\end{array}$ \\
\hline 32 & O relatório está escrito, sem viés, de forma imparcial. & A & Critério satisfatoriamente atendido. \\
\hline & Avaliação da Seção 9 & B & Seção bem atendida de forma geral. \\
\hline & Nota geral & D & Insatisfatório. Importantes omissões. \\
\hline
\end{tabular}

Fonte: Elaborado pelo autor 


\subsubsection{Revisão de qualidade do relatório da Análise de Impacto Cumulativo e Induzido do Projeto Hidrelétrico Rampur}

A revisão de qualidade (Quadro 27) evidencia que, de modo geral, a avaliação apresenta informações de maneira satisfatória para uma tomada de decisão (nota C). Com efeito, a primeira seção (nota C) apresenta como maior falha a não apresentação do projeto. Informações a respeito do conteúdo e os objetivos da Hidrelétrica Rampur não são fornecidos.

Na seção 2 (nota B), a única grande omissão é a não consideração de alternativas na definição do escopo de avaliação. Nas seções 3 e 4 todos os critérios foram satisfatoriamente atendidos (nota $\mathrm{A}$ ), ao contrário da seção 5 (nota $\mathrm{G}$ ) cujos critérios não foram atendidos.

Na seção 6 (nota A), todos os critérios foram atendidos satisfatoriamente. Na seção 7 (nota $\mathrm{F}$ ), a avaliação se refere pouco às medidas de mitigação e monitoramento propriamente ditas. A mitigação e o monitoramento focam mais para as instituições (medidas a serem incorporadas por elas para evitar e/ou minimizar impactos) e menos para os impactos levantados. Ademais, a avaliação não se refere a subsequentes AIAs. Na seção 8 (nota F), a avaliação menciona a realização da consulta pública. Porém, não apresenta detalhes de como esta foi feita nem como as opiniões levantadas foram consideradas na avaliação. Na última seção (nota $\mathrm{A}$ ), todos os critérios foram adequadamente atendidos. O relatório apresenta mapas; ilustrações; linguagem simples, clara e concisa facilitando o entendimento. 
Quadro 27 - Revisão de qualidade do relatório da Avaliação de Impacto Cumulativo e Induzido do Projeto Hidrelétrico Rampur

(Continua)

\begin{tabular}{|c|c|c|c|}
\hline & Critério & Nota & Comentários \\
\hline & Seção 1 - Objetivos & & \\
\hline 1 & Descreve o conteúdo e os objetivos principais da ação estratégica. & G & Critério não atendido \\
\hline 2 & $\begin{array}{l}\text { Os objetivos da AAE são apresentados, relacionados aos indicadores e metas, } \\
\text { se for o caso. }\end{array}$ & A & $\begin{array}{l}\text { Boa apresentação dos objetivos da avaliação (pg } \\
\text { 21). }\end{array}$ \\
\hline \multirow[t]{3}{*}{3} & $\begin{array}{l}\text { Os objetivos e indicadores da AAE cobrem uma gama adequada de temas } \\
\text { ambientais/de sustentabilidade, incluindo a biodiversidade, população, saúde } \\
\text { humana, fauna, flora, solo, água, ar, fatores climáticos, o património cultural, } \\
\text { paisagístico e suas inter-relações. Eles integram as questões ambientais, } \\
\text { sociais e econômicos. }\end{array}$ & A & Critério atendido satisfatoriamente. \\
\hline & Avaliação da Seção 1 & $\mathrm{C}$ & Satisfatório. \\
\hline & Seção 2 - Escopo & & \\
\hline 4 & $\begin{array}{l}\text { Autoridades competentes e apropriadas são consultadas para a determinação } \\
\text { do alcance e nível de informações que devem ser incluídas no relatório AAE. }\end{array}$ & A & Critério atendido (pg 23). \\
\hline 5 & $\begin{array}{l}\text { A AAE se concentra em questões importantes e desconsidera as menos } \\
\text { significativas. As razões de desconsideração devem ser documentadas. }\end{array}$ & A & Critério atendido. \\
\hline 6 & Alternativas razoáveis estabelecidas. & $\mathrm{G}$ & Critério não atendido. \\
\hline 7 & $\begin{array}{l}\text { Técnicas, dificuldades processuais e outros problemas (tais como deficiências } \\
\text { técnicas ou falta de know-how) são discutidos. Suposições e incertezas são } \\
\text { explicitadas. }\end{array}$ & $\mathrm{n} / \mathrm{a}$ & \\
\hline
\end{tabular}


(Continuação)

\begin{tabular}{|c|c|c|c|}
\hline & Critério & Nota & Comentários \\
\hline & Avaliação da Seção 2 & $\mathrm{~B}$ & Bem apresentado. Poucas omissões. \\
\hline & Seção 3 - Baseline & & \\
\hline 8 & $\begin{array}{l}\text { Aspectos pertinentes do estado atual do ambiente receptor da ação estratégica } \\
\text { e a sua provável evolução, sem a ação estratégica são descritos. } \\
\text { Características ambientais das zonas susceptíveis de serem significativamente } \\
\text { afetadas são descritas com mais detalhes. }\end{array}$ & A & Critério atendido satisfatoriamente (pg 29-154). \\
\hline 9 & Os objetivos de AAE e dados de coleta da baseline se reforçam mutuamente. & A & Critério atendido satisfatoriamente (pg 29-154). \\
\hline \multirow[t]{3}{*}{10} & $\begin{array}{l}\text { Os métodos utilizados para levantar a baseline são adequados à abrangência e } \\
\text { complexidade da avaliação. }\end{array}$ & $\mathrm{B}$ & $\begin{array}{l}\text { O levantamento da baseline foi feito através de um } \\
\text { levantamento de informações de outros trabalhos. O } \\
\text { levantamento foi condizente com a complexidade } \\
\text { da avaliação. }\end{array}$ \\
\hline & Avaliação da Seção3 & A & Muito satisfatório. \\
\hline & Seção 4 - Links para outras ações estratégicas & & \\
\hline 11 & $\begin{array}{l}\text { As relações entre a ação estratégica e os níveis anteriores e posteriores (na } \\
\text { cadeia de tomada de decisão) são identificadas e explicadas. }\end{array}$ & A & $\begin{array}{l}\text { A avaliação menciona e relaciona todos os projetos } \\
\text { da bacia do rio Satluj. }\end{array}$ \\
\hline \multirow[t]{2}{*}{12} & $\begin{array}{l}\text { Aspectos que geram conflitos entre as ações estratégicas são claramente } \\
\text { documentados; e são feitas recomendações sobre como conciliar as ações } \\
\text { estratégicas, de modo a promover a sustentabilidade. }\end{array}$ & $\mathrm{n} / \mathrm{a}$ & \\
\hline & Avaliação da Seção 4 & A & Muito Satisfatório. \\
\hline
\end{tabular}


(Continuação)

\begin{tabular}{|c|c|c|c|}
\hline & Seção 5 - Alternativas & Nota & Comentários \\
\hline 13 & $\begin{array}{l}\text { As alternativas consideradas são apropriadas para a escala (internacional, } \\
\text { nacional, etc.) e o nível (Política, Plano, Programa) da tomada de decisão. }\end{array}$ & $\mathrm{G}$ & $\begin{array}{l}\text { A avaliação somente analisou a alternativa com o } \\
\text { projeto. }\end{array}$ \\
\hline 14 & $\begin{array}{l}\text { As alternativas consideradas lidam com as questões identificadas na baseline } \\
\text { e/ou buscam alcançar metas de sustentabilidade. }\end{array}$ & G & Critério não atendido. \\
\hline 15 & $\begin{array}{l}\text { As alternativas incluem o "não fazer nada", "fazer o mínimo" e "alternativas } \\
\text { mais benéficas ao ambiente". }\end{array}$ & $\mathrm{G}$ & $\begin{array}{l}\text { Critério não atendido. Apenas foi considerada a } \\
\text { alternativa com o projeto. Ademais alternativas não } \\
\text { foram consideradas. }\end{array}$ \\
\hline 16 & $\begin{array}{l}\text { As razões para descartar alternativas de maiores considerações são } \\
\text { apresentadas. }\end{array}$ & $\mathrm{G}$ & Critério não atendido. \\
\hline \multirow[t]{3}{*}{17} & $\begin{array}{l}\text { Os efeitos ambientais e de sustentabilidade de cada alternativa são } \\
\text { identificados e comparados. }\end{array}$ & $\mathrm{G}$ & Critério não atendido. \\
\hline & Avaliação da Seção 5 & G & Seção não atendida. \\
\hline & Seção 6 - Identificação e avaliação de Impactos & & \\
\hline 18 & $\begin{array}{l}\text { Os prováveis impactos significativos sobre o meio ambiente são identificados } \\
\text { e avaliados. }\end{array}$ & A & Critério muito bem atendido. \\
\hline 19 & $\begin{array}{l}\text { Prováveis impactos indiretos, cumulativos, sinérgicos e secundários são } \\
\text { identificados e avaliados. }\end{array}$ & A & Critério muito bem atendido. \\
\hline 20 & $\begin{array}{l}\text { Foram utilizadas adequadas técnicas de previsão de impacto e de avaliação. A } \\
\text { avaliação do impacto condiz com as normas e regulamentos aceitos } \\
\text { internacionalmente. }\end{array}$ & A & Critério muito bem atendido. \\
\hline
\end{tabular}


(Continuação)

\begin{tabular}{|c|c|c|c|}
\hline & Critério & Nota & Comentários \\
\hline & Avaliação da Seção 6 & A & Seção bem atendida. \\
\hline & Seção 7 - Mitigação e monitoramento & & \\
\hline 21 & $\begin{array}{l}\text { As medidas previstas para evitar, reduzir, compensar e/ou melhorar quaisquer } \\
\text { impactos significativos da ação estratégica são indicadas. }\end{array}$ & $\mathrm{D}$ & $\begin{array}{l}\text { A avaliação se refere pouco às medidas de } \\
\text { mitigação propriamente ditas. A mitigação é muito } \\
\text { mais focada nas medidas a serem incorporadas por } \\
\text { instituições para evitar e/ou minimizar impactos. }\end{array}$ \\
\hline 22 & Medidas de monitoramento dos impactos são explicitadas. & $\mathrm{D}$ & $\begin{array}{l}\text { A avaliação pouco se refere às medidas de monito- } \\
\text { ramento em si. O monitoramento é muito mais } \\
\text { focado nas medidas a serem incorporadas por } \\
\text { instituições para evitar e/ou minimizar impactos. }\end{array}$ \\
\hline \multirow[t]{3}{*}{23} & Links para AIA de projetos e outras AAE são explicitados. & G & Critério não atendido \\
\hline & Avaliação da Seção 7 & $\mathrm{~F}$ & Insatisfatório. Importantes omissões. \\
\hline & Seção 8 - Consulta & & \\
\hline 24 & $\begin{array}{l}\text { As autoridades ambientais e outras e o público é dada a oportunidade, dentro } \\
\text { de um prazo adequado, de expressar a sua opinião sobre a AAE antes da } \\
\text { adoção da ação estratégica. }\end{array}$ & $\mathrm{F}$ & $\begin{array}{l}\text { Critério muito mal atendido. O relatório menciona a } \\
\text { realização de consulta pública sem apresentar } \\
\text { informações da maneira que esta foi realizada. }\end{array}$ \\
\hline \multirow[t]{2}{*}{25} & Os órgãos públicos e relevantes tiveram uma resposta sobre suas colocações. & $\mathrm{F}$ & $\begin{array}{l}\text { Critério muito mal atendido. O relatório menciona a } \\
\text { realização de consulta pública sem apresentar } \\
\text { informações da maneira que esta foi conduzida. }\end{array}$ \\
\hline & Avaliação da Seção 8 & $\mathrm{~F}$ & Insatisfatório. Importantes omissões. \\
\hline
\end{tabular}


(Conclusão)

\begin{tabular}{l|l|c|c}
\hline & Seção 9 - Relatório de AAE & Nota & Comentários \\
\hline 26 & O relatório descreve como a AAE foi realizada. & A & Satisfatório. Critério bem atendido. \\
\hline 27 & O relatório identifica o tomador de decisão e a entidade que realizou a AAE. & A & Satisfatório.Critério bem atendido. \\
\hline 28 & $\begin{array}{l}\text { O relatório é claro e conciso em seu layout e apresentação. É apresentado } \\
\text { como um todo integrado, usa mapas e outras ilustrações quando necessário. }\end{array}$ & A & Satisfatório. Critério bem atendido. \\
\hline 29 & No relatório, a linguagem usada é simples e clara. & A & Satisfatório. Critério bem atendido. \\
\hline 30 & $\begin{array}{l}\text { O relatório descreve a metodologia utilizada na AAE, inclusive quem foi } \\
\text { consultado e como. }\end{array}$ & A & Satisfatório. Critério bem atendido. \\
\hline 31 & O relatório se concentra nas grandes questões. & A & Satisfatório. Critério bem atendido. \\
\hline 32 & O relatório está escrito, sem viés, de forma imparcial. & A & Satisfatório. Critério bem atendido. \\
\hline & Avaliação da Seção 9 & C & Satisfatório. Seção bem atendida. \\
\hline & Nota geral & Satisfatório de forma geral. \\
\hline
\end{tabular}

Fonte: Elaborado pelo autor 


\subsubsection{Síntese dos Resultados}

Observa-se no Quadro 28 e nas figuras 25 e 26 que apenas dois relatórios (Avaliação Ambiental do Projeto Energia Manantali e Avaliação de Impacto Cumulativo e Induzido do Projeto Hidrelétrico Rampur) apresentaram informações suficientes para a tomada de decisão. Ao analisar as seções, nota-se que os critérios da primeira seção foram atendidos de maneira satisfatória em geral. Todavia, em quase todos os casos analisados, a apresentação do projeto e de seus objetivos foi omitida.

Os critérios da segunda seção foram satisfatoriamente atendidos na metade dos casos. Chama a atenção o fato de que os atores-chave não foram envolvidos na metade dos casos. Na terceira seção, observa-se um grande contraste: de um lado, constata-se que todos os critérios não são atendidos (Avaliação Ambiental Setorial do Projeto de Desenvolvimento de Energia Nepal e Análise de Impacto Cumulativo do Projeto Hidrelétrico Nam Theun 2) e de outro lado percebe-se que os critérios são satisfatoramente atendidos (Avaliação de Impacto Cumulativo do Projeto Hidrelétrico Kabeli “A” e Avaliação de Impacto Cumulativo e Induzido do Projeto Hidrelétrico Rampur). O critério relativo à relação entre os objetivos da avaliação e a baseline se destaca, pois não foi atendido em quatro dos seis casos.

$\mathrm{Na}$ quarta seção, os critérios foram adequadamente atendidos exceto para as Avaliação de Impacto Cumulativo do Projeto Hidrelétrico Kabeli “A” e Análise de Impacto Cumulativo do Projeto Hidrelétrico Nam Theun 2. Os critérios da quinta seção foram muito mal atendidos de forma geral. A Avaliação de Impacto Cumulativo e Induzido do Projeto Hidrelétrico Rampur chama a atenção, pois não atendeu a nenhum critério. Nessa seção, os critérios 15,16 e 17 se destacam, pois não foram atendidos em mais da metade dos casos.

$\mathrm{Na}$ sexta seção, os critérios foram adequadamente atendidos exceto para dois casos: a Avaliação Ambiental Regional do Projeto Energia Gasosa Kribi e Avaliação Ambiental Setorial do Projeto de Desenvolvimento de Energia Nepal. Para essa última, nenhum critério da seção foi atendido.

Na sétima seção, os critérios foram mal atendidos de forma geral. Para a Avaliação de Impacto Cumulativo do Projeto Hidrelétrico Kabeli “A” e Análise de Impacto Cumulativo do Projeto Hidrelétrico Nam Theun 2, nenhum critério foi atendido. A Avaliação Ambiental Regional do Projeto Energia Gasosa Kribi, Avaliação Ambiental Setorial do Projeto de Desenvolvimento de Energia Nepal e a Avaliação de Impacto Cumulativo e Induzido do Projeto Hidrelétrico Rampur apresentaram muito mal as informações, enquanto a Avaliação 
Ambiental do Projeto Energia Manantali teve todos os critérios satisfatoriamente apresentados.

Na seção 8, três casos (Avaliação Ambiental do Projeto Energia Manantali, Análise de Impacto Cumulativo do Projeto Hidrelétrico Nam Theun 2 e Avaliação de Impacto Cumulativo e Induzido do Projeto Hidrelétrico Rampur) tiveram os critérios muitos mal atendidos, um caso (Avaliação Ambiental Setorial do Projeto de Desenvolvimento de Energia Nepal) não atendeu a nenhum dos critérios e dois casos (Avaliação Ambiental Regional do Projeto Energia Gasosa Kribi e Avaliação de Impacto Cumulativo do Projeto Hidrelétrico Kabeli “A”) apresentaram as informações de forma satisfatória.

$\mathrm{Na}$ nona seção, os critérios foram adequadamente atendidos de forma geral. A Avaliação de Impacto Cumulativo e Induzido do Projeto Hidrelétrico Rampur se destaca com a nota A. Avaliação Ambiental Setorial do Projeto de Desenvolvimento de Energia Nepal obteve a nota C. Esta foi a menor nota. 
Quadro 28 - Revisão de qualidade dos relatórios

(continua)

\begin{tabular}{|c|c|c|c|c|c|c|c|}
\hline & & Manantali & Kribi & $\begin{array}{l}\text { Energia } \\
\text { Nepal }\end{array}$ & Kabeli "A" & $\begin{array}{l}\text { Nam } \\
\text { Theun } 2\end{array}$ & Rampur \\
\hline & \multicolumn{7}{|l|}{ Seção 1 - Objetivos } \\
\hline & Critério & Nota & Nota & Nota & Nota & Nota & Nota \\
\hline 1 & Descreve o conteúdo e os objetivos principais da ação estratégica. & A & $\mathrm{F}$ & G & $\mathrm{D}$ & G & G \\
\hline 2 & $\begin{array}{l}\text { Os objetivos da AAE são apresentados, relacionados aos indicadores e } \\
\text { metas, se for o caso. }\end{array}$ & G & $\mathrm{C}$ & $\mathrm{C}$ & D & $\mathrm{C}$ & A \\
\hline 3 & $\begin{array}{l}\text { Os objetivos e indicadores da AAE cobrem uma gama adequada de } \\
\text { temas ambientais/de sustentabilidade, incluindo a biodiversidade, } \\
\text { população, saúde humana, fauna, flora, solo, água, ar, fatores climáticos, } \\
\text { o património cultural, paisagístico e suas inter-relações. Eles integram } \\
\text { as questões ambientais, sociais e econômicos. }\end{array}$ & G & A & A & $\mathrm{C}$ & $\mathrm{C}$ & A \\
\hline & Avaliação da Seção 1 & $\mathbf{F}$ & $\mathbf{C}$ & $\mathbf{C}$ & $\mathbf{C}$ & D & C \\
\hline
\end{tabular}

Seção 2 - Escopo

\begin{tabular}{l|l|c|c|c|c|c}
\hline & Critério & & & & & \\
\hline 4 & $\begin{array}{l}\text { Autoridades competentes e apropriadas são consultadas para a } \\
\text { determinação do alcance enível de informações que devem ser incluídas } \\
\text { no relatório AAE. }\end{array}$ & G & G & G & A & F \\
\hline 5 & $\begin{array}{l}\text { A AAE se concentra em questões importantes e desconsidera os menos } \\
\text { significativos. As razões de desconsideração devem ser documentadas. }\end{array}$ & B & G & F & E & E \\
\hline
\end{tabular}


(Continuação)

\begin{tabular}{l|l|c|c|c|c|c|c|}
\hline \multicolumn{2}{l|}{ Critério } & Manantali & Kribi & $\begin{array}{l}\text { Energia } \\
\text { Nepal }\end{array}$ & Kabeli "A" & $\begin{array}{l}\text { Nam } \\
\text { Theun 2 }\end{array}$ & Rampur \\
\hline 6 & Alternativas razoáveis estabelecidas. & A & A & C & G \\
\hline 7 & $\begin{array}{l}\text { Técnicas, dificuldades processuais e outros problemas (tais como } \\
\text { deficiências técnicas ou falta de know-how) são discutidos. Suposições } \\
\text { e incertezas são explicitadas. }\end{array}$ & A & B & G \\
\hline & Avaliação da Seção 2 & C & E & F & C \\
\hline
\end{tabular}

Seção 3 - Baseline

\begin{tabular}{|c|c|c|c|c|c|c|c|}
\hline & Critério & & & & & & \\
\hline 8 & $\begin{array}{l}\text { Aspectos pertinentes do estado atual do ambiente receptor da ação } \\
\text { estratégica e a sua provável evolução, sem a ação estratégica são } \\
\text { descritos. Características ambientais das zonas susceptíveis de serem } \\
\text { significativamente afetadas são descritas com mais detalhes. }\end{array}$ & B & A & G & A & $\mathrm{G}$ & A \\
\hline 9 & $\begin{array}{l}\text { Os objetivos de AAE e dados de coleta da baseline se reforçam } \\
\text { mutuamente. }\end{array}$ & G & G & $\mathrm{G}$ & $\mathrm{C}$ & $\mathrm{G}$ & A \\
\hline \multirow[t]{2}{*}{10} & $\begin{array}{l}\text { Os métodos utilizados para levantar a baseline são adequados à } \\
\text { abrangência e complexidade da avaliação. }\end{array}$ & G & A & $\mathrm{G}$ & $\mathrm{B}$ & $\mathrm{n} / \mathrm{a}$ & $\mathrm{n} / \mathrm{a}$ \\
\hline & Avaliação da Seção3 & $\mathbf{F}$ & $\mathbf{C}$ & G & $\mathbf{B}$ & $\mathbf{G}$ & $\mathbf{A}$ \\
\hline
\end{tabular}


(Continuação)

\begin{tabular}{|c|c|c|c|c|c|c|c|}
\hline \multicolumn{2}{|r|}{ Seção 4 - Links para outras ações estratégicas } & \multirow{2}{*}{\begin{tabular}{|c|} 
Manantali \\
B
\end{tabular}} & \multirow{2}{*}{ Kribi } & \multirow{2}{*}{$\begin{array}{r}\text { Energia } \\
\text { Nepal } \\
\text { B }\end{array}$} & \multirow{2}{*}{$\begin{array}{c}\text { Kabeli "A" } \\
\text { G }\end{array}$} & \multirow{2}{*}{\begin{tabular}{|c|}
$\begin{array}{l}\text { Nam } \\
\text { Theun } 2\end{array}$ \\
F
\end{tabular}} & \multirow{2}{*}{$\begin{array}{c}\text { Rampur } \\
\text { A }\end{array}$} \\
\hline 11 & $\begin{array}{l}\text { As relações entre a ação estratégica e os níveis anteriores e posteriores } \\
\text { (na cadeia de tomada de decisão) são identificadas e explicadas. }\end{array}$ & & & & & & \\
\hline \multirow[t]{2}{*}{12} & $\begin{array}{l}\text { Aspectos que geram conflitos entre as ações estratégicas são claramente } \\
\text { documentados; e são feitas recomendações sobre como conciliar as } \\
\text { ações estratégicas, de modo a promover a sustentabilidade. }\end{array}$ & $\mathrm{n} / \mathrm{a}$ & $\mathrm{n} / \mathrm{a}$ & $\mathrm{n} / \mathrm{a}$ & $\mathrm{n} / \mathrm{a}$ & $\mathrm{n} / \mathrm{a}$ & $\mathrm{n} / \mathrm{a}$ \\
\hline & Avaliação da Seção 4 & B & $\mathbf{A}$ & $\mathbf{B}$ & G & $\mathbf{F}$ & $\mathbf{A}$ \\
\hline
\end{tabular}

\section{Seção 5 - Alternativas}

\begin{tabular}{|c|c|c|c|c|c|c|c|}
\hline & Critério & & & & & & \\
\hline 13 & $\begin{array}{l}\text { As alternativas consideradas são apropriadas para a escala } \\
\text { (internacional, nacional, etc.) e o nível (Política, Plano, Programa) da } \\
\text { tomada de decisão. }\end{array}$ & $\mathrm{C}$ & $\mathrm{C}$ & $\mathrm{C}$ & G & $\mathrm{C}$ & G \\
\hline 14 & $\begin{array}{l}\text { As alternativas consideradas lidam com as questões identificadas na } \\
\text { baseline e/ou buscam alcançar metas de sustentabilidade. }\end{array}$ & A & A & $\mathrm{G}$ & A & $\mathrm{E}$ & G \\
\hline 15 & $\begin{array}{l}\text { As alternativas incluem o "não fazer nada", "fazer o mínimo" e } \\
\text { "alternativas mais benéficas ao ambiente". }\end{array}$ & $\mathrm{G}$ & $\mathrm{E}$ & G & G & $\mathrm{F}$ & G \\
\hline 16 & $\begin{array}{l}\text { As razões para descartar alternativas de maiores considerações são } \\
\text { apresentadas. }\end{array}$ & $\mathrm{B}$ & $\mathrm{F}$ & $\mathrm{B}$ & G & $\mathrm{G}$ & G \\
\hline 17 & $\begin{array}{l}\text { Os efeitos ambientais e de sustentabilidade de cada alternativa são } \\
\text { identificados e comparados. }\end{array}$ & A & G & G & G & $\mathrm{D}$ & G \\
\hline
\end{tabular}


(Continuação)

\begin{tabular}{l|l|l|l|l|l|l|l|}
\hline \multicolumn{2}{l|}{ Critério } & Manantali & Kribi & $\begin{array}{l}\text { Energia } \\
\text { Nepal }\end{array}$ & $\begin{array}{l}\text { Nam } \\
\text { Theun 2 }\end{array}$ & Rampur \\
\hline & Avaliação da Seção 5 & C & F & F & F & D \\
\hline
\end{tabular}

Seção 6 - Identificação e avaliação de Impactos

\begin{tabular}{|c|c|c|c|c|c|c|c|}
\hline & Critério & & & & & & \\
\hline 18 & $\begin{array}{l}\text { Os prováveis impactos significativos sobre o meio ambiente são } \\
\text { identificados e avaliados. }\end{array}$ & $\mathrm{B}$ & $\mathrm{F}$ & $\mathrm{G}$ & $\mathrm{B}$ & A & A \\
\hline 19 & $\begin{array}{l}\text { Prováveis impactos indiretos, cumulativos, sinergéticos e secundários } \\
\text { são identificados e avaliados. }\end{array}$ & B & $\mathrm{F}$ & G & $\mathrm{E}$ & $\mathrm{E}$ & A \\
\hline \multirow[t]{2}{*}{20} & $\begin{array}{l}\text { Foram utilizadas adequadas técnicas de previsão de impacto e de } \\
\text { avaliação. A avaliação do impacto condiz com as normas e } \\
\text { regulamentos aceitos internacionalmente. }\end{array}$ & A & $\mathrm{E}$ & $\mathrm{G}$ & $\mathrm{B}$ & $\mathrm{B}$ & A \\
\hline & Avaliação da Seção 6 & $\mathbf{B}$ & $\mathbf{F}$ & $\mathbf{G}$ & $\mathbf{C}$ & $\mathbf{C}$ & A \\
\hline \multicolumn{8}{|c|}{ Seção 7 - Mitigação e monitoramento } \\
\hline & Critério & & & & & & \\
\hline 21 & $\begin{array}{l}\text { As medidas previstas para evitar, reduzir, compensar e/ou melhorar } \\
\text { quaisquer impactos significativos da ação estratégica são indicadas. }\end{array}$ & A & $\mathrm{D}$ & $\mathrm{F}$ & G & $\mathrm{G}$ & $\mathrm{D}$ \\
\hline
\end{tabular}


(Continuação)

\begin{tabular}{|c|c|c|c|c|c|c|c|}
\hline \multicolumn{2}{|c|}{ Critério } & \multirow{2}{*}{$\begin{array}{c}\text { Manantali } \\
\text { A }\end{array}$} & \multirow{2}{*}{$\begin{array}{c}\text { Kribi } \\
\text { F }\end{array}$} & \multirow{2}{*}{$\begin{array}{l}\text { Energia } \\
\text { Nepal } \\
\text { F }\end{array}$} & \multirow{2}{*}{$\begin{array}{c}\text { Kabeli "A" } \\
\text { G }\end{array}$} & \multirow{2}{*}{$\begin{array}{l}\text { Nam } \\
\text { Theun } 2 \\
\text { G }\end{array}$} & \multirow{2}{*}{$\begin{array}{c}\text { Rampur } \\
\text { D }\end{array}$} \\
\hline 22 & $\begin{array}{l}\text { As medidas previstas para evitar, reduzir, compensar e/ou melhorar } \\
\text { quaisquer impactos significativos da ação estratégica são indicadas. }\end{array}$ & & & & & & \\
\hline \multirow[t]{2}{*}{23} & Links para AIA de projetos e outras AAE são explicitados. & $\mathrm{n} / \mathrm{a}$ & B & $\mathrm{C}$ & $\mathrm{G}$ & G & G \\
\hline & Avaliação da Seção 7 & $\mathbf{A}$ & $\mathbf{E}$ & $\mathbf{F}$ & G & G & $\mathbf{F}$ \\
\hline
\end{tabular}

\section{Seção 8 - Consulta}

\begin{tabular}{|c|c|c|c|c|c|c|c|}
\hline & Critério & & & & & & \\
\hline 24 & $\begin{array}{l}\text { Às autoridades ambientais e outras e o público é dada a oportunidade, } \\
\text { dentro de um prazo adequado, de expressar a sua opinião sobre a AAE } \\
\text { antes da adopção da ação estratégica. }\end{array}$ & $\mathrm{E}$ & $\mathrm{B}$ & $\mathrm{G}$ & A & $\mathrm{F}$ & $F$ \\
\hline \multirow[t]{2}{*}{25} & $\begin{array}{l}\text { Os órgãos públicos e relevantes tiveram uma resposta sobre a suas } \\
\text { colocações. }\end{array}$ & G & A & $\mathrm{G}$ & $\mathrm{D}$ & $\mathrm{F}$ & $\mathrm{F}$ \\
\hline & Avaliação da Seção8 & $\mathbf{F}$ & $\mathbf{B}$ & $\mathbf{G}$ & $\mathbf{B}$ & $\mathbf{F}$ & $\mathbf{F}$ \\
\hline
\end{tabular}

\section{Seção 9 - Relatório de AAE}

\begin{tabular}{l|l|l|l|l|l|l}
\hline & Critério & & & & & \\
\hline 26 & O relatório descreve como a AAE foi realizada. & A & A & C & G \\
\hline
\end{tabular}


(Conclusão)

\begin{tabular}{|c|c|c|c|c|c|c|c|}
\hline \multicolumn{2}{|c|}{ Critério } & \multirow{2}{*}{\begin{tabular}{|c|} 
Manantali \\
B
\end{tabular}} & \multirow{2}{*}{ Kribi } & \multirow{2}{*}{$\begin{array}{r}\begin{array}{l}\text { Energia } \\
\text { Nepal }\end{array} \\
\mathrm{C}\end{array}$} & \multirow{2}{*}{$\begin{array}{c}\text { Kabeli "A" } \\
\text { A }\end{array}$} & \multirow{2}{*}{\begin{tabular}{|c|} 
Nam \\
Theun 2
\end{tabular}} & \multirow{2}{*}{ Rampur } \\
\hline 27 & $\begin{array}{l}\text { O relatório identifica o tomador de decisão e a entidade que realizou a } \\
\text { AAE. }\end{array}$ & & & & & & \\
\hline 28 & $\begin{array}{l}\text { O relatório é claro e conciso em seu layout e apresentação, É } \\
\text { apresentado como um todo integrado, e usa mapas e outras ilustrações } \\
\text { quando necessário. }\end{array}$ & $\mathrm{B}$ & B & $\mathrm{E}$ & B & A & A \\
\hline 29 & $\begin{array}{l}\text { O relatório é claro e conciso em seu layout e apresentação, É } \\
\text { apresentado como um todo integrado, e usa mapas e outras ilustrações } \\
\text { quando necessário. }\end{array}$ & A & A & A & A & A & A \\
\hline 30 & $\begin{array}{l}\text { O relatório descreve a metodologia utilizada na } \mathrm{AAE} \text {, inclusive quem } \\
\text { foi consultado e como. }\end{array}$ & G & $\mathrm{D}$ & G & $\mathrm{C}$ & $\mathrm{B}$ & A \\
\hline 31 & $\begin{array}{l}\text { O relatório descreve a metodologia utilizada na AAE, inclusive quem } \\
\text { foi consultado e como. }\end{array}$ & A & $?$ & G & $\mathrm{B}$ & $\mathrm{E}$ & A \\
\hline \multirow[t]{3}{*}{32} & O relatório está escrito, sem viés de forma imparcial. & A & A & A & A & A & A \\
\hline & Avaliação da Seção 9 & B & $\mathbf{B}$ & $\mathbf{C}$ & B & $\mathbf{B}$ & $\mathbf{A}$ \\
\hline & Nota Geral & $\mathbf{C}$ & $\mathbf{E}$ & $\mathbf{F}$ & D & D & B \\
\hline
\end{tabular}

Fonte: Elaborado pelo autor 
Figura 25 - Revisão de qualidade dos relatórios

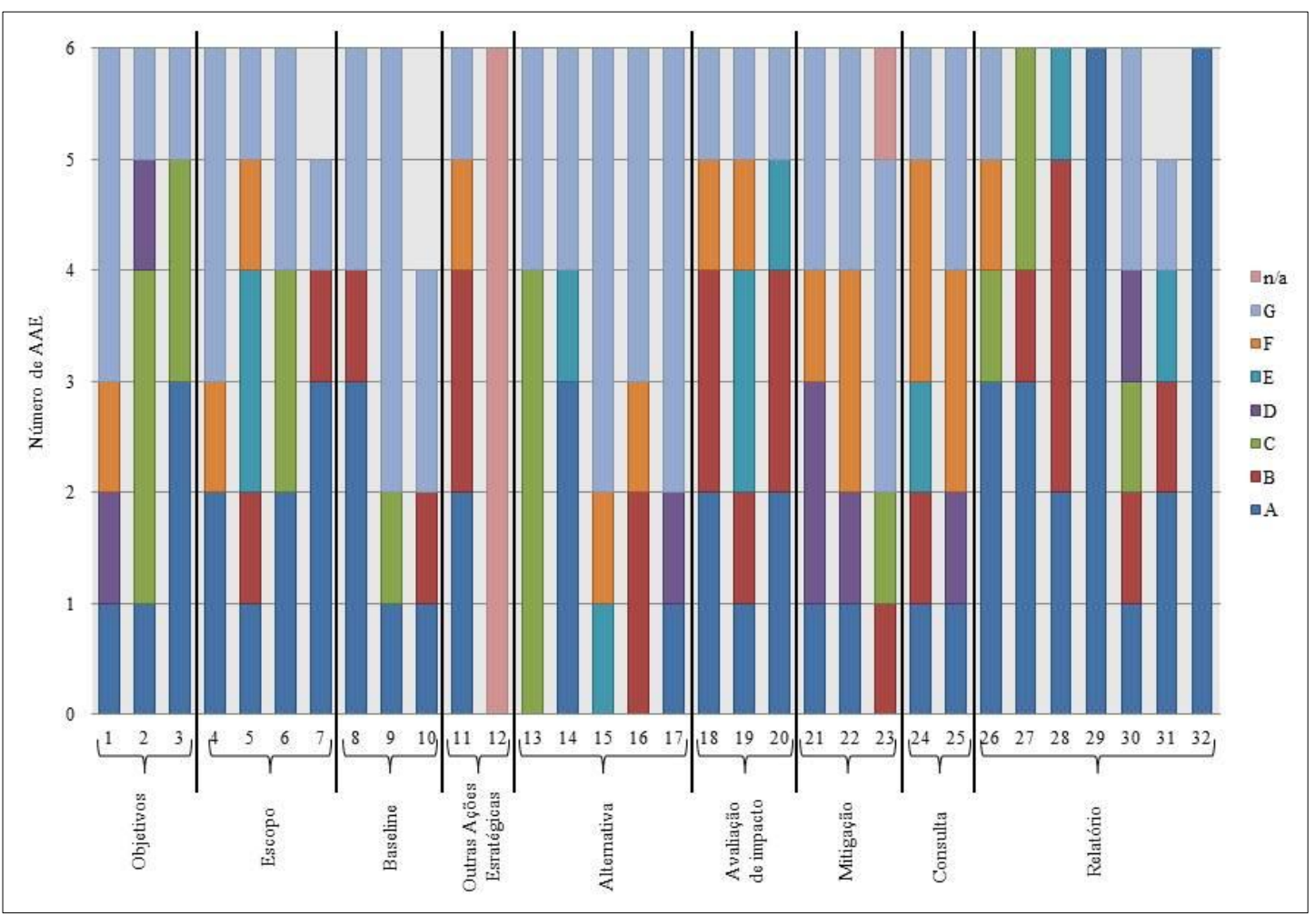

Fonte: Elaborado pelo autor

Figura 26 - Seções das revisões de qualidade dos relatórios

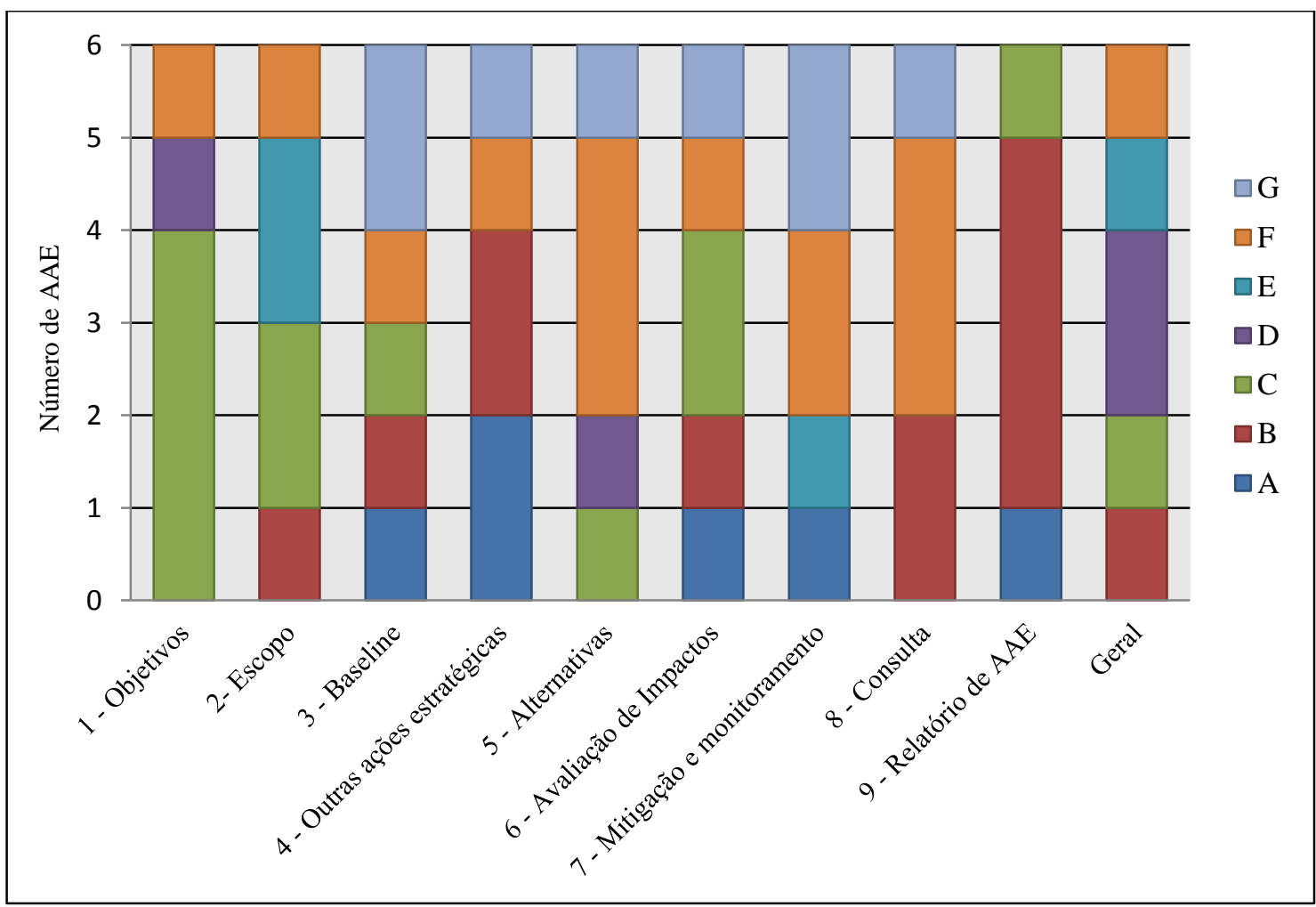

Fonte: Elaborado pelo autor 


\subsubsection{Discussão}

Ao analisar as figuras 25 e 26 como também o Quadro 28 que apresenta os resultados das revisões de qualidade de relatórios, percebe-se que apenas dois relatórios (Avaliação Ambiental do Projeto Energia Manantali e Avaliação de Impacto Cumulativo e Induzido do Projeto Hidrelétrico Rampur) apresentaram informações suficientes para a tomada de decisão. Ao examinar as seções, nota-se que os critérios da primeira seção foram adequadamente atendidos de maneira geral. Todavia, em quase todos os casos analisados, a apresentação do projeto assim como seus objetivos foi omitida. Esta falha é grave uma vez que o projeto constitui o objeto de estudo da avaliação.

Os critérios da segunda seção foram satisfatoriamente atendidos na metade dos casos. Chama a atenção o fato de que os atores-chave não foram envolvidos na metade dos casos. É importante ressaltar que todos os casos analisados são de categoria A. Assim sendo, devem-se realizar no mínimo duas consultas aos stakeholders de acordo com as políticas ambientais da AMD voltadas para a Avaliação Ambiental Estratégica. No entanto, não foi feita a primeira consulta em metade dos casos analisados. Esta falha é muito grave, uma vez que a participação de atores-chave está entre os fatores mais citados que influenciam positivamente o impacto da AAE na tomada de decisão (RUNHAAR; DRIESSEN, 2007). No início de um processo de AAE, as partes interessadas, muitas vezes, tentam trazer suas ideias e valores, especialmente na fase de definição do escopo e desenvolvimento de alternativas. Com isso, novos atores podem entrar na arena do processo decisório, atores com objetivos e pontos de vista distintos sobre como as decisões devem ser tomadas (RUNHAAR, 2009). A etapa de definição de escopo é uma etapa-chave uma vez que nele se define o conteúdo da avaliação ambiental. No âmbito das Instituições Internacionais de Desenvolvimento, a definição do escopo é feita em conjunto com o mutuário. Os resultados obtidos mostram que em $50 \%$ dos casos não houve envolvimento dos atores-chave nesta etapa. Ainda na segunda seção, os resultados mostram que os aspectos-chave do escopo não são devidamente apresentados. Não há explicação sobre a identificação desses aspectos. Essa seção também destaca a falta de dados e informações como sendo as mais frequentes dificuldades encontradas pelos consultores. A falta de dado principalmente nos países em desenvolvimento tem sido apontado por Alshuwaikhat (2005). De acordo com o autor, dados inadequados ou indisponíveis prejudicam a anticipação e o monitoramento de impactos. Para Fischer (2007) e Therivel (2004) há muitas razões para melhorar a participação pública: esta aumenta a 
transparência no processo de tomada de decisão; previne futuro confronto e controvérsia devido à oposição da opinião pública; e valida o processo de AAE.

$\mathrm{Na}$ terceira seção, observa-se um grande contraste com, de um lado, todos os critérios não atendidos (Avaliação Ambiental Setorial do Projeto de Desenvolvimento de Energia Nepal e Análise de Impacto Cumulativo do Projeto Hidrelétrico Nam Theun 2) e, de outro lado, critérios satisfatoriamente atendidos (Avaliação de Impacto Cumulativo do Projeto Hidrelétrico Kabeli "A” e Avaliação de Impacto Cumulativo e Induzido do Projeto Hidrelétrico Rampur). O critério relativo à relação entre os objetivos da avaliação e a baseline se destaca, pois não foi atendido em quatro dos seis casos. Os resultados também mostram que os dados da baseline são muitas vezes oriundos de outros trabalhos. Isso corrobora com o ponto de vista dos consultores que consideram a falta de dados como sendo a maior dificuldade encontrada (ver critério 7 da seção 2) nas aplicações.

$\mathrm{Na}$ quarta seção, os critérios foram satisfatoriamente atendidos exceto para as Avaliação de Impacto Cumulativo do Projeto Hidrelétrico Kabeli “A” e Análise de Impacto Cumulativo do Projeto Hidrelétrico Nam Theun 2. A relação das ações estratégicas com outros projetos ou PPP foi evidenciada, principalmente, quando se tratam de ações da mesma região ou bacia. A relação da AAE com PPP é importante para prevenir conflitos, sobreposições e duplicação de tarefas. No tocante a projetos, a AAE e a AIA de projeto devem ser aplicadas em sequência (ALSHUWAIKHAT, 2005; FISCHER, 2003; LEE; WALSH, 1992; NOBLE, 2009; PARTIDÁRIO, 2007). Desta forma, é importante que haja menção de diretrizes a serem seguidas pelas AA posteriores.

Os critérios da quinta seção foram muito mal atendidos de forma geral. A Avaliação de Impacto Cumulativo e Induzido do Projeto Hidrelétrico Rampur chama a atenção, pois não atendeu a nenhum critério. Nesta seção, os critérios 15,16 e 17 chamam a atenção, pois não foram atendidos em mais da metade dos casos. Os resultados obtidos corroboram com a literatura que aponta a etapa de alternativas como um dos passos menos bem atendidos (MALVESTIO, 2013; MALVESTIO; MONTAÑO, 2013). Na maioria dos casos, apenas o cenário com o projeto foi levado em consideração. Embora o levantamento de dimensões estratégicas mostre a consideração de outras alternativas na concepção das ações estratégicas, essas alternativas não foram avaliadas. A literatura aponta o potencialidade da Avaliação Ambiental Estratégica considerar uma ampla variedade de alternativas (ALSHUWAIKHAT, 2005; LEE; WALSH, 1992; NOBLE, 2009; PARTIDÁRIO, 1996, 2000, 2007). No entanto, nos casos analisados, a maioria dos projetos já eram definidos levando as avaliações a restrigir-se às alternativas envolvendo os projetos. O caso do Projeto Energia Gasosa Kribi 
ilustra essa situação. No momento da condução da Avaliação Ambiental Regional, a implementação do projeto já estava em andamento.

Na sexta seção, os critérios foram apropriadamente atendidos exceto para dois casos: a Avaliação Ambiental Regional do Projeto Energia Gasosa Kribi e Avaliação Ambiental Setorial do Projeto de Desenvolvimento de Energia Nepal. Para esta última, nenhum critério da seção foi atendido. Nessa seção destaca-se o fato de que os impactos identificados pelas avaliações ambientais cumulativas apresentam muitas deficiências. Os efeitos cumulativos avaliados são restritos aos indicadores. Os estudos não consideram efeitos cumulativos de dois indicadores diferentes.

Na sétima seção, os critérios foram mal atendidos de forma geral. Para a Avaliação de Impacto Cumulativo do Projeto Hidrelétrico Kabeli “A” e Análise de Impacto Cumulativo do Projeto Hidrelétrico Nam Theun 2, nenhum critério foi atendido. Os relatórios da Avaliação Ambiental Regional do Projeto Energia Gasosa Kribi, Avaliação Ambiental Setorial do Projeto de Desenvolvimento de Energia Nepal e a Avaliação de Impacto Cumulativo e Induzido do Projeto Hidrelétrico Rampur apresentaram muito mal as informações enquanto a Avaliação Ambiental do Projeto Energia Manantali teve todos os critérios satisfatoriamente apresentados. Chama a atenção o fato de que a maioria das avaliações não apontou para as AIA de projetos uma vez que estas as anteciparam. Também se observou que as avaliações não se limitaram ao apontamento de medidas de mitigação e monitoramento relacionadas aos impactos previamente investigados. As instituições também foram alvos dessas medidas. Este achado está de acordo com o papel da AAE no âmbito do Banco Mundial defendido por Cashmore, Richardson e Axelsson (2014) e Richardson e Cashmore (2011). Para esses autores a Avaliação Ambiental Estratégica pode ser vista como um instrumento para a construção de olhares críticos sobre a cultura política nos países em desenvolvimento, a fim de sugerir reformas. Por meio dessa ferramenta, busca-se promover novas normas estruturais (nomeadamente, boa governança) e estimular a aceitação de novas tendências.

Na seção 8, três casos (Avaliação Ambiental do Projeto Energia Manantali, Análise de Impacto Cumulativo do Projeto Hidrelétrico Nam Theun 2 e Avaliação de Impacto Cumulativo e Induzido do Projeto Hidrelétrico Rampur) tiveram os critérios muitos mal atendidos, um caso (Avaliação Ambiental Setorial do Projeto de Desenvolvimento de Energia Nepal) não atendeu a nenhum dos critérios e dois casos (Avaliação Ambiental Regional do Projeto Energia Gasosa Kribi e Avaliação de Impacto Cumulativo do Projeto Hidrelétrico Kabeli “A”) apresentaram as informações de forma razoavelmente satisfatória. Nessa seção percebe-se que as consultas foram feitas. Fato que é positivo uma vez que na maioria das 
vezes trata-se de populações pobres. No entanto, a maneira como as consultas foram conduzidas não é adequadamente apresentada. Também não se menciona nos relatórios se as considerações apontadas nas consultas públicas foram levadas em conta no relatório final. A ineficiência da participação pública nos processos de AAE também tem sido apontado por González et al. (2014). Segundo os autores a deficiência das estratégias de consulta pública no Mexico e na China é responsável pelo baixo envolvimento das partes interessadas. Partidário (1996) vai além da indicação de deficiências de participação pública nos processos de AAE: para a autora, o envolvimento público limitado é um dos entraves à implementação da AAE. No entanto, para Lobos e Partidário (2014), mesmo nos países sem quadro legal para AAE, há casos com participação púbica ampla e inclusiva proporcionando discussões efetivas entre os consultores e as partes interessadas. Percebe-se que é possível tornar o processo de participação pública mais que uma simples comunicação e consulta à população.

$\mathrm{Na}$ nona seção, os critérios foram adequadamente atendidos de forma geral. No entanto, chama à atenção a escrita do relatório. As etapas realizadas não são satisfatoriamente descritas no relatório. O Projeto Hidrelétrico Rampur é um exemplo. A consulta pública foi feita, mas não foi relatada no relatório. O documento apenas menciona a realização da etapa sem explicar como foi feita. 


\section{CONCLUSÕES E CONSIDERAÇÕES FINAIS}

Para levar a cabo a presente pesquisa e alcançar os seus objetivos, três etapas fundamentais foram seguidas.

$\mathrm{Na}$ primeira etapa, foi feito um levantamento e análise das políticas ambientais voltadas para Avaliação Ambiental Estratégica das quatro maiores Instituições Internacionais de Financiamento. Observou-se que essas diretrizes ambientais são compatíveis com praticamente todos os aspectos de boas práticas preconizados na literatura, à exceção das diretrizes voltadas à escolha de alternativas. Enquanto as AMDs vão além das boas práticas no que diz respeito às consultas à população, elas ficam aquém em relação às alternativas a serem consideradas pela avaliação. Ademais, no Banco Asiático de Desenvolvimento e Banco Africano de Desenvolvimento, as políticas ambientais voltadas para Avaliação Ambiental Estratégica limitam a aplicação dessa ferramenta aos níveis de planos e programas apesar de esse instrumento poder também ser aplicado a políticas como salientam Lee e Walsh (1992), Partidário (2000) e Therivel (2004). Nas diretrizes ambientais do Banco Interamericano de Desenvolimento, a AAE só se aplica às operações cujos impactos afetam áreas não sujeitas ao trabalho físico. Essa limitação também foi observado na política ambiental voltadas para Avaliação Ambiental Estratégica do Banco Africano de Desenvolvimento.

O levantamento das Avaliações Ambientais Estratégicas solicitadas pelas Agencias Multilaterais de Desenvolvimento até o ano de 2014 evidencia um aumento do número de aplicações desse instrumento ao longo do tempo. Achado que confirma o papel das Instituições Internacionais de Financiamento na disseminação da Avaliação Ambiental Estratégica.

$\mathrm{Na}$ segunda etapa, os resultados obtidos ressaltam a importância de olhar para os atributos de um instrumento de planejamento para classificá-lo como ação estratégica. Observou-se que os projetos analisados (salvo o projeto de Desenvolvimento de Energia Nepal e o projeto de Energia Manantali) são de baixo nível estratégico. Também constastouse uma busca por parte dos Termos de Referência e das Avaliações ambientais de se adequar aos diversos contextos de aplicação. Fato que revela tentativas de adaptação ao contexto.

Na terceira etapa, observou-se que, de forma geral, as informações não são adequadas para auxiliar a tomada de decisão. A entrada tardia da AAE no processo de tomada de decisão e a falta de dados foram as dificuldades citadas nos relatórios pelos consultores como justificativas para adequar às aplicações aos contextos deixando de realizar algumas tarefas. 
As seções de alternativas como também de medidas de mitigação e monitoramento se destacam por ter a maioria dos critérios avaliada negativamente. A consideração de alternativas também se destacou de modo negativo, sendo o aspecto-chave menos presente nos casos analisados.

A presente dissertação objetivou caracterizar o uso de Avaliações Ambientais Estratégicas solicitadas pelas Instituições Internacionais de Financiamento. Através da abordagem empírica adotada neste trabalho, foi possível chegar à finalidade pretendida de realçar fatores específicos que caracterizam a amostra analisada. É importante ressaltar que os resultados obtidos não podem ser generalizados, restringindo-se aos seis casos investigados. 


\section{REFERÊNCIA}

ALSHUWAIKHAT, H. M., Strategic environmental assessment can help solve environmental impact assessment failures in developing countries, Environmental Impact Assessment Review, p. 307-317, 2005.

ANNANDALE, D.; BAILEY, J.; OUANO, E.; EVANS, W.; KING, P. The potential role of Strategic Environmental Assessment in the activities of Multi-lateral Development Banks, Environmental Impact Assessment Review, v. 21, p. 407-429, 2001.

ARVIN, M., Greening Aid? Understanding the Environmental Impact of Development Assistance, The Journal of Development Studies, v. 44, n. 10, p 1554-1555, 2008.

ASIAN DEVELOPMENT BANK, Annual Report 2002, Singapore, 2003 a.

ASIAN DEVELOPMENT BANK, Environmental Assessment Guidelines, 2003b.

AXELSSON, A.; ANNANDALE, D.; CASHMORE, M.; SLUNGE, D.; EKBOM, A.; LOAYZA, F.; VERHEEM, R. Policy SEA: lessons from development co-operation, Impact Assessment and Project Appraisal, iFirst Article, p. 1-6, 2012.

BANCO AFRICANO DE DESENVOLVIMENTO, Relatório Anual 2010, 2011.

BANCO INTERAMERICANO DE DESENVOLVIMENTO, Relatório Anual 2000, Washington DC, 2000.

BANCO INTERAMERICANO DE DESENVOLVIMENTO, Relatório Anual 2005, Washington DC, 2006.

BANCO INTERAMERICANO DE DESENVOLVIMENTO, Relatório Anual 2012, Escritório de Relações Externas, Washington DC, 2013.

BANCO MUNDIAL, Relatório Anual de 2012 do Banco Mundial: Ano em perspectiva, Escritório de Editora, Relações Exteriores, Washington DC, 2012.

BANCO MUNDIAL, Relatório Anual do Banco Mundial de 2005: Ano em perspectiva, Escritório de Editoria, Assuntos Externos, Washington DC, 2005.

BANQUE AFRICAINE DE DÉVELOPPEMENT, Procédures d'évaluation environnementale et sociale pour les opérations liées au secteur public de la Banque africaine de développement, 29 p., 2001.

BAPTISTA, M. V., BAPTISTA, M. V., Planejamento: Introdução à Metodologia do Planejamento Social, São Paulo, São Paulo: Ed. Moraes, 1981.

BAPTISTA, M. V., Planejamento Social: intencionalidade e instrumentação, 2 ed., São Paulo: Ed. Veras, 2007.

BINA, O. A critical review of the dominant lines of argumentation on the need for strategic environmental assessment, Environmental Impact Assessment Review, v. 27, p. 585-606, 2007. 
BONDE, J.; CHERP A., Quality Review Package for Strategic Environmental Assessments of Land-Use Plans, Impact Assessment and Project Appraisal, v. 18, n. 2, p. 99-110, 2000

BURIAN, P.P. - Do Estudo de Impacto Ambiental à Avaliação Ambiental Estratégica ambivalências do processo de licenciamento ambiental do setor elétrico, Tese de Doutorado em Ciências Sociais apresentada ao Departamento de Sociologia do Instituto de Filosofia e Ciências Humanas da Universidade Estadual de Campinas, 219p., 2006.

CASHMORE, M.; AXELSSON, A. The mediation of environmental assessment's influence: What role for power?, Environmental Impact Assessment Review, v. 39, p. 5-12, 2013.

CASHMORE, M.; RICHARDSON, T.; AXELSSON, A. Seeing power in international development cooperation: environmental policy integration and the World Bank, Transactions of the Institute of British Geographers, v. 39, n. 1, 2014.

CHANCHITPRICHA, C.; BOND, A. Conceptualising the effectiveness of impact assessment processes. Environmental Impact Assessment Review, v. 43, p. 65-72, 2013.

CONNELLY, S.; RICHARDSON, T. Value-driven SEA: time for an environmental justice perspective?, Environmental Impact Assessment Review, v. 25, p. 391-409, 2005.

DALAL-CLAYTON, B.; SADLER, B. Strategic environmental assessment: a sourcebook and reference guide to international experience. London. Earthscan. 2005. 470 p.

DHI WATER AND ENVIRONMENT, Environmental Assessment for Rampur Hydropower Project in Himachal Pradesh, India, Executive Summary, Report n. 38535, 2007.

DOREN, D. V.; DRIESSEN, P. P. J.; SCHIJF, B.; RUNHAAR, H. A. C., Evaluating the substantive effectiveness of SEA: Towards a better understanding. Environmental Impact Assessment Review, v. 38, p. 120-130, 2013.

EALES, R. P.; SHEATE, W. R. Effectiveness of Policy Level Environmental and Sustainability Assessment: challenges and lessons from recent practice. Journal of Environmental Assessment Policy and Management. v. 13, n. 1, p. 39-65, 2011.

FISCHER, T. B. Reviewing the quality of strategic environmental assessment reports for English spatial plan core strategies, Environmental Impact Assessment Review, v. 30, n. 1, p. 62-69, 2010.

FISCHER, T. B. The Theory and Practice of Strategic Environmental Assessment: Towards a More Systematic Approach. London: Earthscan, 2007. 186p.

FISCHER, T. B.; GAZZOLA, P. SEA effectiveness criteria - equally valid in all countries? The case of Italy, Environmental Impact Assessment Review, v. 26, p. 396-409, 2006.

FISCHER, T. B.; ONYANGO, V. Strategic Environmental Assessment-related research projects and journal articles: an overview of the past 20 years, Impact Assessment and Project Appraisal, v. 30, n. 4, p. 253-263, 2012.

FISCHER, T.B. Strategic Environmental Assessment in post-modern times, Environmental Impact Assessment Review, v. 23, p. 155-170, 2003. 
GONZÁleZ, J. C. T.; TORRE, M. C. A.; MILÁN, P. M. Present status of the implementation of Strategic Environmental Assessment in Mexico, Journal of Environmental Assessment Policy and Management, v. 16, n. 2, 2014.

GOODLAND, R., Strategic Environmental Assessment and the World Bank Group, International Journal of Sustainable Development \& World Ecology, v. 12, p. 1-11, 2005 .

GRINDLE, M. S., Good Enough Governance Revisited, Development Policy Review, v. 25, n. 5 , p. $553-574,2007$

HERRERA, R. J. Strategic Environmental Assessment: the need to transform the environmental assessment paradigms, Journal of Environmental Assessment Policy and Management, v. 9, n. 2, p. 211-234, 2007.

HICKS, R. L.; PARKS, B. C.; ROBERTS, J. T.; TIERNEY, M. J. Book Reviews - Greening Aid? Understanding the Environmental Impact of Development Assistance. In: Journal of Development Studies, v. 44, n. 10, p. 1554-1560, 2008.

HILDING-RYDEVIK, T.; BJARNADÓTTIR, H. Context awareness and sensitivity in SEA implementation, Environmental Impact Assessment Review, v. 27, p. 666-684, 2007.

IAIA, International Association for Impact Assessment. Principles of Environmental Impact Assessment Best Practice, 1999.

INTER-AMERICAN DEVELOPMENT BANK, Environment and Safeguards Compliance Policy, 2006.

INTER-AMERICAN DEVELOPMENT BANK, Implementation Guidelines for the Environment and Safeguards Compliance Policy, 2007.

JAY, S., Strategic environmental assessment for energy production. Energy Policy, v. 38, n. 7, p. 3489-3497, 2010.

JILIBERTO, R., Recognizing the institutional dimension of strategic environmental assessment, Impact Assessment and Project Appraisal, v. 29, n. 2, p. 133-140, 2011.

JOÃO, E.; MCLAUCHLAN, A. Would you do SEA if you didn't have to?-Reflections on acceptance or rejection of the SEA process, Impact Assessment and Project Appraisal, v. 32, n. 2, p. 87-97, 2014.

KITCHELL, R. E., Planejamento: um sistema para ação, Revista de Administração Pública, v. 1, n. 1, p. 75-101, 1967.

LEE, N.; WALSH, F. Strategic environmental assessment: an overview, Project Appraisal, v. 7, n. 3, p. 126-136, 1992.

LEMOS C. C. de. Avaliação Ambiental Estratégica para o setor de turismo: uma proposta para aplicação no Brasil. Tese (Doutorado) - Escola de Engenharia de São Carlos, Universidade de São Paulo, São Carlos, 2011. 260p. 
LOAYZA, F. Strategic Environmental Assessment in the World Bank, Washington DC, 116 p. 2012.

LOBOS, V.; PARTIDÁRIO, M. Theory versus practice in Strategic Environmental Assessment (SEA), Environmental Impact Assessment Review, v. 48, p. 34-46, 2014.

MALVESTIO, A. C. Análise da efetividade da Avaliação Ambiental Estratégica como instrumento de política ambiental no Brasil. 2013. 198p. Dissertação (Mestrado) - Escola de Engenharia de São Carlos, Universidade de São Paulo, São Carlos, 2013.

MALVESTIO, A. C.; MONTAÑO, M. Effectiveness of Strategic Environmental Assessment applied to renewable energy in Brazil, Journal of Environmental Assessment Policy and Management, v. 15, n. 2, 2013.

MARGATO, V.; SÁNCHEZ, L. E. Quality and outcomes: a critical review of Strategic Environmental Assessment in Brazil, Journal of Environmental Assessment Policy and Management, v. 16, n. 2, 2014.

MCLAUCHLAN, A.; JOÃO, E. The utopian goal of attempting to deliver environmental justice using SEA, Journal of Environmental Assessment Policy and Management, v. 13, n. 1, p 129-158, 2010.

MINISTRY OF WATER RECOURCES, Nepal Power Development Project - Sectoral Environmental Assessment, Report, 1997. E176 v. 2.

MORGAN, R. K., Environmental impact assessment: the state of the art, Impact Assessment and Project Appraisal, v. 30, n. 1, p. 5-14, 2012.

NEPAL ENVIRONMENTAL \& SCIENTIFIC SERVICES (NESS) PRIVATE LIMITED, Cumulative Impact Assessment of Kabeli "A" Hydroelectric Project, Report, Kathmandu, 2011. E2836 v.6.

NOBLE, B. F. Promise and dismay: The state of strategic environmental assessment systems and practices in Canada, Environmental Impact Assessment Review, v. 29, p. 66-75, 2009.

NORWEGIAN CONSULTING COMPANY; ECOLAO, Cumulative Impact Analysis And Nam Theun 2 Contributions, 2004.

PARTIDÁRIO, M. R. Elements of an SEA framework - improving the added-value of SEA, Environmental Impact Assessment Review, v. 20, p. 647-663, 2000.

PARTIDÁRIO, M. R. Scales and associated data - What is enough for SEA needs?, Environmental Impact Assessment Review, v. 27, p. 460-478, 2007.

PARTIDÁRIO, M. R. Strategic Environmental Assessment: key issues emerging from recent practice Environmental Impact Assessment Review, v. 16, p. 31-55, 1996.

PELLIN, A.; LEMOS, C. C.; TACHARD, A.; OLIVEIRA, I. S. D.; SOUZA, M. P. Avaliação Ambiental Estratégica no Brasil: considerações a respeito do papel das agências multilaterais de desenvolvimento, Engenharia Sanitária e Ambiental, v. 16, n.1, p. 27-36, 2011. 
POLIDO, A.; JOÃO, E.; RAMOS, T. B. Sustainability approaches and strategic Environmental Assessment in small islands: An integrative review, Ocean \& Coastal Management, v. 96, p. 138 - 148, 2014.

REES, C. Improving the effectiveness of Environmental Assessment in the World Bank, Environmental Impact Assessment Review, v. 19, p. 333-339, 1999.

RICHARDSON, T.; CASHMORE, M. Power, knowledge and environmental assessment: the World Bank's pursuit of 'good governance', Journal of Political Power, v. 4, n. 1, p 105$125,2011$.

RUNHAAR, H. Putting SEA in context: A discourse perspective on how SEA contributes to decision-making, Environmental Impact Assessment Review, v. 29, p. 200-209, 2009.

RUNHAAR, H.; DRIESSEN, P. P. J., What makes strategic environmental assessment successful environmental assessment? The role of context in the contribution of SEA to decision-making, Impact Assessment and Project Appraisal, v. 25, n. 1, p 2-14, 2007.

SADLER, B.; Environmental Assessment in a changing world: Evaluating practice to improve performance. Internacional Study of the Effectiveness of Environmental Assessment. IAIA e Canadian Environmental Assessment Agency. 1996.

SLUNGE, D.; LOAYZA, F. Greening growth through Strategic Environmental Assessment of sector reforms, Public Administration and Development, v. 32, p. 245-261, 2012.

TETLOW, M. F.; HANUSCH, M. Strategic environmental assessment: the state of the art, Impact Assessment and Project Appraisal, v. 30, n.1, p. 15-24, 2012.

THE WORLD BANK GROUP, Integrated Safeguards Data Sheet, Report n. AC76, 2003a.

THE WORLD BANK GROUP, Updated project Information Document, Report $\mathrm{n}$. AB30, 2003 b.

THE WORLD BANK, Project Appraisal Document on a Proposed IDA Guarantee in the amount of up to CFA 40 Billion (US\$82 Million Equivalent) and on a Proposed IFC a Loan in the amount of up to EUR 64 Million (US\$86 Million Equivalent) to the Kribi Power Development Company for The Kribi Gas Power Project in the Republic of Cameroon, Report n. 53952-CM, 2011.

THE WORLD BANK, Project Appraisal Document on a proposed loan in the amount of US\$400 million to the Satluj Jal Vidyut Nigam LTD with the guarantee of the Republic of India for Rampur Hydropower Project, Report n. 38178-IN, 2007.

THE WORLD BANK; MIGA, Project Appraisal Document on a proposed IDA grant (Nam Theun 2 Social and Environment Project) in the amount of SDR 13.1 million (US\$ 20 million equivalent) to the Lao People's Democratic Republic and a proposed IDA partial risk guarantee in the amount of up to US\$ 50 Million for a syndicated commercial loan and proposed MIGA guarantees of up to US\$ 200 million in Lao People's Democratic Republic and Thailand for a syndicated commercial loan to and an equity investment in The Nam Theun 2 Power Company Limited for the Nam Theun 2 Hydroelectric Project, Report n. 31764-LA, 2005. 
THERIVEL, R. Strategic Environmental Assessment in action. London: Earthscan, 2004.

VERHEEM, R. A. A.; TONK, J. A. M. N. Strategic environmental assessment: one concept, multiple forms, Impact Assessment and Project Appraisal, v. 18, n. 3, p. 177-182, 2000.

VICTOR, D.; AGAMUTHU, P. Policy trends of strategic environmental assessment in Asia, Environmental science \& policy, v. 41, p. 63 - 76, 2014.

WANG, H.; BAI, H.; LIU, J.; XU, H. Measurement indicators and an evaluation approach for assessing Strategic Environmental Assessment effectiveness, Ecological Indicators, v. 23, p. 413-420, 2012.

WOOD, C.; DEJEDDOUR M. Strategic Environmental Assessment: EA of Policies, Plans and Programmes, Impact Assessment, v. 10, n. 1, p. 3-22, 1992

WORLD BANK, Integrated Safeguards Data Sheet - Appraisal Stage, Report n. ISDSA6334, 2013a.

WORLD BANK, Integrated Safeguards Data Sheet - Appraisal Stage, Report n. AC6518, 2011a.

WORLD BANK, Integrated Safeguards Data Sheet - Concept Stage, Report n. AC3644, 2008.

WORLD BANK, Integrated Safeguards Datasheet - Appraisal Stage, Report n. AC6326, 2012.

WORLD BANK, Integrated Safeguards Datasheet - Appraisal Stage, Report n. AC2280, 2007b.

WORLD BANK, Integrated Safeguards Datasheet - Concept Stage, Report n. AC1781, 2005 b.

WORLD BANK, Operational Manual 4.01 - Environmental Assessment, 2013a.

WORLD BANK, Operational Manual, Bank Procedure 2.11 - Environmental Assessment, 2012.

WORLD BANK, Operational Manual, Bank Procedure 4.01 - Environmental Assessment, $2013 b$.

WORLD BANK, Overview of Regional Energy Projects and Project Performance Assessment Report for the Mali, Mauritania and Senegal Regional Hydropower Development Project (Credits 2970,2971 and 2972), Report n. 38134, 2006.

WORLD BANK, Project Appraisal Document on a Proposed IDA Credit SDR 36,80 million in the amount of (US \$50.40 million equivalent) and Proposed IDA Grant of SDR 18,40 million in the amount of (US \$25.20 million equivalent) to Kingdom of Nepal for A Nepal Power Development Project, Report n. 23631-NP, 2003.

WORLD BANK, Project Information Document - Appraisal Stage, Report n. PIDA2482, $2013 b$. 
WORLD BANK, Project Information Document - Appraisal Stage, Report n. AB2296, 2007a.

WORLD BANK, Project Information Document - Appraisal Stage, Report n. AB6787, $2011 b$.

WORLD BANK, Project Information Document - Appraisal Stage, Report n. AB6777, 2011c.

WORLD BANK, Project Information Document - Concept Stage, Report n. AB1781, 2005a.

WORLD BANK, Project Information Document - Concept Stage, Report n. AB6663, 2010.

WORLD BANK, Project Information Document, Report n. 30966, 2004.

WORLD BANK, Project Information Document, Report n. 6854, 1998.

WORLD BANK, Project Information Document, Report n. PIC4639, $1997 \mathrm{~b}$.

WORLD BANK, Regional Hydropower Development Project (Mali-Mauritania-

Senegal), Staff Appraisal Report, Report n. 16083-AFR, 1997a. 
APENNICE 1

Avaliações Ambientais Estratégicas recomendadas pelas Agências Multilaterais de Desenvolvimento

(Continua)

\begin{tabular}{|c|c|c|c|c|c|c|c|c|}
\hline & Nome da AAE & Continente & Região & País & Setor & Subsetor & Ano & $\begin{array}{c}\text { AMD } \\
\text { financiadora }\end{array}$ \\
\hline 1 & Kribi Gas Power Project & África & África Central & Camarões & Energia & Termal Power & 2008 & BM \\
\hline 2 & $\begin{array}{l}\text { Cameroon Mining Sector Technical } \\
\text { Assistance Project* }\end{array}$ & África & África Central & Camarões & Mineral & - & 2011 & $\mathrm{BM}$ \\
\hline 3 & $\begin{array}{l}\text { Growth with Governance in the } \\
\text { Minerals Sector Project* }\end{array}$ & África & África Central & R D Congo & Energia e Mineração & & 2010 & BM \\
\hline 4 & $\begin{array}{l}\text { Congo, Democratic Republic of - } \\
\text { Multi-modal Transport* }\end{array}$ & África & África Central & R D Congo & Transporte & Ferrovia & 2008 & $\mathrm{BM}$ \\
\hline 5 & $\begin{array}{l}\text { Enhancing Institutional Capacities on } \\
\text { Reducing Emissions from } \\
\text { Deforestation and Forest Degradation } \\
\text { (REDD) Issues for Sustainable Forest } \\
\text { Management in the Congo Basin } \\
\text { Project* }\end{array}$ & África & África Central & Regional & $\begin{array}{c}\text { Silvicultura e } \\
\text { mudança climática }\end{array}$ & - & 2011 & BM \\
\hline 6 & Country Environmental Analysis & África & África Central & $\begin{array}{l}\text { República Centro- } \\
\text { Africana }\end{array}$ & Nacional & - & 2011 & BM \\
\hline 7 & Country Environmental Analysis & África & África Central & Uganda & Nacional & - & 2011 & $\mathrm{BM}$ \\
\hline 8 & $\begin{array}{l}\text { Forestry and Economic Diversification } \\
\text { Project* }\end{array}$ & África & África Central & República do Congo & Silvicultura & - & 2011 & $\mathrm{BM}$ \\
\hline
\end{tabular}


(Continuação)

\begin{tabular}{|c|c|c|c|c|c|c|c|c|}
\hline & Nome da AAE & Continente & Região & País & Setor & Subsetor & Ano & $\begin{array}{c}\text { AMD } \\
\text { financiadora }\end{array}$ \\
\hline 9 & $\begin{array}{l}\text { Enhancing Institutional Capacities on } \\
\text { REDD issues for Sustainable Forest } \\
\text { Management in the Congo Basin* }\end{array}$ & África & $\begin{array}{l}\text { Bacia do Rio } \\
\text { Congo }\end{array}$ & Bacia do Rio Congo & Silvicultura & - & 2011 & $\mathrm{BM}$ e BAD \\
\hline 10 & $\begin{array}{l}\text { Niger Basin Water Resources } \\
\text { Development and Sustainable } \\
\text { Ecosystems Management Project }\end{array}$ & África & $\begin{array}{l}\text { Bacia do Rio } \\
\text { Níger }\end{array}$ & Bacia do Rio Níger & Água & - & 2007 & $\mathrm{BAD}$ \\
\hline 11 & $\begin{array}{l}\text { Mara River Basin Management } \\
\text { Project* }\end{array}$ & África & $\begin{array}{l}\text { Bacia do Rio } \\
\text { Nilo }\end{array}$ & Bacia do Rio Nilo & & - & 2009 & $\mathrm{BM}$ e $\mathrm{BAD}$ \\
\hline 12 & $\begin{array}{l}\text { Kagera River Basin Management } \\
\text { Project* }\end{array}$ & África & $\begin{array}{l}\text { Bacia do Rio } \\
\text { Nilo }\end{array}$ & Bacia do Rio Nilo & Água & - & 2009 & $\mathrm{BM}$ e $\mathrm{BAD}$ \\
\hline 13 & $\begin{array}{l}\text { Sio-Malaba-Malakisi River Basin } \\
\text { Management Project* }\end{array}$ & África & $\begin{array}{l}\text { Bacia do Rio } \\
\text { Nilo }\end{array}$ & Bacia do Rio Nilo & Água & - & 2009 & $\mathrm{BM}$ e BAD \\
\hline 14 & $\begin{array}{l}\text { Nile basin Initiative Institutional } \\
\text { Strengthening Project }\end{array}$ & África & $\begin{array}{l}\text { Bacia do Rio } \\
\text { Nilo }\end{array}$ & Bacia do Rio Nilo & Água & - & 2008 & $\mathrm{BAD}$ \\
\hline 15 & $\begin{array}{l}\text { NELSAP Power Development } \\
\text { Program* }\end{array}$ & África & $\begin{array}{l}\text { Bacia do Rio } \\
\text { Nilo }\end{array}$ & Bacia do Rio Nilo & Energia & - & 2010 & $\mathrm{BM}$ e BAD \\
\hline 16 & $\begin{array}{l}\text { SVP-Additional Grant Financing } \\
\text { Regional Power Trade - II* }\end{array}$ & África & $\begin{array}{l}\text { Bacia do Rio } \\
\text { Nilo }\end{array}$ & Bacia do Rio Nilo & Energia & - & 2009 & $\mathrm{BM}$ e BAD \\
\hline 17 & $\begin{array}{l}\text { Country Environmental Analysis } 2010 \\
\text { Benin }\end{array}$ & África & Leste Africano & Benin & Nacional & - & 2010 & $\mathrm{BM}$ \\
\hline 18 & $\begin{array}{l}\text { Strategic Environmental Assessment of } \\
\text { Coffee Sector Reform in Burundi }\end{array}$ & África & Leste Africano & Burundi & Agricultura & - & 2011 & $\mathrm{BM}$ \\
\hline
\end{tabular}


(Continuação)

\begin{tabular}{|c|c|c|c|c|c|c|c|c|}
\hline & Nome da AAE & Continente & Região & País & Setor & Subsetor & Ano & $\begin{array}{c}\text { AMD } \\
\text { financiadora }\end{array}$ \\
\hline 19 & $\begin{array}{l}\text { Eastern Nile First Joint Multipurpose } \\
\text { Program } 2009 \text { Regional Basin }\end{array}$ & África & Leste Africano & $\begin{array}{l}\text { Burundi, Ruanda e } \\
\text { Tanzânia }\end{array}$ & Gestão da Bacia & - & 2009 & $\mathrm{BM}$ \\
\hline 20 & $\begin{array}{l}\text { Evaluation Environnementale et } \\
\text { Sociale Stratégique du Projet de } \\
\text { Développement Rural Intégré } \\
\text { Multinational de la Région Naturelle du } \\
\text { Bugesera, Multinational Rwanda- } \\
\text { Burundi }\end{array}$ & África & Leste Africano & Burundi e Ruanda & Agricultura & - & 2008 & $\mathrm{BAD}$ \\
\hline 21 & Cote d'Ivoire & África & Leste Africano & Cote d'Ivoire & Nacional & - & 2010 & $\mathrm{BM}$ \\
\hline 22 & $\begin{array}{l}\text { Evaluation Environnementale et } \\
\text { Sociale Stratégique du Programme de } \\
\text { Résilience à la Sécheresse et de } \\
\text { Développement Durable dans les Pays } \\
\text { de la Corne de l'Afrique }\end{array}$ & África & Leste Africano & $\begin{array}{l}\text { Djibouti, Etiópia e } \\
\text { Quénia }\end{array}$ & $\begin{array}{l}\text { Mudança climática e } \\
\text { Meio ambiente }\end{array}$ & - & 2012 & $\mathrm{BAD}$ \\
\hline 23 & Country Environmental Analysis & África & Leste Africano & Etiópia & Nacional & - & 2007 & $\mathrm{BM}$ \\
\hline 24 & $\begin{array}{l}\text { Strategic assessment of the Ethiopian } \\
\text { mineral sector }\end{array}$ & África & Leste Africano & Etiópia & Energia e Mineração & - & 2014 & $\mathrm{BM}$ \\
\hline 25 & $\begin{array}{l}\text { Strategic Environmental and Social } \\
\text { Assessment - Drought Resilience and } \\
\text { Sustainable Livelihoods Program in } \\
\text { The Horn of Africa }\end{array}$ & África & Leste Africano & $\begin{array}{l}\text { Etiópia, Eritreia e } \\
\text { Somália }\end{array}$ & $\begin{array}{c}\text { Agricultura e } \\
\text { Recursos Hidrícos }\end{array}$ & - & 2014 & $\mathrm{BAD}$ \\
\hline 26 & $\begin{array}{l}\text { Second Mining Sector Capacity } \\
\text { Building Additional Financing Project* }\end{array}$ & África & Leste Africano & Mauritânia & Energia e Mineração & - & 2006 & $\mathrm{BM}$ \\
\hline 27 & $\begin{array}{l}\text { Kenya - Education Sector Support } \\
\text { Program Project* }\end{array}$ & África & Leste Africano & Quénia & Educação & - & 2005 & $\mathrm{BM}$ \\
\hline
\end{tabular}


(Continuação)

\begin{tabular}{|c|c|c|c|c|c|c|c|c|}
\hline & Nome da AAE & Continente & Região & País & Setor & Subsetor & Ano & $\begin{array}{c}\text { AMD } \\
\text { financiadora }\end{array}$ \\
\hline 28 & Kenya Forests Act 2005 & África & Leste Africano & Quénia & Silvicultura & - & 2007 & $\mathrm{BM}$ \\
\hline 29 & $\begin{array}{l}\text { Nile Equatorial Lakes Region SEA } \\
\text { Parts I and II }\end{array}$ & África & Leste Africano & Regional & Energia & - & 2010 & $\mathrm{BM}$ \\
\hline 30 & $\begin{array}{l}\text { Nile basin Initiative Institutional } \\
\text { Strengthening Project* }\end{array}$ & África & Leste Africano & Regional & Gestão da Bacia & - & 2009 & $\mathrm{BM}$ \\
\hline 31 & $\begin{array}{l}\text { Lake Victoria Environmental } \\
\text { Management Project Phase II }\end{array}$ & África & Leste Africano & Ruanda & Gestão da Bacia & - & 2008 & $\mathrm{BM}$ \\
\hline 32 & $\begin{array}{l}\text { National Irrigation Master Plan and the } \\
\text { National Irrigation Policy }\end{array}$ & África & Leste Africano & Tanzânia & Agricultura & - & 2011 & $\mathrm{BM}$ \\
\hline 33 & $\begin{array}{l}\text { Tanzania Southern Agriculture Growth } \\
\text { Corridor Project }\end{array}$ & África & Leste Africano & Tanzânia & Agricultura & - & 2012 & $\mathrm{BM}$ \\
\hline 34 & $\begin{array}{l}\text { Tanzania Energy Sector Capacity } \\
\text { Assistance Project* }\end{array}$ & África & Leste Africano & Tanzânia & Energia e Mineração & - & 2012 & $\mathrm{BM}$ \\
\hline 35 & Kihansi Area Conservation Plan & África & Leste Africano & Tanzânia & NRM & - & 2000 & BM \\
\hline 36 & $\begin{array}{l}\text { Tanzania Kihansi Area Conservation } \\
\text { Plan }\end{array}$ & África & Leste Africano & Tanzânia & NRM & - & 2000 & $\mathrm{BM}$ \\
\hline 37 & $\begin{array}{l}\text { Sustainable Coastal Livelihoods } \\
\text { Technical Assistance }\end{array}$ & África & Leste Africano & Tanzânia & Pesca & - & 2003 & $\mathrm{BM}$ \\
\hline 38 & Pilot Program for Climate Resilience & África & Leste Africano & Zâmbia & Mudança climática & - & 2010 & $\mathrm{BM}$ \\
\hline 39 & Mineral Development Support Project* & África & Oeste Africano & Burkina Faso & Energia e Mineração & - & 2011 & $\mathrm{BM}$ \\
\hline
\end{tabular}


(Continuação)

\begin{tabular}{|c|c|c|c|c|c|c|c|c|}
\hline & Nome da AAE & Continente & Região & País & Setor & Subsetor & Ano & $\begin{array}{c}\text { AMD } \\
\text { financiadora }\end{array}$ \\
\hline 40 & $\begin{array}{l}\text { Evaluation Environnementale et } \\
\text { Sociale Stratégique du Programme de } \\
\text { Renforcement de la Résilience à } \\
\text { l'insécurité Alimentaire et } \\
\text { Nutritionnelle Récurrente au Sahel }\end{array}$ & África & Oeste Africano & $\begin{array}{l}\text { Burkina Faso, } \\
\text { Gâmbia, Mali, } \\
\text { Mauritânia, Níger, } \\
\text { Senegal e Chad }\end{array}$ & - & - & 2014 & $\mathrm{BAD}$ \\
\hline 41 & $\begin{array}{l}\text { Strategic Environmental and Social } \\
\text { Assessment of the Ghana Rural } \\
\text { Enterprise Programme (Rep II) }\end{array}$ & África & Oeste Africano & Gana & Agricultura & - & 2012 & $\mathrm{BAD}$ \\
\hline 42 & $\begin{array}{l}\text { Natural Resources and Environmental } \\
\text { Governance First, Second and Third } \\
\text { Development Policy Operations }\end{array}$ & África & Oeste Africano & Gana & $\begin{array}{l}\text { Floresta e Gestão de } \\
\text { Recursos Naturais }\end{array}$ & - & 2007 & $\mathrm{BM}$ \\
\hline 43 & Rapid CEA & África & Oeste Africano & Gana & Nacional & - & 2007 & $\mathrm{BM}$ \\
\hline 44 & $\begin{array}{l}\text { Micro, Small, and Medium Enterprise } \\
\text { Project: strategic environmental } \\
\text { assessment for the export processing } \\
\text { zone, Tema* }\end{array}$ & África & Oeste Africano & Gana & Setor privado & - & 1999 & $\mathrm{BM}$ \\
\hline 45 & Gana - PPP Project & África & Oeste Africano & Gana & Transporte & - & 2012 & $\mathrm{BM}$ \\
\hline 46 & $\begin{array}{l}\text { West Africa Agricultural Productivity } \\
\text { Program (WAAPP) }\end{array}$ & África & Oeste Africano & Gana, Mali e Senegal & Agricultura & - & 2007 & $\mathrm{BAD}$ \\
\hline 47 & $\begin{array}{l}\text { Private Sector Rehabilitation and } \\
\text { Agribusiness Development Project }\end{array}$ & África & Oeste Africano & Guiné Bissau & Setor privado & - & 2012 & $\mathrm{BM}$ \\
\hline
\end{tabular}


(Continuação)

\begin{tabular}{|c|c|c|c|c|c|c|c|c|}
\hline & Nome da AAE & Continente & Região & País & Setor & Subsetor & Ano & $\begin{array}{c}\text { AMD } \\
\text { financiadora }\end{array}$ \\
\hline 48 & $\begin{array}{l}\text { West Africa Minerals Sector Strategic } \\
\text { Assessment }\end{array}$ & África & Oeste Africano & $\begin{array}{l}\text { Guiné, Libéria e } \\
\text { Serra Leoa }\end{array}$ & Mineral & - & 2010 & $\mathrm{BM}$ \\
\hline 49 & $\begin{array}{l}\text { Senegal River Basin Multi-purpose } \\
\text { Water Resources Development Project }\end{array}$ & África & Oeste Africano & $\begin{array}{l}\text { Guiné, Mali, } \\
\text { Mauritânia e Senegal }\end{array}$ & Água & - & 2006 & $\mathrm{BM}$ e $\mathrm{BAD}$ \\
\hline 50 & $\begin{array}{l}\text { Liberia - Forest Carbon Partnership } \\
\text { Fund (FCPF) REDD Readiness } \\
\text { Preparation Support }\end{array}$ & África & Oeste Africano & Libéria & Silvicultura & - & 2012 & $\mathrm{BM}$ \\
\hline 51 & Manantali Energy Project & África & Oeste Africano & $\begin{array}{l}\text { Mali, Mauritânia e } \\
\text { Senegal }\end{array}$ & Energia & Hidrelétricidade & 2000 & $\mathrm{BM}$ e $\mathrm{BAD}$ \\
\hline 52 & $\begin{array}{l}\text { Évaluation Environnementale et } \\
\text { Sociale Stratégique du Programme } \\
\text { d'appui au Plan Vert du Maroc }\end{array}$ & África & Oeste Africano & Marrocos & Agricultura & - & 2012 & $\mathrm{BAD}$ \\
\hline 53 & $\begin{array}{l}\text { Evaluation Environnementale et } \\
\text { Sociale Stratégique du Projet Intègre } \\
\text { Eolien et Electrification Rurale Globale }\end{array}$ & África & Oeste Africano & Marrocos & Energia & - & 2011 & BAD \\
\hline 54 & $\begin{array}{l}\text { Mining Sector Capacity Building } \\
\text { Project, } 2^{\text {nd }}\end{array}$ & África & Oeste Africano & Mauritânia & Mineral & - & 2010 & $\mathrm{BM}$ \\
\hline 55 & $\begin{array}{l}\text { Strategic Environmental and Social } \\
\text { Assessment of the Agricultural } \\
\text { Transformation Agenda Support } \\
\text { Program - Phase } 1\end{array}$ & África & Oeste Africano & Nigéria & Agricultura & - & 2013 & $\mathrm{BAD}$ \\
\hline 56 & $\begin{array}{l}\text { Nigeria Power Sector Guarantees } \\
\text { Project }\end{array}$ & África & Oeste Africano & Nigéria & Energia & - & 2011 & $\mathrm{BM}$ \\
\hline 57 & Pilot Program for Climate Resilience & África & Oeste Africano & Nigéria & Mudança climática & - & 2010 & $\mathrm{BM}$ \\
\hline
\end{tabular}


(Continuação)

\begin{tabular}{|c|c|c|c|c|c|c|c|c|}
\hline & Nome da AAE & Continente & Região & País & Setor & Subsetor & Ano & $\begin{array}{c}\text { AMD } \\
\text { financiadora }\end{array}$ \\
\hline 58 & Rapid CEA & África & Oeste Africano & Nigéria & Nacional & - & 2007 & $\mathrm{BM}$ \\
\hline 59 & $\begin{array}{l}\text { West Africa Agricultural Productivity } \\
\text { Program (WAAPP)* }\end{array}$ & África & Oeste Africano & Oeste Africano & Agricultura & - & 2007 & $\mathrm{BM}$ e BAD \\
\hline 60 & Country Environmental Analysis & África & Oeste Africano & Senegal & Nacional & - & 2008 & BM \\
\hline 61 & Sierra Leone Mining Sector Reform & África & Oeste Africano & Serra Leoa & Mineral & & 2008 & $\mathrm{BM}$ \\
\hline 62 & $\begin{array}{l}\text { Madagascar - Irrigation and Watershed } \\
\text { Management Project }\end{array}$ & África & Sul Africano & Madagascar & Gestão da Bacia & $\begin{array}{l}\text { Irrigação e } \\
\text { drenagem }\end{array}$ & 2006 & BM \\
\hline 63 & Country Environmental Analysis & África & Sul Africano & Madagascar & Nacional & - & 2012 & $\mathrm{BM}$ \\
\hline 64 & Shire River Basin Management Project & África & Sul Africano & Malawi & Gestão da Bacia & - & 2010 & $\mathrm{BM}$ \\
\hline 65 & Minerals Sector Review & África & Sul Africano & Malawi & Mineral & - & 2009 & $\mathrm{BM}$ \\
\hline 66 & $\begin{array}{l}\text { Mining Governance and Growth } \\
\text { Support TA Project* }\end{array}$ & África & Sul Africano & Malawi & Mineral & - & 2011 & $\mathrm{BM}$ \\
\hline 67 & ProIRRI & África & Sul Africano & Moçambique & Agricultura & $\begin{array}{l}\text { Irrigação e } \\
\text { drenagem }\end{array}$ & 2010 & $\mathrm{BM}$ \\
\hline 68 & $\begin{array}{l}\text { Market-led Smallholder Development } \\
\text { in the Zambezi Valley* }\end{array}$ & África & Sul Africano & Moçambique & Agricultura & - & 2011 & BM \\
\hline 69 & $\begin{array}{l}\text { Mozambique Mining Technical } \\
\text { Assistance }\end{array}$ & África & Sul Africano & Moçambique & Energia e Mineração & - & 2012 & $\mathrm{BM}$ \\
\hline 70 & $\begin{array}{l}\text { Mega-Infrastructure Regional } \\
\text { Development Project - Mozambique } \\
\text { CESUL }\end{array}$ & África & Sul Africano & Moçambique & Energia e Transporte & - & 2012 & $\mathrm{BM}$ \\
\hline
\end{tabular}


(Continuação)

\begin{tabular}{|c|c|c|c|c|c|c|c|c|}
\hline & Nome da AAE & Continente & Região & País & Setor & Subsetor & Ano & $\begin{array}{c}\text { AMD } \\
\text { financiadora }\end{array}$ \\
\hline 71 & $\begin{array}{l}\text { Spatial Planning Technical Assistance } \\
\text { Project } 7 \text { SESAs: } 1 \text { national, } 6 \text { sub- } \\
\text { regional by economic corridor }\end{array}$ & África & Sul Africano & Moçambique & Infraestrutura & - & 2012 & $\mathrm{BM}$ \\
\hline 72 & Pilot Program for Climate Resilience & África & Sul Africano & Moçambique & Mudança climática & - & 2010 & $\mathrm{BM}$ \\
\hline 73 & $\begin{array}{l}\text { 7th PRSC Stocktaking of Needs across } \\
\text { Sectors for EIAs and SEAs }\end{array}$ & África & Sul Africano & Moçambique & Nacional & - & 2010 & $\mathrm{BM}$ \\
\hline 74 & South Africa Regional Gas Project & África & Sul Africano & $\begin{array}{l}\text { Moçambique e África } \\
\text { do Sul }\end{array}$ & Mineração & Petróleo e gás & 2003 & $\mathrm{BM}$ \\
\hline 75 & Country Environmental Analysis & África & Sul Africano & Namíbia & Nacional & - & 2008 & $\mathrm{BM}$ \\
\hline 76 & $\begin{array}{l}\text { Strategic Environmental and Social } \\
\text { Assessment of the Agriculture } \\
\text { Productivity and Market Enhancement } \\
\text { Project }\end{array}$ & África & Sul Africano & Zâmbia & Agricultura & - & 2014 & $\mathrm{BAD}$ \\
\hline 77 & $\begin{array}{l}\text { Strategic Environmental and Social } \\
\text { Assessment of the Strengthening } \\
\text { Climate Resilience in the Kafue Basin }\end{array}$ & África & Sul Africano & Zâmbia & Agricultura & - & 2013 & $\mathrm{BAD}$ \\
\hline 78 & $\begin{array}{l}\text { Strategic Environmental Assessment: } \\
\text { Developing a Decision Support System } \\
\text { new window }\end{array}$ & $\begin{array}{l}\text { América Latina e } \\
\text { Caribe }\end{array}$ & América Latina & $\begin{array}{l}\text { Apoio regional } \\
\text { Holandês }\end{array}$ & $\begin{array}{l}\text { Meio Ambiente e } \\
\text { Desastres Naturais }\end{array}$ & - & 2007 & BID \\
\hline 79 & Water Sector Reform & $\begin{array}{l}\text { América Latina e } \\
\text { Caribe }\end{array}$ & América Latina & Argentina & Água & - & 1999 & $\mathrm{BM}$ \\
\hline 80 & La Rioja SWAp - (water resources) & $\begin{array}{l}\text { América Latina e } \\
\text { Caribe }\end{array}$ & América Latina & Argentina & Água & - & 2012 & $\mathrm{BM}$ \\
\hline
\end{tabular}


(Continuação)

\begin{tabular}{|c|c|c|c|c|c|c|c|c|}
\hline & Nome da AAE & Continente & Região & País & Setor & Subsetor & Ano & $\begin{array}{c}\text { AMD } \\
\text { financiadora }\end{array}$ \\
\hline 81 & El Niño Emergency Flood Project & $\begin{array}{l}\text { América Latina e } \\
\text { Caribe }\end{array}$ & América Latina & Argentina & Mudança climática & - & 1998 & $\mathrm{BM}$ \\
\hline 82 & $\begin{array}{l}\text { Sustainable Natural Resources } \\
\text { Management }\end{array}$ & $\begin{array}{l}\text { América Latina e } \\
\text { Caribe }\end{array}$ & América Latina & Argentina & Recursos Naturais & - & 2012 & $\mathrm{BM}$ \\
\hline 83 & $\begin{array}{l}\text { Biodiversity in Forestry Landscapes } \\
\text { (GEF) }\end{array}$ & $\begin{array}{l}\text { América Latina e } \\
\text { Caribe }\end{array}$ & América Latina & Argentina & Silvicultura & - & 2012 & $\mathrm{BM}$ \\
\hline 84 & $\begin{array}{l}\text { Evaluación ambiental estratégica - } \\
\text { Proyecto de Mejora Integral del } \\
\text { Ferrocarril Gral Roca: Ramal } \\
\text { Colnstitución }\end{array}$ & $\begin{array}{l}\text { América Latina e } \\
\text { Caribe }\end{array}$ & América Latina & Argentina & Transporte & - & 2013 & BID \\
\hline 85 & Calafate Tourism SEA & $\begin{array}{l}\text { América Latina e } \\
\text { Caribe }\end{array}$ & América Latina & Argentina & Turismo & - & 2006 & $\mathrm{BM}$ \\
\hline 86 & $\begin{array}{l}\text { Evaluación Ambiental Estratégica de } \\
\text { Desarrollo de Corredores Turísticos }\end{array}$ & $\begin{array}{l}\text { América Latina e } \\
\text { Caribe }\end{array}$ & América Latina & Argentina & Turismo & - & 2011 & BID \\
\hline 87 & $\begin{array}{l}\text { Evaluación Ambiental Estratégica de } \\
\text { las áreas de intervención del Programa } \\
\text { de Desarrollo Turistico Sustentable de } \\
\text { la Provincia de Salta }\end{array}$ & $\begin{array}{l}\text { América Latina e } \\
\text { Caribe }\end{array}$ & América Latina & Argentina & Turismo & - & 2012 & BID \\
\hline 88 & $\begin{array}{l}\text { Evaluación Ambiental Estratégica - } \\
\text { Programa de Riego con Enfoque de } \\
\text { Cuencas II }\end{array}$ & $\begin{array}{l}\text { América Latina e } \\
\text { Caribe }\end{array}$ & América Latina & Bolívia & $\begin{array}{l}\text { Meio ambiente e } \\
\text { desastres naturais }\end{array}$ & - & 2013 & BID \\
\hline 89 & $\begin{array}{l}\text { Strategic Environmental Assessment of } \\
\text { the Northern Corridor La Paz- } \\
\text { Guayaramerín }\end{array}$ & $\begin{array}{l}\text { América Latina e } \\
\text { Caribe }\end{array}$ & América Latina & Bolívia & Transporte & Rodovia & 2003 & BID \\
\hline
\end{tabular}


(Continuação)

\begin{tabular}{|c|c|c|c|c|c|c|c|c|}
\hline & Nome da AAE & Continente & Região & País & Setor & Subsetor & Ano & $\begin{array}{c}\text { AMD } \\
\text { financiadora }\end{array}$ \\
\hline 90 & $\begin{array}{l}\text { Strategic Environmental Assessment of } \\
\text { the Santa Cruz-Puerto Suárez } \\
\text { Transportation Corridor }\end{array}$ & $\begin{array}{l}\text { América Latina e } \\
\text { Caribe }\end{array}$ & América Latina & Bolívia & Transporte & Rodovia & 2000 & BID \\
\hline 91 & Roads and Airport Transport & $\begin{array}{l}\text { América Latina e } \\
\text { Caribe }\end{array}$ & América Latina & Bolívia & Transporte & Rodovia & 2012 & BM \\
\hline 92 & Gasbol pipeline & $\begin{array}{l}\text { América Latina e } \\
\text { Caribe }\end{array}$ & América Latina & Bolívia, Brasil & - & - & $\begin{array}{l}2002- \\
2012\end{array}$ & BM \\
\hline 93 & Ceara - PROGERIRH Water & $\begin{array}{l}\text { América Latina e } \\
\text { Caribe }\end{array}$ & América Latina & Brasil & Água & - & 2002 & BM \\
\hline 94 & $\begin{array}{l}\text { Strategic Environmental Assessment: } \\
\text { Regional Urban Development Program } \\
\text { - Ceará }\end{array}$ & $\begin{array}{l}\text { América Latina e } \\
\text { Caribe }\end{array}$ & América Latina & Brasil & $\begin{array}{l}\text { Desenvolvimento } \\
\text { urbano }\end{array}$ & $\begin{array}{l}\text { Desenvolvimento } \\
\text { urbano }\end{array}$ & 2008 & $\mathrm{BM}$ and BID \\
\hline 95 & Urban Consolidation of Paulínia & $\begin{array}{l}\text { América Latina e } \\
\text { Caribe }\end{array}$ & América Latina & Brasil & $\begin{array}{l}\text { Desenvolvimento } \\
\text { urbano }\end{array}$ & $\begin{array}{l}\text { Desenvolvimento } \\
\text { urbano }\end{array}$ & 2004 & BID \\
\hline 96 & Energy and Mining TAL & $\begin{array}{l}\text { América Latina e } \\
\text { Caribe }\end{array}$ & América Latina & Brasil & Energia e Mineração & - & 2012 & BM \\
\hline 97 & $\begin{array}{l}\text { AAE do Programa de Desenvolvimento } \\
\text { Sustentável do Acre - PDSA II }\end{array}$ & $\begin{array}{l}\text { América Latina e } \\
\text { Caribe }\end{array}$ & América Latina & Brasil & $\begin{array}{l}\text { Meio ambiente e } \\
\text { desastres naturais }\end{array}$ & $\begin{array}{l}\text { Meio ambiente e } \\
\text { desastres naturais }\end{array}$ & 2012 & BID \\
\hline 98 & $\begin{array}{l}\text { AAE do Programa de Transporte } \\
\text { Urbano do Distrito Federal }\end{array}$ & $\begin{array}{l}\text { América Latina e } \\
\text { Caribe }\end{array}$ & América Latina & Brasil & Transporte & - & 2007 & BID \\
\hline 99 & $\begin{array}{l}\text { AAE do Programa de Acessos Viarios } \\
\text { a Municipios de Minas Gerais - } \\
\text { PROACESSO }\end{array}$ & $\begin{array}{l}\text { América Latina e } \\
\text { Caribe }\end{array}$ & América Latina & Brasil & Transporte & - & 2005 & BID \\
\hline
\end{tabular}


(Continuação)

\begin{tabular}{|c|c|c|c|c|c|c|c|c|}
\hline & Nome da AAE & Continente & Região & País & Setor & Subsetor & Ano & $\begin{array}{c}\text { AMD } \\
\text { financiadora }\end{array}$ \\
\hline 100 & Federal Road Transport* & $\begin{array}{l}\text { América Latina e } \\
\text { Caribe }\end{array}$ & América Latina & Brasil & Transporte & - & 2012 & $\mathrm{BM}$ \\
\hline 101 & AAE do PRODETUR Espírito Santo & $\begin{array}{l}\text { América Latina e } \\
\text { Caribe }\end{array}$ & América Latina & Brasil & Turismo & - & 2013 & BID \\
\hline 102 & AAE do PRODETUR Pará & $\begin{array}{l}\text { América Latina e } \\
\text { Caribe }\end{array}$ & América Latina & Brasil & Turismo & - & 2012 & BID \\
\hline 103 & $\begin{array}{l}\text { AAE do programa de desenvolvimento } \\
\text { turístico de Sergipe }\end{array}$ & $\begin{array}{l}\text { América Latina e } \\
\text { Caribe }\end{array}$ & América Latina & Brasil & Turismo & - & 2013 & BID \\
\hline 104 & PRODETUR NATIONAL-Bahia & $\begin{array}{l}\text { América Latina e } \\
\text { Caribe }\end{array}$ & América Latina & Brasil & Turismo & - & 2012 & BID \\
\hline 105 & Santiago Transport SEA & $\begin{array}{l}\text { América Latina e } \\
\text { Caribe }\end{array}$ & América Latina & Chile & Transporte & - & $\begin{array}{l}2002- \\
2012\end{array}$ & $\mathrm{BM}$ \\
\hline 106 & Water and Sanitation Sector SEA & $\begin{array}{l}\text { América Latina e } \\
\text { Caribe }\end{array}$ & América Latina & Colômbia & Água & - & 2001 & $\mathrm{BM}$ \\
\hline 107 & Energy Policy SEA & $\begin{array}{l}\text { América Latina e } \\
\text { Caribe }\end{array}$ & América Latina & Colômbia & Energia & - & 1993 & $\mathrm{BM}$ \\
\hline 108 & $\begin{array}{l}\text { Preparation of the Infrastructure Project } \\
\text { for the Pasto - Mocoa Road }\end{array}$ & $\begin{array}{l}\text { América Latina e } \\
\text { Caribe }\end{array}$ & América Latina & Colômbia & Transporte & - & 2006 & BID \\
\hline 109 & $\begin{array}{l}\text { Strategic Environmental Studies for } \\
\text { Guyana e Suriname }\end{array}$ & $\begin{array}{l}\text { América Latina e } \\
\text { Caribe }\end{array}$ & América Latina & Guiana e Suriname & $\begin{array}{l}\text { Meio Ambiente e } \\
\text { Desastres Naturais }\end{array}$ & $\begin{array}{l}\text { Meio Ambiente e } \\
\text { Desastres Naturais }\end{array}$ & 2006 & BID \\
\hline 110 & $\begin{array}{l}\text { Development of a New Sustainable } \\
\text { Energy Matrix (NUMES) }\end{array}$ & $\begin{array}{c}\text { América Latina e } \\
\text { Caribe }\end{array}$ & América Latina & Peru & Energia & - & 2010 & BID \\
\hline
\end{tabular}


(Continuação)

\begin{tabular}{|c|c|c|c|c|c|c|c|c|}
\hline & Nome da AAE & Continente & Região & País & Setor & Subsetor & Ano & $\begin{array}{l}\text { AMD } \\
\text { financiadora }\end{array}$ \\
\hline 111 & Mining & $\begin{array}{l}\text { América Latina e } \\
\text { Caribe }\end{array}$ & América Latina & Peru & Mineração & - & 2005 & $\mathrm{BM}$ \\
\hline 112 & Lima Urban Transport* & $\begin{array}{l}\text { América Latina e } \\
\text { Caribe }\end{array}$ & América Latina & Peru & Transporte & - & $\begin{array}{l}2002- \\
2012\end{array}$ & $\mathrm{BM}$ \\
\hline 113 & $\begin{array}{l}\text { Evaluación Ambiental Estratégica de la } \\
\text { Línea CCLIP }\end{array}$ & $\begin{array}{l}\text { América Latina e } \\
\text { Caribe }\end{array}$ & América Latina & Uruguai & Água e saneamento & - & 2011 & BID \\
\hline 114 & Power Sector Reform & $\begin{array}{l}\text { América Latina e } \\
\text { Caribe }\end{array}$ & América Latina & Venezuela & Energia & - & 2001 & $\mathrm{BM}$ \\
\hline 115 & Port Sector Modernization & $\begin{array}{l}\text { América Latina e } \\
\text { Caribe }\end{array}$ & Caribe & Belize & Transporte & - & 1999 & BID \\
\hline 116 & El Salvador Country Land Assessment & $\begin{array}{l}\text { América Latina e } \\
\text { Caribe }\end{array}$ & Caribe & El Salvador & $\begin{array}{l}\text { Agricultura, pesca e } \\
\text { silvicultura }\end{array}$ & - & 2012 & $\mathrm{BM}$ \\
\hline 117 & $\begin{array}{l}\text { Intervención en El Corredor la Libertad } \\
\text { - San Salvdor y la Bahía de Jiquilisco } \\
\text { Programa de Inversión ES-L } 1066 \\
\text { Evaluación Ambiental Estratégica }\end{array}$ & $\begin{array}{l}\text { América Latina e } \\
\text { Caribe }\end{array}$ & Caribe & El Salvador & Turismo & - & 2013 & BID \\
\hline 118 & $\begin{array}{l}\text { Evaluación Ambiental Estratégica de la } \\
\text { Franja Costera Marítima }\end{array}$ & $\begin{array}{l}\text { América Latina e } \\
\text { Caribe }\end{array}$ & Caribe & El Salvador & Transporte & - & 2013 & BID \\
\hline 119 & Private Participation in Infrastructure & $\begin{array}{l}\text { América Latina e } \\
\text { Caribe }\end{array}$ & Caribe & Guatemala & Infraestrutura & - & 1997 & $\mathrm{BM}$ \\
\hline 120 & $\begin{array}{l}\text { Strategic Environmental assessment of } \\
\text { the Strategic and Investment Plan }\end{array}$ & $\begin{array}{l}\text { América Latina e } \\
\text { Caribe }\end{array}$ & Caribe & Haiti & $\begin{array}{c}\text { Agricultura e } \\
\text { desenvolvimento } \\
\text { rural }\end{array}$ & - & 2013 & BID \\
\hline
\end{tabular}


(Continuação)

\begin{tabular}{|c|c|c|c|c|c|c|c|c|}
\hline & Nome da AAE & Continente & Região & País & Setor & Subsetor & Ano & $\begin{array}{c}\text { AMD } \\
\text { financiadora }\end{array}$ \\
\hline 121 & $\begin{array}{l}\text { SEA of the Productive Infrastructure } \\
\text { Program }\end{array}$ & $\begin{array}{l}\text { América Latina e } \\
\text { Caribe }\end{array}$ & Caribe & Haiti & $\begin{array}{l}\text { Desenvolvimento } \\
\text { Urbano e Habitação }\end{array}$ & - & 2012 & BID \\
\hline 122 & $\begin{array}{l}\text { Strategic Environmental and Social } \\
\text { Analysis of the Sustainable Coastal } \\
\text { Tourism Program }\end{array}$ & $\begin{array}{l}\text { América Latina e } \\
\text { Caribe }\end{array}$ & Caribe & Haiti & Turismo & - & 2014 & BID \\
\hline 123 & Tourism & $\begin{array}{l}\text { América Latina e } \\
\text { Caribe }\end{array}$ & Caribe & Honduras & Turismo & - & 2004 & $\mathrm{BM}$ \\
\hline 124 & Country Environmental Assessment & $\begin{array}{l}\text { América Latina e } \\
\text { Caribe }\end{array}$ & Caribe & Jamaica & $\begin{array}{l}\text { Meio Ambiente e } \\
\text { Desastres Naturais }\end{array}$ & - & 2006 & BID \\
\hline 125 & Rio Apatlaco Watershed SEA & $\begin{array}{l}\text { América Latina e } \\
\text { Caribe }\end{array}$ & Caribe & México & - & - & $\begin{array}{l}2002- \\
2012\end{array}$ & BM \\
\hline 126 & Michoacan Climate SEA & $\begin{array}{l}\text { América Latina e } \\
\text { Caribe }\end{array}$ & Caribe & México & - & - & 2010 & $\mathrm{BM}$ \\
\hline 127 & Environment DPL (CEA) & $\begin{array}{l}\text { América Latina e } \\
\text { Caribe }\end{array}$ & Caribe & México & - & - & 2006 & BM \\
\hline 128 & $\begin{array}{l}\text { Evaluación Ambiental Estratégica - } \\
\text { Sostenibilidad Servicios de Agua } \\
\text { Potable Comunidades Rurales }\end{array}$ & $\begin{array}{l}\text { América Latina e } \\
\text { Caribe }\end{array}$ & Caribe & México & Água e saneamento & - & 2013 & BID \\
\hline 129 & $\begin{array}{l}\text { Evaluación Ambiental Estratégica - } \\
\text { Sostenibilidad Servicios de Agua } \\
\text { Potable y Saneamiento Comunidades } \\
\text { Rurales III }\end{array}$ & $\begin{array}{l}\text { América Latina e } \\
\text { Caribe }\end{array}$ & Caribe & México & Água e saneamento & - & 2011 & BID \\
\hline 130 & Modernization of Irrigation SEA & $\begin{array}{l}\text { América Latina e } \\
\text { Caribe }\end{array}$ & Caribe & México & Agricultura & - & $\begin{array}{l}2002- \\
2012\end{array}$ & $\mathrm{BM}$ \\
\hline
\end{tabular}


(Continuação)

\begin{tabular}{|c|c|c|c|c|c|c|c|c|}
\hline & Nome da AAE & Continente & Região & País & Setor & Subsetor & Ano & $\begin{array}{c}\text { AMD } \\
\text { financiadora }\end{array}$ \\
\hline 131 & Energy SEA & $\begin{array}{l}\text { América Latina e } \\
\text { Caribe }\end{array}$ & Caribe & México & Energia & - & $\begin{array}{l}2002- \\
2012\end{array}$ & BM \\
\hline 132 & Tehuantepec Wind Power (GEF) & $\begin{array}{l}\text { América Latina e } \\
\text { Caribe }\end{array}$ & Caribe & México & Energia & Eólica & 2012 & $\mathrm{BM}$ \\
\hline 133 & Tourism & $\begin{array}{l}\text { América Latina e } \\
\text { Caribe }\end{array}$ & Caribe & México & Turismo & - & 2005 & BM \\
\hline 134 & Water and Sanitation & $\begin{array}{l}\text { América Latina e } \\
\text { Caribe }\end{array}$ & Caribe & $\begin{array}{l}\text { República } \\
\text { Dominicana }\end{array}$ & Água & - & 2010 & BM \\
\hline 135 & $\begin{array}{l}\text { SESA for the REDD+ readiness } \\
\text { supported by FCPF program grants }\end{array}$ & $\begin{array}{l}\text { América Latina e } \\
\text { Caribe }\end{array}$ & Regional & $\begin{array}{l}\text { Colômbia, Costa } \\
\text { Rica, El Salvador, } \\
\text { México e Nicarágua }\end{array}$ & - & - & 2012 & BM \\
\hline 136 & $\begin{array}{l}\text { Core Environment Program and } \\
\text { Biodiversity Conservation Corridors } \\
\text { Initiative in the Greater Mekong } \\
\text { Subregion }\end{array}$ & Ásia & Leste Asiático & Camboja & $\begin{array}{c}\text { Agricultura e recursos } \\
\text { naturais }\end{array}$ & - & 2008 & $\mathrm{ADB}$ \\
\hline 137 & $\begin{array}{l}\text { Strategic Environmental Assessment of } \\
\text { the North South Economic Corridor } \\
\text { Strategy and Action Plan }\end{array}$ & Ásia & Leste Asiático & Camboja & Turismo & - & 2008 & $\mathrm{ADB}$ \\
\hline 138 & $\begin{array}{l}\text { Strategic Environmental Assessment of } \\
\text { theTourism Sector in Camboja }\end{array}$ & Ásia & Leste Asiático & Camboja & Turismo & - & 2009 & $\mathrm{ADB}$ \\
\hline
\end{tabular}


(Continuação)

\begin{tabular}{|c|c|c|c|c|c|c|c|c|}
\hline & Nome da AAE & Continente & Região & País & Setor & Subsetor & Ano & $\begin{array}{c}\text { AMD } \\
\text { financiadora }\end{array}$ \\
\hline 139 & $\begin{array}{l}\text { SEA for Sino-Singapore Tianjian Eco- } \\
\text { City }\end{array}$ & Ásia & Leste Asiático & China & Multisetor & - & 2008 & $\mathrm{BM}$ \\
\hline 140 & China Country Environmental Analysis & Ásia & Leste Asiático & China & País & - & 2014 & $\mathrm{ADB}$ \\
\hline 141 & $\begin{array}{l}\text { Environmental Assessment for } \\
\text { Wuhan's Urban Transport } \\
\text { Development strategy }\end{array}$ & Ásia & Leste Asiático & China & Transporte & - & 2005 & $\mathrm{BM}$ \\
\hline 142 & $\begin{array}{l}\text { SEA Scoping Study on China's } \\
\text { Railway Sector }\end{array}$ & Ásia & Leste Asiático & China & Transporte & Ferrovia & 2006 & $\mathrm{BM}$ \\
\hline 143 & $\begin{array}{l}\text { SEA for Hubei Road Network Plan } \\
(2002-2020)\end{array}$ & Ásia & Leste Asiático & China & Transporte & Rodovia & 2008 & $\mathrm{BM}$ \\
\hline 144 & $\begin{array}{l}\text { SEA of Tourism Development in the } \\
\text { Guizhou Province }\end{array}$ & Ásia & Leste Asiático & China & Turismo & - & 2007 & BM \\
\hline 145 & $\begin{array}{l}\text { Strategic Impact Assessment for } \\
\text { Hydropower Lao } 2004 \text { Hydropower }\end{array}$ & Ásia & Leste Asiático & Laos & Energia & Hidrelétricidade & 2004 & $\mathrm{BM}$ \\
\hline 146 & $\begin{array}{l}\text { Cumulative Impact Assessment for } \\
\text { Nam Theun } 2 \text { Hydroelectric Project } \\
\text { Lao } 2005 \text { Hydropower }\end{array}$ & Ásia & Leste Asiático & Laos & Energia & Hidrelétricidade & 2005 & BM \\
\hline 147 & $\begin{array}{l}\text { Lao People's Democratic Republic: } \\
\text { Preparing the Cumulative Impact } \\
\text { Assessment for the Nam Ngum } 3 \\
\text { Hydropower Project }\end{array}$ & Ásia & Leste Asiático & Laos & Energia & Hidrelétricidade & 2007 & $\mathrm{ADB}$ \\
\hline 148 & $\begin{array}{l}\text { Southern Gobi Regional Environmental } \\
\text { Assessment }\end{array}$ & Ásia & Leste Asiático & Mongólia & Mineração & - & 2010 & $\mathrm{BM}$ \\
\hline
\end{tabular}


(Continuação)

\begin{tabular}{|c|c|c|c|c|c|c|c|c|}
\hline & Nome da AAE & Continente & Região & País & Setor & Subsetor & Ano & $\begin{array}{c}\text { AMD } \\
\text { financiadora }\end{array}$ \\
\hline 149 & $\begin{array}{l}\text { National Performance Assessment and } \\
\text { Subregional Strategic Environment } \\
\text { Framework in the Greater Mekong } \\
\text { Subregion }\end{array}$ & Ásia & Leste Asiático & Região do Mekong & $\begin{array}{c}\text { Agricultura e recursos } \\
\text { naturais }\end{array}$ & $\begin{array}{l}\text { Gestão de } \\
\text { Recursos naturais a } \\
\text { base de água }\end{array}$ & 2006 & ADB \\
\hline 150 & $\begin{array}{l}\text { Strategic Environmental Assessment of } \\
\text { the Greater Mekong Subregion master } \\
\text { plan }\end{array}$ & Ásia & Leste Asiático & Região do Mekong & Multisetor & - & 2010 & ADB \\
\hline 151 & $\begin{array}{l}\text { Pilot Strategic Environmental } \\
\text { Assessment in the Hydropower Sub- } \\
\text { sector: Risks to Biodiversity from the } \\
\text { 6th Power Development Plan }\end{array}$ & Ásia & Leste Asiático & Vietnã & Energia & Hidrelétricidade & 2007 & BM \\
\hline 152 & $\begin{array}{l}\text { SEA of the Hydropower Master Plan in } \\
\text { the Context of the Power Development } \\
\text { Plan VI }\end{array}$ & Ásia & Leste Asiático & Vietnã & Energia & Hidrelétricidade & 2009 & $\mathrm{BM}$ e $\mathrm{ADB}$ \\
\hline 153 & SEA Trung Son Hydropower Project & Ásia & Leste Asiático & Vietnã & Energia & Hidrelétricidade & 2012 & BM \\
\hline 154 & $\begin{array}{l}\text { Technical Assistance Socialist Republic } \\
\text { of Viet Nam: Capacity Building in the } \\
\text { Strategic Environmental Assessment of } \\
\text { the Hydropower Project }\end{array}$ & Ásia & Leste Asiático & Vietnã & Energia & Hidrelétricidade & 2005 & $\mathrm{ADB}$ \\
\hline 155 & $\begin{array}{l}\text { The National Plan For Power } \\
\text { Development for the Period 2011-2020 } \\
\text { with Perspective to } 2030 \text { (PDP VII) }\end{array}$ & Ásia & Leste Asiático & Vietnã & Energia & $\begin{array}{l}\text { Hidrelétricidade, } \\
\text { termoeletricidade, } \\
\text { Nucleoeletricidade }\end{array}$ & 2011 & ADB \\
\hline 156 & $\begin{array}{l}\text { REA Mekong Delta Water } \\
\text { Management for Rural Development } \\
\text { Project* }\end{array}$ & Ásia & Leste Asiático & Vietnã & Gestão da água & - & 2011 & $\mathrm{BM}$ \\
\hline
\end{tabular}


(Continuação)

\begin{tabular}{|c|c|c|c|c|c|c|c|c|}
\hline & Nome da AAE & Continente & Região & País & Setor & Subsetor & Ano & $\begin{array}{c}\text { AMD } \\
\text { financiadora }\end{array}$ \\
\hline 157 & $\begin{array}{l}\text { SEA to Inform the National Forestry } \\
\text { Master Plan } 2010-2020\end{array}$ & Ásia & Leste Asiático & Vietnã & Silvicultura & - & 2011 & $\mathrm{BM}$ \\
\hline 158 & SESA for REDD+ & Ásia & Leste Asiático & Vietnã & Silvicultura & - & 2012 & $\mathrm{BM}$ \\
\hline 159 & $\begin{array}{l}\text { REA for Mindanao Rural Development } \\
\text { Program-I (Adaptable Program Loan } \\
\text { 2)* }\end{array}$ & Ásia & Pacífico & Filipinas & Multisetor & - & 2006 & $\mathrm{BM}$ \\
\hline 160 & Country Environmental Analysis & Ásia & Pacífico & Filipinas & País & - & 2009 & $\mathrm{BM}$ \\
\hline 161 & $\begin{array}{l}\text { EA Second Women's Health e Safe } \\
\text { Motherhood Project* }\end{array}$ & Ásia & Pacífico & Filipinas & Saúde & - & 2010 & $\mathrm{BM}$ \\
\hline 162 & $\begin{array}{l}\text { REA for Manila Third Sewerage } \\
\text { Project }\end{array}$ & Ásia & Pacífico & Filipinas & Tratamento de água & Saneamento & 2005 & $\mathrm{BM}$ \\
\hline 163 & $\begin{array}{l}\text { Strategic Assessment for Spatial } \\
\text { Planning in Papua Province }\end{array}$ & Ásia & Pacífico & Indonésia & Multisetor & - & 2008 & $\mathrm{BM}$ \\
\hline 164 & $\begin{array}{l}\text { Investing in a More Sustainable } \\
\text { Indonesia: Country Environmental } \\
\text { Analysis }\end{array}$ & Ásia & Pacífico & Indonésia & País & - & 2009 & $\mathrm{BM}$ \\
\hline 165 & SESA FCPF REDD Readiness & Ásia & Pacífico & Indonésia & Silvicultura & - & 2012 & $\mathrm{BM}$ \\
\hline 166 & $\begin{array}{l}\text { GEF Vanuatu and SPREP Portfolio } \\
\text { Evaluation - Global Environmental } \\
\text { Benefits Assessment }\end{array}$ & Ásia & Pacífico & Vanuatu & Country & - & 2014 & $\mathrm{BM}$ \\
\hline 167 & $\begin{array}{l}\text { Mining Sector - Sustainable } \\
\text { Development of Natural Resources } \\
\text { Project II }\end{array}$ & Ásia & Sul Asiático & Afeganistão & Mineração & - & 2012 & $\mathrm{BM}$ \\
\hline
\end{tabular}


(Continuação)

\begin{tabular}{|c|c|c|c|c|c|c|c|c|}
\hline & Nome da AAE & Continente & Região & País & Setor & Subsetor & Ano & $\begin{array}{c}\text { AMD } \\
\text { financiadora }\end{array}$ \\
\hline 168 & Bangladesh Sundarbans & Ásia & Sul Asiático & Bangladesh & $\begin{array}{l}\text { Desenvolvimento } \\
\text { regional }\end{array}$ & - & 2012 & $\mathrm{BM}$ \\
\hline 169 & $\begin{array}{l}\text { Bangladesh Country Environmental } \\
\text { Analysis }\end{array}$ & Ásia & Sul Asiático & Bangladesh & País & - & 2006 & BM \\
\hline 170 & Dhaka Metropolitan Development Plan & Ásia & Sul Asiático & Bangladesh & Urbano & - & 2007 & BM \\
\hline 171 & $\begin{array}{l}\text { Coastal Embankment Improvement } \\
\text { Project }\end{array}$ & Ásia & Sul Asiático & Bangladesh & Zona Costeira & - & 2012 & BM \\
\hline 172 & Urban Development Project* & Ásia & Sul Asiático & Butão & Urbano & - & 1999 & BM \\
\hline 173 & $\begin{array}{l}\text { Haryana State Highway Upgrading } \\
\text { Project (dropped) }\end{array}$ & Ásia & Sul Asiático & Índia & Transporte & Rodovia & 1997 & BM \\
\hline 174 & National Dairy Support Project & Ásia & Sul Asiático & Índia & Agricultura & - & 2011 & $\mathrm{BM}$ \\
\hline 175 & $\begin{array}{l}\text { Rajasthan Water Sector Restructuring } \\
\text { Project }\end{array}$ & Ásia & Sul Asiático & Índia & Água & - & 2000 & $\mathrm{BM}$ \\
\hline 176 & $\begin{array}{l}\text { Tamil Nadu Water Resources } \\
\text { Consolidation Project - Palar Basin }\end{array}$ & Ásia & Sul Asiático & Índia & Água & - & 2004 & $\mathrm{BM}$ \\
\hline 177 & $\begin{array}{l}\text { Tamil Nadu Water Resources } \\
\text { Consolidation Project - Cooum Basin }\end{array}$ & Ásia & Sul Asiático & Índia & Água & - & 2009 & BM \\
\hline 178 & $\begin{array}{l}\text { Uttar Pradesh Water Sector } \\
\text { Restructuring Project -- Ghagra-Gomti } \\
\text { Basin }\end{array}$ & Ásia & Sul Asiático & Índia & Água & Renováveis & 2009 & $\mathrm{BM}$ \\
\hline
\end{tabular}


(Continuação)

\begin{tabular}{|c|c|c|c|c|c|c|c|c|}
\hline & Nome da AAE & Continente & Região & País & Setor & Subsetor & Ano & $\begin{array}{c}\text { AMD } \\
\text { financiadora }\end{array}$ \\
\hline 179 & $\begin{array}{l}\text { National Ganga River Basin Project } \\
\text { SBA }\end{array}$ & Ásia & Sul Asiático & Índia & Água & - & 2011 & $\mathrm{BM}$ \\
\hline 180 & $\begin{array}{l}\text { National Ganga River Basin Project } \\
\text { Strategic Environmental, Economic, } \\
\text { and Social Assessment }\end{array}$ & Ásia & Sul Asiático & Índia & Água & - & 2012 & $\mathrm{BM}$ \\
\hline 181 & Ecodevelopment Project* & Ásia & Sul Asiático & Índia & Conservação & - & 1998 & BM \\
\hline 182 & $\begin{array}{l}\text { Integrated Watershed Development } \\
\text { Project (Hills II)* }\end{array}$ & Ásia & Sul Asiático & Índia & $\begin{array}{l}\text { Desenvolvimento } \\
\text { Rural }\end{array}$ & - & 1999 & $\mathrm{BM}$ \\
\hline 183 & $\begin{array}{l}\text { Karnataka Watershed Development } \\
\text { Project }\end{array}$ & Ásia & Sul Asiático & Índia & $\begin{array}{l}\text { Desenvolvimento } \\
\text { Rural }\end{array}$ & - & 2002 & $\mathrm{BM}$ \\
\hline 184 & West Bengal Sundarbans & Ásia & Sul Asiático & Índia & $\begin{array}{l}\text { Desenvolvimento } \\
\text { regional }\end{array}$ & - & 2011 & $\mathrm{BM}$ \\
\hline 185 & Rampur Hydropower Development & Ásia & Sul Asiático & Índia & Energia & Hidrelétricidade & 2006 & $\mathrm{BM}$ \\
\hline 186 & $\begin{array}{l}\text { Vishnugad Pipalkoti Hydro Electric } \\
\text { Project }\end{array}$ & Ásia & Sul Asiático & Índia & Energia & Hidrelétricidade & 2009 & $\mathrm{BM}$ \\
\hline 187 & Luhri Hydro Electric Project & Ásia & Sul Asiático & Índia & Energia & Hidrelétricidade & 2012 & $\mathrm{BM}$ \\
\hline 188 & $\begin{array}{l}\text { Towards Sustainable Mineral-Intensive } \\
\text { Growth in Orissa }\end{array}$ & Ásia & Sul Asiático & Índia & Energia e Mineração & - & 2007 & $\mathrm{BM}$ \\
\hline 189 & $\begin{array}{l}\text { Bihar, India State Environmental and } \\
\text { Social Analysis }\end{array}$ & Ásia & Sul Asiático & Índia & Energia e Mineração & - & 2012 & $\mathrm{BM}$ \\
\hline
\end{tabular}


(Continuação)

\begin{tabular}{|c|c|c|c|c|c|c|c|c|}
\hline & Nome da AAE & Continente & Região & País & Setor & Subsetor & Ano & $\begin{array}{c}\text { AMD } \\
\text { financiadora }\end{array}$ \\
\hline 190 & India Country Environmental Analysis & Ásia & Sul Asiático & Índia & País & - & 2007 & $\mathrm{BM}$ \\
\hline 191 & Tamil Nadu Road Sector Project & Ásia & Sul Asiático & Índia & Transporte & & 1999 & $\mathrm{BM}$ \\
\hline 192 & Gujarat State Highway Project & Ásia & Sul Asiático & Índia & Transporte & Rodovia & 1998 & $\mathrm{BM}$ \\
\hline 193 & Rajasthan State Highways Project* & Ásia & Sul Asiático & Índia & Transporte & Rodovia & 1998 & $\mathrm{BM}$ \\
\hline 194 & Road Maintenance and Development & Ásia & Sul Asiático & Nepal & Transporte & Rodovia & 1999 & $\mathrm{BM}$ \\
\hline 195 & Third National Highway Project* & Ásia & Sul Asiático & Índia & Transporte & Rodovia & 2000 & $\mathrm{BM}$ \\
\hline 196 & $\begin{array}{l}\text { Mizoram State Road and Rural } \\
\text { Development Project }\end{array}$ & Ásia & Sul Asiático & Índia & Transporte & Rodovia & 2001 & $\mathrm{BM}$ \\
\hline 197 & $\begin{array}{l}\text { Kerala State Transport Project, Road } \\
\text { Component }\end{array}$ & Ásia & Sul Asiático & Índia & Transporte & Rodovia & 2001 & $\mathrm{BM}$ \\
\hline 198 & $\begin{array}{l}\text { Karnataka State Highways } \\
\text { Improvement Project }\end{array}$ & Ásia & Sul Asiático & Índia & Transporte & Rodovia & 2001 & $\mathrm{BM}$ e ADB \\
\hline 199 & Uttar Pradesh State Roads Project & Ásia & Sul Asiático & Índia & Transporte & Rodovia & 2001 & BM \\
\hline 200 & Power Development Project & Ásia & Sul Asiático & Nepal & Energia & Hidrelétricidade & 1999 & $\mathrm{BM}$ \\
\hline 201 & Nepal Hydropower Sector & Ásia & Sul Asiático & Nepal & Energia & Hidrelétricidade & 2010 & BM \\
\hline 202 & Kabeli 'A' Hydro Electric Project & Ásia & Sul Asiático & Nepal & Energia & Hidrelétricidade & 2011 & $\mathrm{BM}$ \\
\hline 203 & Nepal Country Environmental Analysis & Ásia & Sul Asiático & Nepal & País & - & 2007 & $\mathrm{BM}$ \\
\hline 204 & National Drainage Program Project & Ásia & Sul Asiático & Paquistão & Agricultura & - & 1993 & $\mathrm{BM}$ \\
\hline
\end{tabular}


(Conclusão)

\begin{tabular}{|c|c|c|c|c|c|c|c|c|}
\hline & Nome da AAE & Continente & Região & País & Setor & Subsetor & Ano & $\begin{array}{c}\text { AMD } \\
\text { financiadora }\end{array}$ \\
\hline 205 & $\begin{array}{l}\text { Balochistan Small Scale Irrigation } \\
\text { Project* }\end{array}$ & Ásia & Sul Asiático & Paquistão & Agricultura & - & 2005 & $\mathrm{BM}$ \\
\hline 206 & $\begin{array}{l}\text { Water Sector Capacity Building and } \\
\text { Advisory Services Project (in progress) }\end{array}$ & Ásia & Sul Asiático & Paquistão & Água & - & 2013 & $\mathrm{BM}$ \\
\hline 207 & Green Industrial Growth & Ásia & Sul Asiático & Paquistão & Indústria & - & 2012 & $\mathrm{BM}$ \\
\hline 208 & $\begin{array}{l}\text { Pakistan Strategic Country } \\
\text { Environmental Assessment }\end{array}$ & Ásia & Sul Asiático & Paquistão & País & - & 2006 & $\mathrm{BM}$ \\
\hline 209 & $\begin{array}{l}\text { Greening Growth in Pakistan through } \\
\text { Transport Sector Reforms - A Strategic } \\
\text { Environmental, Poverty, and Social } \\
\text { Assessment }\end{array}$ & Ásia & Sul Asiático & Paquistão & Transporte & - & 2013 & $\mathrm{BM}$ \\
\hline 210 & $\begin{array}{l}\text { Highway Rehabilitation Project } \\
\text { Sectoral Social and Environmental } \\
\text { Assessment }\end{array}$ & Ásia & Sul Asiático & Paquistão & Transporte & - & 2003 & $\mathrm{BM}$ \\
\hline 211 & $\begin{array}{l}\text { Pakistan Strategic Environmental, } \\
\text { Poverty and Social Assessment of } \\
\text { Trade and Transport Sector Reforms }\end{array}$ & Ásia & Sul Asiático & Paquistão & Transporte & Rodovia & 2011 & $\mathrm{BM}$ \\
\hline 212 & $\begin{array}{l}\text { Central Asia South Asia Electricity } \\
\text { Transmission and Trade Project - } \\
\text { Regional Environmental Assessment }\end{array}$ & Ásia & Sul Asiático & $\begin{array}{l}\text { Paquistão, } \\
\text { Tajaquistão, } \\
\text { Afeganistão }\end{array}$ & Energia & Hidrelétricidade & 2013 & $\mathrm{BM}$ \\
\hline 213 & $\begin{array}{l}\text { Kosovo Country Environmental } \\
\text { Analysis }\end{array}$ & Eurásia & $\begin{array}{l}\text { Europa e Ásia } \\
\text { central }\end{array}$ & Kosovo & $\begin{array}{l}\text { Energia, setor público } \\
\quad \text { e silvicultura }\end{array}$ & - & 2013 & $\mathrm{BM}$ \\
\hline 214 & $\begin{array}{l}\text { Cumulative Environmental Impact } \\
\text { Assessment for Hydropower Projects in } \\
\text { Turkey }\end{array}$ & Eurásia & - & Turquia & Water & - & 2012 & $\mathrm{BM}$ \\
\hline
\end{tabular}

